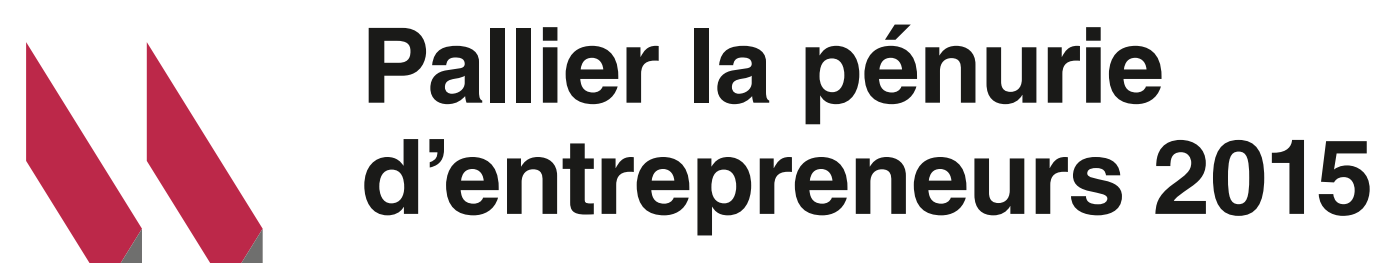

POLITIQUES EN FAVEUR DU TRAVAIL INDÉPENDANT ET DE L'ENTREPRENEURIAT

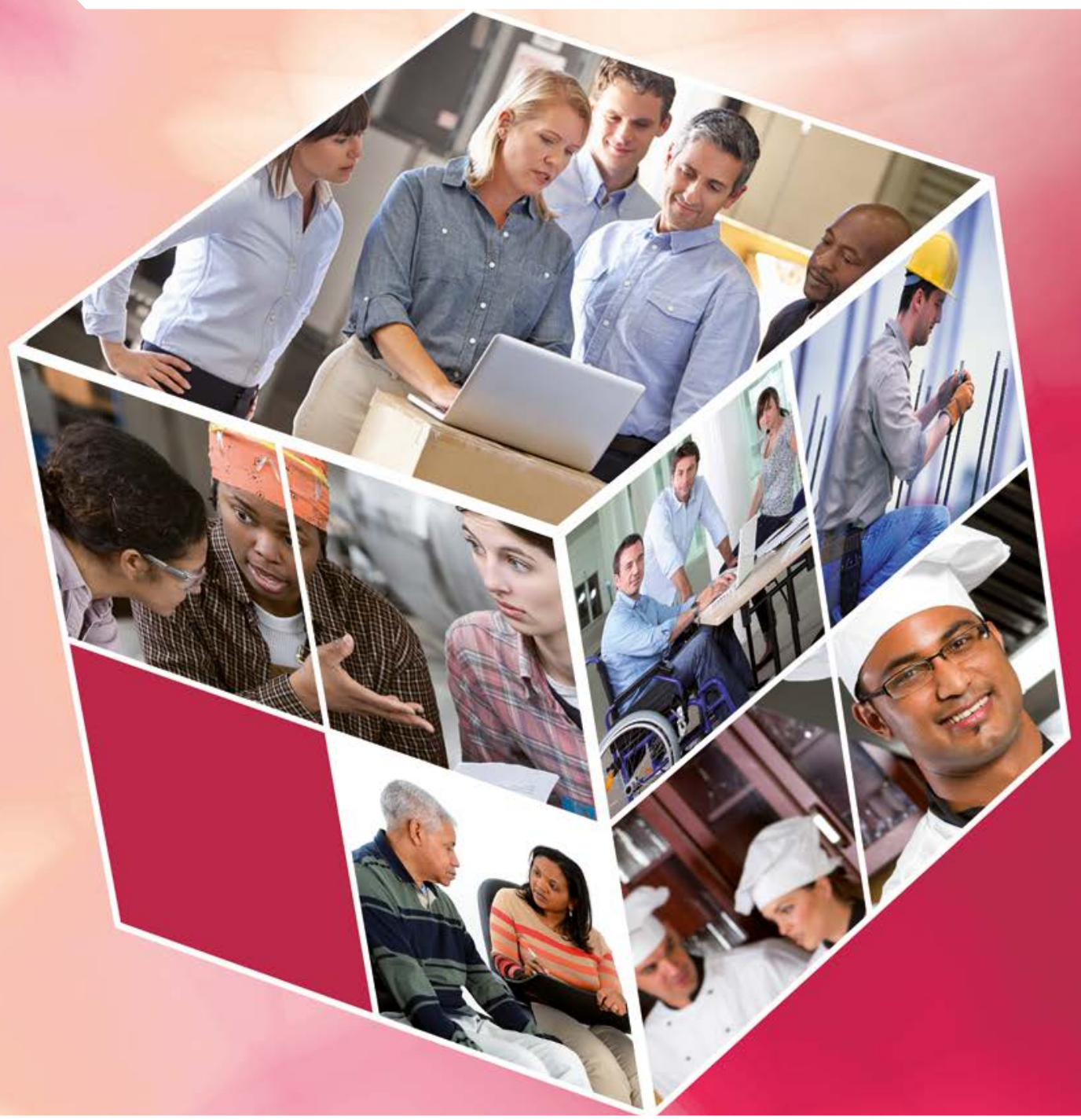

Q $)$ OCDE

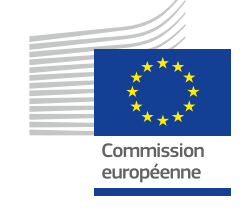




\section{Pallier la pénurie d'entrepreneurs 2015}

\section{POLITIQUES EN FAVEUR DU TRAVAIL INDÉPENDANT ET DE L'ENTREPRENEURIAT}

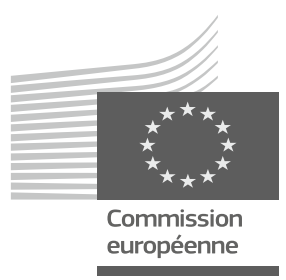


Cet ouvrage est publié sous la responsabilité du Secrétaire général de l'OCDE. Les opinions et les interprétations exprimées ne reflètent pas nécessairement les vues officielles des pays membres de l'OCDE ou celles de l'Union européenne (UE).

Ce document et toute carte qu'il peut comprendre sont sans préjudice du statut de tout territoire, de la souveraineté s'exerçant sur ce dernier, du tracé des frontières et limites internationales, et du nom de tout territoire, ville ou région.

\section{Merci de citer cet ouvrage comme suit:}

OCDE/Union européenne (2016), Pallier la pénurie d'entrepreneurs 2015 : Politiques en faveur du travail indépendant et de l'entrepreneuriat, Éditions OCDE.

http://dx.doi.org/10.1787/9789264249936-fr

ISBN 978-92-64-24991-2 (print)

ISBN 978-92-64-24993-6 (PDF)

Commission européenne

ISBN 978-92-79-43503-4 (print)

ISBN 978-92-79-43500-3 (PDF)

Numéro de catalogue

KE-04-14-958-FR-C (print)

KE-04-14-958-FR-N (PDF)

Crédits photos: Couverture: @ ririro/Shutterstock.com, @ auremar - Fotolia.com, ๑ Rob - Fotolia.com, ๑ michaeljung - Fotolia.com, @ Monkey Business Images /Shutterstock.com, @ Stockbyte/Collection/Guetty Images, @ jetta production/Collection/Guetty Images

Les corrigenda des publications de l'OCDE sont disponibles sur: www.oecd.org/publishing/corrigenda.

○ OCDE/Union européenne 2016

La copie, le téléchargement ou l'impression du contenu OCDE pour une utilisation personnelle sont autorisés. Il est possible d'inclure des extraits de publications, de bases de données et de produits multimédia de l'OCDE dans des documents, présentations, blogs, sites Internet et matériel pédagogique, sous réserve de faire mention de la source et du copyright. Toute demande en vue d'un usage public ou commercial ou concernant les droits de traduction devra être adressée à rights@oecd.org. Toute demande d'autorisation de photocopier une partie de ce contenu à des fins publiques ou commerciales devra être soumise au Copyright Clearance Center (CCC), info@copyright.com, ou au Centre français d'exploitation du droit de copie (CFC), contact@cfcopies.com. 


\section{Préface}

L

a crise économique nous a laissé un lourd héritage, notamment un taux de chômage élevé, en particulier chez les jeunes. Dans de nombreux pays européens, le chômage des jeunes est en moyenne deux fois supérieur à celui des adultes. D’autres groupes sont concernés. La participation et les résultats des femmes, des immigrés et des seniors sur le marché du travail sont également plus faibles. D'après les prévisions de l'Organisation de coopération et de développement économiques (OCDE), ces problèmes ont peu de chances d'être résolus rapidement.

Nous devons adopter une approche globale pour bâtir un avenir fondé sur l'inclusion et la croissance. L'initiative de l'OCDE pour une croissance inclusive a permis d'identifier plusieurs actions politiques pour y parvenir, notamment l'acquisition de compétences et l'entrepreneuriat. Cet ouvrage se concentre sur l'entrepreneuriat inclusif, qui vise à offrir aux personnes issues de différents milieux la possibilité de créer une entreprise ou de s'établir comme indépendant. Les politiques gouvernementales peuvent aider les chômeurs ou les personnes défavorisées sur le marché du travail à acquérir des compétences entrepreneuriales et à accéder aux financements et aux réseaux professionnels pour qu'ils puissent créer leur propre emploi. Parallèlement, il est important que les responsables politiques accompagnent ces efforts en continuant à soutenir le développement des compétences et de la culture entrepreneuriales.

Cet ouvrage fournit des données sur les taux d'entrepreneuriat et de travail indépendant des femmes, des jeunes, des seniors, des chômeurs et des personnes d'origine étrangère vivant au sein de l'Union européenne et sur la nature des obstacles auxquels ils sont confrontés. Il aborde également deux thèmes politiques clés, à savoir la capacité des entrepreneurs issus de groupes défavorisés ou sous-représentés à créer des entreprises à forte croissance et les clés pour concevoir des mécanismes efficaces de coaching et de mentorat en faveur de ces groupes défavorisés.

Il a été prouvé que les politiques d'entrepreneuriat inclusif peuvent produire des résultats dans ces domaines. Nous devons cependant veiller à ne pas créer des attentes trop grandes. En effet, l'entrepreneuriat ne convient pas à tout le monde et ne pourra résoudre l'ensemble des défis du marché du travail de l'Union européenne. Mais le coût de l'inaction est extraordinairement élevé. Il faut saisir l'occasion de stimuler le soutien à l'entrepreneuriat et au travail indépendant dans le cadre des outils utilisés par les gouvernements pour promouvoir la participation au marché du travail.

Je voudrais remercier la direction générale de l'emploi, des affaires sociales et de l'inclusion de la Commission européenne d'avoir travaillé en collaboration avec l'OCDE sur ce projet important. J'espère par ailleurs que les responsables politiques aux niveaux national, régional et local mettront à profit les conseils politiques présentés dans cet ouvrage au moment d'élaborer et d'entreprendre des actions de promotion et de soutien en faveur de l'entrepreneuriat inclusif.

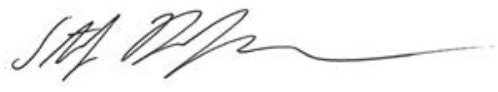

Stefan Kapferer

directeur par intérim du Centre pour l'entrepreneuriat, les PME et le développement local et vice-secrétaire général de l'Organisation de coopération et de développement économiques 
En juin 2015, plus de 23 millions de personnes étaient au chômage dans l'Union européenne, dont la moitié depuis plus d'un an. La création d'emplois constitue donc clairement une priorité de l'Union européenne et de ses pays membres. L'entrepreneuriat est un moteur de création d'emplois important.

L'Union européenne soutient fermement le développement de l'entrepreneuriat au sein de toutes les catégories de population. L'entrepreneuriat et le travail indépendant sont des leviers importants de la stratégie Europe 2020 pour une croissance intelligente, durable et inclusive. Plusieurs initiatives phares soutiennent explicitement l'entrepreneuriat, notamment la stratégie pour des compétences nouvelles et des emplois, Jeunesse en mouvement et la Plateforme européenne contre la pauvreté et l'exclusion sociale. Cette stratégie a été renforcée par le plan d'action «Entrepreneuriat 2020».

Alors que débute la nouvelle période de programmation 2014-2020, nous ne devons pas négliger certains des principaux Fonds structurels à la disposition de ces initiatives. Le Fonds social européen (FSE) contribue à soutenir l'entrepreneuriat et le travail indépendant au travers de l'objectif thématique «Promouvoir l'emploi et soutenir la mobilité de la main-d'œuvre». Les pays de l'Union européenne peuvent avoir recours au FSE pour cofinancer des programmes de formation à l'entrepreneuriat et mettre en place les infrastructures de soutien de l'entrepreneuriat. L'une des initiatives les plus importantes de la nouvelle période de programmation est l'initiative Jeunesse en mouvement (YEI), qui inclut notamment la Garantie pour la jeunesse. Cette initiative offre un soutien financier supplémentaire aux efforts destinés à aider les jeunes à accéder au marché du travail, y compris les initiatives en faveur du travail indépendant, entrepris dans les régions les plus touchées par le chômage des jeunes.

Toutefois, à l'heure actuelle, les États membres ne tirent pas pleinement profit des ressources européennes et nationales disponibles et sous-exploitent le potentiel de l'entrepreneuriat dans leurs politiques actives du marché du travail. J'espère que cet ouvrage permettra de mieux faire connaître aux responsables politiques les différentes approches possibles pour promouvoir l'entrepreneuriat inclusif. Cet ouvrage, réalisé en partenariat avec l'OCDE, constitue une base de connaissances et une source d'inspiration pour les responsables politiques. Je les encourage à utiliser ces recommandations et orientations pour concevoir et mettre en œuvre leurs projets en faveur de l'entrepreneuriat inclusif, et de s'inspirer des exemples de politiques.

Enfin, j'aimerais remercier l'OCDE pour sa participation à ce programme de travail majeur.

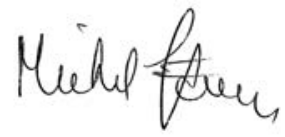

Michel Servoz, directeur général de la direction générale de l'emploi, des affaires sociales et de l'inclusion, Commission européenne 


\section{Remerciements}

L Programme pour le Développement économique et la création d'emplois au niveau local (LEED) du Centre pour l'entrepreneuriat, les PME et le développement local de l'OCDE et la direction générale de l'emploi, des affaires sociales et de l'inclusion de la Commission européenne portant sur les politiques d'entrepreneuriat inclusif en Europe.

Ce rapport a été élaboré et publié sous la direction de Jonathan Potter, économiste en chef du Centre pour l'entrepreneuriat, les PME et le développement local de l'OCDE, assisté par David Halabisky, économiste au programme LEED de l'OCDE, qui s'est chargé d'une bonne partie de la rédaction et de la préparation et qui a coordonné les contributions écrites des divers auteurs.

Les membres du Secrétariat de l'OCDE et les experts externes suivants ont fourni du matériel: David Deakins, David Halabisky, Jonathan Potter, Stuart Thompson et Karl Wennberg. D'autres contributions ont été rédigées par Sergio Destefanis, Joanne Gillen, Nadine Levratto et Kerstin Wilde.

Ce rapport a bénéficié de commentaires et d'apports de la Commission européenne, direction générale de l'emploi, des affaires sociales et de l'inclusion, ainsi que de contributions majeures de Ciprian Alionescu, Jayson Dong, Guy Lejeune, Andrea Maier, Frédéric Merméty, Michal Petrik et Mindaugas Veromejus.

Quant à l'OCDE, elle a instauré un comité directeur composé de Carin Holmquist, David Smallbone et Friederike Welter et chargé de guider la publication. Ce comité a par ailleurs émis des remarques et des suggestions précieuses.

Nous remercions également Niels Bosma et Jonathan Levie de la Global Entrepreneurship Research Association pour leurs données pertinentes.

Un certain nombre de correspondants nationaux ont contribué aux descriptions de politiques du chapitre 3 de ce rapport, à savoir: Rocky Adiguna, Leonie Baldacchino, Inga Blaziene, Lucie Bucinová, Anca Dodescu, Paula Fitzsimmons, Denise Fletcher, João Gonçalves, Elias Hadjielias, Stefan Hardonk, Eva Heckl, Carin Holmquist, Michael Holz, Annemarie Jepsen, Marina Kaas, Dimitris Karantinos, Teemu Kautonen, Nadine Levratto, Francisco Liñán, Augusto Medina, Anna Pilková, Panikkos Poutziouris, Shirley Pulis Xerxen, Olga Rastrigina, Petra Reszketo, Paolo Rosso, Slavica Singer, Karin Širec, Jacqueline Snijders, Douglas Thompson, Kiril Todorov, Katarzyna Trojnarska, Amber van der Graaf, Elisa Veronesi et Friederike Welter. 



\section{Table des matières}

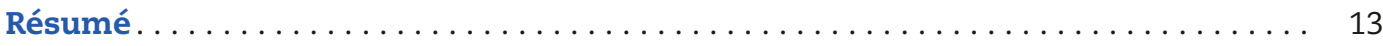

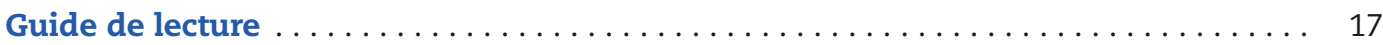

Chapitre 1. La politique d'entrepreneuriat inclusif de l'Union européenne ....... 23

Qu'est-ce qu'une politique d'entrepreneuriat inclusif?................ 24

Pourquoi les politiques d'entrepreneuriat inclusif sont-elles si importantes? . . . 25

Guide de lecture de la présente publication $\ldots \ldots \ldots \ldots \ldots \ldots \ldots \ldots \ldots \ldots \ldots$

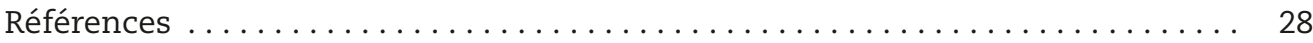

PARTIE I

L'entrepreneuriat inclusif en Europe - Taux d'activité et obstacles

Chapitre 2. Le travail indépendant et l'entrepreneuriat chez les femmes ....... 31

Le travail indépendant chez les femmes ..................... 32

Activités exercées par des femmes tout au long du cycle de vie entrepreneuriale $\quad 37$

Heures de travail des femmes indépendantes . . . . . . . . . . . . . . 40

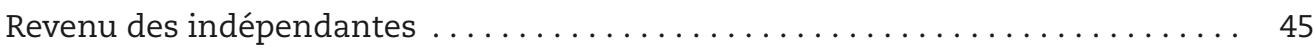

Le manque de compétences entrepreneuriales: un obstacle à la création

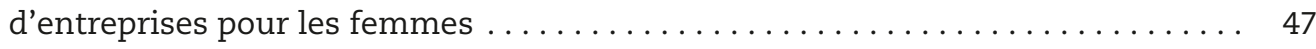

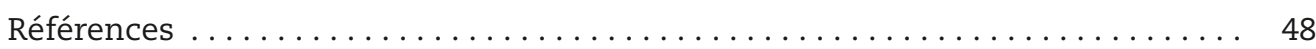

Chapitre 3. Le travail indépendant et l'entrepreneuriat chez les jeunes......... 49

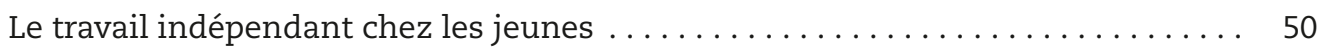

Activités indépendantes exercées par les jeunes tout au long du cycle de vie

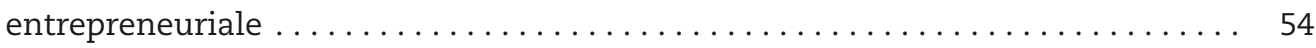

Le manque de compétences entrepreneuriales: un obstacle à la création

d'entreprises pour les jeunes. . . . . . . . . . . . . . . . . . . . 57

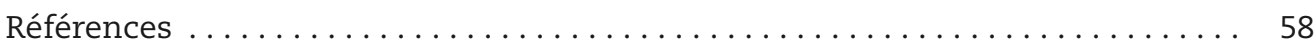

Chapitre 4. Le travail indépendant et l'entrepreneuriat chez les seniors . . . . . . . . 59

Le travail indépendant chez les seniors . . . . . . . . . . . . . . 60

Activités exercées par les seniors tout au long du cycle de vie entrepreneuriale . . 64

Le manque de compétences entrepreneuriales: un obstacle à la création

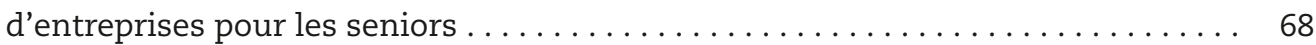

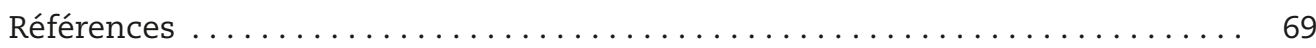


Chapitre 5. Le travail indépendant et l'entrepreneuriat chez les chômeurs . . . . . 71

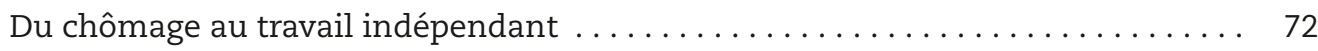

Quitter le chômage pour débuter une activité indépendante.......... 75

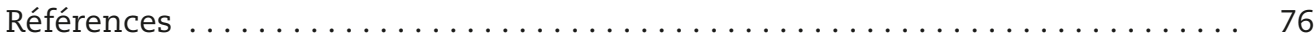

Chapitre 6. Le travail indépendant et l'entrepreneuriat chez les personnes nées à

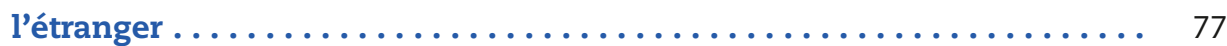

Le travail indépendant chez les personnes nées à l'étranger . . . . . . . . . 78

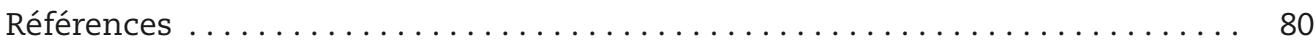

PARTIE II

Les politiques d'entrepreneuriat inclusif

Chapitre 7. Soutenir la croissance des entrepreneurs appartenant

à des groupes sous-représentés et défavorisés ...............

Le potentiel de croissance des entrepreneurs appartenant à des groupes

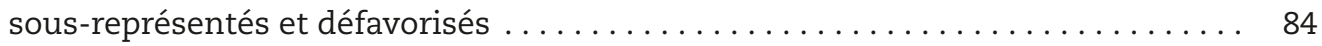

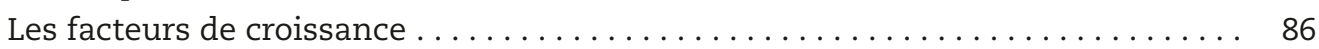

Politiques en faveur de la croissance des entrepreneurs appartenant

à des groupes sous-représentés et défavorisés................... 91

Mettre en place des programmes de soutien à la croissance . . . . . . . . . . . . . . 101

Conclusions et recommandations politiques . . . . . . . . . . . . . . . . . . 102

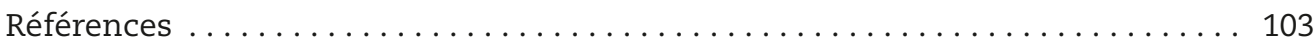

Chapitre 8. Mécanismes de coaching et de mentorat efficaces pour les entrepreneurs appartenant à des groupes sous-représentés et défavorisés . . . . . . . 107

Nature et définition du coaching et du mentorat ................... 108

Avantages $d u$ mentorat et du coaching . . . . . . . . . . . . . . . . . . 110

Approches politiques du coaching et du mentorat pour les entrepreneurs appartenant à des groupes sous-représentés et défavorisés . . . . . . . . . 111

Clés pour concevoir des programmes de coaching et de mentorat efficaces pour les entrepreneurs appartenant à des groupes sous-représentés et défavorisés . . 120

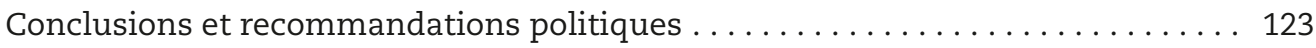

Références ... . . . . . . . . . . . . . . . . . . . . . . . . . . . . . . . . . . . . . . . 124

PARTIE III

Profils des pays: exemples de politiques et données clés sur l'entrepreneuriat inclusif

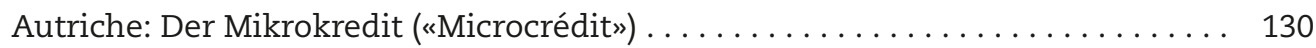

Belgique: Hazo vzw . . . . . . . . . . . . . . . . . . . . . . 132

Bulgarie: Entrepreneurship Development Network (EDN) . . . . . . . . . . 134

Croatie: projet A.C.T.I.V.E. (Activity and Creativity Through Ideas

and Ventures $=$ Employment $) \ldots \ldots \ldots \ldots \ldots \ldots \ldots \ldots \ldots \ldots \ldots \ldots \ldots \ldots \ldots \ldots$ 
Chypre: Agrotoepixeirein: renforcer l'entrepreneuriat des jeunes et des femmes dans les zones rurales. . . . . . . . . . . . . . . 138

République tchèque: aide au travail indépendant des personnes souffrant de problèmes de santé en Bohême centrale . . . . . . . . . . . . . 140

Danemark: Igangz . . . . . . . . . . . . . . . . . . . . . . . . . . . . 142

Estonie: StartSmart! . . . . . . . . . . . . . . . . . . . . . . . . . . . . . . 144

Finlande: Atelier d'aide à la création d'entreprises destiné aux moins de 30 ans . 146 France: ouvrir les portes de la banque aux jeunes entrepreneurs . . . . . . . . . . . . 148

Allemagne: Bundesweite Gründerinnenagentur (BGA) (Agence nationale d'activités et de services d'aide à la création d'entreprises par des femmes). . . . 150 Grèce: entrepreneuriat innovant des jeunes . . . . . . . . . . . . . . . . . . . . 152 Hongrie: centre musical Snétberger. . . . . . . . . . . . . . . . . . . . . . . 154 Irlande: Enterprise Ireland Female Entrepreneurship Strategy . . . . . . . . . . . 156 Italie: couveuse d'entreprises sociales «FabriQ" . . . . . . . . . . . . 158 Lettonie: mesures d'encouragement en faveur de l'innovation et de la création d'entreprises chez les jeunes. . . . . . . . . . . . . . 160 Lituanie: aide au travail indépendant . . . . . . . . . . . . . . . . . 162 Luxembourg: programme de mentorat d'entreprises . . . . . . . . . . . . . . . . . . 164 Malte: projet My WoW . . . . . . . . . . . . . . . . . . . . . . 166 Pays-Bas: Bbz 2004, Besluit Bijstand voor Zelfstandigen (Aide à la décision pour les entrepreneurs) . . . . . . . . . . . . . . 168 Pologne: Wings for business: un atelier pour l'entrepreneuriat des personnes handicapées. .170 Portugal: projet pour la promotion de l'entrepreneuriat des immigrés (PEI) . . . . 172 Roumanie: Fem.RRom . . . . . . . . . . . . . . . . . . . . . . . . . 174 République slovaque: contribution financière au travail indépendant . . . . . . . 176 Slovénie: P2P - Podjetnice za podjetnice do enakih možnosti v podjetništuu (Les femmes entrepreneurs pour l'égalité des chances entrepreneuriales des femmes $) \ldots \ldots \ldots \ldots \ldots \ldots \ldots \ldots \ldots \ldots \ldots \ldots \ldots \ldots \ldots \ldots \ldots \ldots$

Espagne: Red de Cooperación de Emprendedoras (Réseau de coopération

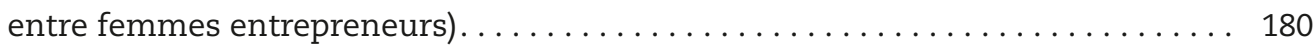

Suède: Inkubator $55+\ldots \ldots \ldots \ldots \ldots \ldots \ldots \ldots \ldots \ldots \ldots \ldots \ldots \ldots \ldots$

Royaume-Uni: Buy Sunderland First . . . . . . . . . . . . . . . . . . . . . 184

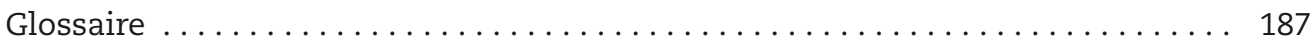

\section{Tableaux}

8.1. Composants clés des services de coaching et de mentorat destinés aux entrepreneurs............................... 109

8.2. Résumé des avantages des services de coaching et de mentorat destinés aux entrepreneurs sous-représentés et défavorisés .............. 111

9.1. Inventaire des mesures politiques décrites . . . . . . . . . . . . . . . . 129

\section{Graphiques}

1.1. Taux de chômage de l'Union européenne $\ldots \ldots \ldots \ldots \ldots \ldots \ldots \ldots \ldots \ldots \ldots$

1.2. Taux de participation au marché du travail de l'Union européenne . . . . . . . 25

1.3. Proportion de la population de l'EU-28 menacée de pauvreté ou d'exclusion

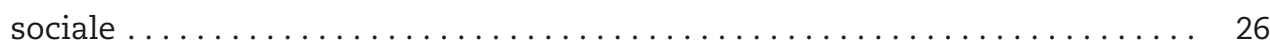

1.4. Dépenses au titre des programmes de soutien au marché du travail et d'incitation à la création d'entreprises, $2011 \ldots \ldots \ldots \ldots \ldots \ldots \ldots$ 
1.5. Participation au marché du travail à la suite d'une période de chômage

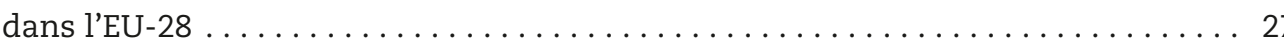

2.1. Taux de travail indépendant des hommes et des femmes dans l'EU-28,

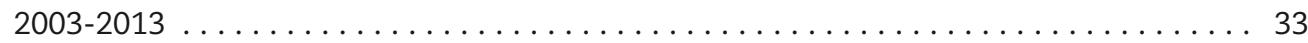

2.2. Taux de travail indépendant des hommes et des femmes par pays 2003-2013 . . . 34

2.3. Proportion d'indépendants (hommes et femmes) employant des salariés dans l'EU-28, 2003-2013 .............................. 35

2.4. Proportion d'indépendants (hommes et femmes) employant des salariés

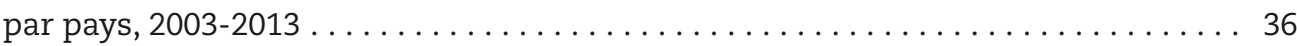

2.5. Taux de travail indépendant des hommes et des femmes par secteur

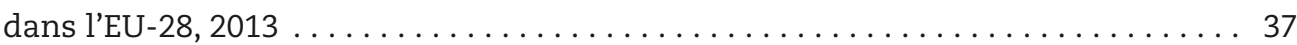

2.6. Taux d'entrepreneuriat naissant chez les hommes et les femmes, 2009-2013 (combinés) . . . . . . . . . . . . . . . . . . . . . . . . . . . 38

2.7. Taux de détention de nouvelles entreprises chez les hommes et les femmes, 2009-2013 (combinés) . . . . . . . . . . . . . . 39

2.8. Taux de détention d'entreprises établies chez les hommes et les femmes, 2009-2013 (combinés) . . . . . . . . . . . . . . . . . . . . . . . . . . 40

2.9. Nombre moyen d'heures de travail hebdomadaires des indépendants (hommes et femmes) dans l'EU-28, 2003-2013 . .................... 41

2.10. Nombre moyen d'heures de travail hebdomadaires des indépendants (hommes et femmes) par pays, $2003-2013 \ldots \ldots \ldots \ldots \ldots \ldots \ldots \ldots \ldots . \ldots . \ldots . \ldots 2$

2.11. Nombre moyen d'heures de travail hebdomadaires des indépendants (hommes et femmes) employant du personnel dans l'EU-28, 2003-2013 . . . . . . 43

2.12. Nombre moyen d'heures de travail hebdomadaires des indépendants (hommes et femmes) employant du personnel par pays, 2003-2013 . . . . . . . 44

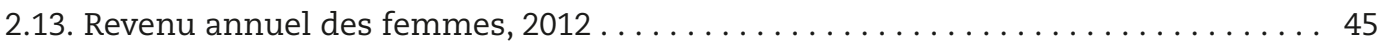

2.14. Revenu annuel des femmes par pays, 2012 .................. 46

2.15. Manque de compétences entrepreneuriales en tant qu'obstacle à la création d'entreprises pour les hommes et les femmes dans l'EU-28, 2009-2013 . . . . . . 48

3.1. Taux de travail indépendant des jeunes dans l'EU-28, 2003-2013 . . . . . . . . 50

3.2. Taux de travail indépendant des jeunes par pays $2003-2013 \ldots \ldots \ldots \ldots \ldots \ldots$. . . . 51

3.3. Proportion de jeunes indépendants employant du personnel dans l'EU-28, 2003-2013.............................. 52

3.4. Proportion de jeunes indépendants employant du personnel par pays,

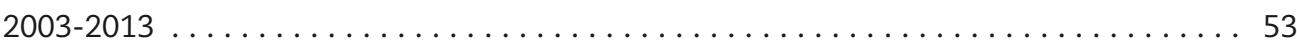

3.5. Taux de travail indépendant des jeunes par secteur dans l'EU-28, 2013 . . . . . 54

3.6. Taux d'entrepreneuriat naissant chez les jeunes, 2009-2013 (combinés) . . . . . . 55

3.7. Taux de détention de nouvelles entreprises chez les jeunes, 2009-2013 (combinés) . . . . . . . . . . . . . . . . . . . . . . . . . 56

3.8. Taux de détention d'entreprises établies chez les jeunes, 2009-2013 (combinés) . . . . . . . . . . . . . . . . . . . . . . . . 57

3.9. Compétences entrepreneuriales en tant qu'obstacle à la création d'entreprises

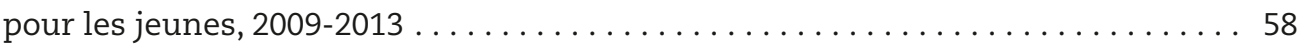

4.1. Taux de travail indépendant des seniors dans l'EU-28, 2003-2013 . . . . . . . . 60

4.2. Taux de travail indépendant des seniors par pays, 2003-2013 . . . . . . . . . 61

4.3. Proportion de seniors indépendants employant du personnel dans l'EU-28, 2003-2013 
4.4. Proportion de seniors indépendants employant du personnel par pays,

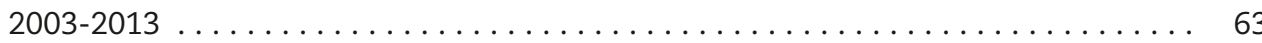

4.5. Taux de travail indépendant des seniors par secteur dans l'EU-28, 2013 . . . . 64

4.6. Taux d'entrepreneuriat naissant chez les seniors, 2009-2013 (combinés) . . . . . . . . . . . . . . . . . . . . . . . . . . 65

4.7. Taux de détention de nouvelles entreprises chez les seniors, 2009-2013 (combinés) .................................. 66

4.8. Taux de détention d'entreprises établies chez les seniors, 2009-2013 (combinés) . . . . . . . . . . . . . . . . . . . . . . . .

4.9. Manque de compétences entrepreneuriales en tant qu'obstacle à la création d'entreprises pour les seniors, $2009-2013$. . . . . . . . . . . . . . 68

5.1. Proportion de chômeurs à la recherche d'un travail indépendant dans l'EU-28, 2013.

5.2. Proportion de chômeurs à la recherche d'un travail indépendant par

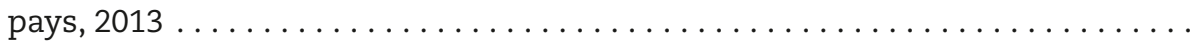

5.3. Proportion de jeunes et de seniors sans emploi à la recherche d'un travail

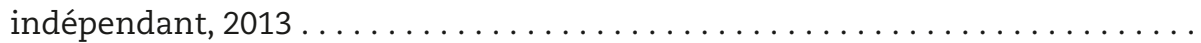

5.4. Proportion de chômeurs (hommes et femmes) à la recherche d'un travail indépendant dans l'EU-28, 2003-2013 . . . . . . . . . . . . . . .

5.5. Proportion de jeunes et de seniors sans emploi à la recherche d'un travail indépendant dans l'EU-28, 2003-2013 . . . . . . . . . . . . . . . . .

5.6. Potentiel de travailleurs indépendants chez les chômeurs dans l'EU-28,

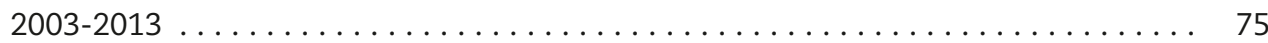

5.7. Potentiel de travailleurs indépendants chez les chômeurs, $2013 \ldots \ldots$. . . . . 76

6.1. Proportion de travailleurs indépendants nés en dehors de leur pays de résidence, $2013 \ldots \ldots \ldots \ldots \ldots \ldots \ldots \ldots \ldots \ldots \ldots$

6.2. Taux de travail indépendant des personnes d'origine étrangère par État

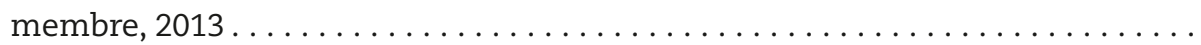

6.3. Proportion des travailleurs indépendants d'origine étrangère employant

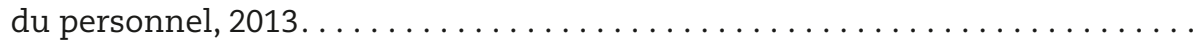

7.1. Prévisions de croissance chez les femmes entrepreneurs, 2009-2013 (combinés) . . . . . . . . . . . . . . . . . . . . . . . . . . . . . .

7.2. Prévisions de croissance chez les entrepreneurs jeunes et seniors, 2009-2013 (combinés) . . . . . . . . . . . . . . . . . . . . . . . 88

10.1. Données relatives à l'entrepreneuriat et au travail indépendant en Autriche . . 131

11.1. Données relatives à l'entrepreneuriat et au travail indépendant en Belgique . . 133

12.1. Données relatives à l'entrepreneuriat et au travail indépendant en Bulgarie . . 135

13.1. Données relatives à l'entrepreneuriat et au travail indépendant en Croatie . . 137

14.1. Données relatives à l'entrepreneuriat et au travail indépendant à Chypre . . . 139

15.1. Données relatives à l'entrepreneuriat et au travail indépendant en République tchèque.

16.1. Données relatives à l'entrepreneuriat et au travail indépendant au Danemark 143 17.1. Données relatives à l'entrepreneuriat et au travail indépendant en Estonie . . . 145 18.1. Données relatives à l'entrepreneuriat et au travail indépendant en Finlande. . 147 19.1. Données relatives à l'entrepreneuriat et au travail indépendant en France. . . 149 20.1. Données relatives à l'entrepreneuriat et au travail indépendant en Allemagne 151 21.1. Données relatives à l'entrepreneuriat et au travail indépendant en Grèce. . . . 153 
22.1. Données relatives à l'entrepreneuriat et au travail indépendant en Hongrie. . . . 155

23.1. Données relatives à l'entrepreneuriat et au travail indépendant en Irlande . . . . 157

24.1. Données relatives à l'entrepreneuriat et au travail indépendant en Italie . . . . . . 159

25.1. Données relatives à l'entrepreneuriat et au travail indépendant en Lettonie . . . . 161

26.1. Données relatives à l'entrepreneuriat et au travail indépendant en Lituanie . . . . 163

27.1. Données relatives à l'entrepreneuriat et au travail indépendant au

Luxembourg ......................................... 165

28.1. Données relatives à l'entrepreneuriat et au travail indépendant à Malte. . . . . . 167

29.1. Données relatives à l'entrepreneuriat et au travail indépendant aux Pays-Bas... 169

30.1. Données relatives à l'entrepreneuriat et au travail indépendant en Pologne. . . . 171

31.1. Données relatives à l'entrepreneuriat et au travail indépendant au Portugal . . . 173

32.1. Données relatives à l'entrepreneuriat et au travail indépendant en Roumanie. . 175

33.1. Données relatives à l'entrepreneuriat et au travail indépendant en

République slovaque .......................................... 177

34.1. Données relatives à l'entrepreneuriat et au travail indépendant en Slovénie . . . 179

35.1. Données relatives à l'entrepreneuriat et au travail indépendant en Espagne . . . . 181

36.1. Données relatives à l'entrepreneuriat et au travail indépendant en Suède . . . . . 183

37.1. Données relatives à l'entrepreneuriat et au travail indépendant au

Royaume-Uni . . . . . . . . . . . . . . . . . . . . . . . . . . . . 185

\section{Suivez les publications de l'OCDE sur:}

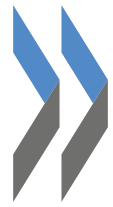

http://twitter.com/OECD_Pubs

iftp://www.facebook.com/OECDPublications

in. http://www.linkedin.com/groups/OECD-Publications-4645871

You Tube http://www.youtube.com/oecdilibrary

Alerts http://www.oecd.org/oecddirect/

Ce livre contient des...

En bas des tableaux ou graphiques de cet ouvrage, vous trouverez des StatLinks त्ताई de retranscrire dans votre navigateur Internet le lien commençant par: http://dx.doi.org, ou de cliquer sur le lien depuis la version PDF de l'ouvrage. 
Pallier la pénurie d'entrepreneurs

Politiques en faveur du travail indépendant et de l'entrepreneuriat

๑ OCDE/UNION EUROPÉENNE 2016

\section{Résumé}

\section{Le défi de la création d'emplois}

Malgré certains signes de reprise après la récente crise économique, les marchés européens du travail connaissent toujours de nombreuses difficultés. Le chômage reste l'une des principales priorités politiques des différents gouvernements européens et la question dans tous les esprits est «comment créer des emplois?». La reprise ne créant pas d'emplois, il est très difficile pour les jeunes d'accéder au marché du travail, et difficile pour les chômeurs et les inactifs d'y revenir. Cette situation aura des conséquences à long terme, tant sur les individus que sur la société dans son ensemble.

Il n'existe pas de solution miracle pour répondre à ce défi de l'emploi. Une approche diversifiée, associant des mesures visant à améliorer l'environnement macroéconomique et à stimuler les investissements, ainsi que des mesures politiques pour répondre aux enjeux du marché du travail, sera nécessaire. Les politiques en faveur de l'entrepreneuriat inclusif peuvent faire partie de cet ensemble de mesures. Ces politiques ont pour objectif de s'assurer que toutes les catégories de personnes, quelles que soient leurs expériences ou caractéristiques personnelles, ont la possibilité de créer leur propre entreprise et de travailler comme indépendant.

\section{L'entrepreneuriat au sein des groupes sous-représentés et défavorisés}

En 2014, 30,6 millions de personnes travaillaient en indépendant dans l'Union européenne. Parmi elles, 24,5 millions étaient des femmes, des jeunes (15-24 ans), des seniors (50-64 ans), des personnes sans emploi au cours de l'année précédente ou nées hors de l'Union européenne. Bien qu'elles représentent la majorité des travailleurs indépendants, les personnes issues de ces groupes ont généralement plus de difficultés à créer et développer leur entreprise que le reste de la population et de meilleurs résultats pourraient être obtenus si ces obstacles étaient surmontés. De plus, les entrepreneurs et travailleurs indépendants issus des groupes défavorisés et sous-représentés ont tendance à enregistrer de moins bons résultats (en ce qui concerne les recettes et les revenus, par exemple), ce qui réduit leurs chances de succès.

\section{Les politiques d'entrepreneuriat inclusif}

\section{Entreprises en expansion}

Les politiques d'entrepreneuriat inclusif peuvent contribuer de façon importante à surmonter les obstacles à la création d'entreprises de qualité par des groupes sous-représentés et défavorisés. Elles peuvent porter sur plusieurs domaines, notamment les institutions (y compris culturelles), les réglementations, l'accès aux financements et les compétences entrepreneuriales. En revanche, elles négligent souvent de soutenir la croissance des entreprises en améliorant la qualité des start-up. Le soutien et la survie des entreprises constituent l'un des principaux thèmes de ce rapport. On suppose souvent que les entreprises des groupes victimes d'exclusion sociale sont unipersonnelles et opèrent dans des secteurs à faible croissance. Ce n'est évidemment pas toujours le cas. Les femmes, les jeunes, les seniors, les immigrés ou les membres issus de minorités ethniques sont presque aussi nombreux que les entrepreneurs hommes d'âge moyen (25-49 ans) à posséder du personnel (27\% contre $29 \%$ ). De plus, nombre 
d'entrepreneurs appartenant à ces groupes visent une croissance élevée. Les jeunes (18-30 ans) sont, par exemple, $30 \%$ plus susceptibles que la population générale des entrepreneurs de créer au moins 19 emplois au cours des cinq premières années d'activité. Le rôle des politiques ici est double. Premièrement, elles doivent davantage axer le financement, le conseil et la formation sur la promotion de la croissance plutôt que sur la promotion de la création d'entreprises comme fin en soi. Deuxièmement, elles peuvent inciter plus de personnes à créer une entreprise orientée vers la croissance, par exemple par le biais d'actions destinées à les aider à avoir confiance en elles et à les motiver pour se développer. Les programmes tels que «Going for Growth» en Irlande cherchent à motiver et soutenir les créatrices d'entreprises dans le cadre de groupes de pairs. Cette initiative est relativement peu onéreuse (1 500 euros par personne), tandis qu'une cohorte (60 femmes) du programme 2013 a pu créer 50 emplois l'année suivante. Outre la motivation, les entreprises en développement ont également besoin de financements. Les fonds spéciaux, comme le Seed Money Fund dans la province de Trente en Italie, sont efficaces pour soutenir le développement d'entreprises innovantes gérées par des entrepreneurs issus de groupes minoritaires. Ce fonds lance des appels à propositions ciblés pour financer des projets innovants qui s'adressent à des groupes spécifiques d'entrepreneurs, comme les jeunes ou les femmes. En 2011, 40 entreprises ont pu être financées pour un budget total de 4,5 millions d'euros.

\section{Coaching et mentorat}

L'un des meilleurs moyens pour aider les entrepreneurs à acquérir les compétences indispensables pour réussir est d'offrir des services de coaching et de mentorat. La plupart des initiatives de politique publique ont recours à des coaches et des mentors bénévoles appartenantà la communauté locale des entrepreneurs. Pour accroître leurs chances de réussite, ces initiatives doivent former les coaches et mentors et utiliser un processus d'appariement tenant compte des caractéristiques personnelles et professionnelles des participants. Un autre exemple est celui du Centre Ergani dans le nord de la Grèce. Fondé en 1991, il propose un programme de mentorat pour les femmes entrepreneurs et fait appel à des femmes bénévoles issues des communautés locales. Le mentorat et le coaching par les pairs est une autre méthode qui a fait ses preuves auprès des entrepreneurs minoritaires. Ces approches permettent en effet de renforcer le niveau de participation, les entrepreneurs étant plus susceptibles de s'identifier à leurs pairs qu'à des professionnels du coaching. Cet aspect est particulièrement important pour les groupes tels que les entrepreneurs issus des minorités ethniques, qui participent généralement peu aux programmes d'aide du secteur public.

\section{Principales recommandations politiques}

- Soutenir la création et le développement d'entreprises grâce à des mesures politiques en faveur de l'entrepreneuriat inclusif. Soutenir en priorité la croissance des entrepreneurs désireux de se développer.

- Promouvoir des modèles de réussite d'entreprises issues de toutes les catégories sociales et notamment des femmes, des jeunes, des seniors, des personnes handicapées, immigrées et issues de minorités ethniques. Inspirer les entrepreneurs potentiels et démontrer qu'il est possible de créer et de développer son entreprise.

- Créer des réseaux pour les entrepreneurs qui cherchent à se développer, en particulier ceux issus de groupes minoritaires qui manquent souvent de compétences entrepreneuriales et de ressources financières. Même si le développement de réseaux au sein de chaque groupe social peut contribuer à créer une communauté solidaire, il est également important de mettre en relation ces entrepreneurs avec le monde général de l'entreprise, afin d'optimiser la mise en commun des connaissances et des ressources. 
- Fournir un soutien aux entreprises en développement par le biais des canaux de soutien traditionnels. Pour ce faire, il sera nécessaire de fournir des services de proximité et d'aide ciblés pour nouer un premier contact avec les membres des groupes défavorisés et sousreprésentés.

- Soutenir l'acquisition de compétences entrepreneuriales et la confiance en soi grâce au coaching et au mentorat. Recourir à un processus d'appariement reposant sur des critères clairement définis tels que le sexe, l'origine ethnique et le secteur d'activité. Limiter le coaching et le mentorat à une durée d'un à deux ans pour ne pas mettre en place une relation de dépendance entre le mentor et le bénéficiaire.

- Dispenser une formation aux mentors et aux coaches, notamment une formation psychosociale portant sur les problèmes et défis particuliers auxquels font face les entrepreneurs défavorisés, et pour améliorer leurs compétences en communication.

- Augmenter la fréquence des évaluations solides pour mesurer l'impact des programmes d'entrepreneuriat inclusif afin de créer une base de connaissances qui pourra faciliter l'élaboration des politiques. Ces évaluations doivent non seulement examiner l'efficacité et le rapport coût/efficacité, mais également les risques d'effets d'aubaine (un entrepreneur qui ne modifie pas son comportement en fonction du soutien fourni) et d'effets de déplacement (par exemple, un soutien qui porte préjudice à un autre entrepreneur). 



\section{Guide de lecture}

Ce guide de lecture fournit des informations et des indications méthodologiques concernant les données utilisées dans cet ouvrage: 1) programme d'indicateurs de l'entrepreneuriat OCDE-Eurostat; 2) enquête Eurostat sur les forces de travail; 3) Global Entrepreneurship Monitor; 4) statistiques sur le revenu et les conditions de vie.

Ce

tte partie fournit des informations sur les principales sources de données utilisées dans cet ouvrage. Elle fournit également des indications méthodologiques et décrit les principaux concepts statistiques utilisés. Des renvois et des références sont proposés aux lecteurs qui souhaiteraient obtenir de plus amples informations.

Attention, étant donné que cet ouvrage s'appuie sur plusieurs sources de données, les concepts et définitions de ces sources ne sont pas toujours cohérents. Ces disparités sont plus manifestes lorsque les données sont présentées par âge. Par exemple, l'enquête sur les forces de travail d'Eurostat prend en compte les personnes dès l'âge de 15 ans. Eurostat définit ainsi les jeunes comme tous les individus âgés de 15 à 24 ans. D'autres sources de données, parmi lesquelles le Global Entrepreneurship Monitor, sondent les personnes âgées de 18 à 64 ans et ont dès lors une autre définition de la jeunesse. Pour le Global Entrepreneurship Monitor, les jeunes sont âgés de 18 à 30 ans. Le même problème se pose pour les données relatives aux entrepreneurs plus âgés. Malgré les efforts pour harmoniser autant que possible les données rapportées, des différences subsistent. Les chiffres et textes indiquent clairement les définitions présentées et discutées.

\section{Programme d'indicateurs de l'entrepreneuriat OCDE-Eurostat}

Mené conjointement par la direction des statistiques de l'OCDE et Eurostat, le programme d'indicateurs de l'entrepreneuriat (PIE) OCDE-Eurostat vise à développer des indicateurs de l'entrepreneuriat pertinents sur le plan politique et comparables au niveau international en vue de soutenir les travaux analytiques et de politique relatifs à l'entrepreneuriat. À cette fin, le programme a élaboré un cadre d'analyse et de mesure de l'entrepreneuriat ainsi qu'une méthodologie pour la production de statistiques harmonisées sur l'entrepreneuriat. Ce cadre introduit une distinction conceptuelle entre la performance entrepreneuriale (c'est-à-dire le type et la quantité d'entrepreneuriat), les déterminants de l'entrepreneuriat (c'est-à-dire les facteurs influençant la performance entrepreneuriale) et les impacts sociaux et économiques de l'entrepreneuriat.

L'implication directe des instituts nationaux des statistiques (INS) de l'OCDE et des pays partenaires en vue de produire des statistiques harmonisées sur l'entrepreneuriat constitue un trait caractéristique de ce programme, qui distingue clairement le PIE d'autres initiatives internationales. Jusqu'à présent, les données produites ont porté sur un ensemble clé d'indicateurs de la performance entrepreneuriale, à savoir les statistiques sur la démographie des entreprises relatives à la naissance, au décès, à la survie et à la croissance des entreprises, ainsi que les statistiques sur l'impact des naissances et décès d'entreprises sur la création et la destruction d'emplois. Les statistiques officielles sont produites chaque année par les INS, conformément à la méthodologie figurant dans l'ouvrage 
Eurostat-OECD Manual on Business Demography Statistics (2007 — http://www.oecd.org/std/39974460. pdf). Disponible sur OECD.Stat (http://stats.oecd.org/), cette base de données couvre quelque 25 pays et est mise à jour chaque année.

La méthodologie recommande d'employer des registres d'entreprises pour calculer les indicateurs de démographie des entreprises. Afin d'accroître la comparabilité internationale, et vu l'exclusion des firmes n'employant pas de personnel du registre des entreprises de certains pays, l'unité statistique adoptée pour les données de démographie des entreprises du PIE est l'entreprise comportant au moins un employé. Les sociétés avec personnel sont par ailleurs plus pertinentes d'un point de vue économique pour leur contribution à la création d'emplois et leurs plus grandes probabilités d'innovation.

S'agissant d'un programme à long terme, le PIE a été élaboré pour répondre aux nouveaux besoins exprimés par les responsables politiques et la communauté des chercheurs. Dans cette optique, le programme s'est récemment penché sur la question de la mesure de l'entrepreneuriat vert et a commencé à rassembler des indicateurs portant sur les femmes et l'entrepreneuriat. D'autre part, pour répondre à la demande de mises à jour trimestrielles, le programme a établi une nouvelle série d'«indicateurs récents d'entrepreneuriat», qui livre les dernières tendances en matière de créations et de faillites d'entreprises. Sur le plan des déterminants, le PIE a entamé des recherches en vue d'approfondir la compréhension de la comparabilité internationale de données capitales sur les entreprises.

La publication annuelle Panorama de l'entrepreneuriat (http://www.oecd-ilibrary.org/industry-andservices/panorama-de-l-entrepreneuriat_22266968) présente les principaux résultats ainsi que les développements du PIE.

\section{Encadré 1 - Définition de l'entrepreneuriat par l'OCDE-Eurostat}

Introduit en 2006, le programme d'indicateurs de l'entrepreneuriat OCDE-Eurostat a élaboré des définitions des termes «entrepreneur», «entrepreneuriat» et "activité entrepreneuriale» pour soutenir le développement des indicateurs associés. Le programme reconnaît le désaccord et les diverses perspectives opposant les chercheurs qui se penchent sur cette question et adopte délibérément une approche pragmatique reposant sur deux principes, la pertinence et la mesurabilité. Il importe de souligner que les définitions de l'OCDE et d'Eurostat mettent en exergue la nature dynamique de l'activité entrepreneuriale et sont axées non pas sur les intentions, mais sur les actions. Elles ont pour but de guider la collecte et l'analyse de données:

Les entrepreneurs sont des personnes (propriétaires de leur entreprise) qui cherchent à générer de la valeur via la création ou le développement d'une activité économique en identifiant et en exploitant de nouveaux produits, procédés ou marchés.

L'activité entrepreneuriale est l'action humaine consistant à entreprendre en vue de générer de la valeur via la création ou le développement d'une activité économique en identifiant et en exploitant de nouveaux produits, procédés ou marchés.

L'entrepreneuriat est le phénomène associé à l'activité entrepreneuriale.

Ces définitions distinguent l'activité entrepreneuriale de l'activité professionnelle «ordinaire». En outre: i) elles indiquent que des sociétés et autres entreprises peuvent se montrer entrepreneuriales, bien que seuls les individus aux commandes de ces organisations et les détenant peuvent être considérés comme des entrepreneurs; ii) elles soulignent le fait que l'action entrepreneuriale est manifestée plutôt que planifiée ou voulue; iii) elles n'assimilent pas l'activité entrepreneuriale à la formation de tout «véhicule» spécifique, qu'il soit formel comme une société constituée, ou informel, bien qu'elles autorisent les statistiques de véhicules spécifiques incarnant l'activité entrepreneuriale; et iv) bien qu'elles soient définies dans le contexte des entreprises, elles incluent la création de valeur économique, sociale et culturelle.

Source: Ahmad, N. et Seymour, R. (2008), «Defining Entrepreneurial Activity: Definitions Supporting Frameworks for Data Collection", Document de travail Statistique OCDE 2008/1, Publications OCDE, Paris. 


\section{Encadré 2 - Le cadre d'analyse et de mesure de l'entrepreneuriat du programme d'indicateurs de l'entrepreneuriat (PIE)}

Le PIE admet qu'aucun indicateur ne suffit à lui seul pour englober la complexité de l'entrepreneuriat. C'est pourquoi il a développé un ensemble de mesures destinées à saisir différents aspects ou différents types d'entrepreneuriat. Appelées «indicateurs de performance entrepreneuriale», ces mesures contribuent à analyser des questions clés telles que: Quel est le taux de création de nouvelles entreprises dans un pays? Combien d'emplois sont ainsi générés? Combien de jeunes entreprises survivent les premières années suivant leur création? Innoveront-elles ou exporteront-elles par la suite? Les entreprises sont-elles le plus souvent fondées par des hommes ou des femmes? Investissent-ils dans les mêmes secteurs?

En outre, le programme adopte une approche plus complète de la mesure de l'entrepreneuriat en examinant non seulement la manifestation du phénomène entrepreneurial, mais aussi les facteurs qui l'influencent, ceux-ci allant des conditions du marché aux cadres réglementaires, en passant par la culture et les conditions d'accès au financement. Alors que certains des déterminants sont faciles à mesurer (par exemple, l'existence et le caractère restrictif de lois antitrust ou les coûts administratifs de la constitution d'une nouvelle entreprise dans tel pays), pour d'autres, la difficulté consiste à trouver une mesure appropriée (par exemple, capital-risque et capital venant d'investisseurs-mentors) et/ou à saisir la nature exacte de leur rapport avec l'entrepreneuriat (par exemple, la culture). Le but du PIE est de progresser dans les recherches relatives à ces déterminants moins bien compris et moins facilement mesurables de l'entrepreneuriat.

\begin{tabular}{|c|c|c|c|c|c|c|c|}
\hline \multicolumn{6}{|c|}{ Déterminants } & \multirow{2}{*}{$\begin{array}{l}\text { Performance } \\
\text { entrepreneuriale } \\
\text { Entreprise }\end{array}$} & \multirow[b]{2}{*}{$\begin{array}{l}\text { Création } \\
\text { d'emplois }\end{array}$} \\
\hline $\begin{array}{l}\text { Cadre } \\
\text { réglementaire }\end{array}$ & $\begin{array}{l}\text { Conditions } \\
\text { du marché }\end{array}$ & $\begin{array}{l}\text { Accès au } \\
\text { financement }\end{array}$ & $\begin{array}{l}\text { Création et } \\
\text { diffusion } \\
\text { de connaissances }\end{array}$ & $\begin{array}{l}\text { Performance } \\
\text { entrepreneuriale }\end{array}$ & Culture & & \\
\hline $\begin{array}{l}\text { Obstacles } \\
\text { administratifs } \\
\text { à l'entrée }\end{array}$ & $\begin{array}{l}\text { Législation } \\
\text { antitrust }\end{array}$ & $\begin{array}{l}\text { Accès à } \\
\text { l'emprunt }\end{array}$ & $\begin{array}{l}\text { Investissement } \\
\text { en } R \& D\end{array}$ & $\begin{array}{l}\text { Formation } \\
\text { et expérience des } \\
\text { entrepreneurs }\end{array}$ & $\begin{array}{l}\text { Attitude du public } \\
\text { face aux risques }\end{array}$ & $\begin{array}{l}\text { Création } \\
\text { d'emplois }\end{array}$ & $\begin{array}{l}\text { Croissance } \\
\text { économique }\end{array}$ \\
\hline $\begin{array}{l}\text { Obstacles } \\
\text { administratifs } \\
\text { à la croissance }\end{array}$ & Concurrence & $\begin{array}{l}\text { Investis- } \\
\text { seurs- } \\
\text { mentors }\end{array}$ & $\begin{array}{l}\text { Interface } \\
\text { université/ } \\
\text { industrie }\end{array}$ & \multicolumn{2}{|l|}{$\begin{array}{l}\text { Formation à la gestion } \\
\text { d'entreprise } \\
\text { et à l'entrepreneuriat } \\
\text { (qualifications) }\end{array}$} & $\begin{array}{l}\text { Création de } \\
\text { richesses }\end{array}$ & $\begin{array}{l}\text { Réduction de } \\
\text { la pauvreté }\end{array}$ \\
\hline $\begin{array}{l}\text { Réglementation } \\
\text { des faillites }\end{array}$ & $\begin{array}{l}\text { Accès au } \\
\text { marché } \\
\text { intérieur }\end{array}$ & $\begin{array}{l}\text { Accès au } \\
\text { capital-risque }\end{array}$ & $\begin{array}{l}\text { Coopération } \\
\text { technologique } \\
\text { entre les } \\
\text { entreprises }\end{array}$ & $\begin{array}{l}\text { Infrastructure } \\
\text { entrepreneuriale }\end{array}$ & $\begin{array}{l}\text { Désir de créer } \\
\text { une entreprise }\end{array}$ & & $\begin{array}{l}\text { Formalisation } \\
\text { du secteur } \\
\text { informel }\end{array}$ \\
\hline $\begin{array}{l}\text { Réglementation } \\
\text { en matière de } \\
\text { santé, sécurité et } \\
\text { environnement }\end{array}$ & $\begin{array}{l}\text { Accès aux } \\
\text { marchés } \\
\text { étrangers }\end{array}$ & $\begin{array}{l}\text { Accès à } \\
\text { d'autres } \\
\text { types de fonds } \\
\text { propres }\end{array}$ & $\begin{array}{l}\text { Accès } \\
\text { au haut débit }\end{array}$ & Immigration & $\begin{array}{l}\text { Formation } \\
\text { à l'entrepreneuriat } \\
\text { (état d'esprit) }\end{array}$ & & \\
\hline $\begin{array}{l}\text { Réglementation } \\
\text { des produits }\end{array}$ & $\begin{array}{l}\text { Niveau } \\
\text { d'intervention } \\
\text { du secteur } \\
\text { public }\end{array}$ & $\begin{array}{l}\text { Marchés } \\
\text { boursiers }\end{array}$ & $\begin{array}{l}\text { Accès } \\
\text { au haut débit }\end{array}$ & & & & \\
\hline \multirow{2}{*}{$\begin{array}{l}\text { Réglementation } \\
\text { du marché du travail } \\
\text { Système } \\
\text { judiciaire et } \\
\text { juridique }\end{array}$} & \multirow[t]{4}{*}{$\begin{array}{l}\text { Marchés } \\
\text { publics }\end{array}$} & & & Entreprises & Emploi & \multicolumn{2}{|c|}{ Création de richesses } \\
\hline & & & & $\begin{array}{l}\text { Taux de naissance des } \\
\text { entreprises employant } \\
\text { des salariés }\end{array}$ & $\begin{array}{l}\text { Taux d'entreprises à } \\
\text { forte croissance } \\
\text { (emploi) }\end{array}$ & \multicolumn{2}{|c|}{$\begin{array}{l}\text { Taux d'entreprises à forte } \\
\text { croissance }\end{array}$} \\
\hline $\begin{array}{l}\text { Sécurité sociale } \\
\text { et assurance- } \\
\text { maladie }\end{array}$ & & & & $\begin{array}{l}\text { Taux de décès des } \\
\text { entreprises employant } \\
\text { des salariés }\end{array}$ & $\begin{array}{l}\text { Taux de gazelles } \\
\text { (emploi) }\end{array}$ & \multicolumn{2}{|c|}{$\begin{array}{l}\text { Taux de gazelles (chiffre } \\
\text { d'affaires) }\end{array}$} \\
\hline $\begin{array}{l}\text { Impôts sur le } \\
\text { revenu impôts sur } \\
\text { le patrimoine/legs }\end{array}$ & & & & $\begin{array}{l}\text { Taux de } \\
\text { renouvellement des } \\
\text { entreprises }\end{array}$ & $\begin{array}{l}\text { Taux de propriété de } \\
\text { start-up }\end{array}$ & \multicolumn{2}{|c|}{$\begin{array}{l}\text { Valeur ajoutée par les } \\
\text { entreprises jeunes ou petites }\end{array}$} \\
\hline \multirow[t]{3}{*}{$\begin{array}{l}\text { Impôts sur les } \\
\text { sociétés et sur le } \\
\text { capital }\end{array}$} & $\begin{array}{l}\text { Système des } \\
\text { brevets; } \\
\text { normes }\end{array}$ & & & $\begin{array}{l}\text { Croissance nette } \\
\text { de la population } \\
\text { entrepreneuriale }\end{array}$ & $\begin{array}{l}\text { Taux de propriété } \\
\text { de la population } \\
\text { entrepreneuriale }\end{array}$ & \multicolumn{2}{|c|}{$\begin{array}{l}\text { Contribution à la productivité } \\
\text { des entreprises jeunes ou } \\
\text { petites }\end{array}$} \\
\hline & & & & $\begin{array}{l}\text { Taux de survie après } \\
3 \text { et } 5 \text { ans }\end{array}$ & $\begin{array}{l}\text { Emploi dans les } \\
\text { entreprises de } 3 \text { et } \\
5 \text { ans }\end{array}$ & \multicolumn{2}{|c|}{$\begin{array}{l}\text { Performance de l'innovation } \\
\text { dans les entreprises jeunes ou } \\
\text { petites }\end{array}$} \\
\hline & & & & $\begin{array}{l}\text { Taux de survie après } \\
3 \text { et } 5 \text { ans }\end{array}$ & $\begin{array}{l}\text { Taille moyenne des } \\
\text { entreprises après } \\
3 \text { et } 5 \text { ans }\end{array}$ & \multicolumn{2}{|c|}{$\begin{array}{l}\text { Résultat à l'exportation des } \\
\text { entreprises jeunes ou petites }\end{array}$} \\
\hline
\end{tabular}

Source: OCDE (2014), Panorama de l'entrepreneuriat 2014, publication OCDE. 


\section{Enquête Eurostat sur les forces de travail}

L'enquête Eurostat sur les forces de travail est une étude mensuelle menée auprès des ménages dans tous les États membres de l'Union européenne et collectant des informations à propos du marché du travail. Le présent rapport se concentre sur les données de l'Enquête sur les forces de travail liées au travail indépendant. Eurostat définit un travailleur indépendant comme une personne œuvrant dans sa propre entreprise, son exploitation agricole ou son cabinet professionnel et tirant des avantages économiques de cette occupation, qu'il s'agisse d'un salaire, de bénéfices, d'avantages en nature ou de gains familiaux (dans le cas de personnes travaillant en famille). Les travailleurs bénévoles sont exclus de cette définition. L'objet de l'entreprise n'a aucune influence sur le statut d'indépendant d'un individu; en d'autres termes, l'entreprise peut avoir un but lucratif ou une vocation sociale non lucrative.

L'entreprise des travailleurs indépendants peut employer une personne ou davantage. Cela n'a aucun effet sur leur statut d'indépendant, tant qu'ils travaillent directement pour l'entreprise. Dans ce sens, la même entreprise peut occuper plus d'un indépendant. Par exemple, chaque membre d'un partenariat peut être considéré comme indépendant, aussi longtemps que l'entreprise demeure son activité professionnelle principale. Les dirigeants d'entreprises sont toutefois exclus du groupe des travailleurs indépendants s'ils ne sont pas impliqués dans la gestion journalière de l'entreprise.

Il existe différentes conceptions du travail indépendant:

- l'indépendant pour son propre compte est une personne n'employant aucun salarié pour son activité;

- l'employeur est un indépendant qui emploie du personnel;

- le taux de travail indépendant est défini comme le nombre de travailleurs indépendants, comprenant les indépendants pour leur propre compte et les employeurs (c'est-à-dire les indépendants employant des salariés) par rapport au nombre de travailleurs salariés.

Pour en savoir plus sur l'enquête Eurostat sur les forces de travail, veuillez vous référer à: http://ec.europa.eu/eurostat/web/labour-market/methodology.

\section{Global Entrepreneurship Monitor}

Le Global Entrepreneurship Monitor (GEM) est une initiative internationale qui mesure les activités et attitudes entrepreneuriales de par le monde par le biais d'enquêtes annuelles menées auprès de la population adulte (âgée de 18 ans et plus) des pays participants. Elle collecte les réponses données par les personnes interrogées sur leur attitude à l'égard de l'entrepreneuriat, leurs activités préalables au démarrage d'une entreprise, leur travail pendant la phase initiale de leur entreprise, leur implication lorsque celle-ci est établie et la fermeture de leur entreprise.

Contrairement à d'autres études portant sur les entreprises, le GEM interroge des ménages (des individus) de manière à pouvoir identifier les personnes engagées à divers stades de l'entrepreneuriat. L'unité d'analyse de cette étude étant l'individu plutôt que l'entreprise, cela permet de collecter des informations sur les motivations et aspirations incitant à l'entrepreneuriat ainsi que sur d'autres caractéristiques individuelles.

En 2013, dernière année de collecte des données de référence du présent rapport, le GEM a couvert 70 pays. Depuis 1999, il a examiné plus de 90 pays. Les 28 États de l'Union européenne ont été couverts en 2013, à l'exception de l'Autriche, la Bulgarie, Chypre, du Danemark et de Malte.

En 2013, la taille des échantillons s'est échelonnée de 2000 personnes dans la plupart des pays à 24600 en Espagne. L'échantillon total sur l'ensemble de l'Union européenne regroupait 86237 personnes. Les réponses sont pondérées par âge et par sexe afin que les résultats reflètent la population nationale. Pour une plus grande fiabilité des résultats, les données présentées dans ce chapitre ont été rassemblées (c'est-à-dire combinées) par pays pour les années 2009 à 2013, ce qui augmente considérablement la taille de l'échantillon et autorise l'élaboration de présentations plus détaillées. 
Plusieurs indicateurs du GEM sont mentionnés dans ce rapport:

- Le taux d'entrepreneuriat naissant est la proportion des membres de la population activement impliqués dans la création d'une entreprise dont ils seront propriétaires en tout ou en partie. Cette activité n'a pas rapporté de traitement, de salaire ou toute autre rémunération aux propriétaires depuis plus de trois mois.

- Le taux de détention de nouvelles entreprises est la proportion des membres de la population qui sont actuellement dirigeants-propriétaires d'une nouvelle entreprise qui verse des traitements, des salaires ou toute autre rémunération à ses propriétaires depuis plus de trois mois, mais moins de 42 mois.

- L'indicateur le plus connu publié par le GEM est l'indice d'activité entrepreneuriale totale au stade précoce (TEA), qui est la somme de la proportion de la population engagée dans l'entrepreneuriat naissant et de celle ayant démarré une nouvelle entreprise au cours des 42 derniers mois. Celui-ci mesure la phase préalable au lancement d'une nouvelle entreprise (entrepreneuriat naissant) ainsi que la phase venant directement après ce lancement (gestion-détention d'une nouvelle entreprise).

- Le taux de détention d'entreprises établies du GEM mesure la proportion des membres de la population qui sont actuellement dirigeants-propriétaires d'une entreprise établie qui verse des traitements, salaires ou toute autre rémunération à ses propriétaires depuis plus de 42 mois. Cet indicateur contribue à donner des informations sur le niveau d'activités entrepreneuriales au sein d'une économie.

\section{Encadré 3-Distinctions entre les données relatives au travail indépendant et à la création d'entreprises et celles portant sur la propriété d'entreprise}

- Les données relatives au travail indépendant présentées dans la première partie de cet ouvrage proviennent de l'enquête sur les forces de travail. Elles portent sur des propriétaires-gérants d'entreprises s'octroyant un salaire ou des bénéfices sur le travail qu'ils effectuent pour leur propre compte dans leur entreprise et qui se déclarent indépendants. Les données relatives au travail indépendant se rapportent aux individus n'employant le plus souvent qu'euxmêmes, ou très peu d'autres personnes, dans des sociétés non constituées. Les personnes qui gèrent des sociétés constituées de plus grande envergure ne sont généralement pas déclarées comme travailleurs indépendants. Cela tient au fait qu'elles apparaissent dans les registres du personnel de leur entreprise et qu'elles sont dès lors considérées comme des employés. Ces données excluent également les individus en passe de fonder une entreprise dont la création n'est pas encore aboutie, de même que les propriétaires d'entreprises non impliqués dans l'exploitation quotidienne de celle-ci.

- D'autres données du présent ouvrage sont extraites du Global Entrepreneurship Monitor. Elles couvrent les individus déclarant tenter activement de démarrer leur affaire ou s'occupant déjà de leur entreprise ou de tout type de travail indépendant ou vendant des biens ou des services à des tiers. Cette définition est plus vaste que celle utilisée pour les données relatives au travail indépendant: elle inclut les travailleurs indépendants ainsi que toutes sortes de propriétaires d'entreprise. En particulier, les propriétaires-gérants de sociétés constituées sont englobés, alors qu'ils sont exclus des données sur le travail indépendant. Le Global Entrepreneurship Monitor inclut aussi les personnes qui gèrent une entreprise en tant qu'activité complémentaire, tandis que les données de l'enquête sur les forces de travail portent sur l'activité professionnelle principale. Les chiffres sur le travail indépendant concerneront donc uniquement les personnes qui consacrent plus de temps à cette activité qu'à un autre emploi, tandis que le Global Entrepreneurship Monitor inclut des données sur les entrepreneurs à temps partiel. 
Pour en savoir plus sur les méthodologies employées par le Global Entrepreneurship Monitor, veuillez consulter le «2013 GEM Global Report», disponible sur: http://www.gemconsortium.org/ report.

\section{Statistiques sur le revenu et les conditions de vie}

Les statistiques de l'Union européenne sur le revenu et les conditions de vie (EU-SILC) sont un cadre de référence pour la collecte régulière de données visant l'établissement de statistiques comparatives sur le revenu, la pauvreté, l'exclusion sociale et les conditions de vie. Ces données sont collectées dans les 28 États membres, ainsi qu'en Islande, Norvège, Suisse et Turquie.

Deux types de données sont collectées: des données transversales, obtenues auprès d'environ 130000 ménages et 270000 habitants de l'Union européenne âgés de plus de 16 ans, et des données longitudinales rassemblées auprès de quelque 100000 ménages et 200000 habitants de l'Union européenne âgés de plus de 16 ans. Les données relatives à l'exclusion sociale et aux conditions de logement proviennent de ménages et du travail, et les renseignements relatifs à la santé et à l'éducation proviennent d'individus.

Pour en savoir plus sur les statistiques sur le revenu et les conditions de vie, veuillez consulter: http://ec.europa.eu/eurostat/web/income-and-living-conditions/methodology.

\section{Références}

Ahmad, N. et Seymour, R. (2008), «Defining Entrepreneurial Activity: Definitions Supporting Frameworks for Data Collection», Document de travail Statistique OCDE 2008/1, Publications OCDE, Paris.

Global Entrepreneurship Monitor (2013), «Global Entrepreneurship Monitor 2013 Global Report», disponible sur: http://www.gemconsortium.org/docs/3106/gem-2013-global-report.

OCDE (2014), Panorama de l'entrepreneuriat 2014, Publications OCDE, Paris http://dx.doi. org/10.1787/entrepreneur_aag-2014-fr. 


\section{Chapitre 1}

\section{La politique d'entrepreneuriat inclusif de l'Union européenne}

Le niveau élevé et persistant du chômage et le nombre croissant de personnes menacées de pauvreté et d'exclusion sociale font partie des principales difficultés socio-économiques auxquelles les gouvernements de l'Union européenne doivent faire face. Ce chapitre décrit le rôle que les politiques d'entrepreneuriat inclusif peuvent jouer dans la résolution de ces défis. Le plan du reste de l'ouvrage y est également détaillé.

\section{Note Turquie/Chypre:}

1. Note en bas de page de la Turquie

Les informations figurant dans ce document qui font référence à "Chypre " concernent la partie méridionale de l'Ile. Il n'y a pas d'autorité unique représentant à la fois les Chypriotes turcs et grecs sur l'Ile. La Turquie reconnaît la République Turque de Chypre Nord (RTCN). Jusqu'à ce qu'une solution durable et équitable soit trouvée dans le cadre des Nations Unies, la Turquie maintiendra sa position sur la " question chypriote ".

2. Note en bas de page de tous les États de l'Union européenne membres de l'OCDE et de l'Union européenne La République de Chypre est reconnue par tous les membres des Nations Unies sauf la Turquie. Les informations figurant dans ce document concernent la zone sous le contrôle effectif du gouvernement de la République de Chypre. 


\section{Qu'est-ce qu'une politique d'entrepreneuriat inclusif?}

Les politiques entrepreneuriales sont dites inclusives lorsqu'elles ont pour objectif d'aider les personnes appartenant à un groupe défavorisé ou sous-représenté au sein de l'entrepreneuriat ou sur le marché du travail à créer une entreprise ou à devenir travailleur indépendant. Ces groupes incluent les femmes, les jeunes, les seniors, les personnes issues de minorités ethniques et immigrées, les handicapés et les chômeurs. Ces politiques visent à soutenir tous les modèles d'entrepreneuriat, qu'il s'agisse de sociétés constituées ou non, à but lucratif ou non (y compris l'entrepreneuriat social), à temps plein ou à temps partiel. Ces activités entrepreneuriales peuvent être exercées par des individus ou des équipes, et avoir pour ambition ou non de se développer et de recruter du personnel. Quelles que soient leur ampleur et leur portée, ces activités sont toutes exercées par des personnes qui vivent dans l'incertitude des revenus, contrairement aux salariés.

L'objectif des politiques d'entrepreneuriat inclusif est d'offrir à tous la possibilité de créer et de gérer une entreprise ou d'exercer une activité indépendante, quelles que soient leur expérience et leurs caractéristiques personnelles. Les responsables politiques peuvent contribuer à la réalisation de cet objectif en corrigeant les dysfonctionnements des marchés et des institutions et en remédiant aux défaillances comportementales qui affectent gravement les groupes défavorisés et sous-représentés. Par exemple, ils peuvent chercher à améliorer l'accès aux financements en cas de risque élevé et d'absence de garanties; supprimer les obstacles à l'acquisition de compétences entrepreneuriales et à la constitution de réseaux; instaurer une culture qui encourage l'entrepreneuriat au sein des groupes non traditionnels; sensibiliser davantage aux opportunités, avantages et pratiques de l'entrepreneuriat; et inciter à poursuivre ces activités.

Les résultats escomptés sont doubles. Premièrement, ces politiques doivent contribuer à stimuler et à soutenir la création d'entreprises pérennes par les catégories de population cibles. Elles permettraient ainsi de renforcer le taux d'activité et les liens avec le marché du travail. Les personnes ciblées auraient ainsi la possibilité de percevoir un revenu et d'améliorer leur niveau de vie. De plus, l'entrepreneuriat donne l'occasion de participer plus activement à la société, d'augmenter la confiance en soi, de créer et de consolider les liens existants au sein de la communauté locale. L'entrepreneuriat peut également procurer des avantages économiques lorsqu'il contribue à créer des revenus et des emplois.

Deuxièmement, les politiques d'entrepreneuriat inclusif permettent d'améliorer l'employabilité des personnes cibles. Toutes les personnes ayant bénéficié d'une formation ou d'un soutien à l'entrepreneuriat ne créeront pas forcément une entreprise. Quoi qu'il en soit, les bénéficiaires de ces programmes de formation à l'entrepreneuriat, d'un mentorat ou d'un coaching ou d'une aide à l'élaboration d'un plan d'affaires acquièrent des compétences et une expérience qui peuvent augmenter leur employabilité. Ces politiques peuvent ainsi avoir un impact positif sur l'emploi, même si ces personnes ne créent pas une entreprise pérenne. 


\section{Pourquoi les politiques d'entrepreneuriat inclusif sont-elles si importantes?}

Depuis le début de la crise économique, le taux de chômage a augmenté pour tous les groupes cibles des politiques d'entrepreneuriat inclusif (graphique 1.1). Si le taux de chômage est élevé pour toutes les catégories de population (10\% en moyenne), il est particulièrement catastrophique chez les jeunes puisqu'un quart d'entre eux étaient sans emploi en 2013.

\section{Graphique 1.1. Taux de chômage de l'Union européenne}

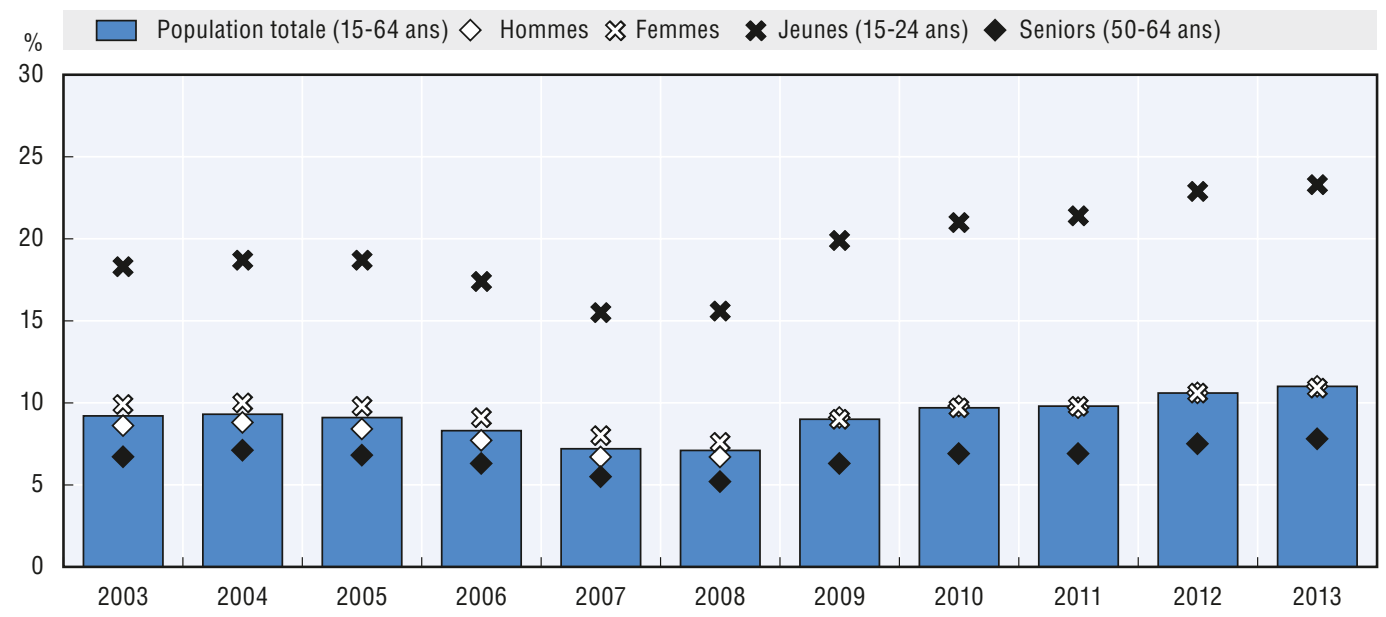

Source: Eurostat (2014), Enquête sur les forces de travail 2003-2013.

StatLink 需正 http://dx.doi.org/10.1787/888933313126

Le taux de chômage ne reflète toutefois que partiellement la situation. Il est également important de tenir compte des taux d'activité, car les personnes qui quittent le marché de travail sont exclues des calculs et des taux de chômage. Le graphique 1.2 présente les taux d'activité des deux principaux groupes cibles des politiques d'entrepreneuriat inclusif. En effet, entre 2008 et 2013, le taux d'activité globale de la population adulte en âge de travailler est resté légèrement supérieur à $70 \%$. En revanche, celui de certains groupes sociaux était nettement inférieur. En 2013, bien qu'ils aient légèrement augmenté par rapport à 2008, les taux d'activités des femmes et des seniors n'étaient que de $66 \%$ et $64 \%$ respectivement. Quant aux jeunes, leur taux d'activité n'était que de 42 \% en 2013, soit une baisse par rapport au taux de 44 \% en 2008.

\section{Graphique 1.2. Taux de participation au marché du travail de l'Union européenne}

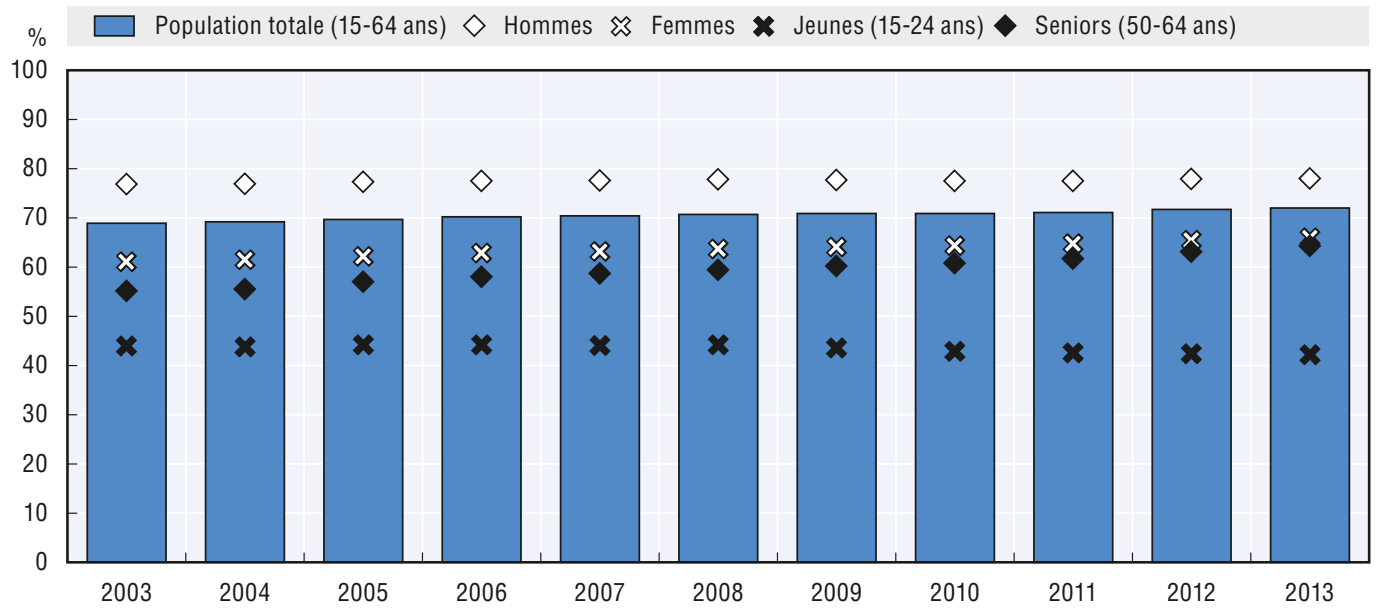

Source: Eurostat (2014), Enquête sur les forces de travail 2003-2013. 
De plus, la pauvreté et l'exclusion sociale affectent l'Union européenne depuis longtemps. En 2012, près d'un quart de la population de l'Union européenne était menacée de pauvreté ou d'exclusion sociale. Cette proportion avait baissé avant la crise, mais le début de la récession a inversé la tendance et entraîné la résurgence de ce problème (graphique 1.3). Le lancement de la stratégie Europe 2020 a été l'occasion de réitérer l'engagement des États membres à résoudre ce problème et à réduire le nombre de personnes menacées de pauvreté de 20 millions d'ici à 2020 (voir http://ec.europa.eu/europe2020/index_fr.htm).

\section{Graphique 1.3. Proportion de la population de l'EU-28 menacée de pauvreté ou d'exclusion sociale}

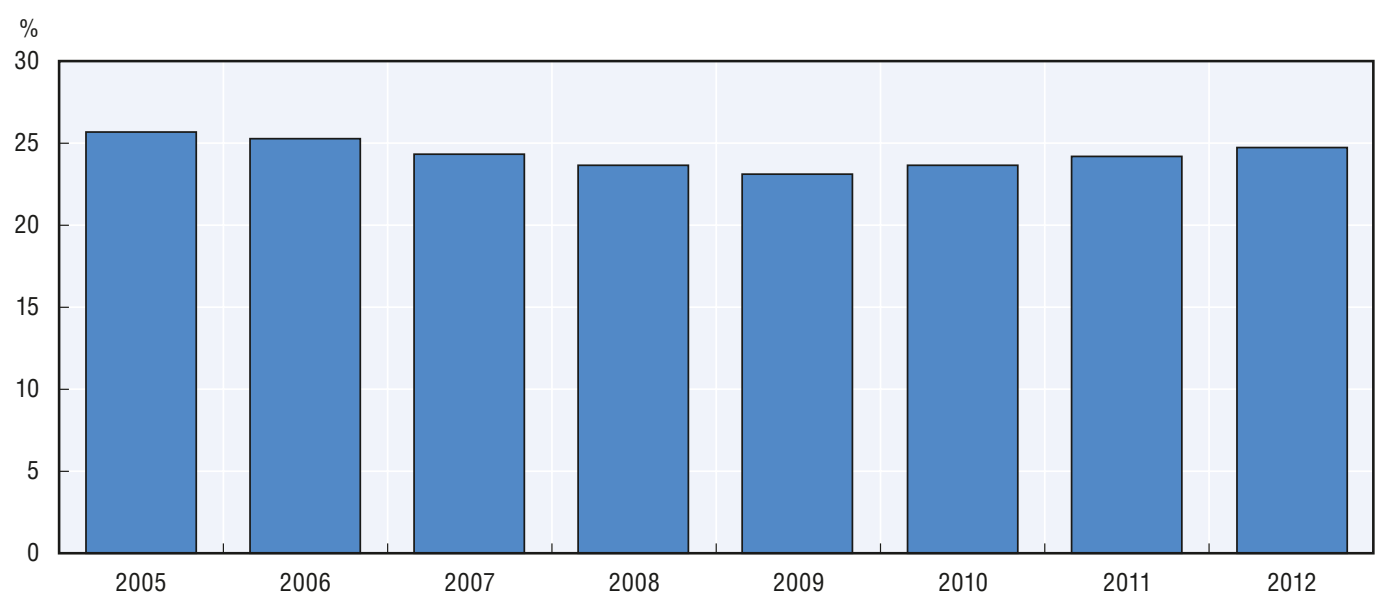

Note: 1. Les données du graphique 1.3 antérieures à 2010 excluent la Croatie. L'inclusion de la Croatie pour les années 2010 à 2012 n'a pas d'impact sur les données fournies.

Source: Eurostat, Statistiques sur le revenu, l'inclusion sociale et les conditions de vie, 2014.

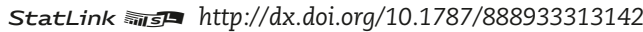

L'adoption de politiques actives du marché du travail constitue le meilleur moyen de lutter efficacement contre la pauvreté et l'exclusion sociale. Ces mesures comprennent des formations, le partage d'emplois, les incitations à l'emploi et les programmes d'aide à la création d'entreprises pour les personnes au chômage, inactives et celles risquant de perdre leur emploi. En 2011, les États membres ont consacré environ 205 milliards d'euros aux politiques actives du marché du travail. Cet effort représente 1,9 \% des PIB de l'ensemble des États membres combinés (graphique 1.4).

Toutefois, sur la totalité des dépenses engagées, seule une infime proportion est allouée aux mesures d'incitation à la création d'entreprises (environ $2 \%$ au niveau européen). Cette proportion varie d'un État membre à l'autre. En République slovaque, ces incitations ont représenté $9 \%$ des dépenses au titre des politiques actives du marché du travail en 2012. Étant donné l'intérêt de nombreux chômeurs ou inactifs pour la création d'entreprises, les obstacles auxquels ils ont tendance à être confrontés en l'absence d'aides publiques, le potentiel des autres possibilités d'emploi et les avantages en termes d'employabilité et de maintien sur le marché du travail à long terme, le travail indépendant et la création d'entreprises ne semblent pas faire l'objet d'une attention suffisante dans le cadre des politiques actives du marché du travail.

Il convient de souligner qu'environ 10 \% des chômeurs ayant réintégré le marché du travail exercent une activité indépendante (graphique 1.5) et que ces programmes procurent également des avantages aux personnes qui ne souhaitent pas créer une entreprise ou qui ont échoué dans cette tentative, notamment en contribuant à augmenter leur niveau de compétences et d'employabilité. À première vue, les $2 \%$ des dépenses des politiques actives du marché du travail alloués au travail indépendant et à la création d'entreprises ne sont pas en adéquation avec ces $10 \%$ de chômeurs créateurs d'entreprise. Cet écart semble davantage dû à un manque de sensibilisation et aux traditions du gouvernement dans ce domaine qu'à un manque d'instruments adaptés. 
Bien sûr, la création d'entreprises et le travail indépendant ne doivent pas être considérés comme la panacée. Ce type de soutien ne convient pas à de nombreux chômeurs et inactifs, ou ne les motive pas. De plus, les interventions doivent être bien conçues pour être efficaces. Cet ouvrage propose deux solutions pour y parvenir et fournit des données prouvant leur efficacité.

\section{Graphique 1.4. Dépenses au titre des programmes de soutien au marché du travail et d'incitation à la création d'entreprises, 2011}

En pourcentage du PIB

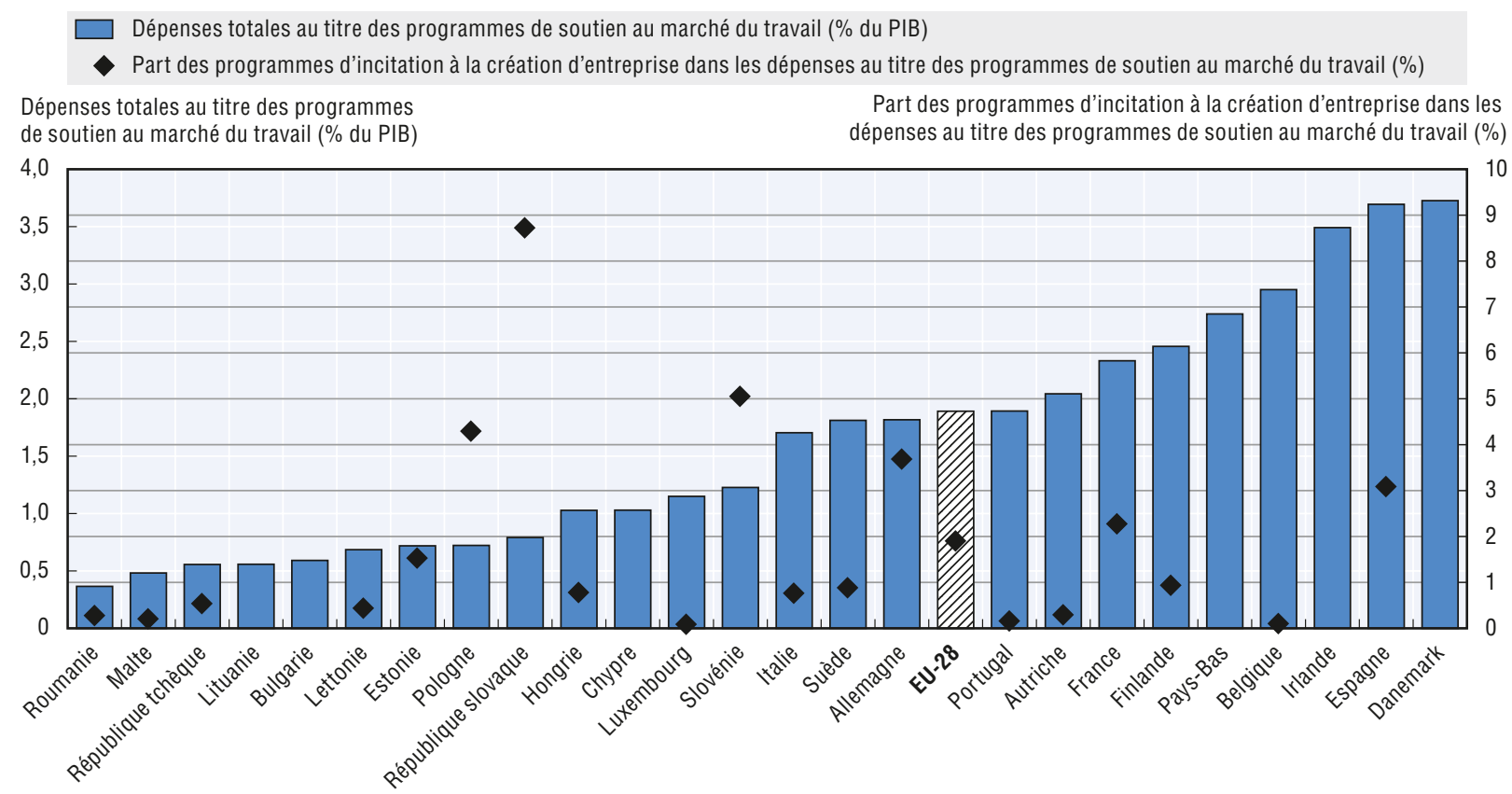

Source: Eurostat (2014c), LMP expenditure by type of action, 2014.

\section{Graphique 1.5. Participation au marché du travail à la suite d'une période de chômage dans l'EU-28}

Proportion de personnes au chômage ayant retrouvé un emploi au cours de l'année suivante

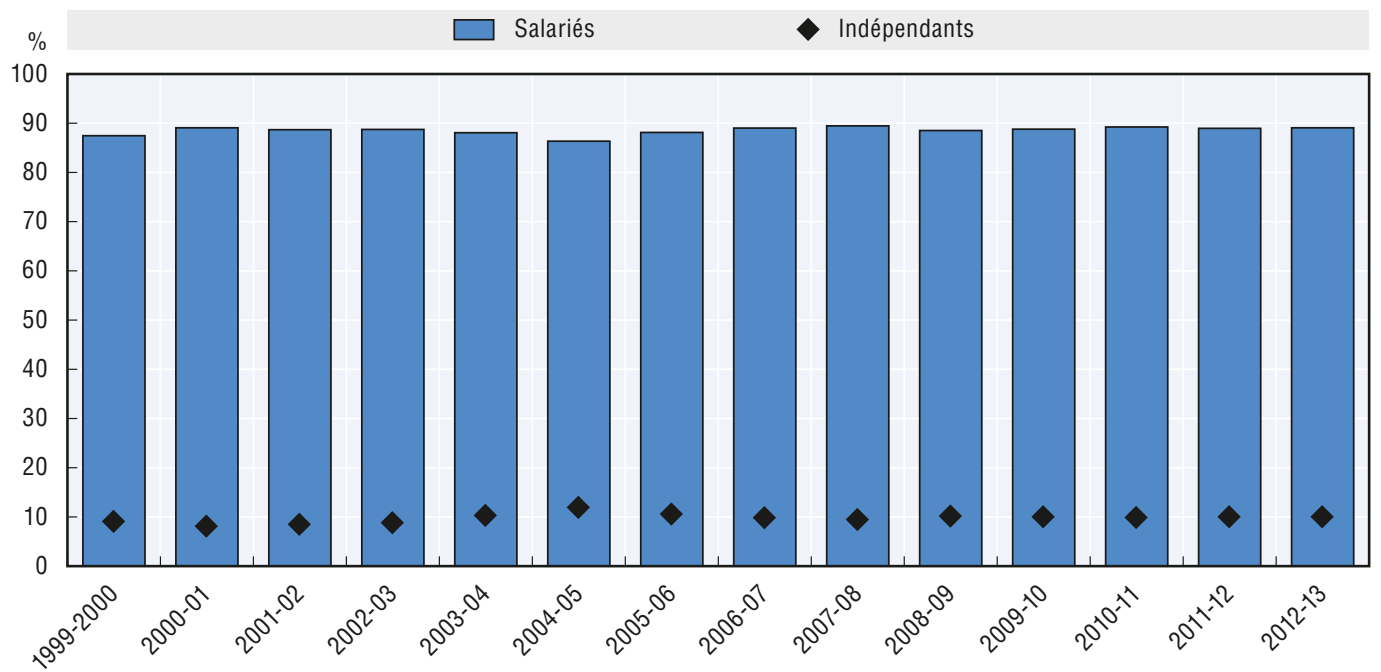

Source: Eurostat, présentations tabulaires spéciales de l'enquête sur les forces de travail, 2000-2013. 


\section{Guide de lecture de la présente publication}

Cet ouvrage examine de quelle façon une politique peut soutenir l'entrepreneuriat inclusif. La première partie présente des données sur le niveau et la qualité du travail indépendant et de la création d'entreprises au sein des principaux groupes défavorisés ou sous-représentés dans le monde de l'entreprise, à savoir les femmes, les jeunes, les seniors, les personnes sans emploi et immigrées dans l’Union européenne.

Le premier chapitre de cette partie, le chapitre 2, commente les données relatives à l'emploi indépendant et autres activités de création d'entreprises des femmes dans l'Union européenne, notamment les proportions et nombres d'entre elles ayant un statut d'indépendant ainsi que les secteurs économiques où elles sont actives. Sont également présentées dans ce chapitre les données du Global Entrepreneurship Monitor portant sur les activités entrepreneuriales des femmes aux différentes étapes du cycle de vie d'une entreprise. Des données supplémentaires tirées de l'étude présentent les obstacles rencontrés par les femmes au moment de démarrer leur entreprise et d'autres caractéristiques clés sur leur entreprise. De même, les chapitres 3 et 4 présentent des données relatives aux activités entrepreneuriales et indépendantes des jeunes et des seniors. Ces données incluent notamment les taux de travail indépendant, la proportion de travailleurs indépendants employant du personnel et les revenus perçus par chaque groupe dans le cadre d'une activité indépendante. Des données sont également présentées afin d'illustrer les activités entrepreneuriales des jeunes et des seniors aux différentes étapes du cycle de vie d'une entreprise. Le chapitre 5 présente des données sur la création d'entreprises et le travail indépendant des chômeurs, notamment la proportion de personnes sans emploi qui cherchent à se lancer dans le travail indépendant et qui se sont effectivement lancées. Le chapitre 6 présente des données sur le travail indépendant des populations nées à l'étranger, notamment leur taux de travail indépendant.

Après avoir présenté les taux d'activités entrepreneuriales des principaux groupes cibles des politiques d'entrepreneuriat inclusif, la deuxième partie de cet ouvrage examine en détail deux questions politiques spécifiques. Le chapitre 7 analyse la façon dont les politiques d'entrepreneuriat inclusif peuvent soutenir la croissance des entreprises créées par des femmes, des jeunes, des seniors et des personnes immigrées. Il présente les obstacles rencontrés par les entreprises en expansion et les mesures que les responsables politiques peuvent prendre pour soutenir le développement des entreprises de ces personnes. Le chapitre 8 présente en détail les dispositifs de coaching et de mentorat qui sont souvent utilisés dans le cadre des mécanismes d'aide publique pour aider les entrepreneurs, y compris ceux issus de groupes sous-représentés et défavorisés, à développer leur entreprise et leurs propres compétences. Ce chapitre traite des différences entre le coaching et le mentorat, de leurs avantages respectifs et des approches les plus efficaces pour concevoir et mettre en œuvre ces dispositifs de coaching et de mentorat dans l'Union européenne. Des exemples d'interventions de toute l'Union européenne viennent illustrer cette discussion.

Enfin, la troisième partie de cet ouvrage présente des mesures d'entrepreneuriat inclusif mises en œuvre dans chacun des 28 États membres. Elle présente pour chaque pays de l'Union européenne une pratique politique instructive de soutien à l'entrepreneuriat inclusif et des données clés relatives au travail indépendant et à l'entrepreneuriat des groupes sous-représentés et défavorisés dans le pays.

\section{Références}

Eurostat (2014), Emploi et chômage (Enquête sur les forces de travail), disponible sur: http://ec.europa. eu/eurostat/web/lfs/data.

Eurostat (2014b), Statistiques sur le revenu, l'inclusion sociale et les conditions de vie, http://ec.europa. eu/eurostat/web/income-and-living-conditions/data.

Eurostat (2014c), Labour market policies: expenditure by type of action, http://ec.europa.eu/eurostat/web/ labour-market/labour-market-policy/database. 
PARTIE I

\section{L'entrepreneuriat inclusif en Europe - Taux d'activité et obstacles}





\section{Chapitre 2}

\section{Le travail indépendant et l'entrepreneuriat chez les femmes}

Ce chapitre présente des données sur le travail indépendant et les activités entrepreneuriales des femmes au sein de l'Union européenne. Il fournit des informations sur le nombre de femmes qui travaillent comme indépendantes et sur les principales caractéristiques de leurs activités. Il présente également des données attestant que le manque de compétences constitue un obstacle à l'entrepreneuriat. Les données présentées concernent l'ensemble de l'Union européenne et chacun de ses États membres.

Note Turquie/Chypre:

1. Note en bas de page de la Turquie

Les informations figurant dans ce document qui font référence à " Chypre " concernent la partie méridionale de l'Ile. Il n'y a pas d'autorité unique représentant à la fois les Chypriotes turcs et grecs sur l'Ile. La Turquie reconnaît la République Turque de Chypre Nord (RTCN). Jusqu'à ce qu'une solution durable et équitable soit trouvée dans le cadre des Nations Unies, la Turquie maintiendra sa position sur la " question chypriote".

2. Note en bas de page de tous les États de l'Union européenne membres de l'OCDE et de l'Union européenne La République de Chypre est reconnue par tous les membres des Nations Unies sauf la Turquie. Les informations figurant dans ce document concernent la zone sous le contrôle effectif du gouvernement de la République de Chypre. 


\section{Le travail indépendant chez les femmes}

- En 2013, 9,6 millions de femmes exerçaient une activité indépendante dans l'Union européenne, soit deux fois moins que les hommes (21 millions).

- Le taux de travail indépendant des femmes était de 9,7 \% en 2013. Ce taux varie d'un État membre à l'autre, mais il représente environ la moitié du taux masculin (18,3\%).

- En 2013, 24 \% des femmes indépendantes employaient des salariés, contre 31,1 \% des hommes indépendants. Cependant, les femmes étaient plus susceptibles d'avoir du personnel dans certains États membres, notamment en Hongrie où environ 40 \% des femmes indépendantes avaient des employés.

- La proportion de femmes indépendantes faisant appel à du personnel a baissé au cours de la dernière décennie.

L'emploi peut revêtir différentes formes. Certaines personnes sont salariées ou exercent une activité indépendante tandis que d'autres travaillent dans une entreprise familiale. Ces activités professionnelles peuvent être à temps plein ou partiel, à durée déterminée ou indéterminée. Aucune de ces caractéristiques n'est figée: les changements d'activités professionnelles sont fréquents, et il n'est pas rare de cumuler plusieurs activités. Par exemple, certaines personnes occupent plusieurs emplois à temps partiel, ou complètent leur emploi salarié à temps plein par une activité indépendante à temps partiel.

Le travail indépendant concerne les activités exercées par une personne pour son propre compte, c'est-à-dire son entreprise, son exploitation agricole ou autres pratiques professionnelles d'où elle tire un revenu, qu'il s'agisse d'un salaire, de bénéfices, d'avantages en nature ou de gains familiaux (pour les travailleurs familiaux). Le bénévolat est exclu de cette définition. Si de nombreux travailleurs indépendants ne travaillent que pour leur propre compte, certains ont des employés. Veuillez vous reporter au guide de lecture au début de cet ouvrage pour plus d'informations sur les notions et les sources de données utilisées.

Le graphique 2.1 présente les taux de travail indépendant des hommes et des femmes dans l'Union européenne entre 2003 et 2013, c'est-à-dire la proportion de personnes qui exercent une activité indépendante. En 2013, l’Union européenne comptait 9,6 millions de femmes indépendantes, soit deux fois moins que les hommes (21 millions). Le taux de travail indépendant des femmes s'élevait à 9,7 \%, loin derrière le taux masculin de 18,3\%. Ces taux sont restés stables entre 2003 et 2013. 


\section{Graphique 2.1. Taux de travail indépendant des hommes et des femmes dans l'EU-28, 2003-2013}

Pourcentage des 15-64 ans

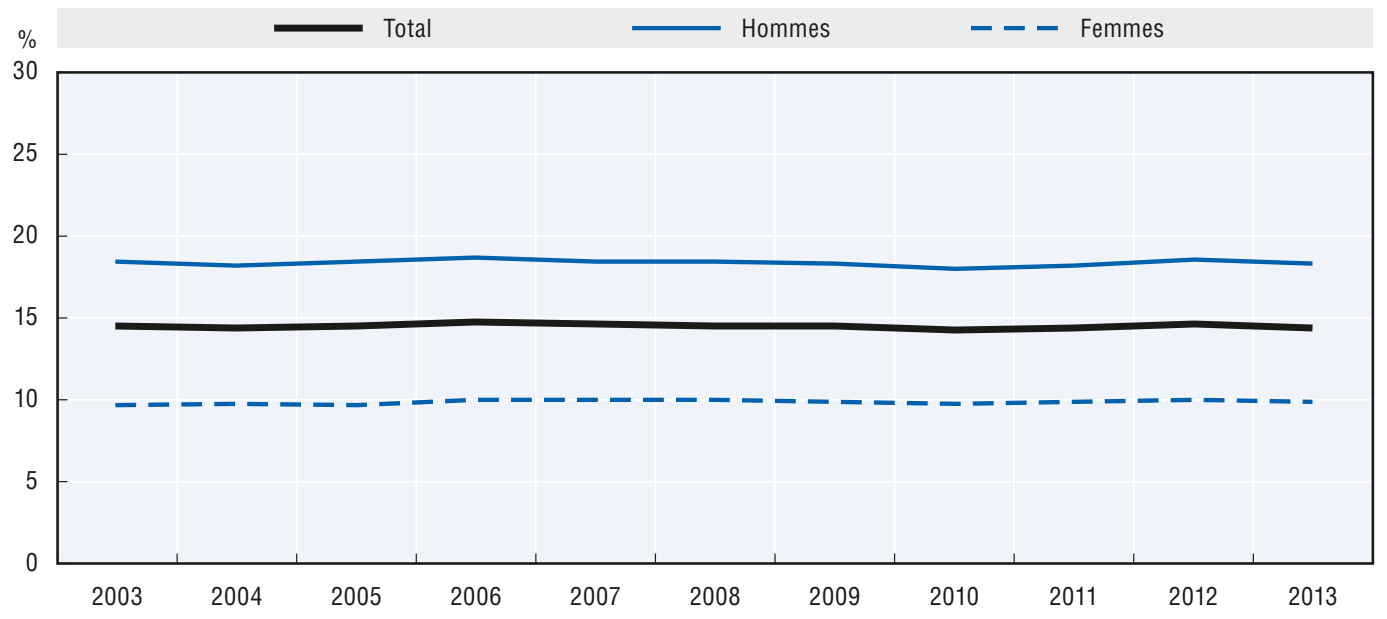

Source: Eurostat (2014), Enquête sur les forces de travail 2003-2013.

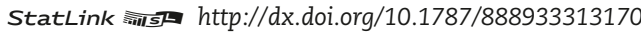

Le graphique 2.2 présente les taux de travail indépendant des hommes et des femmes de chaque État membre sur la même période, et révèle des disparités importantes entre les différents États membres. En 2013, ces taux s'échelonnaient de 5 \% au Danemark à 23,5 \% en Grèce. Ces disparités importantes entre les États membres peuvent s'expliquer par plusieurs facteurs tels que les conditions actuelles du marché du travail, les opportunités d'emploi, les comportements sociaux à l'égard de la participation des femmes au marché du travail et les facteurs macroéconomiques.

Bien qu'il soit inférieur à celui des hommes dans tous les États membres, le taux de travail indépendant des femmes n'est pas bas dans tous les États membres. Ainsi, en Grèce, le taux de travail indépendant des femmes en 2013 était supérieur à celui des hommes dans tous les États membres, à l'exception de l'Italie (et de la Grèce).

Le taux de travail indépendant des femmes a également varié dans chaque État membre entre 2003 et 2013. Pendant cette période, il a augmenté dans 18 États membres et baissé dans 10. Le taux de travail indépendant des femmes a enregistré la hausse la plus importante en République slovaque (+4,4 points de pourcentage) et le recul le plus fort en Pologne (-6,1 points de pourcentage). 


\section{Graphique 2.2. Taux de travail indépendant des hommes et des femmes par pays 2003-2013}

Pourcentage des 15-64 ans
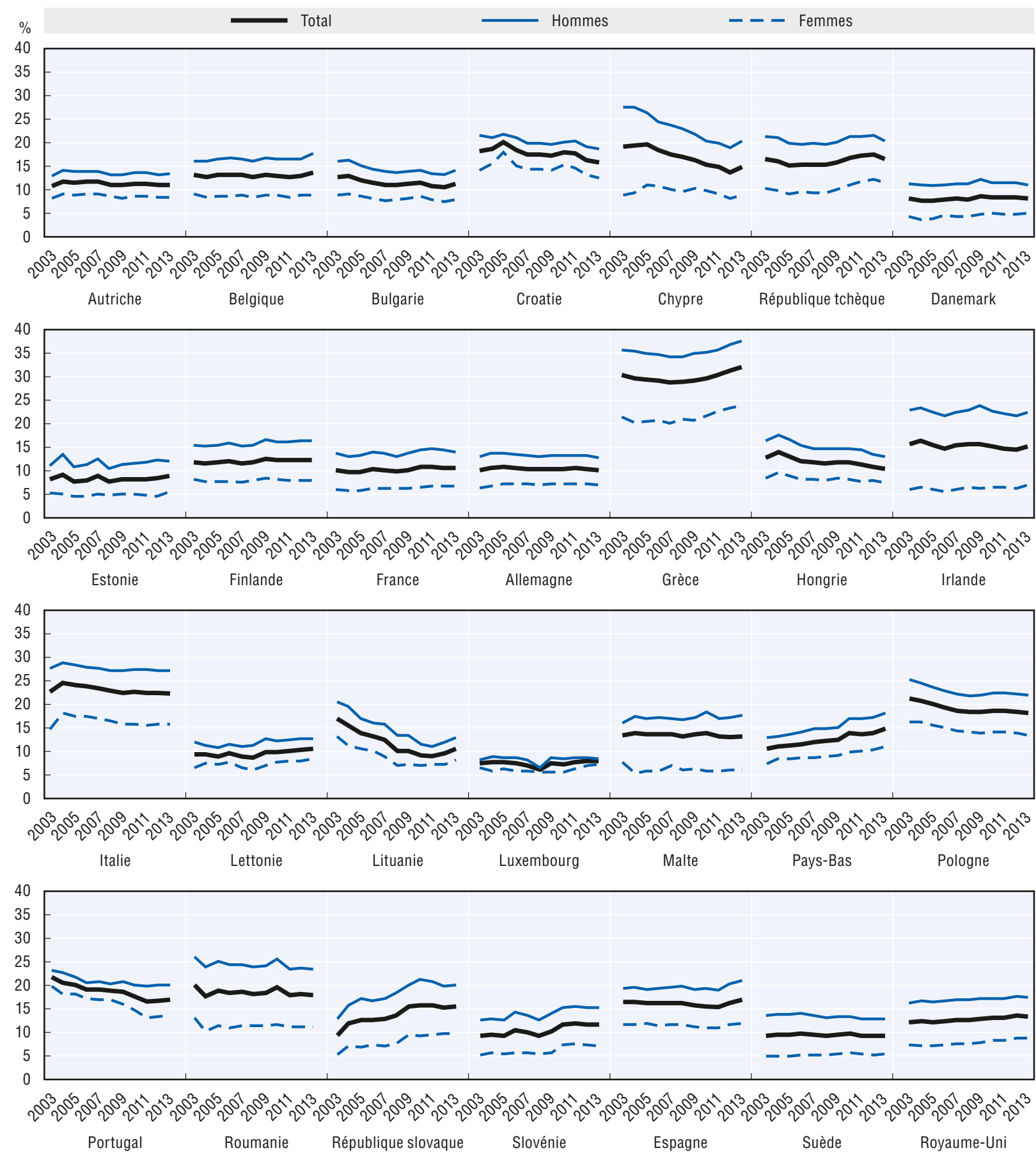

Source: Eurostat (2014), Enquête sur les forces de travail 2003-2013.

StatLink ainst http://dx.doi.org/10.1787/888933313185 
La proportion des indépendants, hommes et femmes, employant des salariés est présentée au graphique 2.3. En 2013, 24 \% des femmes indépendantes employaient des salariés, contre 31,1\% des hommes indépendants. Sur les 9,6 millions de femmes indépendantes en 2013, seulement 2,3 millions avaient des employés. La proportion de travailleurs indépendants, hommes et femmes, employant du personnel a baissé entre 2003 et 2013 pour atteindre pratiquement le même niveau (15\% pour les femmes et $16 \%$ pour les hommes).

\section{Graphique 2.3. Proportion d'indépendants (hommes et femmes) employant des salariés dans l'EU-28, 2003-2013}

Pourcentage des 15-64 ans

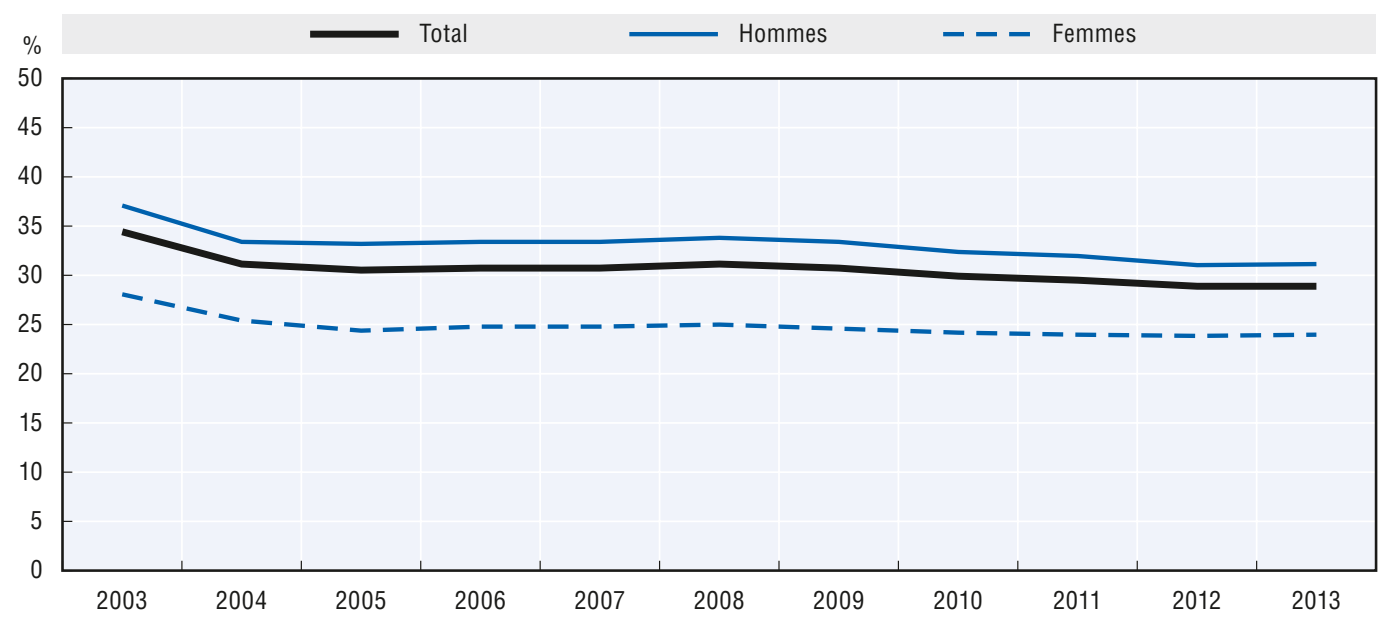

Source: Eurostat (2014), Enquête sur les forces de travail 2003-2013.

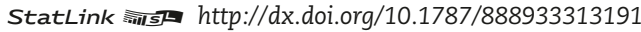

Le graphique 2.4 présente la proportion des travailleurs indépendants employant du personnel par État membre et par sexe. En 2013, les femmes indépendantes de Hongrie étaient les plus susceptibles d'avoir du personnel puisque $40 \%$ d'entre elles employaient au moins une personne. Plus d'un tiers des femmes indépendantes au Danemark, en Allemagne, en Irlande et au Luxembourg employaient des salariés. À l'inverse, les femmes indépendantes en Roumanie étaient les moins susceptibles d'avoir du personnel, puisque seules 7,3\% d'entre elles employaient des salariés en 2013.

Les taux de travail indépendant des hommes et des femmes par secteur d'activité en 2013 sont présentés au graphique 2.5. Bien qu'ils varient sensiblement selon le secteur d'activité, les taux des femmes restent inférieurs à ceux des hommes, quel que soit le secteur, à l'exception de la catégorie Autres services (par exemple, activités d'organisations associatives, réparation d'ordinateurs et de biens personnels et domestiques). Le taux de travail indépendant des femmes était en effet légèrement supérieur à celui des hommes dans ce secteur (30,2 \% contre $28,1 \%)$. En revanche, il représentait moins de la moitié du taux des hommes dans les secteurs d'activité suivants: construction, transports et logistique, services financiers et assurances, immobilier et éducation. 


\section{Graphique 2.4. Proportion d'indépendants (hommes et femmes) employant des salariés par pays, 2003-2013}

Pourcentage des 15-64 ans
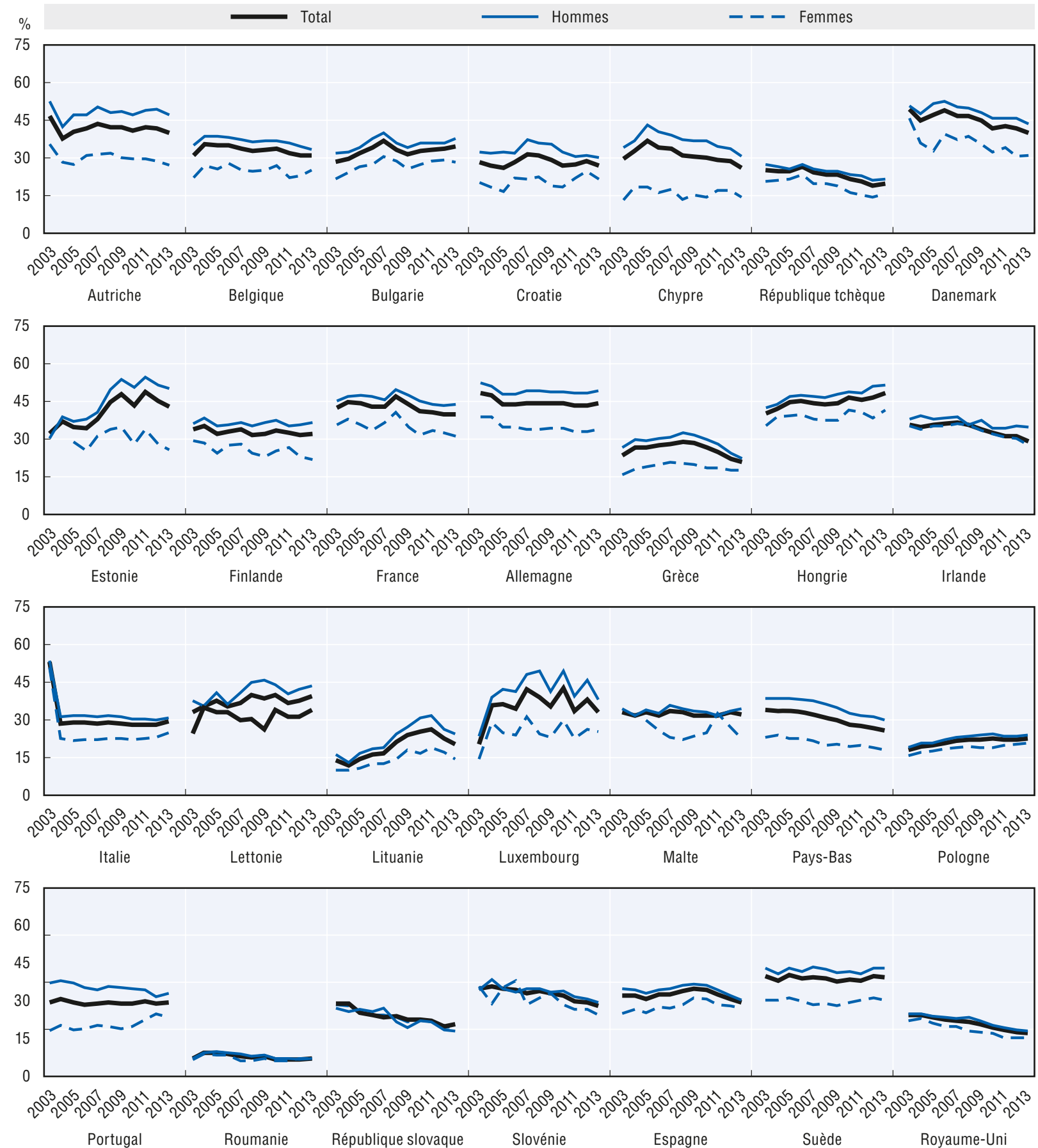

Source: Eurostat (2014), Enquête sur les forces de travail 2003-2013. 


\section{Graphique 2.5. Taux de travail indépendant des hommes et des femmes par secteur dans l'EU-28, 2013}

Pourcentage des 15-64 ans

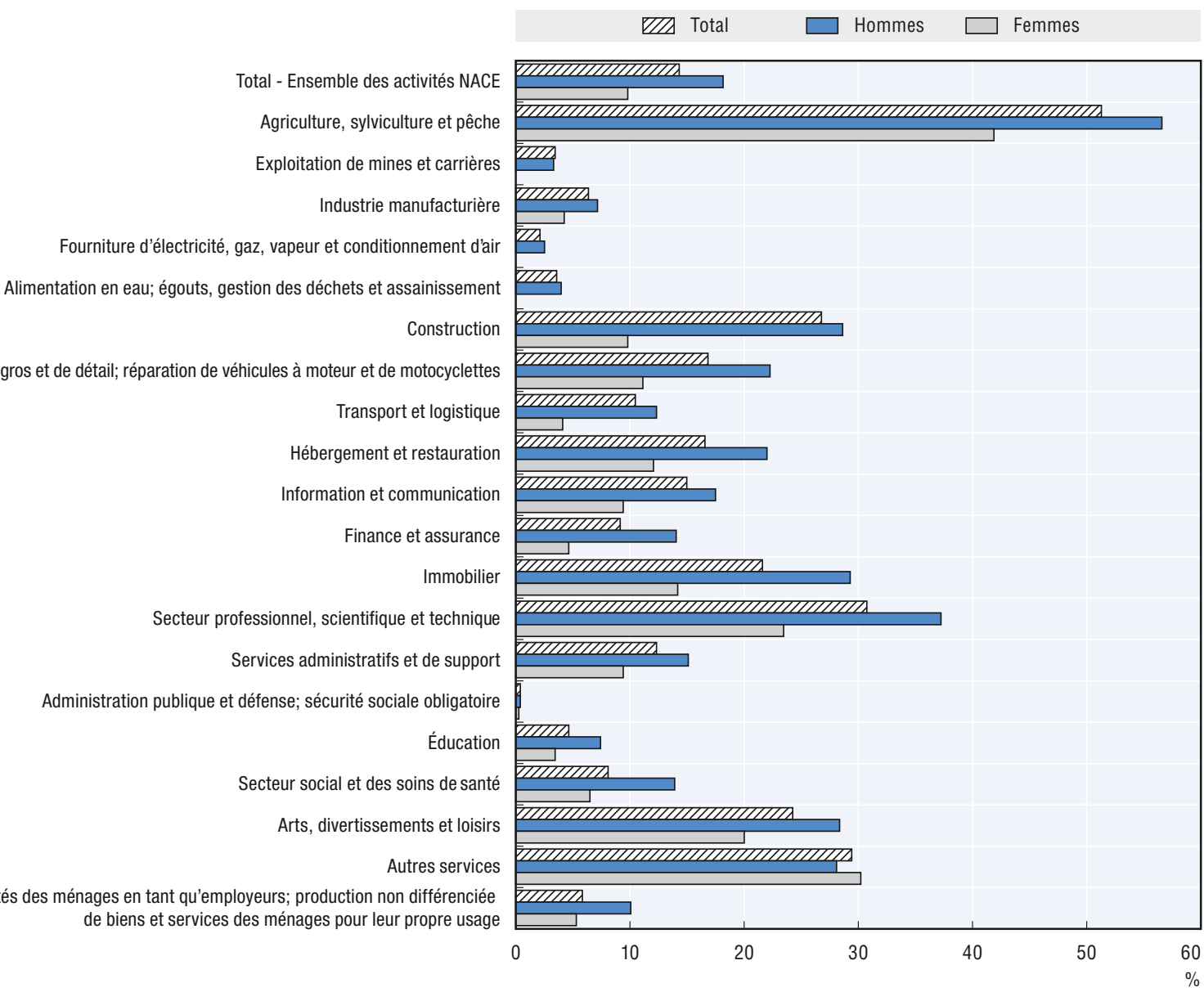

Source: Eurostat (2014), Enquête sur les forces de travail 2003-2013.

\section{Activités exercées par des femmes tout au long du cycle de vie entrepreneuriale}

- Les femmes ont eu moins tendance que les hommes à s'engager dans la création d'entreprises dans les pays de l'Union européenne entre 2009 et 2013 (2,5 \% contre 4,6 \%).

- De même, les femmes étaient environ deux fois moins susceptibles que les hommes de détenir une nouvelle entreprise dans l'Union européenne (1,8\% contre 3,5\%).

- Elles ont également eu moins tendance que les hommes à posséder une entreprise établie (3,7 \% contre $7,8 \%)$.

- Les femmes ont néanmoins participé très activement aux trois étapes de cycle de vie d'une entreprise dans plusieurs États membres, en particulier en Lettonie et en Autriche.

Les graphiques 2.6, 2.7 et 2.8 présentent les taux d'activité entrepreneuriale des femmes et des hommes dans les États membres de l'Union européenne aux différentes étapes du cycle de vie d'une entreprise. Tout d'abord, le graphique 2.6 présente les taux d'entrepreneuriat naissant des hommes 


\section{Graphique 2.6. Taux d'entrepreneuriat naissant chez les hommes et les femmes, 2009-2013 (combinés)}

Pourcentage des 18-64 ans

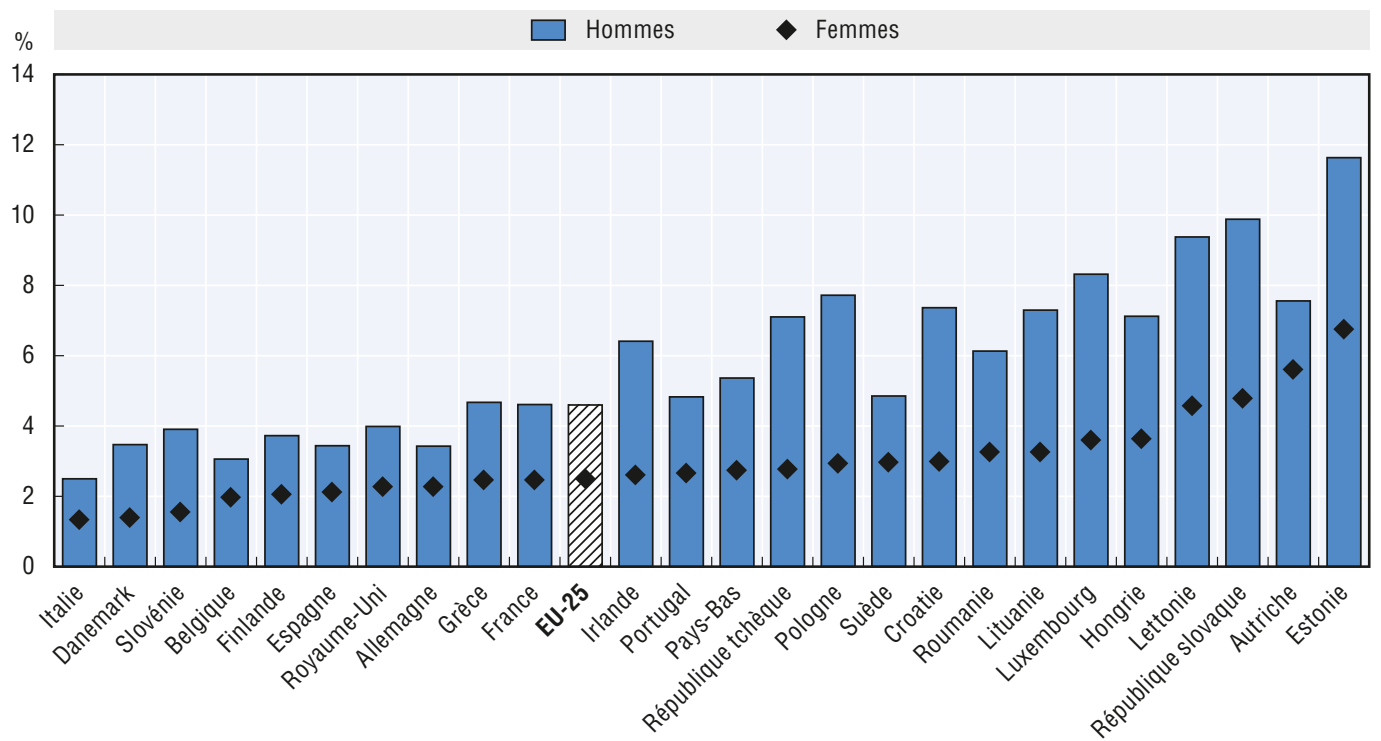

Notes: 1. Les pays de l'Union européenne ayant participé à l'enquête Global Entrepreneurship Monitor pendant cette période sont: la Belgique, la République tchèque, l'Allemagne, l'Estonie, l'Irlande, la Grèce, l'Espagne, la France, la Croatie, l'Italie, la Lettonie, la Lituanie, la Hongrie, les Pays-Bas, l'Autriche, la Pologne, le Portugal, la Roumanie, la Slovénie, la Slovaquie, la Finlande, la Suède et le Royaume-Uni. 2. Les données présentées dans ce graphique ont été combinées: elles cumulent les résultats des enquêtes annuelles portant sur la période 2009-2013. Certains pays n'ont pas pris part aux enquêtes GEM réalisées chaque année, mais ont été inclus dans les graphiques: la République tchèque (2011 et 2013), le Danemark (2009, 2010, 2011, 2012), l'Estonie (2012, 2013), l'Irlande (2010, 2011, 2012, 2013), l'Italie (2009, 2010, 2012, 2013), la Lituanie (2011, 2012, 2013), le Luxembourg (2013), l'Autriche (2012, 2013), la Pologne (2011, 2012, 2013), le Portugal (2010, 2011, 2012, 2013), la Slovaquie (2011, 2012, 2013), et la Suède $(2010,2011,2012,2013)$. 3. Le taux d'entrepreneuriat naissant est défini comme la proportion de la population adulte (âgée de 18 à 64 ans) activement engagée dans la création d'une entreprise qu'elle détiendra seule ou en copropriété; cette entreprise ne peut pas avoir octroyé de traitements, salaires ou toute autre rémunération à ses propriétaires depuis plus de trois mois.

Source: Global Entrepreneurship Monitor (GEM) (2014), présentations tabulaires spéciales des enquêtes 2009-2013 sur la population adulte, extraites du Global Entrepreneurship Monitor.

StatLink 部正 http://dx.doi.org/10.1787/888933313228

et des femmes par État membre entre 2009 et 2013. Ce taux mesure la proportion d'adultes déclarant être activement impliqués dans la création d'une entreprise qu'ils détiennent seuls ou en copropriété. Cette activité ne doit pas avoir rapporté de traitements, de salaires ou toute autre rémunération à ses propriétaires depuis plus de trois mois. Pour en savoir plus sur cette notion et sur cette source de données, nous vous renvoyons au guide de lecture proposé au début de cet ouvrage.

À l'échelle de l'Union européenne, les femmes ont eu moins tendance que les hommes à être des entrepreneurs naissants entre 2009 et 2013 (2,5\% contre 4,6\%). Ces taux varient d'un État membre à l'autre. En ce qui concerne les femmes, ces taux s'échelonnaient de 1,3\% en Italie à 6,8 \% en Estonie. Ces chiffres montrent que, même si les femmes ont eu moins tendance à se lancer dans la création d'entreprises que les hommes, elles ont œuvré assez activement pour devenir des entrepreneurs dans certains États membres. En effet, en Lettonie, République slovaque, Autriche et Estonie, les femmes ont été plus susceptibles que les hommes (et les femmes) d'Italie, du Danemark, de Slovénie, de Belgique, de Finlande, d'Espagne et du Royaume-Uni d'être des entrepreneurs naissants.

Le graphique 2.7 présente le taux de propriété de nouvelles entreprises. Il indique la proportion de la population adulte déclarant être actuellement dirigeant-propriétaire d'une nouvelle entreprise qui verse des traitements, des salaires ou toute autre rémunération à ses propriétaires depuis plus de trois mois, mais moins de 42 mois. À l'échelle de l'Union européenne, les femmes étaient deux fois moins susceptibles que les hommes d'être propriétaires d'une nouvelle entreprise (1,8\% contre 3,5\%). Cependant, comme pour le graphique 2.6, les taux varient selon les pays. Les États membres où 


\section{Graphique 2.7. Taux de détention de nouvelles entreprises chez les hommes et les femmes, 2009-2013 (combinés)}

Pourcentage des 18-64 ans

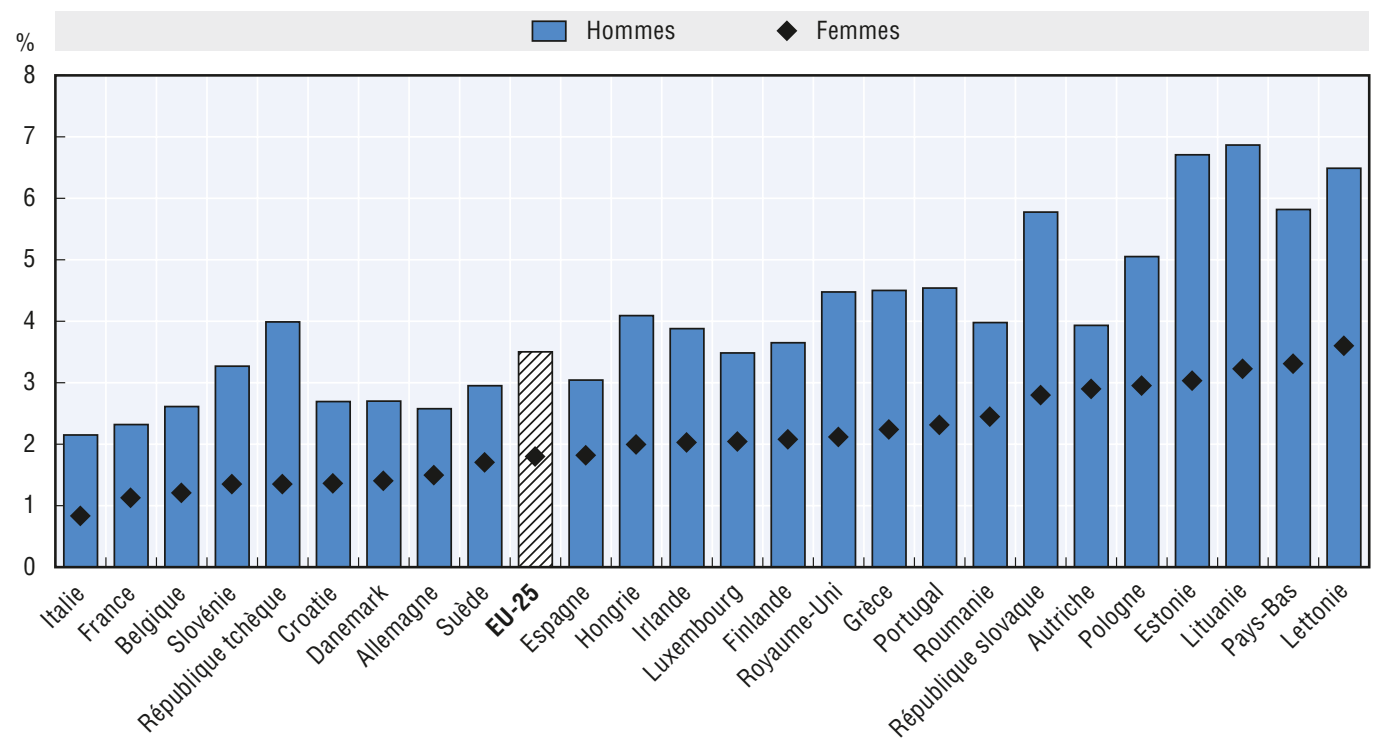

Notes: 1. Les pays de l'Union européenne ayant participé à l'enquête Global Entrepreneurship Monitor pendant cette période sont: la Belgique, la République tchèque, l'Allemagne, l'Estonie, l'Irlande, la Grèce, l'Espagne, la France, la Croatie, l'Italie, la Lettonie, la Lituanie, la Hongrie, les Pays-Bas, l'Autriche, la Pologne, le Portugal, la Roumanie, la Slovénie, la Slovaquie, la Finlande, la Suède et le Royaume-Uni. 2. Les données présentées dans ce graphique ont été combinées: elles cumulent les résultats des enquêtes annuelles portant sur la période 2009-2013. Certains pays n'ont pas pris part aux enquêtes GEM réalisées chaque année, mais ont été inclus dans les graphiques: la République tchèque (2011 et 2013), le Danemark (2009, 2010, 2011, 2012), l'Estonie (2012, 2013), l'Irlande (2010, 2011, 2012, 2013), l'Italie (2009, 2010, 2012, 2013), la Lituanie (2011, 2012, 2013), le Luxembourg (2013), l'Autriche (2012, 2013), la Pologne (2011, 2012, 2013), le Portugal (2010, 2011, 2012, 2013), la Slovaquie (2011, 2012, 2013), et la Suède (2010, 2011, 2012, 2013). 3. Le taux de détention de nouvelles entreprises est la proportion de la population adulte gérant ou possédant actuellement une nouvelle entreprise qui verse des traitements, des salaires ou toute autre rémunération à ses propriétaires depuis plus de trois mois, mais moins de 42 mois.

Source: Global Entrepreneurship Monitor (GEM) (2014), présentations tabulaires spéciales des enquêtes 2009-2013 sur la population adulte, extraites du Global Entrepreneurship Monitor.

StatLink 젶ㄴ http://dx.doi.org/10.1787/888933313234

les femmes étaient les moins susceptibles de posséder une nouvelle entreprise sont l'Italie (0,8 \%), la France $(1,1 \%)$ et la Belgique (1,2 \%). Elles étaient les plus susceptibles d'être propriétaires d'une nouvelle entreprise en Lituanie (3,2 \%), aux Pays-Bas (3,3\%) et en Lettonie (3,6 \%).

Les taux de détention d'entreprises établies sont présentés au graphique 2.8. Il indique la part de population adulte qui se déclare gérant-propriétaire d'une entreprise établie qui verse des traitements, salaires, ou toute autre rémunération aux propriétaires depuis plus de 42 mois. Étant donné que les femmes sont moins susceptibles que les hommes de créer ou de détenir une entreprise, il n'est pas surprenant qu'elles soient également moins susceptibles de posséder une entreprise établie (3,7 \% contre 7,8\%). Même si les taux de détention d'entreprises établies par des femmes varient selon les États membres, ces disparités ne sont pas aussi marquées que pour les hommes. Les taux de détention d'une entreprise établie des femmes étaient les plus faibles au Luxembourg (2\%), en France (2,2 \%) et en Croatie (2,5\%), et les plus élevés aux Pays-Bas $(5,5 \%)$, en Autriche (5,9\%) et en Grèce $(7,5 \%)$. En Grèce, le taux de détention d'une entreprise établie des femmes était supérieur à celui des hommes en Allemagne, Belgique, Croatie, Danemark, France, Italie, Luxembourg et Roumanie. 


\section{Graphique 2.8. Taux de détention d'entreprises établies chez les hommes et les femmes, 2009-2013 (combinés)}

Pourcentage des 18-64 ans

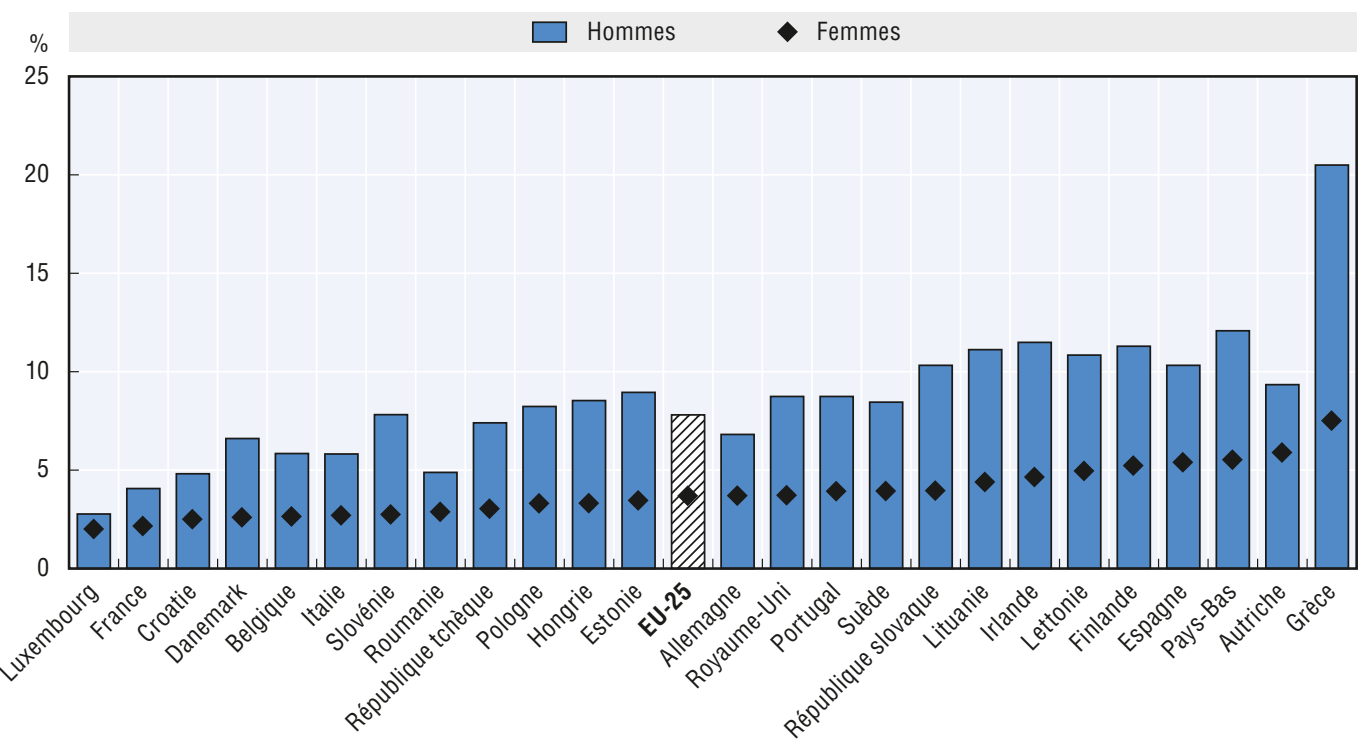

Notes: 1. Les pays de l’Union européenne ayant participé à l'enquête Global Entrepreneurship Monitor pendant cette période sont: la Belgique, la République tchèque, l'Allemagne, l'Estonie, l'Irlande, la Grèce, l'Espagne, la France, la Croatie, l'Italie, la Lettonie, la Lituanie, la Hongrie, les Pays-Bas, l'Autriche, la Pologne, le Portugal, la Roumanie, la Slovénie, la Slovaquie, la Finlande, la Suède et le Royaume-Uni. 2. Les données présentées dans ce graphique ont été combinées: elles cumulent les résultats des enquêtes annuelles portant sur la période 2009-2013. Certains pays n'ont pas pris part aux enquêtes GEM réalisées chaque année, mais ont été inclus dans les graphiques: la République tchèque (2011 et 2013), le Danemark (2009, 2010, 2011, 2012), l'Estonie (2012, 2013), l'Irlande (2010, 2011, 2012, 2013), l'Italie (2009, 2010, 2012, 2013), la Lituanie (2011, 2012, 2013), le Luxembourg (2013), l'Autriche (2012, 2013), la Pologne (2011, 2012, 2013), le Portugal (2010, 2011, 2012, 2013), la Slovaquie (2011, 2012, 2013), et la Suède (2010, 2011, 2012, 2013). 3. Le taux de détention d'entreprises établies désigne la proportion des membres de la population adulte qui sont actuellement dirigeants-propriétaires d'une entreprise établie qui verse des traitements, des salaires ou toute autre rémunération à ses propriétaires depuis plus de 42 mois. Cet indicateur renseigne sur le niveau d'activités entrepreneuriales au sein d'une économie.

Source: Global Entrepreneurship Monitor (GEM) (2014), présentations tabulaires spéciales des enquêtes 2009 -2013 sur la population adulte, extraites du Global Entrepreneurship Monitor.

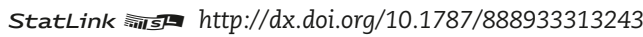

\section{Heures de travail des femmes indépendantes}

- En 2013, les femmes indépendantes dans l'Union européenne ont travaillé en moyenne plus d'heures par semaine que les salariées, mais moins que les hommes indépendants.

- En 2013, le nombre médian d'heures de travail hebdomadaires des femmes indépendantes variait sensiblement selon les pays de l'Union européenne. C'est en Autriche et en Belgique que les femmes indépendantes ont travaillé le plus grand nombre d'heures (plus de 50 heures).

- Les femmes indépendantes employant du personnel ont travaillé en moyenne 3 heures de plus que celles qui n'en ont pas. 
En moyenne, les femmes indépendantes travaillent plus d'heures par semaine que les salariées (graphique 2.9). En 2013, elles ont en effet travaillé 41,5 heures par semaine, contre 40 heures pour les salariées. Par rapport aux hommes indépendants, les femmes indépendantes ont travaillé en moyenne 3,6 heures de moins par semaine (48,7 heures par semaine contre 45,1$)$. Le nombre d'heures de travail hebdomadaires des femmes indépendantes a légèrement baissé entre 2004 et 2013 (1,3 heure).

\section{Graphique 2.9. Nombre moyen d'heures de travail hebdomadaires des indépendants (hommes et femmes) dans l'EU-28, 2003-2013}

Heures de travail hebdomadaires des 18-64 ans travaillant à temps plein

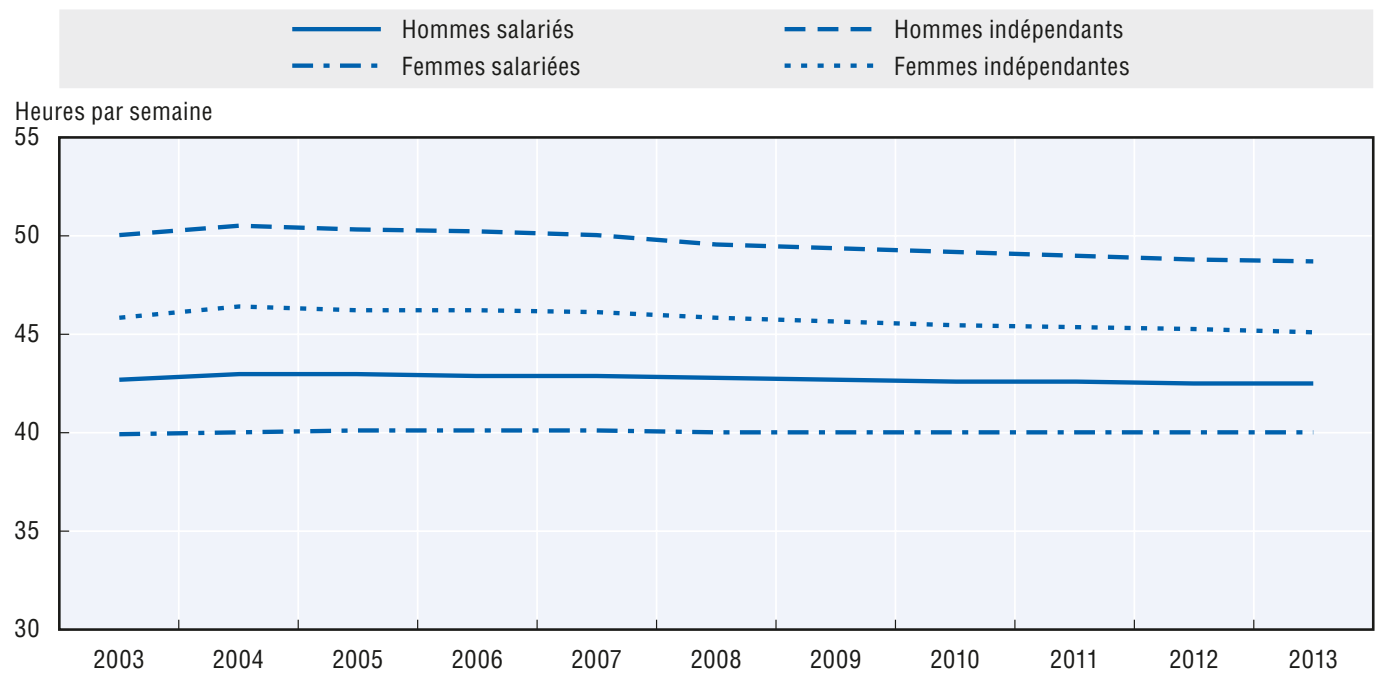

Source: Eurostat (2014), Enquête sur les forces de travail 2003-2013..

StatLink त्नाज्ञ http://dx.doi.org/10.1787/888933313255

Le graphique 2.10 présente le nombre d'heures de travail hebdomadaires des indépendants et des salariés dans chaque État membre entre 2003 et 2013. Le nombre moyen d'heures de travail hebdomadaires des femmes indépendantes varie sensiblement selon les pays de l'Union européenne. En 2013, les femmes indépendantes en Autriche et en Belgique ont travaillé plus de 50 heures par semaine en moyenne. C'est en Lituanie (40,5 heures) et en Roumanie (38,3 heures) qu'elles ont, en moyenne, le moins travaillé. Le nombre moyen d'heures de travail hebdomadaires des femmes indépendantes a augmenté dans cinq États membres et reculé dans 17 autres. 


\section{Graphique 2.10. Nombre moyen d'heures de travail hebdomadaires des indépendants (hommes et femmes) par pays, 2003-2013}

Heures de travail hebdomadaires des 18-64 ans travaillant à temps plein
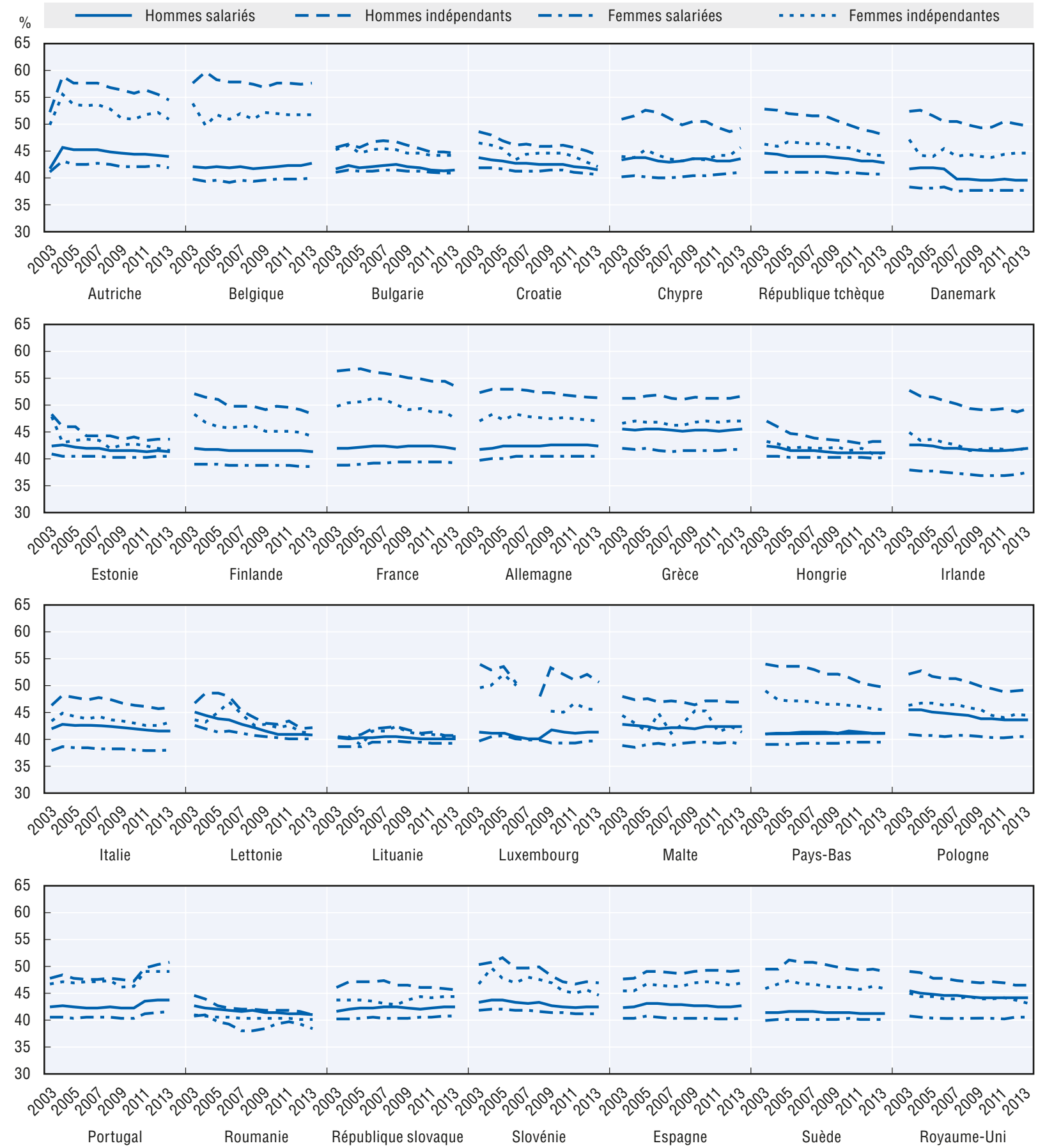

Source: Eurostat (2014), Enquête sur les forces de travail 2003-2013. 
Les femmes indépendantes employant des salariés travaillent en moyenne plus d'heures hebdomadaires que celles qui n'en ont pas (graphique 2.11) En 2013, les femmes indépendantes employant du personnel ont travaillé en moyenne 2,1 heures de plus par semaine (47,2 heures contre 45,1 heures). En moyenne, les femmes indépendantes employant du personnel travaillent 4,3 heures de moins par semaine que les hommes indépendants qui emploient des salariés.

\section{Graphique 2.11. Nombre moyen d'heures de travail hebdomadaires des indépendants (hommes et femmes) employant du personnel dans l'EU-28, 2003-2013}

Heures de travail hebdomadaires des 18-64 ans travaillant à temps plein

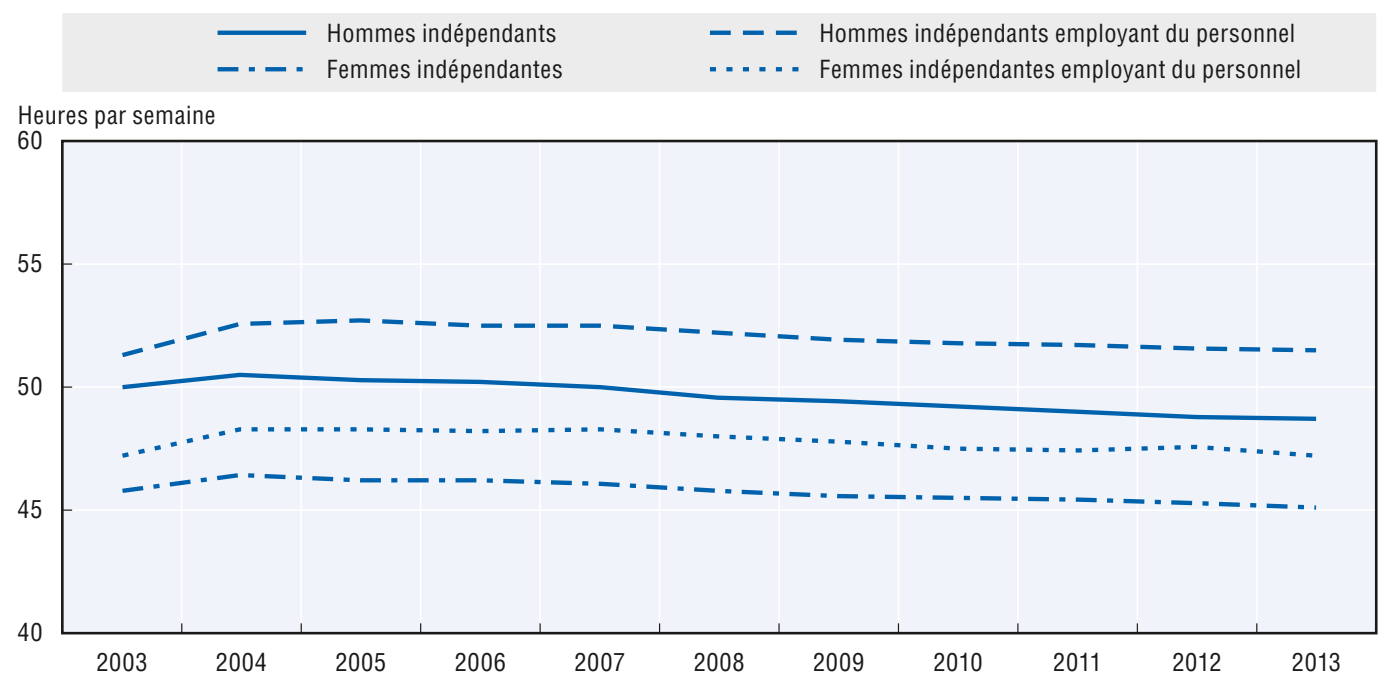

Source: Eurostat (2014), Enquête sur les forces de travail 2003-2013.

StatLink त्ञाजा http://dx.doi.org/10.1787/888933313275

Le nombre moyen d'heures de travail hebdomadaires des femmes indépendantes employant du personnel a varié sensiblement d'un État membre à l'autre entre 2003 et 2013 (graphique 2.12). C'est en Bulgarie, en Estonie, en Hongrie, en Lettonie et en Lituanie que le nombre moyen d'heures de travail hebdomadaires des femmes indépendantes avec ou sans personnel présentait l'écart le plus faible. 


\section{Graphique 2.12. Nombre moyen d'heures de travail hebdomadaires des indépendants} (hommes et femmes) employant du personnel par pays, 2003-2013

Heures de travail hebdomadaires des 18-64 ans travaillant à temps plein
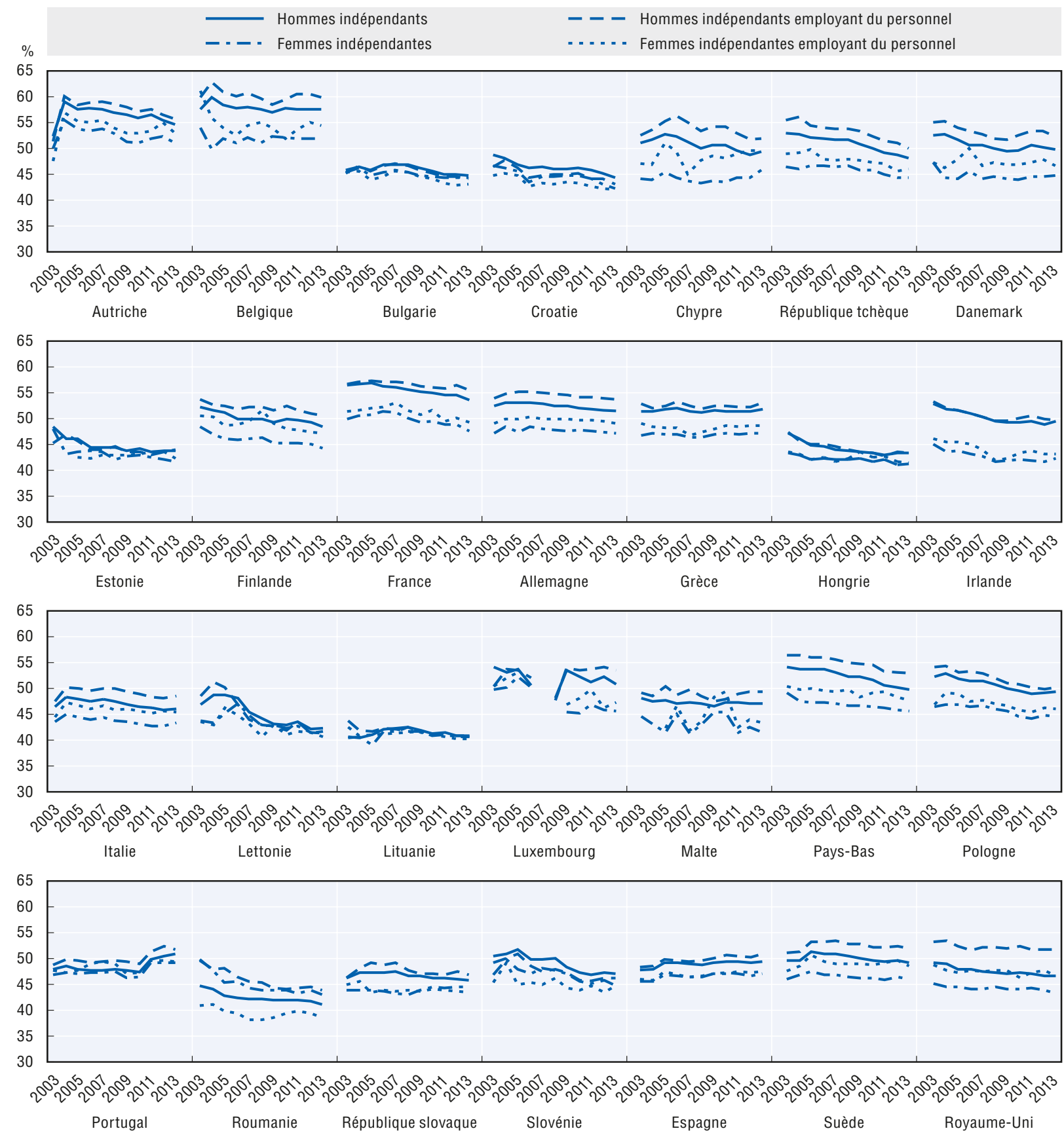

Source: Eurostat (2014), Enquête sur les forces de travail 2003-2013. 


\section{Revenu des indépendantes}

- En 2012, les revenus des femmes indépendantes ont été légèrement inférieurs à ceux perçus par les hommes indépendants dans l'Union européenne.

- Au cours de cette même année, les salariées ont gagné en moyenne 4200 euros de plus par an que les femmes indépendantes.

En 2012, au sein de l'Union européenne, le revenu médian annuel des femmes indépendantes était de 14554 euros. Il est inférieur à celui des salariées, qui était de 18771 euros (graphique 2.13). Dans la plupart des États membres, le revenu médian des salariées était supérieur à celui des femmes indépendantes (graphique 2.14). Seules les femmes indépendantes en Bulgarie, en République tchèque, en France, en Hongrie et au Luxembourg ont enregistré un revenu médian légèrement supérieur à celui des salariées.

Graphique 2.13. Revenu annuel des femmes, 2012

Revenu médian net des activités professionnelles à temps plein

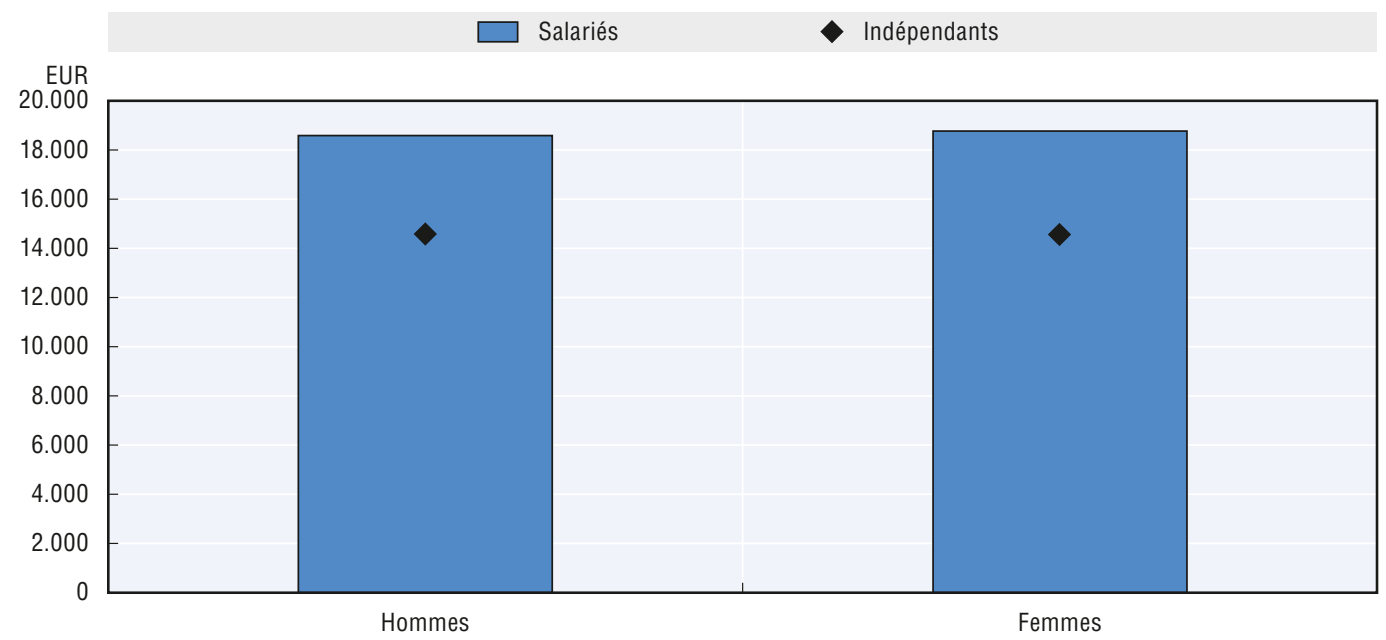

Source: Eurostat (2014b), Statistiques sur le revenu et les conditions de vie 2013.

StatLink त्ञाज http://dx.doi.org/10.1787/888933313290

En 2012, le revenu médian des femmes indépendantes était équivalent à celui des hommes indépendants dans l'Union européenne (graphique 2.13). On constate néanmoins des variations notables entre les États membres. Peu de différences apparaissent entre les États membres en ce qui concerne le revenu médian des hommes et des femmes indépendants, même si en France, au Luxembourg, à Malte et en Espagne, le revenu médian perçu par les femmes indépendantes est considérablement plus élevé que celui des hommes indépendants (graphique 2.14). 
Graphique 2.14. Revenu annuel des femmes par pays, 2012

Revenu médian net des activités professionnelles à temps plein
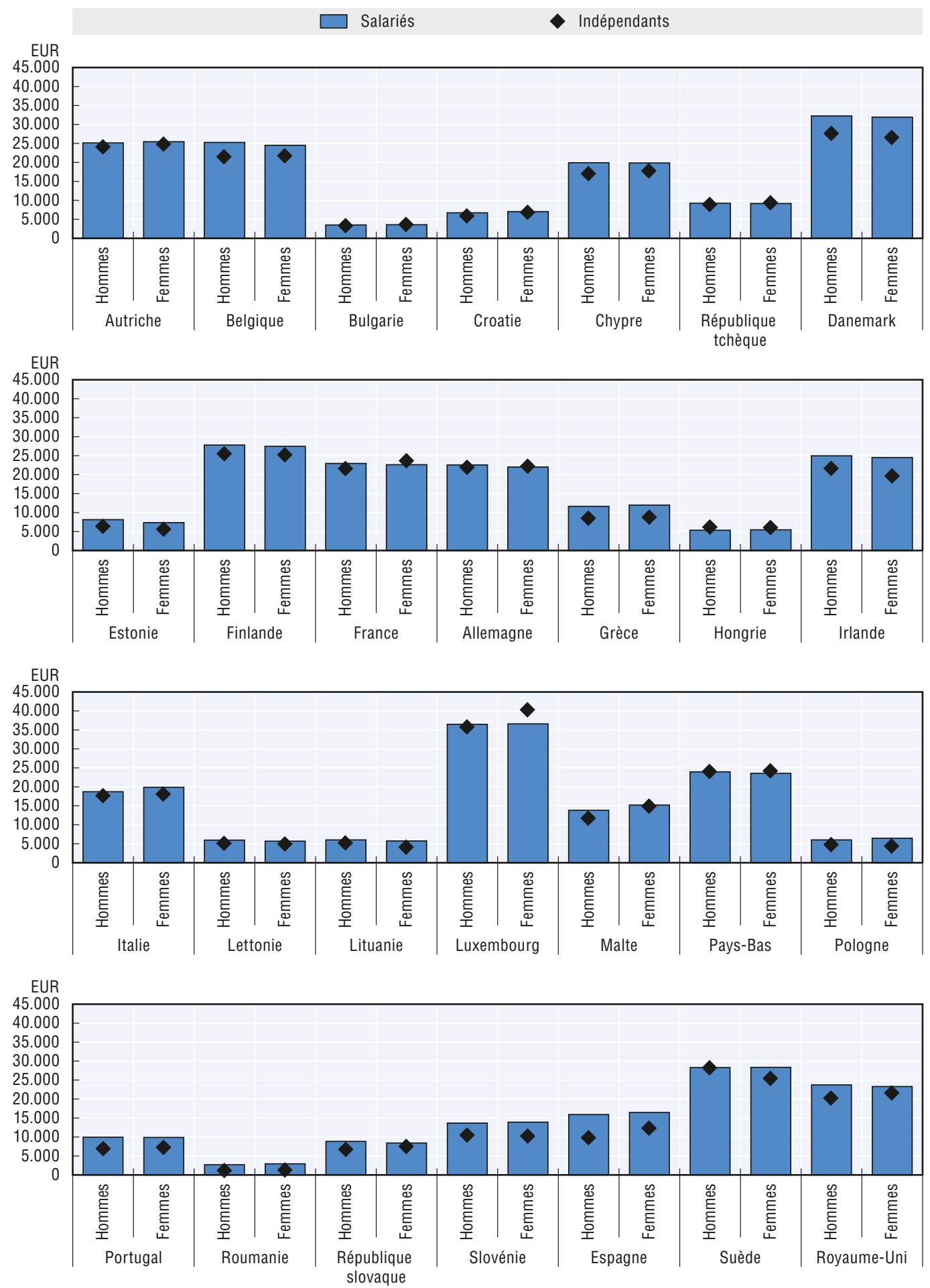

Source: Eurostat (2014b), Statistiques sur le revenu et les conditions de vie 2013.

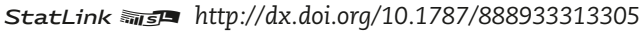




\section{Le manque de compétences entrepreneuriales: un obstacle à la création d'entreprises pour les femmes}

- Entre 2009 et 2013 dans l'Union européenne, les femmes ont eu moins tendance que les hommes à penser qu'elles disposaient des compétences et connaissances nécessaires pour créer leur entreprise.

- Le sentiment de posséder les compétences et connaissances requises pour créer une entreprise a varié selon les États membres de l'Union européenne au cours de cette période. En Autriche, en Grèce, en Slovénie et en Espagne, les femmes étaient plus de deux fois plus susceptibles que celles au Luxembourg de penser qu'elles disposaient de ces compétences entrepreneuriales.

Le manque de compétences entrepreneuriales est souvent considéré comme l'un des principaux obstacles à la création d'entreprises. Les compétences entrepreneuriales sont un ensemble de capacités comprenant la gestion des risques, l'identification des opportunités, la planification, la gestion financière, ainsi que des traits de caractère comme l'esprit d'initiative et la capacité à motiver les autres. Même si ces compétences ne sont pas toujours indispensables pour gérer une entreprise avec succès, elles augmentent nettement les chances de survie et de prospérité de cette dernière.

Le graphique 2.15 illustre la proportion de la population adulte dans chaque État membre qui estime disposer des compétences et connaissances entrepreneuriales requises pour créer une entreprise. Globalement, un tiers des femmes de l'Union européenne pensait disposer des compétences et connaissances nécessaires à la création d'une entreprise entre 2009 et 2013, contre 49 \% des hommes. En d'autres termes, les deux tiers des femmes estimaient ne pas avoir les compétences et connaissances requises pour créer une entreprise. Ces chiffres démontrent clairement que les politiques publiques peuvent intervenir utilement dans ce domaine.

Dans les États membres, les proportions de femmes qui pensent disposer des compétences et connaissances nécessaires à la création d'une entreprise vont de $20 \%$ au Luxembourg à $43 \%$ en Slovénie. Dans tous les pays de l'Union européenne, les femmes ont eu moins tendance que les hommes à penser qu'elles disposaient des compétences et connaissances nécessaires pour créer une entreprise. En valeur absolue, l'écart entre les hommes et les femmes à cet égard était le plus marqué aux Pays-Bas (23 points de pourcentage) et le plus faible en Espagne (11 points de pourcentage). 


\section{Graphique 2.15. Manque de compétences entrepreneuriales en tant qu'obstacle à} la création d'entreprises pour les hommes et les femmes dans l'EU-28, 2009-2013

"Avez-vous les compétences et connaissances nécessaires pour créer une entreprise?» Pourcentage des 18-64 ans ayant répondu «oui»

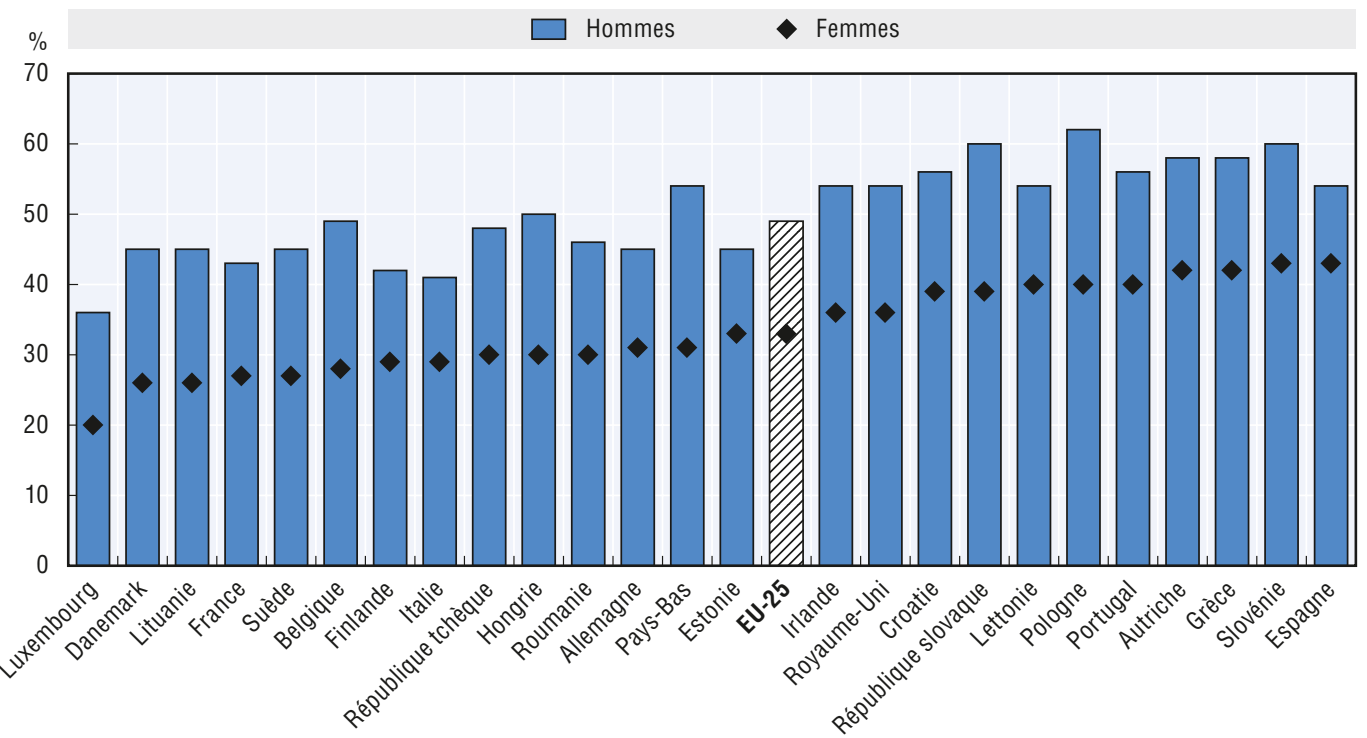

Notes: 1. Les pays de l'Union européenne ayant participé à l'enquête Global Entrepreneurship Monitor pendant cette période sont: la Belgique, la République tchèque, l'Allemagne, l'Estonie, l'Irlande, la Grèce, l'Espagne, la France, la Croatie, l'Italie, la Lettonie, la Lituanie, la Hongrie, les Pays-Bas, l'Autriche, la Pologne, le Portugal, la Roumanie, la Slovénie, la Slovaquie, la Finlande, la Suède et le Royaume-Uni. 2. Les données présentées dans ce graphique ont été combinées: elles cumulent les résultats des enquêtes annuelles portant sur la période 2009-2013. Certains pays n'ont pas pris part aux enquêtes GEM réalisées chaque année, mais ont été inclus dans les graphiques: la République tchèque (2011 et 2013), le Danemark (2009, 2010, 2011, 2012), l'Estonie (2012, 2013), l'Irlande (2010, 2011, 2012, 2013), l'Italie (2009, 2010, 2012, 2013), la Lituanie (2011, 2012, 2013), le Luxembourg (2013), l'Autriche (2012, 2013), la Pologne (2011, 2012, 2013), le Portugal $(2010,2011,2012,2013)$, la Slovaquie $(2011,2012,2013)$, et la Suède $(2010,2011,2012,2013)$.

Source: Global Entrepreneurship Monitor (GEM) (2014), présentations tabulaires spéciales des enquêtes 2009-2013 sur la population adulte, extraites du Global Entrepreneurship Monitor.

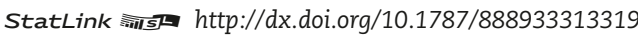

\section{Références}

Eurostat (2014), Employment and unemployment (LFS), http://ec.europa.eu/eurostat/web/lfs/data.

Eurostat (2014b), Statistics on Income, Social Inclusion, and Living Conditions (SILC), http://ec.europa. eu/eurostat/web/income-and-living-conditions/data.

Global Entrepreneurship Monitor (GEM) (2014), Special tabulations of the 2009-13 adult population surveys from Global Entrepreneurship Monitor. 


\title{
Chapitre 3
}

\section{Le travail indépendant et l'entrepreneuriat chez les jeunes}

\begin{abstract}
Ce chapitre traite des activités d'indépendant et d'entrepreneuriat exercées par les jeunes. Les données présentées indiquent la proportion de jeunes actifs exerçant une activité indépendante et entrepreneuriat, ainsi que les caractéristiques principales de ces activités. Ce chapitre présente également des données permettant d'évaluer la mesure dans laquelle le manque de compétences et connaissances constitue un obstacle à l'entrepreneuriat. Les données présentées concernent l'ensemble de l'Union européenne et chacun de ses États membres.
\end{abstract}

\section{Note Turquie/Chypre:}

1. Note en bas de page de la Turquie

Les informations figurant dans ce document qui font référence à "Chypre " concernent la partie méridionale de l'Ile. Il n'y a pas d'autorité unique représentant à la fois les Chypriotes turcs et grecs sur l'Ile. La Turquie reconnaît la République Turque de Chypre Nord (RTCN). Jusqu'à ce qu'une solution durable et équitable soit trouvée dans le cadre des Nations Unies, la Turquie maintiendra sa position sur la "question chypriote".

2. Note en bas de page de tous les États de l'Union européenne membres de l'OCDE et de l'Union européenne La République de Chypre est reconnue par tous les membres des Nations Unies sauf la Turquie. Les informations figurant dans ce document concernent la zone sous le contrôle effectif du gouvernement de la République de Chypre. 


\section{Le travail indépendant chez les jeunes}

- En 2013, les jeunes (15-24 ans) étaient nettement moins susceptibles d'exercer une activité indépendante que la population adulte (15-64 ans). Le taux de travail indépendant des jeunes était de $4,2 \%$, contre $14,4 \%$ pour les adultes, dans l'Union européenne.

- Alors que le taux de travail indépendant des jeunes est resté stable pendant dix ans, il a augmenté dans 17 États membres en 2013.

- Le plus souvent, les jeunes indépendants n'ont pas d'employés. Seuls 81200 d'entre eux (10,5\%) employaient au moins une personne en 2013.

Le graphique 3.1 présente les taux de travail indépendant des jeunes (15-24 ans) entre 2009 et 2013. Il apparaît clairement que les jeunes de l'Union européenne sont nettement moins susceptibles que la population adulte (15-64 ans) d'exercer une activité indépendante. En 2013, le taux de travail indépendant des jeunes était de $4,2 \%$, soit moins d'un tiers du taux de la population adulte $(14,4 \%)$. Les taux de travail indépendant des jeunes et des adultes sont restés relativement stables pendant dix ans. Pour plus de détails sur les notions et définitions utilisées dans ce chapitre, et sur les sources de données présentées, veuillez vous référer au guide de lecture en début d'ouvrage.

\section{Graphique 3.1. Taux de travail indépendant des jeunes dans l'EU-28, 2003-2013} Pourcentage du taux d'emploi total

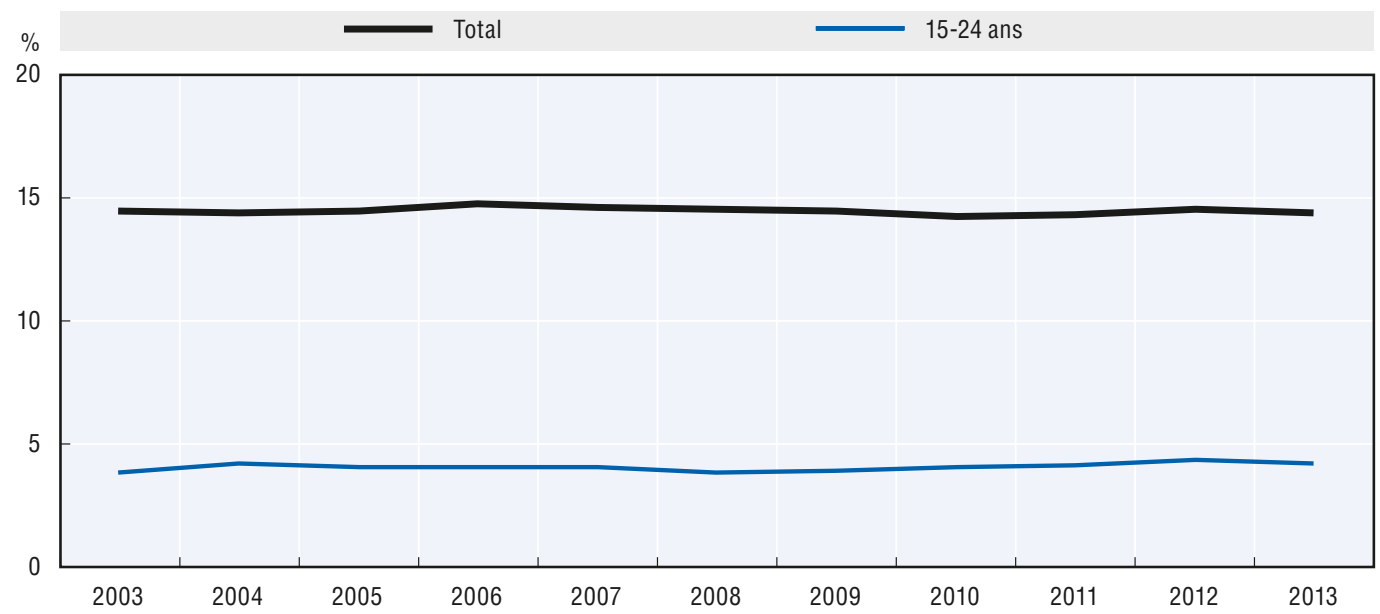

Source: Eurostat (2014), Enquête sur les forces de travail 2003-2013.

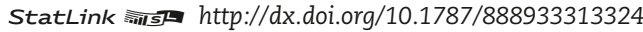

Les taux de travail indépendant des jeunes dans tous les États membres de l'Union européenne pour la période 2003-2013 sont présentés au graphique 3.2. Ils étaient relativement faibles en Autriche, au Danemark, en Allemagne, en Irlande et en Suède. L'écart entre les taux de travail indépendant des adultes et des jeunes était relativement élevé en Irlande. Pendant 
dix ans, les taux de travail indépendant des jeunes ont augmenté dans 17 États membres, baissé dans neuf et sont restés stables dans deux d'entre eux. En valeur absolue, les plus fortes hausse et baisse ont été observées respectivement en République slovaque (4,6 points de pourcentage) et en Pologne (2,3 points de pourcentage).

\section{Graphique 3.2. Taux de travail indépendant des jeunes par pays 2003-2013}

Pourcentage du taux d'emploi total
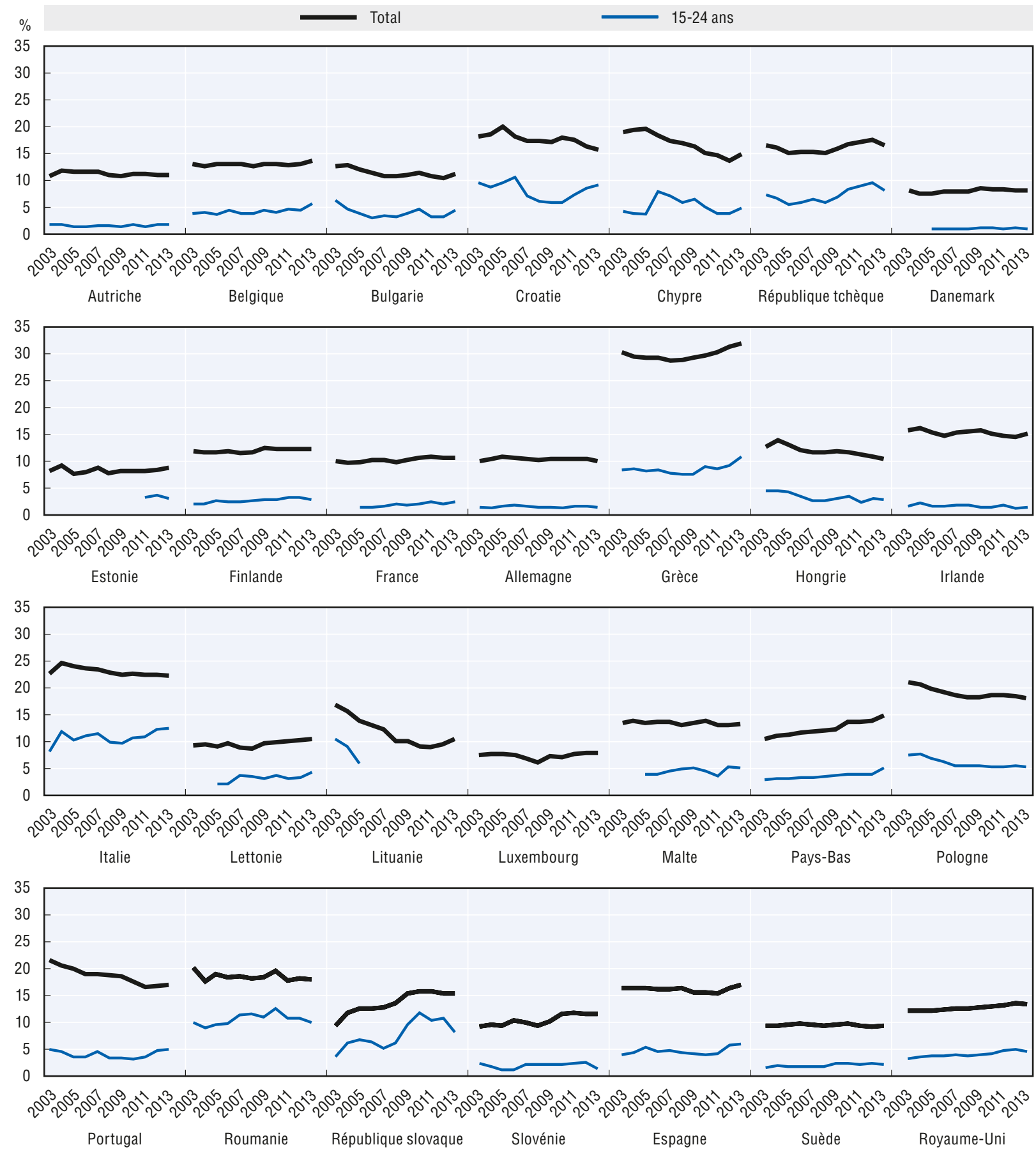

Source: Eurostat (2014), Enquête sur les forces de travail 2003-2013. 
Le graphique 3.3 illustre la proportion de jeunes indépendants employant du personnel au sein de l'Union européenne. En 2013, 10,5 \% des jeunes indépendants employaient au moins un salarié, soit environ un tiers de la proportion de la population adulte (28,8 \%). La proportion de jeunes indépendants employant du personnel a considérablement baissé entre 2003 et 2013, passant de 19,1 \% à 10,5 \%. Même si cette tendance à la baisse a également touché la population adulte, le recul a été plus marqué chez les jeunes.

\section{Graphique 3.3. Proportion de jeunes indépendants employant du personnel dans l'EU-28, 2003-2013}

Pourcentage du taux d'emploi total

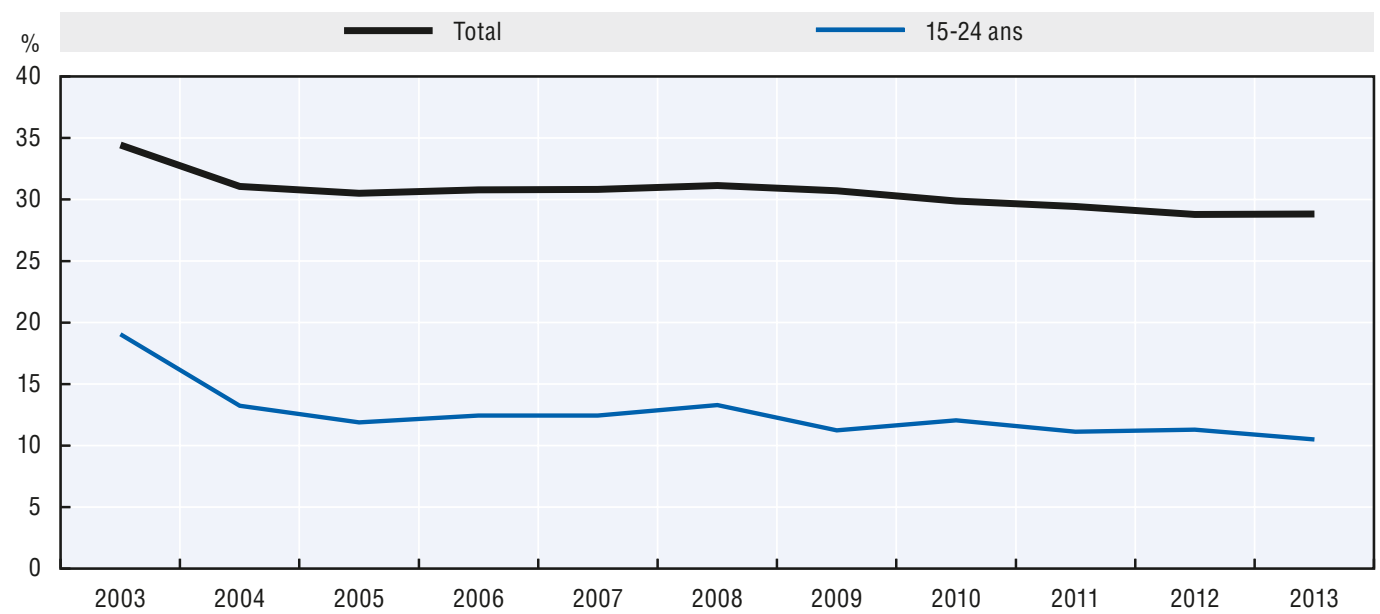

Source: Eurostat (2014), Enquête sur les forces de travail 2003-2013.

Le graphique 3.4 présente la part des jeunes indépendants faisant appel à des employés dans chaque État membre de l'Union européenne. Ces données ne sont pas disponibles pour tous les pays mais, lorsqu'elles le sont, elles confirment que les jeunes indépendants ont eu moins tendance à employer du personnel que les adultes entre 2003 et 2013. De plus, la proportion de jeunes indépendants employant du personnel varie sensiblement d'un État membre à l'autre (de $4 \%$ seulement aux Pays-Bas à 32,8 \% en Hongrie). Enfin, même si la proportion de jeunes indépendants a nettement baissé au sein de l'Union européenne entre 2003 et 2013, elle a augmenté dans certains pays comme la Pologne (de 10,3 \% à 16,4 \%).

Les taux de travail indépendant des jeunes par secteur d'activité présentés au graphique 3.5 montrent que les jeunes ont eu moins tendance à exercer une activité indépendante, quel que soit le secteur, que les adultes. En 2013, les taux de travail indépendant étaient les plus faibles dans les secteurs suivants: production (1,2\%), secteur social et des soins de santé (2\%) et hébergement et restauration (2,5\%). L'éducation était le seul secteur où les taux de travail indépendant des jeunes et des adultes étaient équivalents (4,5\% pour les jeunes et 4,6\% pour les adultes). 
Graphique 3.4. Proportion de jeunes indépendants employant du personnel par pays, 2003-2013 Pourcentage du taux d'emploi total
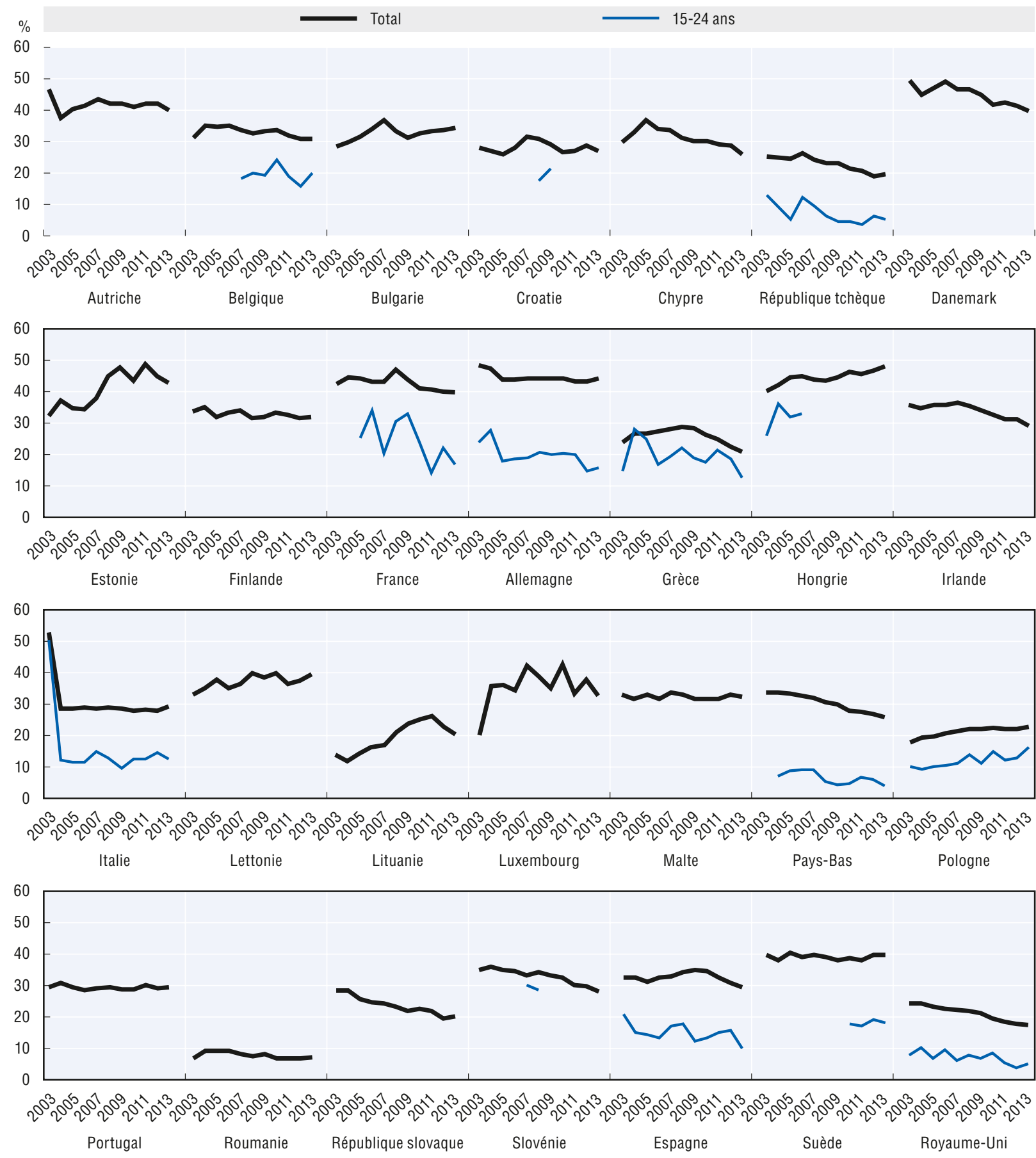

Source: Eurostat (2014), Enquête sur les forces de travail 2003-2013. 
Graphique 3.5. Taux de travail indépendant des jeunes par secteur dans l'EU-28, 2013

Pourcentage du taux d'emploi total

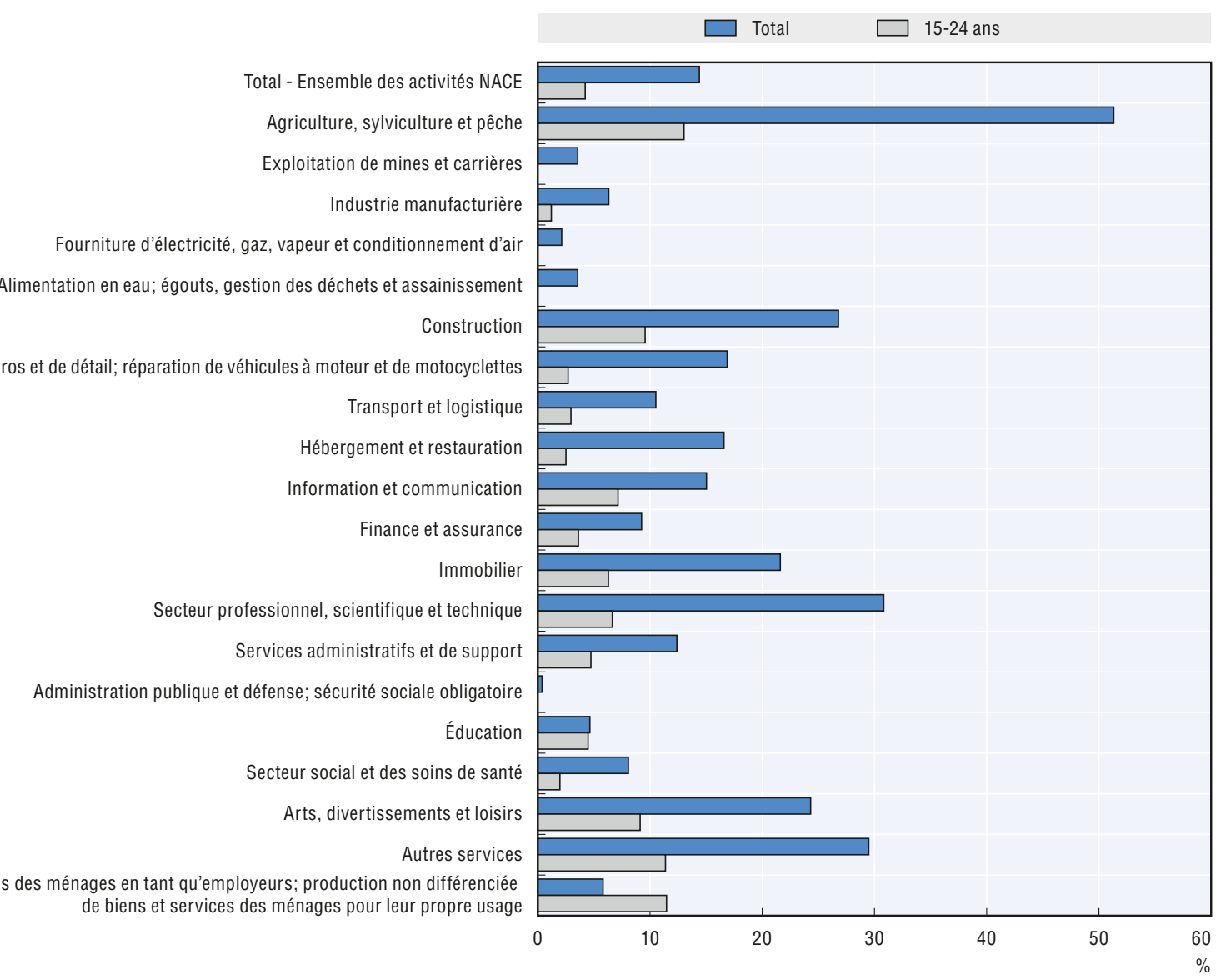

Source: Eurostat (2014), Enquête sur les forces de travail 2003-2013.

\section{Activités indépendantes exercées par les jeunes tout au long du cycle de vie entrepreneuriale}

- À l'échelle de l'Union européenne, les jeunes (18-30 ans) ont eu plus tendance que les adultes (18-64 ans) à être impliqués dans la création ou la détention d'une nouvelle entreprise entre 2009 et 2013. Un peu plus de $4 \%$ des jeunes dans l'Union européenne ont participé à la création d'une entreprise et 3,5\% des jeunes ont possédé une nouvelle entreprise au cours de cette période.

- En revanche, moins de $2 \%$ des jeunes européens étaient propriétaires d'une entreprise établie ayant opéré pendant plus de 42 mois entre 2009 et 2013. Ce chiffre représente environ un tiers de la proportion des adultes détenant une entreprise établie au cours de cette période.

Les taux d'entrepreneuriat naissant des jeunes (18-30 ans) de tous les États membres de l'Union européenne pour la période 2009-2013 sont présentés au graphique 3.6. Ce taux mesure la proportion d'adultes déclarant être activement engagés dans la création d'une entreprise qu'ils détiennent seuls ou en copropriété. Cette activité ne doit pas avoir rapporté de traitements, de salaires ou toute autre rémunération à ses propriétaires depuis plus de trois mois. Pour en savoir 
plus sur cette notion et sur cette source de données, nous vous renvoyons au guide de lecture proposé au début de cet ouvrage.

\section{Graphique 3.6. Taux d'entrepreneuriat naissant chez les jeunes, 2009-2013 (combinés)} Pourcentage de la population

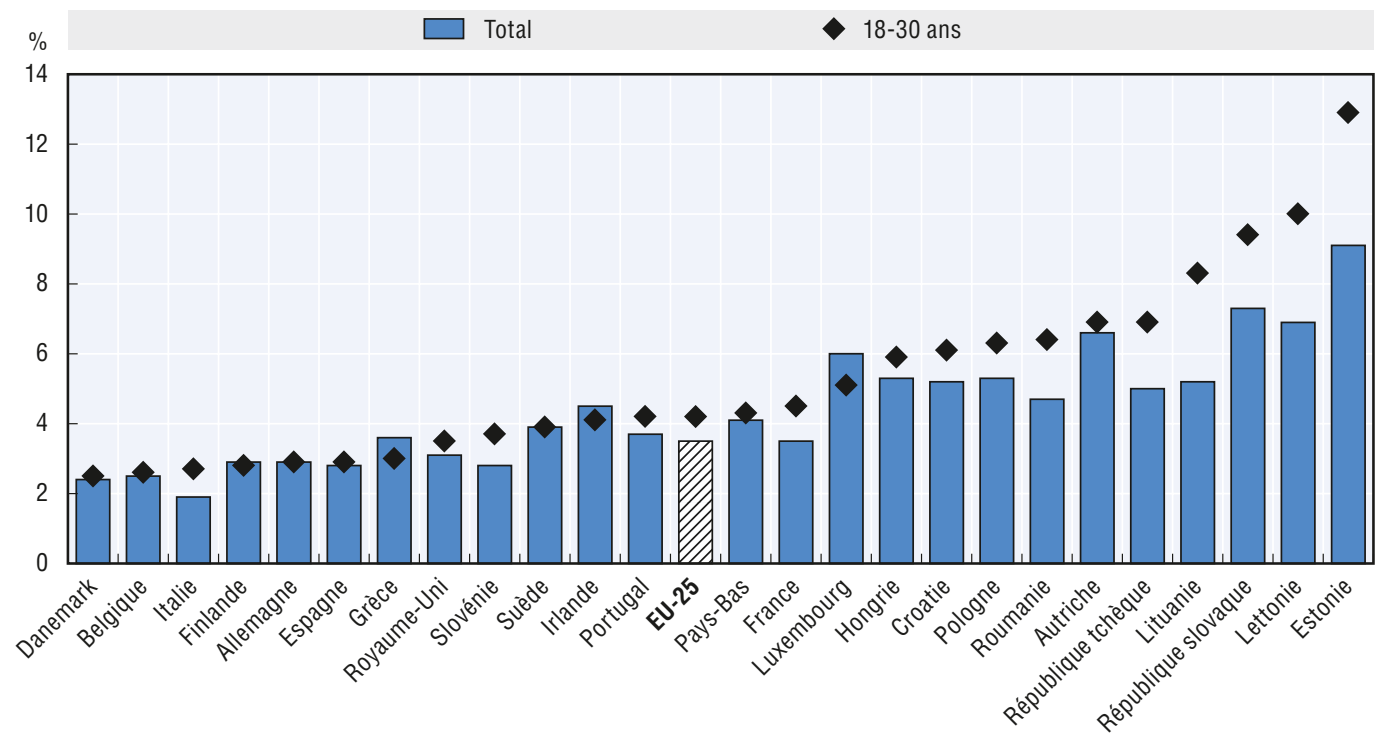

Notes: 1. Les pays de l'Union européenne ayant participé à l'enquête Global Entrepreneurship Monitor pendant cette période sont: la Belgique, la République tchèque, l'Allemagne, l'Estonie, l'Irlande, la Grèce, l'Espagne, la France, la Croatie, l'Italie, la Lettonie, la Lituanie, la Hongrie, les Pays-Bas, l'Autriche, la Pologne, le Portugal, la Roumanie, la Slovénie, la Slovaquie, la Finlande, la Suède et le Royaume-Uni. 2. Les données présentées dans ce graphique ont été combinées: elles cumulent les résultats des enquêtes annuelles portant sur la période 2009-2013. Certains pays n'ont pas pris part aux enquêtes GEM réalisées chaque année, mais ont été inclus dans les graphiques: la République tchèque (2011 et 2013), le Danemark (2009, 2010, 2011, 2012), l'Estonie (2012, 2013), l'Irlande (2010, 2011, 2012, 2013), l'Italie (2009, 2010, 2012, 2013), la Lituanie (2011, 2012, 2013), le Luxembourg (2013), l'Autriche (2012, 2013), la Pologne (2011, 2012, 2013), le Portugal (2010, 2011, 2012, 2013), la Slovaquie (2011, 2012, 2013), et la Suède $(2010,2011,2012,2013)$. 3. Le taux d'entrepreneuriat naissant est défini comme la proportion de la population adulte (âgée de 18 à 64 ans) activement engagée dans la création d'une entreprise qu'elle détiendra seule ou en copropriété; cette entreprise ne peut pas avoir octroyé de traitements, salaires ou toute autre rémunération à ses propriétaires depuis plus de trois mois.

Source: Global Entrepreneurship Monitor (GEM) (2014), présentations tabulaires spéciales des enquêtes 2009-2013 sur la population adulte, extraites du Global Entrepreneurship Monitor.

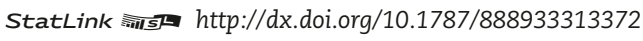

Globalement, les taux d'entrepreneuriat naissant des jeunes et des adultes étaient équivalents au cours de cette période. Un peu plus de $4 \%$ des jeunes étaient des entrepreneurs naissants, contre 3,5 \% des adultes. C'est en Estonie (12,9\%), en Lettonie (10\%), en République slovaque $(9,4 \%)$ que les taux d'entrepreneuriat naissant des jeunes ont été les plus élevés. Les taux les plus bas ont été enregistrés au Danemark (2,5\%), en Belgique (2,6 \%) et en Italie (2,7 \%). Les taux des jeunes et des adultes sont globalement équivalents dans la plupart des États membres. Dans certains pays, en particulier ceux enregistrant des taux élevés d'entrepreneuriat naissant chez les jeunes, il existe toutefois un écart très net entre les jeunes et les adultes. En République tchèque, en Lituanie, en République slovaque, en Lettonie et en Estonie, les taux d'entrepreneuriat naissant des jeunes étaient plus de $30 \%$ supérieurs à ceux des adultes.

Le taux de détention de nouvelles entreprises chez les jeunes entre 2009 et 2013 sont présentés par pays au graphique 3.7. Ce taux mesure la proportion de la population adulte qui est actuellement dirigeant-propriétaire d'une nouvelle entreprise qui verse des traitements, des salaires ou toute autre rémunération à ses propriétaires depuis plus de trois mois, mais moins de 42 mois. En d'autres termes, il mesure les activités entrepreneuriales qui succèdent immédiatement à la création d'entreprises. À l'échelle de l’Union européenne, le taux de détention de nouvelles entreprises chez les jeunes était légèrement supérieur à celui des adultes 
entre 2009 et 2013 (3,5\% contre 2,6\%). Il existe une corrélation étroite entre le taux d'entrepreneuriat naissant et le taux de détention de nouvelles entreprises. Il n'est donc pas surprenant que les pays présentant un taux élevé d'entrepreneuriat naissant enregistrent également un taux élevé de détention de nouvelles entreprises. Les pays ayant enregistré les taux de détention de nouvelles entreprises les plus élevés chez les jeunes entre 2009 et 2013 étaient la Lituanie (6,9\%), l’Estonie (6,7 \%) et la Lettonie (6,5\%). Les États membres présentant les taux de détention de nouvelles entreprises les plus faibles chez les jeunes entre 2009 et 2013 étaient l'Italie (2,1\%), la France (2,3\%), la Belgique (2,6\%) et l'Allemagne (2,6 \%).

\section{Graphique 3.7. Taux de détention de nouvelles entreprises chez les jeunes, 2009-2013 (combinés)}

Pourcentage de la population

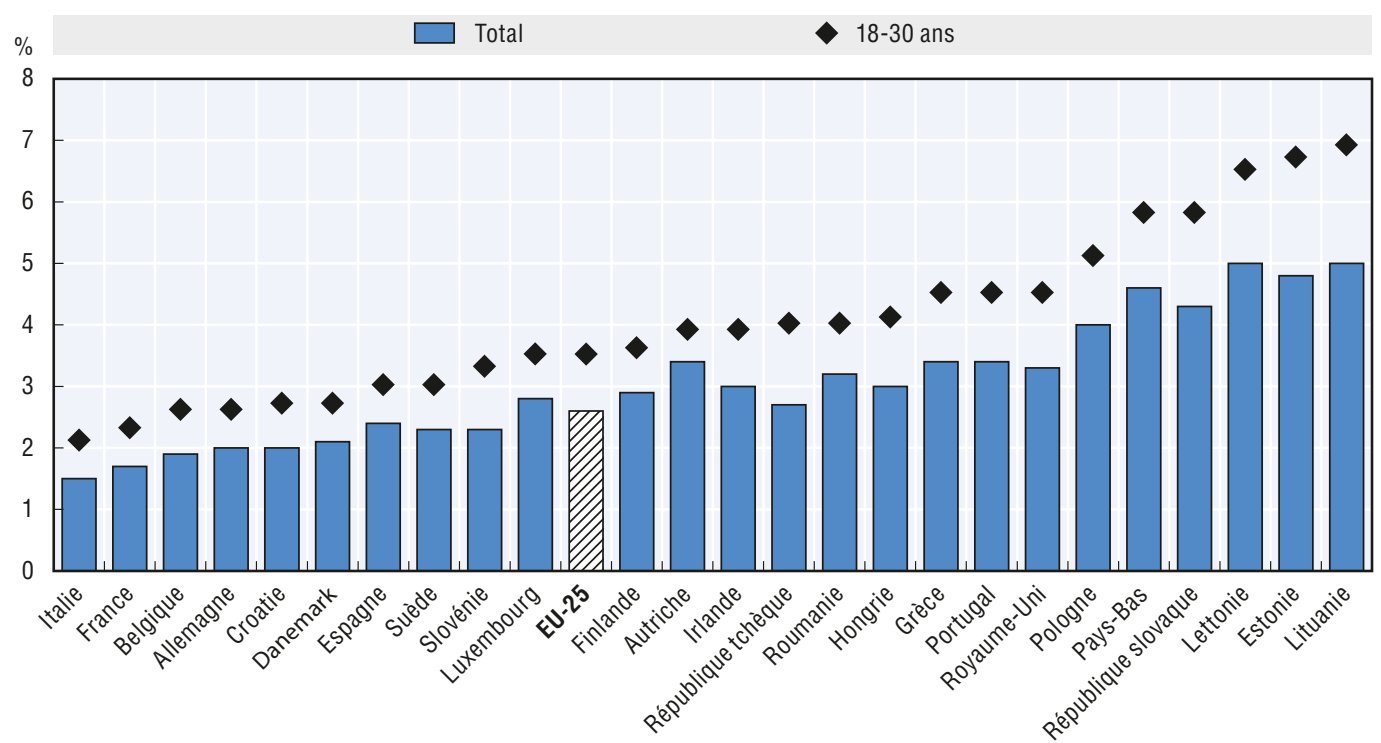

Notes: 1. Les pays de l'Union européenne ayant participé à l'enquête Global Entrepreneurship Monitor pendant cette période sont: la Belgique, la République tchèque, l'Allemagne, l'Estonie, l'Irlande, la Grèce, l'Espagne, la France, la Croatie, l'Italie, la Lettonie, la Lituanie, la Hongrie, les Pays-Bas, l'Autriche, la Pologne, le Portugal, la Roumanie, la Slovénie, la Slovaquie, la Finlande, la Suède et le Royaume-Uni. 2. Les données présentées dans ce graphique ont été combinées: elles cumulent les résultats des enquêtes annuelles portant sur la période 2009-2013. Certains pays n'ont pas pris part aux enquêtes GEM réalisées chaque année, mais ont été inclus dans les graphiques: la République tchèque (2011 et 2013), le Danemark (2009, 2010, 2011, 2012), l'Estonie (2012, 2013), l'Irlande (2010, 2011, 2012, 2013), l'Italie (2009, 2010, 2012, 2013), la Lituanie (2011, 2012, 2013), le Luxembourg (2013), l'Autriche (2012, 2013), la Pologne (2011, 2012, 2013), le Portugal (2010, 2011, 2012, 2013), la Slovaquie $(2011,2012,2013)$, et la Suède $(2010,2011,2012,2013)$. 3. Le taux de détention de nouvelles entreprises est la proportion de la population adulte gérant ou possédant actuellement une nouvelle entreprise qui verse des traitements, des salaires ou toute autre rémunération à ses propriétaires depuis plus de trois mois, mais moins de 42 mois.

Source: Global Entrepreneurship Monitor (GEM) (2014), présentations tabulaires spéciales des enquêtes 2009 -2013 sur la population adulte, extraites du Global Entrepreneurship Monitor.

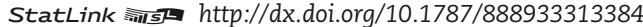

Le graphique 3.8 présente le taux de détention d'entreprises établies, qui mesure la proportion des membres de la population adulte qui sont actuellement dirigeants-propriétaires d'une entreprise établie qui verse des traitements, des salaires ou toute autre rémunération à ses propriétaires depuis plus de 42 mois. À l'échelle de l'Union européenne, le taux de détention d'entreprises établies chez les jeunes était nettement inférieur à celui des adultes (1,7\% pour les jeunes sur la période de 2009 à 2013, contre 5,7 \% pour les adultes), alors que leur taux de création d'entreprises était supérieur à celui des adultes. Cette tendance a pu être observée dans tous les États membres sur cette période. Les taux de détention d'entreprises établies chez les jeunes étaient les plus élevés en Lettonie (2,8 \%), en République slovaque $(2,9 \%)$ et en Grèce $(8,1 \%)$. Ils étaient les plus bas au Danemark $(0,7 \%)$, au Luxembourg (0, 7 \%) et en France (0,8 \%). C'est au Danemark (84,8 \%), au Royaume-Uni 
(82,3 \%) et en Suède (80,6 \%) que l'écart entre jeunes et adultes en termes de détention d'entreprises établies était le plus marqué en valeur relative. Les écarts les plus faibles ont été enregistrés en Roumanie (41 \%), Grèce (42,1\%) et en République slovaque (59,2 \%).

\section{Graphique 3.8. Taux de détention d'entreprises établies chez les jeunes, 2009-2013 (combinés)}

Pourcentage de la population

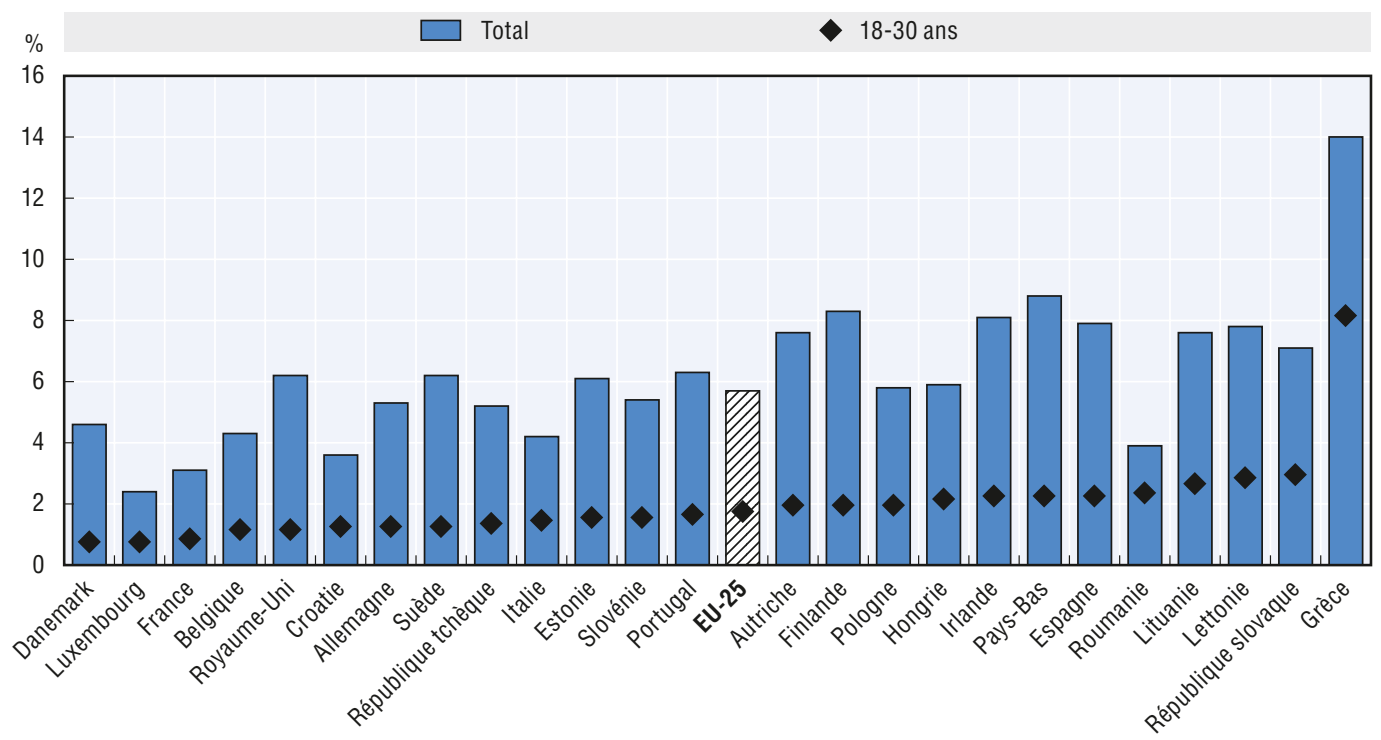

Notes: 1. Les pays de l'Union européenne ayant participé à l'enquête Global Entrepreneurship Monitor pendant cette période sont: la Belgique, la République tchèque, l'Allemagne, l'Estonie, l'Irlande, la Grèce, l'Espagne, la France, la Croatie, l'Italie, la Lettonie, la Lituanie, la Hongrie, les Pays-Bas, l'Autriche, la Pologne, le Portugal, la Roumanie, la Slovénie, la Slovaquie, la Finlande, la Suède et le Royaume-Uni. 2. Les données présentées dans ce graphique ont été combinées: elles cumulent les résultats des enquêtes annuelles portant sur la période 2009-2013. Certains pays n'ont pas pris part aux enquêtes GEM réalisées chaque année, mais ont été inclus dans les graphiques: la République tchèque (2011 et 2013), le Danemark (2009, 2010, 2011, 2012), l'Estonie (2012, 2013), l'Irlande (2010, 2011, 2012, 2013), l'Italie (2009, 2010, 2012, 2013), la Lituanie (2011, 2012, 2013), le Luxembourg (2013), l'Autriche (2012, 2013), la Pologne (2011, 2012, 2013), le Portugal (2010, 2011, 2012, 2013), la Slovaquie $(2011,2012,2013)$, et la Suède $(2010,2011,2012,2013)$. 3. Le taux de détention d'entreprises établies désigne la proportion des membres de la population adulte qui sont actuellement dirigeants-propriétaires d'une entreprise établie qui verse des traitements, des salaires ou toute autre rémunération à ses propriétaires depuis plus de 42 mois. Cet indicateur renseigne sur le niveau d'activités entrepreneuriales au sein d'une économie.

Source: Global Entrepreneurship Monitor (GEM) (2014), présentations tabulaires spéciales des enquêtes 2009-2013 sur la population adulte, extraites du Global Entrepreneurship Monitor.

StatLink (inाs http://dx.doi.org/10.1787/888933313398

\section{Le manque de compétences entrepreneuriales: un obstacle à la création d'entreprises pour les jeunes}

- Dans la plupart des pays de l'Union européenne, la majorité des jeunes estiment ne pas posséder les compétences et connaissances requises pour créer une entreprise.

- Au cours de la période 2009-2013, les jeunes (18-30 ans) dans l'Union européenne ont eu un peu moins tendance que les adultes à estimer posséder les compétences et connaissances requises pour créer une entreprise ( $36 \%$ contre $41 \%)$.

- Cependant, dans plusieurs pays de l'Union européenne, les jeunes étaient aussi susceptibles, voire un peu plus, que les adultes de penser disposer de telles compétences. Par exemple, en République slovaque, plus de $50 \%$ des jeunes ont déclaré disposer des compétences et connaissances requises pour créer une entreprise. 
Entre 2009 et 2013, les jeunes ont eu un peu moins tendance que les adultes à penser qu'ils disposaient des compétences et connaissances nécessaires pour créer leur entreprise (graphique 3.9). Globalement, $36 \%$ des jeunes estimaient disposer les compétences et connaissances nécessaires à la création d'entreprises, contre $41 \%$ des adultes. Dans la plupart des pays de l'Union européenne, les jeunes ont eu moins tendance que les adultes à estimer disposer des compétences et connaissances nécessaires pour créer leur entreprise. Les seules exceptions sont l'Italie, la Roumanie, la Lettonie et la République slovaque.

La proportion des jeunes considérant disposer des compétences et connaissances nécessaires varie sensiblement entre les États membres. Moins de $30 \%$ des jeunes au Luxembourg, au Danemark, en Finlande, en Allemagne et en Suède ont indiqué avoir les compétences et connaissances nécessaires pour créer leur entreprise, contre plus de $50 \%$ des jeunes en République slovaque.

\section{Graphique 3.9. Compétences entrepreneuriales en tant qu'obstacle à la création d'entreprises pour les jeunes, 2009-2013}

«Avez-vous les compétences et connaissances nécessaires pour créer une entreprise?» Pourcentage de la population ayant répondu «oui»

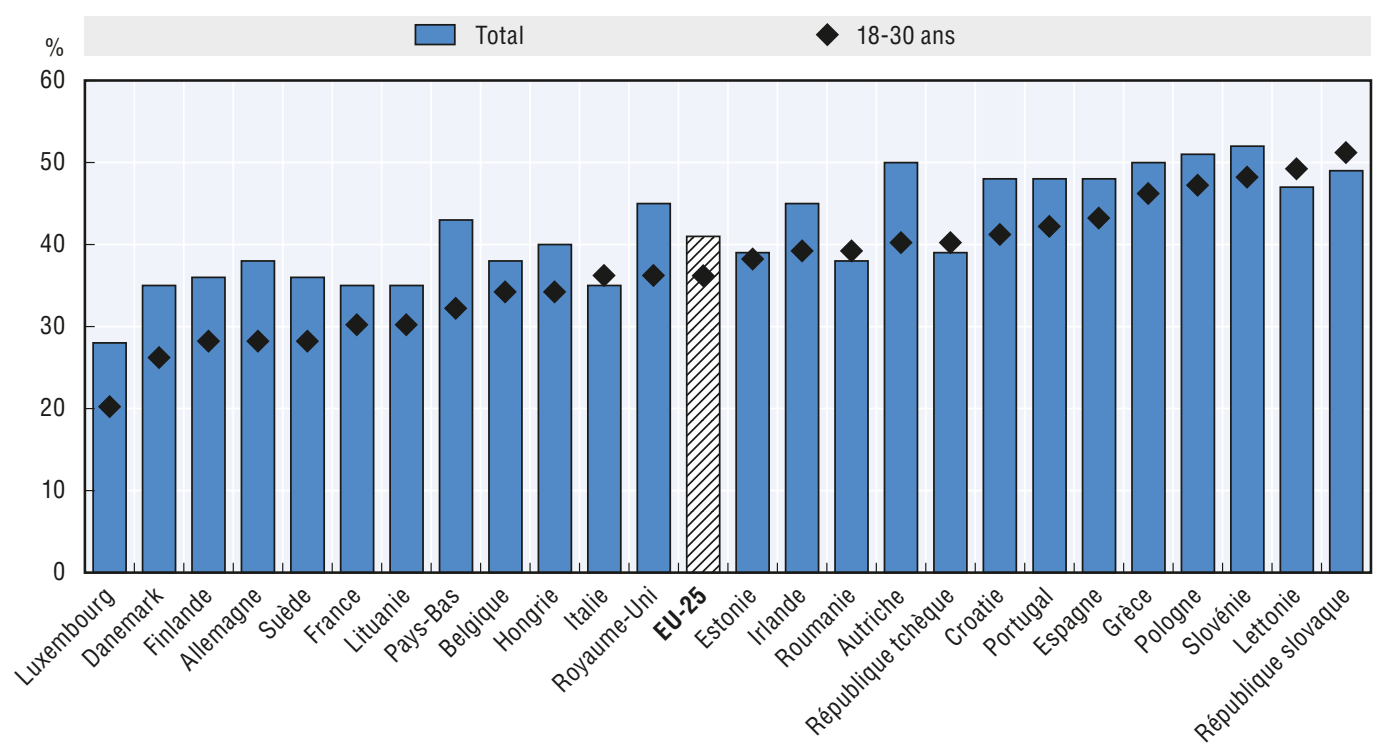

Source: Global Entrepreneurship Monitor (GEM) (2014), présentations tabulaires spéciales des enquêtes 2009-2013 sur la population adulte, extraites du Global Entrepreneurship Monitor.

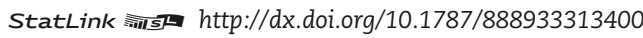

\section{Références}

Eurostat (2014), Emploi et chômage (Enquête sur les forces de travail), disponible sur: http://ec.europa. eu/eurostat/web/lfs/data.

Global Entrepreneurship Monitor (GEM) (2014), Présentations tabulaires spéciales des enquêtes 2009-2013 sur la population adulte, extraites du Global Entrepreneurship Monitor. 


\section{Chapitre 4}

\section{Le travail indépendant et l'entrepreneuriat chez les seniors}

Ce chapitre traite des activités indépendantes et entrepreneuriales exercées par les seniors (50-64 ans). Il fournit des informations sur le taux de travail indépendant des seniors ainsi que la proportion d'entre eux engagés dans la création d'une entreprise. Des données sur les principales caractéristiques des activités indépendantes des seniors sont également présentées, ainsi que la mesure dans laquelle le manque de compétences et de connaissances constitue un obstacle à l'entrepreneuriat. Les données présentées concernent l'ensemble de l'Union européenne et chacun de ses États membres.

\section{Note Turquie/Chypre:}

1. Note en bas de page de la Turquie

Les informations figurant dans ce document qui font référence à "Chypre " concernent la partie méridionale de l'Ile. Il n'y a pas d'autorité unique représentant à la fois les Chypriotes turcs et grecs sur l'Ile. La Turquie reconnaît la République Turque de Chypre Nord (RTCN). Jusqu'à ce qu'une solution durable et équitable soit trouvée dans le cadre des Nations Unies, la Turquie maintiendra sa position sur la " question chypriote".

2. Note en bas de page de tous les États de l'Union européenne membres de l'OCDE et de l'Union européenne La République de Chypre est reconnue par tous les membres des Nations Unies sauf la Turquie. Les informations figurant dans ce document concernent la zone sous le contrôle effectif du gouvernement de la République de Chypre. 


\section{Le travail indépendant chez les seniors}

- En 2013, les seniors (50-64 ans) de l'Union européenne étaient plus susceptibles d'exercer une activité indépendante que les jeunes (15-24 ans) et que les adultes en général (15-64 ans). Près de $20 \%$ des seniors actifs étaient indépendants.

- En 2013, sur les 11,2 millions de seniors indépendants dans l'Union européenne, près d'un tiers employait au moins un salarié (3,4 millions). Ce taux est similaire à celui de la population totale en âge de travailler.

- La proportion de seniors indépendants employant du personnel a considérablement varié entre les États membres: près de la moitié des seniors actifs en Hongrie (47 \%) employaient du personnel.

Les seniors (50-64 ans) ont eu davantage tendance à exercer une activité indépendante que la population adulte en âge de travailler (15-64 ans) entre 2003 et 2013. Comme le graphique 4.1 l'indique, le travail indépendant est une source importante de maintien dans l'emploi pour les seniors. À l'échelle de l'Union européenne, 18,9 \% des seniors actifs étaient indépendants en 2013, contre 14,4 \% de l'ensemble de la population adulte. Le taux de travail indépendant des adultes est resté stable entre 2003 et 2013. En revanche, celui des seniors a connu un léger recul, passant de 21,4 \% en 2003 à 18,9\% en 2013.

\section{Graphique 4.1. Taux de travail indépendant des seniors dans l'EU-28, 2003-2013}

Travail indépendant en pourcentage du taux d'emploi total

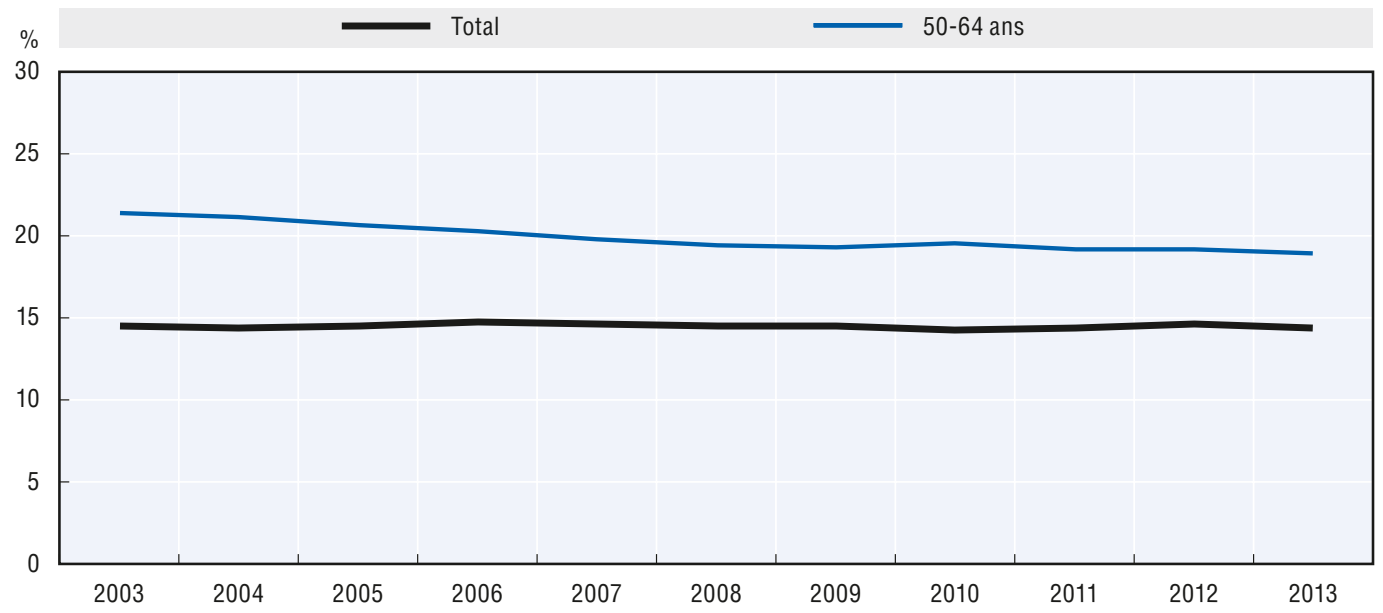

Source: Eurostat (2014), Enquête sur les forces de travail 2003-2013.

StatLink तiाs http://dx.doi.org/10.1787/888933313415

Dans tous les États membres de l'Union européenne, le taux de travail indépendant des seniors a été supérieur à celui des adultes sur la période 2003-2013 (graphique 4.2). En 2013, il était compris entre 9,6 \% en Estonie et 46,4 \% en Grèce. Entre 2003 et 2013, le taux de travail indépendant des seniors a augmenté dans sept États membres et reculé dans 21 d'entre eux. 
En valeur absolue, la plus forte hausse a été enregistrée en République tchèque $(+3,1$ points de pourcentage) et la plus forte baisse au Portugal (- 11 points de pourcentage).

\section{Graphique 4.2. Taux de travail indépendant des seniors par pays, 2003-2013}

Pourcentage du taux d'emploi total
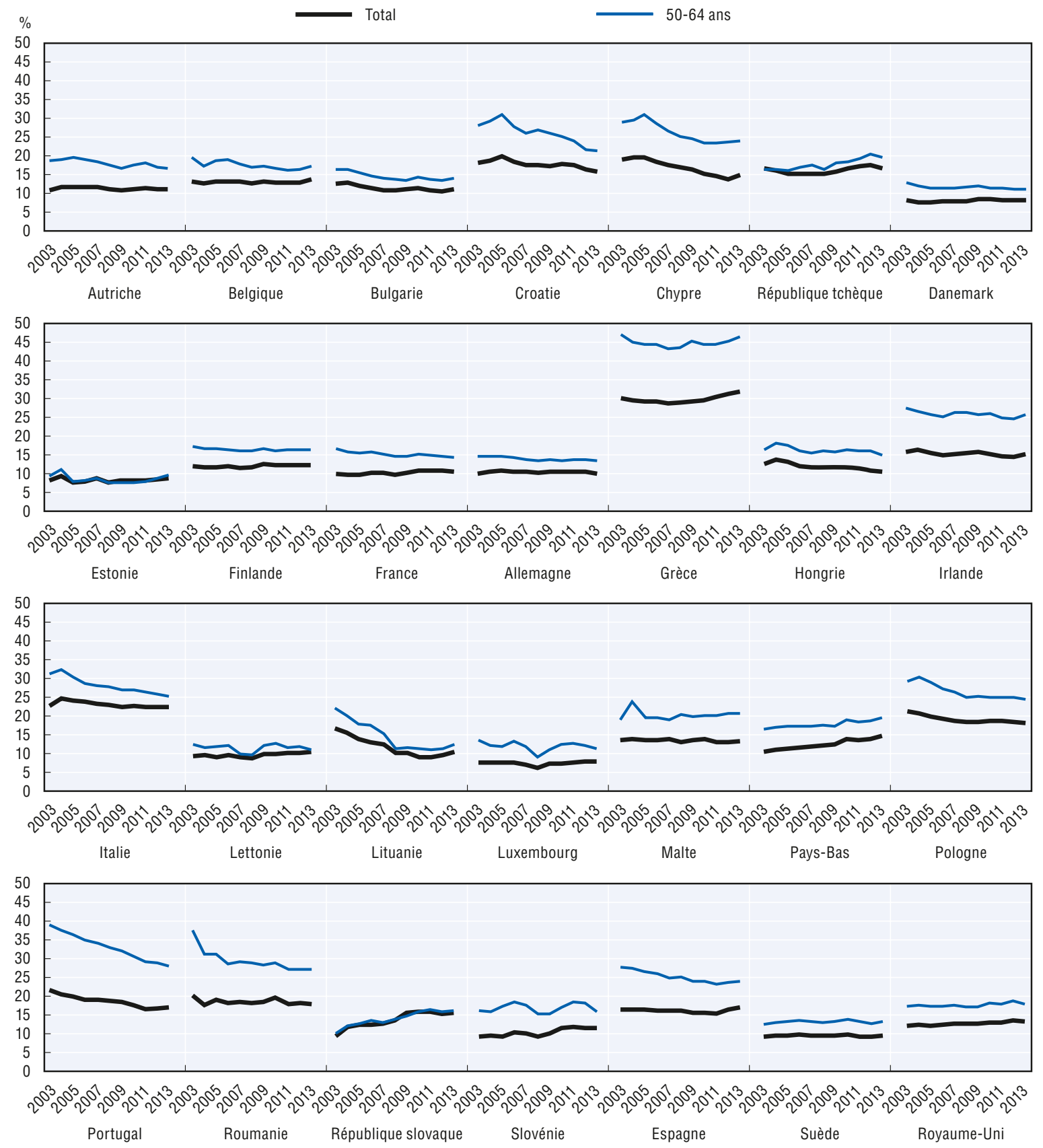

Source: Eurostat (2014), Enquête sur les forces de travail 2003-2013. 
Un peu plus de $30 \%$ des seniors indépendants dans l'Union européenne employaient du personnel en 2013. Sur les 11,2 millions de seniors indépendants, 3,4 millions employaient au moins un salarié. Cette proportion est à peu près équivalente à celle des adultes indépendants. Depuis 2003, la proportion de seniors et d'adultes employant du personnel a baissé. Chez les seniors, elle est passée de 34 \% en 2003 à 30,7 \% en 2013. La proportion d'indépendants adultes a chuté dans les mêmes proportions (de 34,4 \% en 2003 à 28,8 \% en 2013).

La proportion de seniors indépendants faisant appel à des employés dans l'Union européenne est présentée au graphique 4.3. En 2013, la proportion de seniors indépendants employant du personnel était de $30,7 \%$. Cette proportion est légèrement supérieure à celle des indépendants dans leur ensemble (28,8 \%). Entre 2003 et 2013, on constate très peu de différences entre la proportion de seniors indépendants employant du personnel et celle de l'ensemble des indépendants employant du personnel.

\section{Graphique 4.3. Proportion de seniors indépendants employant du personnel dans l'EU-28, 2003-2013}

Pourcentage du taux d'emploi total

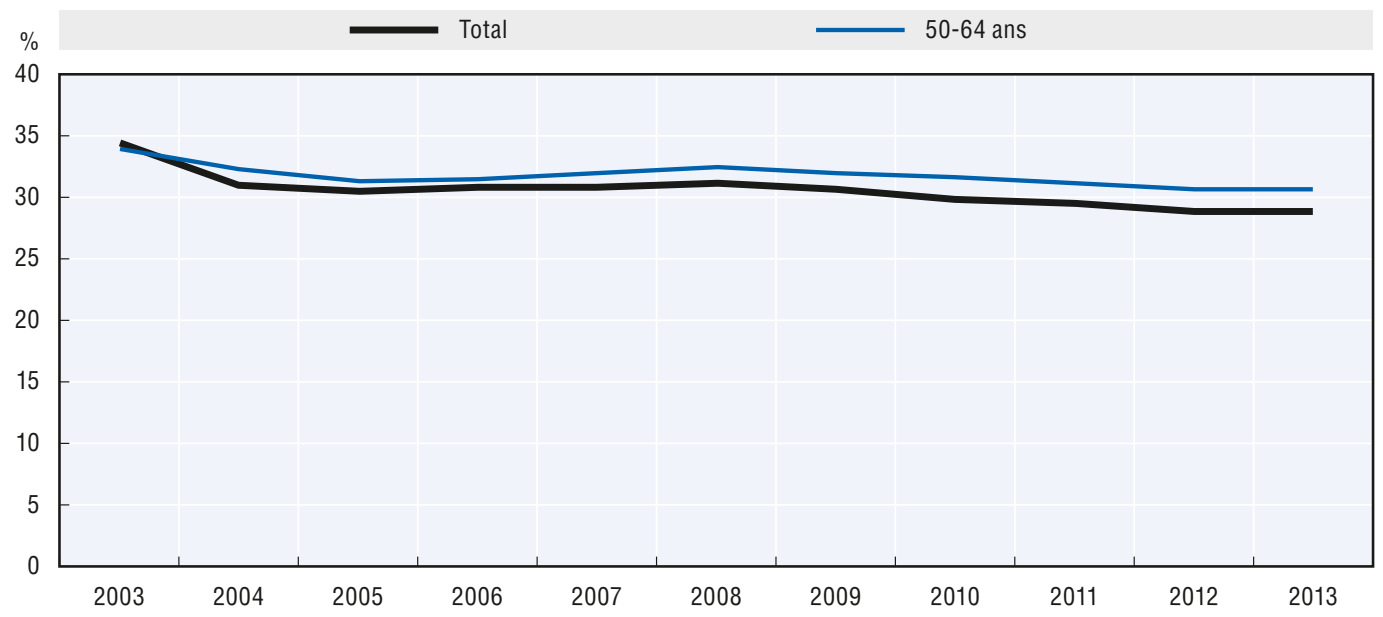

Source: Eurostat (2014), Enquête sur les forces de travail 2003-2013.

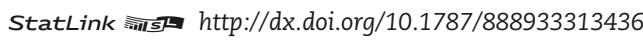

Le graphique 4.4 présente la part des seniors indépendants faisant appel à des employés dans chaque État membre entre 2003 et 2013. Les États membres où les seniors indépendants ont eu le plus tendance à employer des salariés étaient la Hongrie (46,9\%), l'Allemagne (46,5\%) et l'Autriche (44,6\%). La proportion d'adultes indépendants employant du personnel était supérieure à celle des seniors dans 15 États membres en 2013 alors qu'à l'échelle de l'Union européenne, les seniors indépendants étaient plus susceptibles d'employer du personnel que l'ensemble des adultes indépendants. 
Graphique 4.4. Proportion de seniors indépendants employant du personnel par pays, 2003-2013 Pourcentage du taux d'emploi total
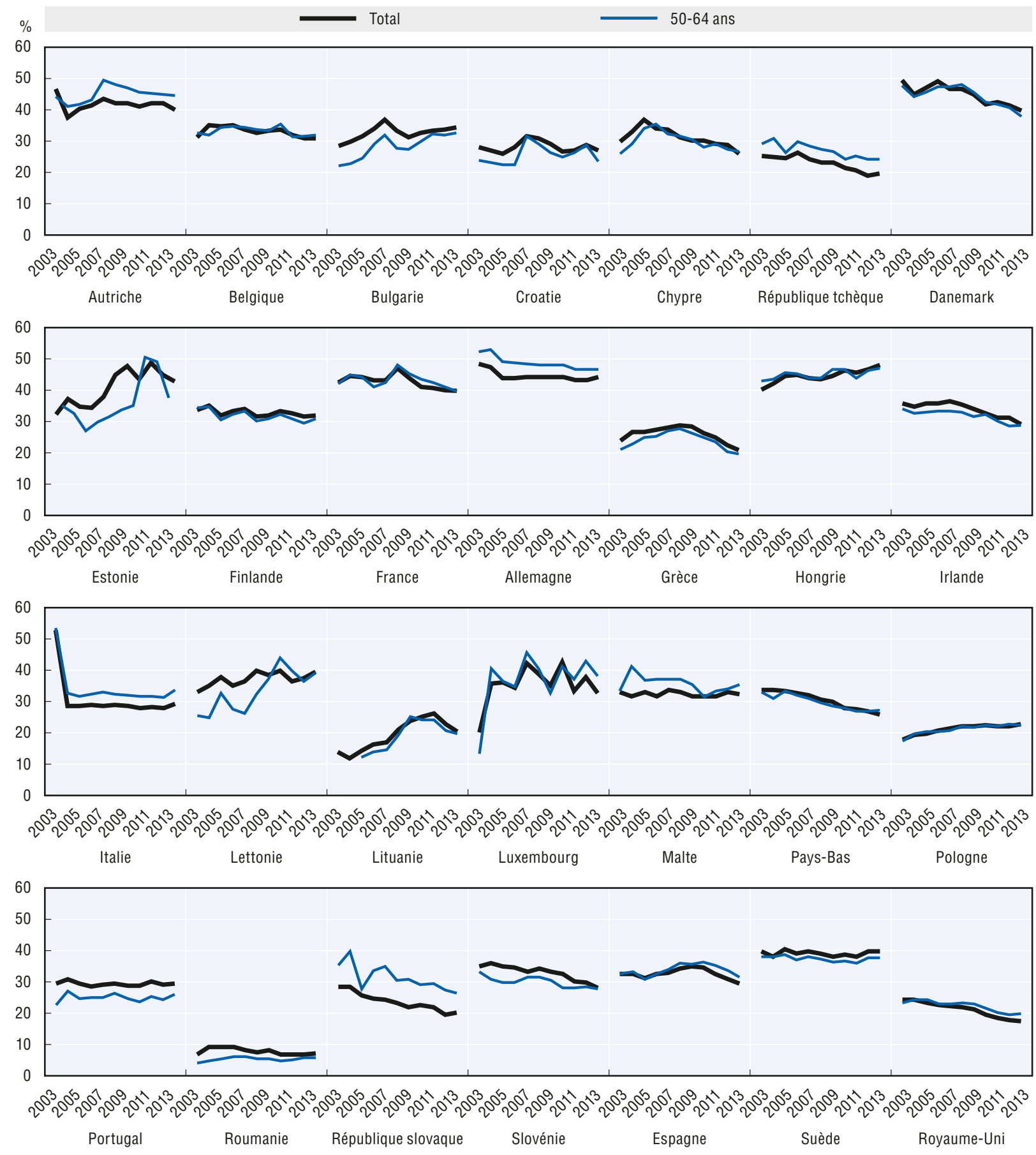

Source: Eurostat (2014), Enquête sur les forces de travail 2003-2013.

Les taux de travail indépendant des seniors par secteur en 2013 sont présentés au graphique 4.5. Les seniors étaient plus susceptibles d'exercer une activité indépendante que les adultes, quel que soit le secteur d'activité, à l'exception des domaines suivants: fourniture d'électricité, gaz, vapeur et conditionnement d'air; alimentation en eau; égouts, gestion des déchets et assainissement; administration publique et défense; sécurité sociale obligatoire; éducation; et 
activités ménagères en tant qu'employeur. Les taux de travail indépendant des seniors dans ces secteurs étaient équivalents à ceux des adultes. En 2013, les secteurs où les taux de travail indépendant des seniors étaient nettement supérieurs à ceux des adultes étaient l'hébergement et la restauration (13,1 points de pourcentage), l'agriculture, la foresterie et la pêche (12,3 points de pourcentage) et les activités scientifiques, professionnelles et techniques (11,8 points de pourcentage).

\section{Graphique 4.5. Taux de travail indépendant des seniors par secteur dans l’EU-28, 2013}

Pourcentage du taux d'emploi total

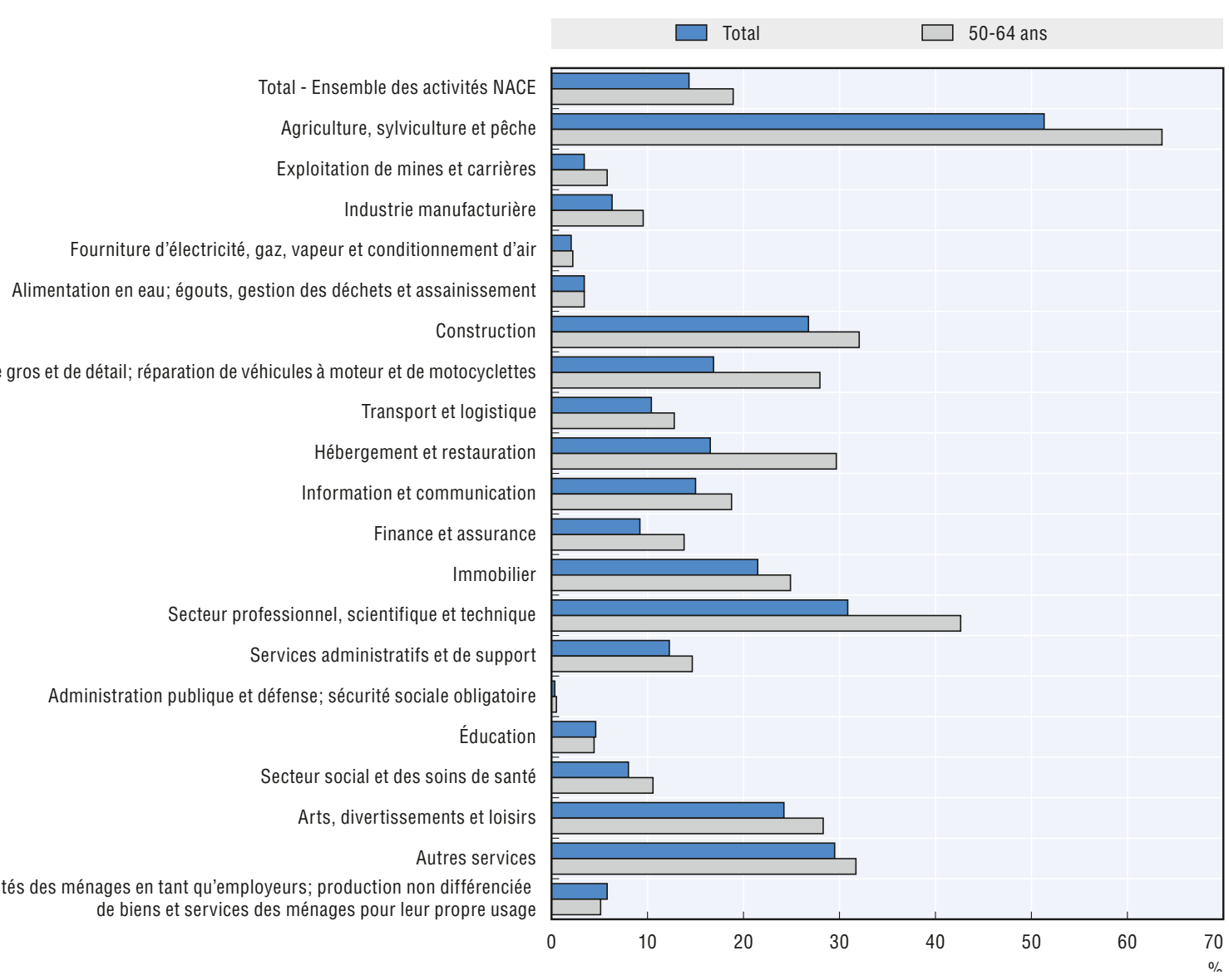

Source: Eurostat (2014), Enquête sur les forces de travail 2003-2013.

- Entre 2009 et 2013, les seniors (50-64 ans) étaient moins susceptibles que l'ensemble de la population adulte d'être impliqués dans la création d'une entreprise au sein de l'Union européenne (2,2 \% contre 3,5\%). Au Luxembourg, plus de 5,8\% des seniors ont créé une entreprise au cours de cette période.

- À l'échelle de l'Union européenne, les seniors (50-64 ans) étaient aussi susceptibles de posséder une nouvelle entreprise que tous les adultes (18-64 ans). Leurs taux de détention de nouvelles entreprises étaient respectivement de 2,9\% et 2,6\%. Dans certains États membres de l'Union européenne, les seniors étaient bien plus susceptibles de détenir une nouvelle entreprise. En Estonie, par exemple, ils étaient 45 \% plus susceptibles de détenir une nouvelle entreprise que l'ensemble des adultes en âge de travailler au cours de cette période. 
- Les seniors étaient également un peu plus susceptibles d'être propriétaires d'une entreprise établie que l'ensemble des adultes en âge de travailler entre 2009 et 2013 (7,4 \% contre $5,7 \%$ ). Cette tendance se vérifie dans tous les États membres, même s'il existe des variations entre les pays. Le Luxembourg est le pays qui enregistre la plus faible proportion de seniors propriétaires d'une entreprise établie $(3,8 \%)$, tandis que la plus forte est observée en Grèce $(14,8 \%)$.

\section{Activités exercées par les seniors tout au long du cycle de vie entrepreneuriale}

Les taux d'entrepreneuriat naissant des seniors (50-64 ans) dans les pays de l'Union européenne entre 2009 et 2013 sont présentés au graphique 4.6. Ce taux mesure la proportion d'adultes déclarant être activement engagés dans la création d'une entreprise qu'ils détiennent seuls ou en copropriété. Cette activité ne doit pas avoir rapporté de traitements, de salaires ou toute autre rémunération à ses propriétaires depuis plus de trois mois. Pour en savoir plus sur cette notion et sur cette source de données, nous vous renvoyons au guide de lecture proposé au début de cet ouvrage.

\section{Graphique 4.6. Taux d'entrepreneuriat naissant chez les seniors, 2009-2013 (combinés)}

Pourcentage de la population

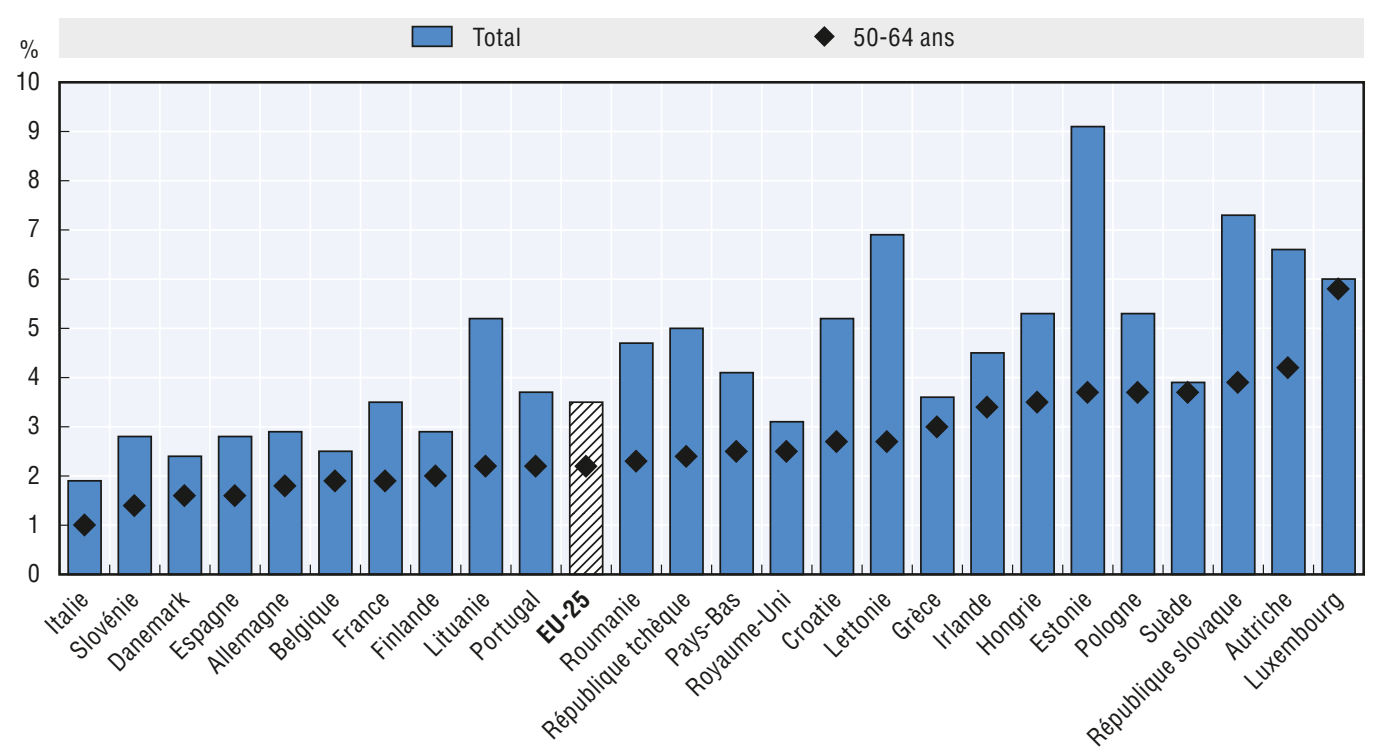

Notes: 1. Les pays de l'Union européenne ayant participé à l'enquête Global Entrepreneurship Monitor pendant cette période sont: la Belgique, la République tchèque, l'Allemagne, l'Estonie, l'Irlande, la Grèce, l'Espagne, la France, la Croatie, l'Italie, la Lettonie, la Lituanie, la Hongrie, les Pays-Bas, l'Autriche, la Pologne, le Portugal, la Roumanie, la Slovénie, la Slovaquie, la Finlande, la Suède et le Royaume-Uni. 2. Les données présentées dans ce graphique ont été combinées: elles cumulent les résultats des enquêtes annuelles portant sur la période 2009-2013. Certains pays n'ont pas pris part aux enquêtes GEM réalisées chaque année, mais ont été inclus dans les graphiques: la République tchèque (2011 et 2013), le Danemark $(2009,2010,2011,2012)$, l'Estonie (2012, 2013), l'Irlande (2010, 2011, 2012, 2013), l'Italie (2009, 2010, 2012, 2013), la Lituanie (2011, 2012, 2013), le Luxembourg (2013), l'Autriche (2012, 2013), la Pologne (2011, 2012, 2013), le Portugal (2010, 2011, 2012, 2013), la Slovaquie (2011, 2012, 2013), et la Suède $(2010,2011,2012,2013)$. 3. Le taux d'entrepreneuriat naissant est défini comme la proportion de la population adulte (âgée de 18 à 64 ans) activement engagée dans la création d'une entreprise qu'elle détiendra seule ou en copropriété; cette entreprise ne peut pas avoir octroyé de traitements, salaires ou toute autre rémunération à ses propriétaires depuis plus de trois mois.

Source: Global Entrepreneurship Monitor (GEM) (2014), présentations tabulaires spéciales des enquêtes 2009-2013 sur la population adulte, extraites du Global Entrepreneurship Monitor.

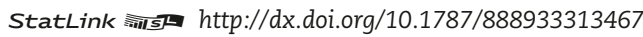


Entre 2009 et 2013, les seniors de l’Union européenne étaient moins susceptibles que la population adulte globale (18-64 ans) d'être impliqués dans des activités d'entrepreneuriat naissant. À l'échelle de l'Union européenne, le taux d'entrepreneuriat naissant des seniors était de 2,2 \% sur cette période, contre 3,5\% des adultes en âge de travailler. Au niveau national, il est compris entre $1 \%$ en Italie et 5,8 \% au Luxembourg. Si l'on compare le taux des seniors avec celui des adultes au niveau national, l'écart le plus marqué est observé en Estonie (5,4 points de pourcentage) et le plus faible au Luxembourg (0,2 point de pourcentage).

Les taux de détention de nouvelles entreprises sont globalement équivalents pour les seniors et les adultes dans la plupart des États membres de l’Union européenne (graphique 4.7). Le taux de détention de nouvelles entreprises correspond à la proportion de la population adulte actuellement dirigeant-propriétaire d'une nouvelle entreprise qui verse des traitements, des salaires ou toute autre rémunération à ses propriétaires depuis plus de trois mois, mais moins de 42 mois. À l'échelle de l'Union européenne, le taux de détention de nouvelles entreprises des seniors était de 2,9 \% pour la période 2009-2013, contre 2,6 \% pour les adultes. Au niveau national, il était compris entre 1,4\% en Italie et au Danemark et $7 \%$ au Luxembourg. L'écart entre les seniors et les adultes en âge de travailler était marginal dans la plupart des États membres. Cependant, l'écart était de 2,2 points de pourcentage (45\% du taux des adultes) en Estonie.

\section{Graphique 4.7. Taux de détention de nouvelles entreprises chez les seniors, 2009-2013 (combinés)}

Pourcentage de la population

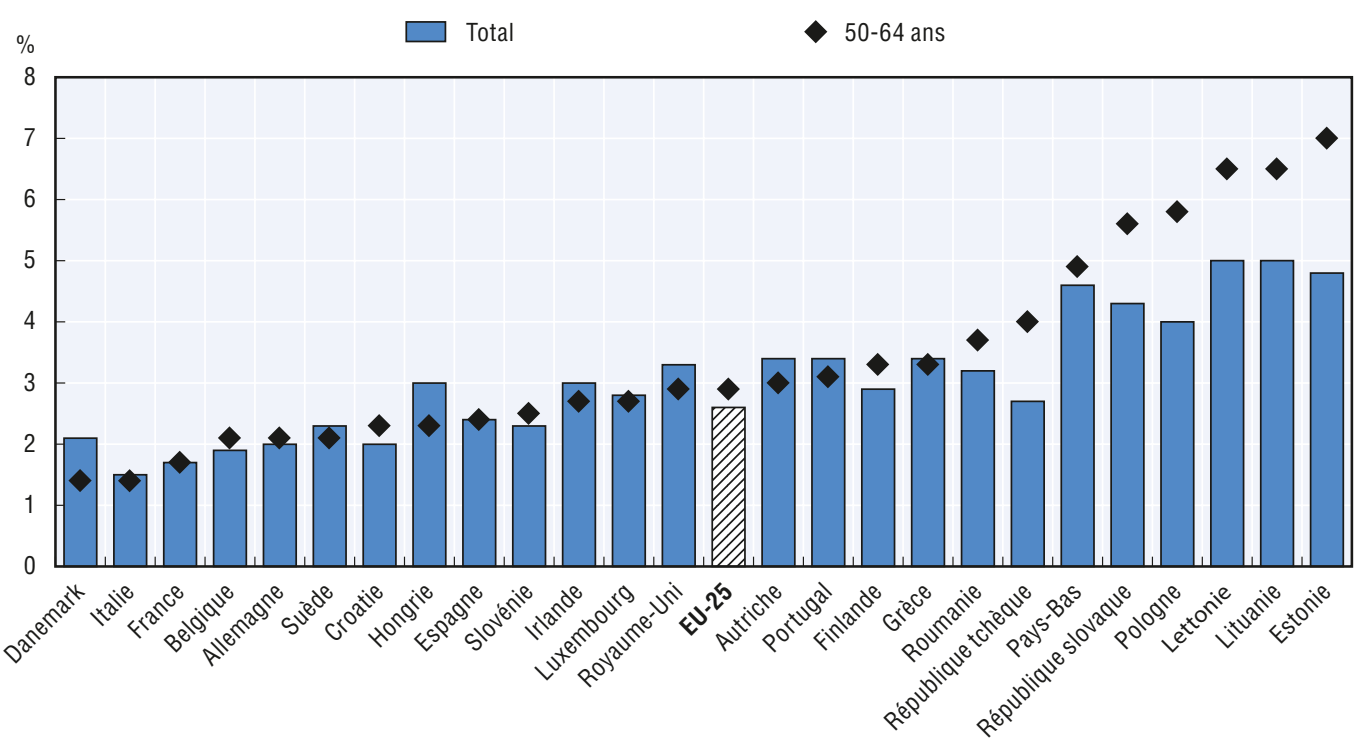

Notes: 1. Les pays de l'Union européenne ayant participé à l'enquête Global Entrepreneurship Monitor pendant cette période sont: la Belgique, la République tchèque, l'Allemagne, l'Estonie, l'Irlande, la Grèce, l'Espagne, la France, la Croatie, l'Italie, la Lettonie, la Lituanie, la Hongrie, les Pays-Bas, l'Autriche, la Pologne, le Portugal, la Roumanie, la Slovénie, la Slovaquie, la Finlande, la Suède et le Royaume-Uni. 2. Les données présentées dans ce graphique ont été combinées: elles cumulent les résultats des enquêtes annuelles portant sur la période 2009-2013. Certains pays n'ont pas pris part aux enquêtes GEM réalisées chaque année, mais ont été inclus dans les graphiques: la République tchèque (2011 et 2013), le Danemark (2009, 2010, 2011, 2012), l'Estonie (2012, 2013), l'Irlande (2010, 2011, 2012, 2013), l'Italie (2009, 2010, 2012, 2013), la Lituanie (2011, 2012, 2013), le Luxembourg (2013), l'Autriche (2012, 2013), la Pologne (2011, 2012, 2013), le Portugal (2010, 2011, 2012, 2013), la Slovaquie $(2011,2012,2013)$, et la Suède $(2010,2011,2012,2013)$. 3. Le taux de détention de nouvelles entreprises est la proportion de la population adulte gérant ou possédant actuellement une nouvelle entreprise qui verse des traitements, des salaires ou toute autre rémunération à ses propriétaires depuis plus de trois mois, mais moins de 42 mois.

Source: Global Entrepreneurship Monitor (GEM) (2014), présentations tabulaires spéciales des enquêtes 2009-2013 sur la population adulte, extraites du Global Entrepreneurship Monitor.

StatLink (inis http://dx.doi.org/10.1787/888933313470 
Malgré un taux de création d'entreprises inférieur, les seniors étaient plus susceptibles de posséder une entreprise établie que les adultes en âge de travailler. Cela s'explique en partie par le fait que les seniors ont disposé de plus de temps pour établir leur entreprise. Cela peut également démontrer leur plus grande capacité à rendre viable une entreprise. C'est le cas dans tous les États membres de l'Union européenne, à l'exception de l'Italie où les taux de détention d'une entreprise établie par des seniors et des adultes en âge de travailler étaient équivalents (graphique 4.8). Les propriétaires d'entreprises établies sont des adultes qui possèdent et gèrent une entreprise établie qui verse des traitements, des salaires ou toute autre rémunération à ses propriétaires depuis plus de 42 mois. Entre 2009 et 2013, 7,4 \% des seniors dans l'Union européenne en âge de travailler (50-64 ans) étaient propriétaires d'une entreprise établie, soit plus que la proportion d'adultes en âge de travailler dans l'ensemble de l'Union européenne $(5,7 \%)$. Les seniors étaient les plus susceptibles de détenir une entreprise établie en Irlande $(13,1 \%)$ et en Grèce $(14,8 \%)$, soit plus de trois fois plus qu'au Luxembourg $(3,8 \%)$, en Italie $(3,9 \%)$, en Croatie (4,3\%) et en France (4,3\%).

\section{Graphique 4.8. Taux de détention d'entreprises établies chez les seniors, 2009-2013 (combinés)}

Pourcentage de la population

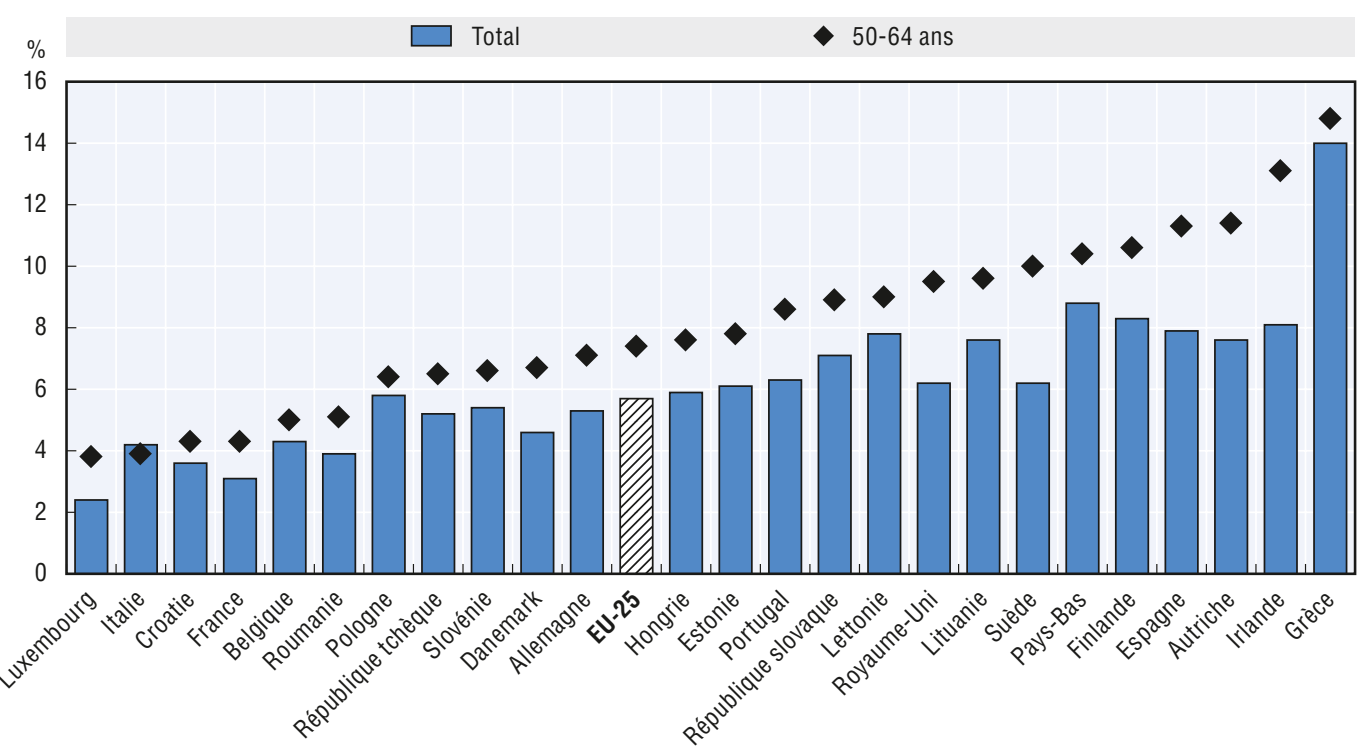

Notes: 1. Les pays de l'Union européenne ayant participé à l'enquête Global Entrepreneurship Monitor pendant cette période sont: la Belgique, la République tchèque, l'Allemagne, l'Estonie, l'Irlande, la Grèce, l'Espagne, la France, la Croatie, l'Italie, la Lettonie, la Lituanie, la Hongrie, les Pays-Bas, l'Autriche, la Pologne, le Portugal, la Roumanie, la Slovénie, la Slovaquie, la Finlande, la Suède et le Royaume-Uni. 2. Les données présentées dans ce graphique ont été combinées: elles cumulent les résultats des enquêtes annuelles portant sur la période 2009-2013. Certains pays n'ont pas pris part aux enquêtes GEM réalisées chaque année, mais ont été inclus dans les graphiques: la République tchèque (2011 et 2013), le Danemark (2009, 2010, 2011, 2012), l'Estonie (2012, 2013), l'Irlande (2010, 2011, 2012, 2013), l'Italie (2009, 2010, 2012, 2013), la Lituanie (2011, 2012, 2013), le Luxembourg (2013), l'Autriche (2012, 2013), la Pologne (2011, 2012, 2013), le Portugal (2010, 2011, 2012, 2013), la Slovaquie $(2011,2012,2013)$, et la Suède $(2010,2011,2012,2013)$. 3. Le taux de détention d'entreprises établies désigne la proportion des membres de la population adulte qui sont actuellement dirigeants-propriétaires d'une entreprise établie qui verse des traitements, des salaires ou toute autre rémunération à ses propriétaires depuis plus de 42 mois. Cet indicateur renseigne sur le niveau d'activités entrepreneuriales au sein d'une économie.

Source: Global Entrepreneurship Monitor (GEM) (2014), présentations tabulaires spéciales des enquêtes 2009-2013 sur la population adulte, extraites du Global Entrepreneurship Monitor.

StatLink 青IS $h$ ttp://dx.doi.org/10.1787/888933313489 


\section{Le manque de compétences entrepreneuriales: un obstacle à la création d'entreprises pour les seniors}

- Entre 2009 et 2013, au sein de l'Union européenne, les seniors étaient aussi susceptibles que les adultes en âge de travailler de déclarer disposer des compétences et connaissances requises pour créer une entreprise (39\% contre $41 \%$ ).

- La proportion des seniors qui estiment posséder les connaissances et compétences nécessaires pour créer une entreprise varie sensiblement selon les pays. En Italie, moins de $30 \%$ des seniors estiment posséder les compétences et connaissances nécessaires pour créer leur entreprise, contre plus de $50 \%$ en Autriche.

Le graphique 4.9 présente la proportion de seniors (50-64 ans) qui estiment disposer des compétences et connaissances nécessaires pour créer une entreprise. À l'échelle de l'Union européenne, $39 \%$ des seniors estiment posséder les compétences requises pour créer une entreprise, soit quasiment autant que les adultes en âge de travailler dans leur ensemble (41\%). La proportion de seniors qui estiment disposer des compétences et connaissances nécessaires varie d'un État membre à l'autre (de $28 \%$ en Italie à $53 \%$ en Autriche). Dans presque tous les États membres, les proportions de seniors et d'adultes en âge de travailler déclarant disposer des compétences et connaissances nécessaires pour créer une entreprise sont similaires. L'écart est souvent de l'ordre de 5 points de pourcentage. Toutefois, les seniors étaient moins susceptibles que les adultes en âge de travailler de penser avoir les compétences et connaissances nécessaires en République slovaque (6 points de pourcentage), en Italie et en Roumanie (7 points de pourcentage pour les deux), en Estonie et en Lettonie (8 points de pourcentage pour les deux).

\section{Graphique 4.9. Manque de compétences entrepreneuriales en tant qu'obstacle à la création d'entreprises pour les seniors, 2009-2013}

«Avez-vous les compétences et connaissances nécessaires pour créer une entreprise?» Pourcentage de la population ayant répondu «oui»

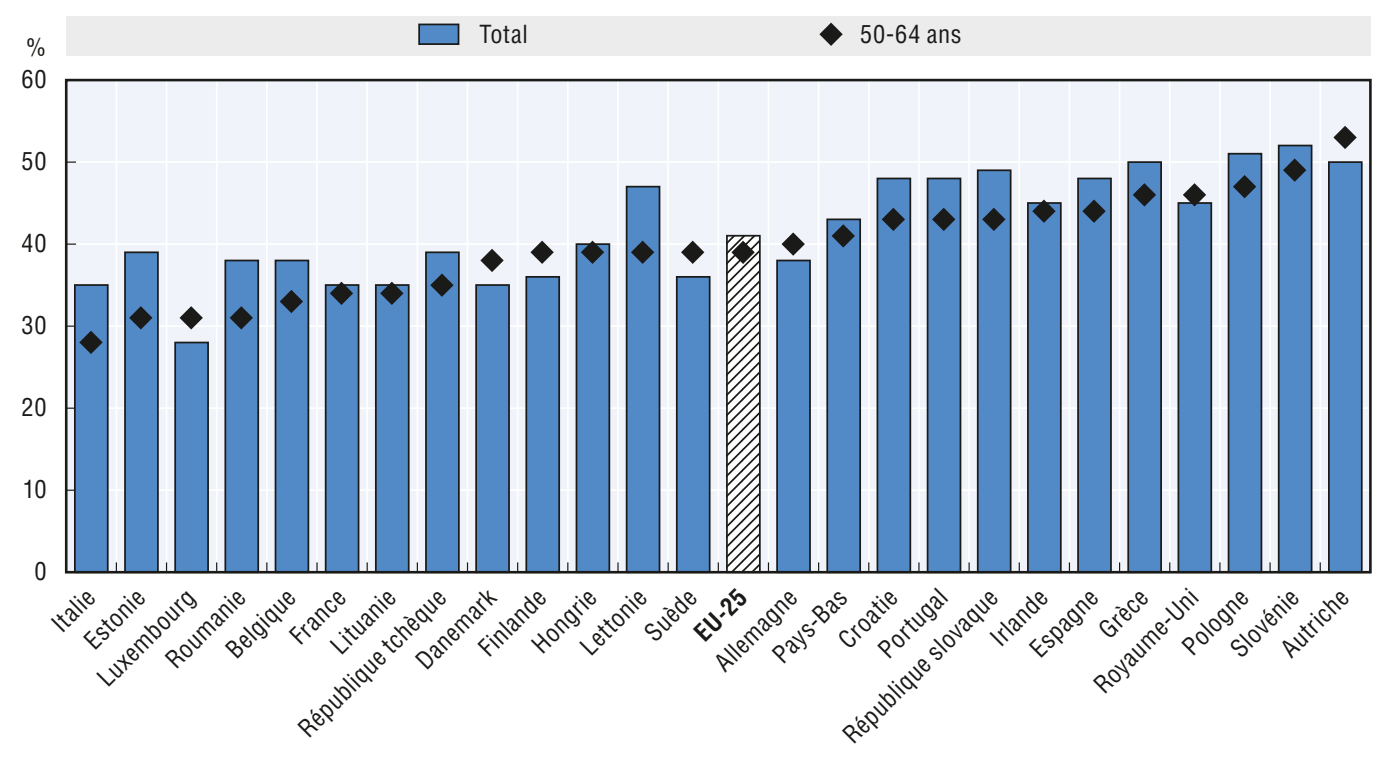

Source: Global Entrepreneurship Monitor (GEM) (2014), présentations tabulaires spéciales des enquêtes 2009-2013 sur la population adulte, extraites du Global Entrepreneurship Monitor. 


\section{Références}

Eurostat (2014b), Statistiques sur le revenu, l'inclusion sociale et les conditions de vie, http://ec.europa. eu/eurostat/web/lfs/data.

Global Entrepreneurship Monitor (GEM) (2014), Présentations tabulaires spéciales des enquêtes 2009-2013 sur la population adulte, extraites du Global Entrepreneurship Monitor. 



\section{Chapitre 5}

\section{Le travail indépendant et l'entrepreneuriat chez les chômeurs}

Ce chapitre traite de la proportion de chômeurs qui cherchent un emploi indépendant et de la proportion qui réussit à se reconvertir dans une activité indépendante. Les données sont présentées par sexe et par âge pour l'ensemble de l'Union européenne et pour chaque État membre.

\section{Note Turquie/Chypre:}

1. Note en bas de page de la Turquie

Les informations figurant dans ce document qui font référence à " Chypre " concernent la partie méridionale de l'Ile. Il n'y a pas d'autorité unique représentant à la fois les Chypriotes turcs et grecs sur l'Ile. La Turquie reconnaît la République Turque de Chypre Nord (RTCN). Jusqu'à ce qu'une solution durable et équitable soit trouvée dans le cadre des Nations Unies, la Turquie maintiendra sa position sur la " question chypriote".

2. Note en bas de page de tous les États de l'Union européenne membres de l'OCDE et de l'Union européenne La République de Chypre est reconnue par tous les membres des Nations Unies sauf la Turquie. Les informations figurant dans ce document concernent la zone sous le contrôle effectif du gouvernement de la République de Chypre. 


\section{Du chômage au travail indépendant}

- Relativement peu de chômeurs cherchent à réintégrer le marché du travail par la voie du travail indépendant. Sur les 26,2 millions de chômeurs que comptait l'Union européenne en 2013, seuls 540000 d'entre eux ont tenté d'exercer une activité indépendante (2,1\%).

- Cette proportion diffère considérablement d'un pays à l'autre (de 0,7 \% en République slovaque à $7 \%$ en Roumanie).

- La proportion des chômeurs cherchant à retrouver un emploi par le biais du travail indépendant a augmenté à la suite de la crise économique mondiale de 2008.

Sur les 26,2 millions de chômeurs que comptait l'Union européenne en 2013, seuls 540000 d'entre eux ont tenté de réintégrer le monde du travail en exerçant une activité indépendante. En d'autres termes, seuls 2,1 \% des chômeurs ont activement cherché à créer leur activité par le biais du travail indépendant (graphique 5.1). Les hommes au chômage ont eu plus tendance que les femmes dans la même situation à se tourner vers le travail indépendant $(2,5 \%$ contre 1,5 \%). Les jeunes chômeurs (15-24 ans) étaient moins susceptibles que la population globale des chômeurs de se tourner vers le travail indépendant (1,1\%), tandis que les seniors (50-64 ans) ont eu plus tendance à s'orienter vers ce type d'emploi $(2,5 \%)$.

\section{Graphique 5.1. Proportion de chômeurs à la recherche d'un travail indépendant dans l'EU-28, 2013 \\ Pourcentage de chômeurs}

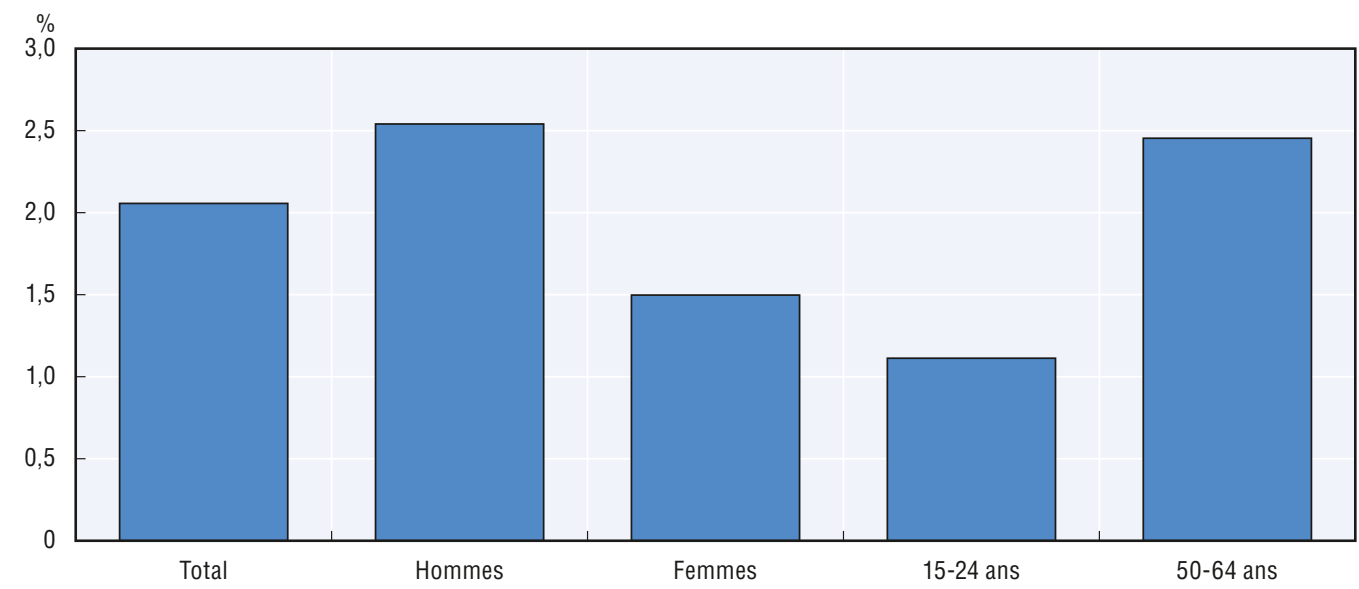

Source: Eurostat (2014), Enquête sur les forces de travail 2003-2013.

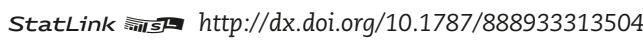

En 2013, la proportion de chômeurs à la recherche d'un travail indépendant a sensiblement varié selon les États membres. Globalement, elle était comprise entre 0,7 \% en République slovaque et $7 \%$ en Roumanie. La part des femmes au chômage à la recherche d'un travail indépendant était comprise entre 0,7 \% en Pologne et 4,4 \% en Roumanie (graphique 5.2). De la 
même façon, la part des jeunes cherchant un emploi indépendant était comprise entre 0,9 \% en République tchèque et 7,7 \% en Roumanie, et celle des seniors entre 1,4\% en Italie et $6,5 \%$ en Irlande (graphique 5.3). Il convient toutefois de préciser que ces données ne sont pas présentées pour de nombreux États membres de l'Union européenne. Le nombre trop restreint de chômeurs ayant cherché un travail indépendant ne permet pas de tirer des conclusions fiables.

\section{Graphique 5.2. Proportion de chômeurs à la recherche d'un travail indépendant par pays, 2013}

Pourcentage de chômeurs

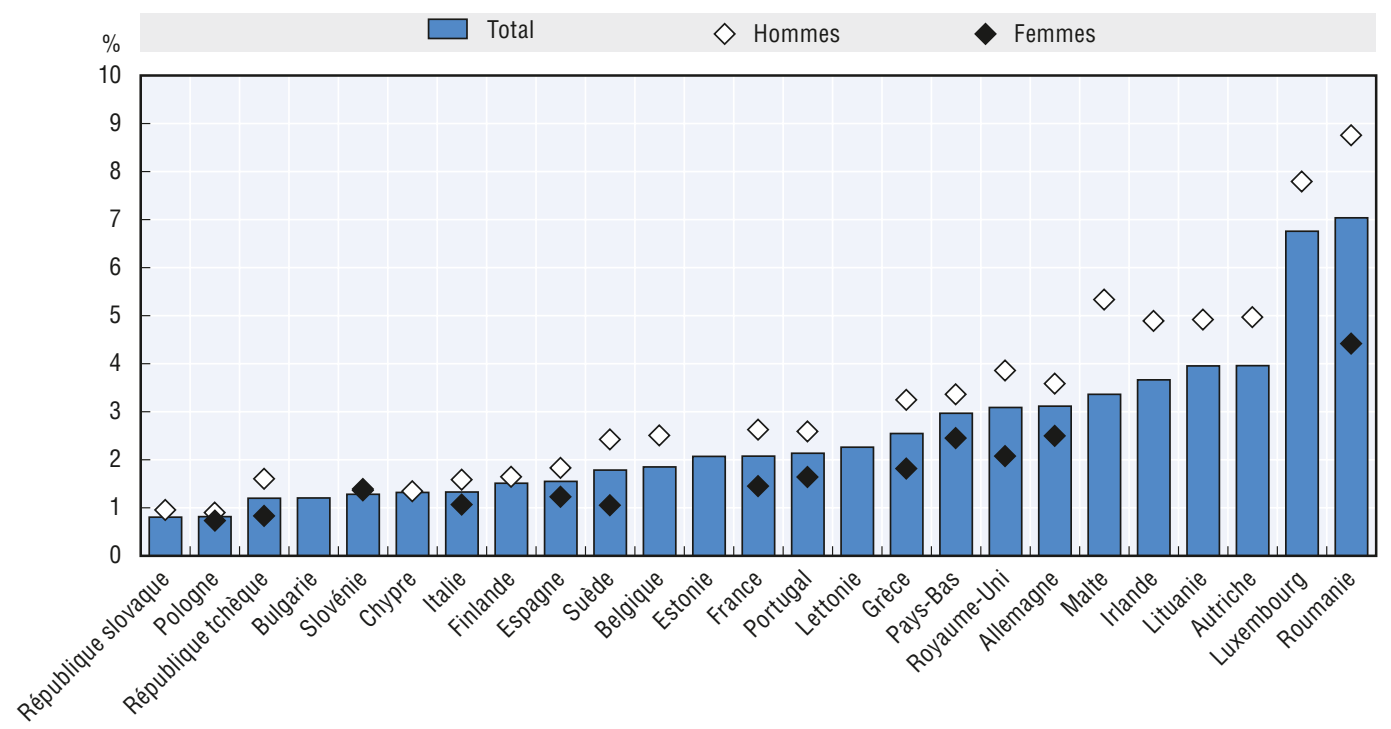

Source: Eurostat (2014), Enquête sur les forces de travail 2003-2013.

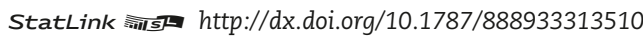

\section{Graphique 5.3. Proportion de jeunes et de seniors sans emploi à la recherche d'un travail indépendant, 2013}

Pourcentage de chômeurs

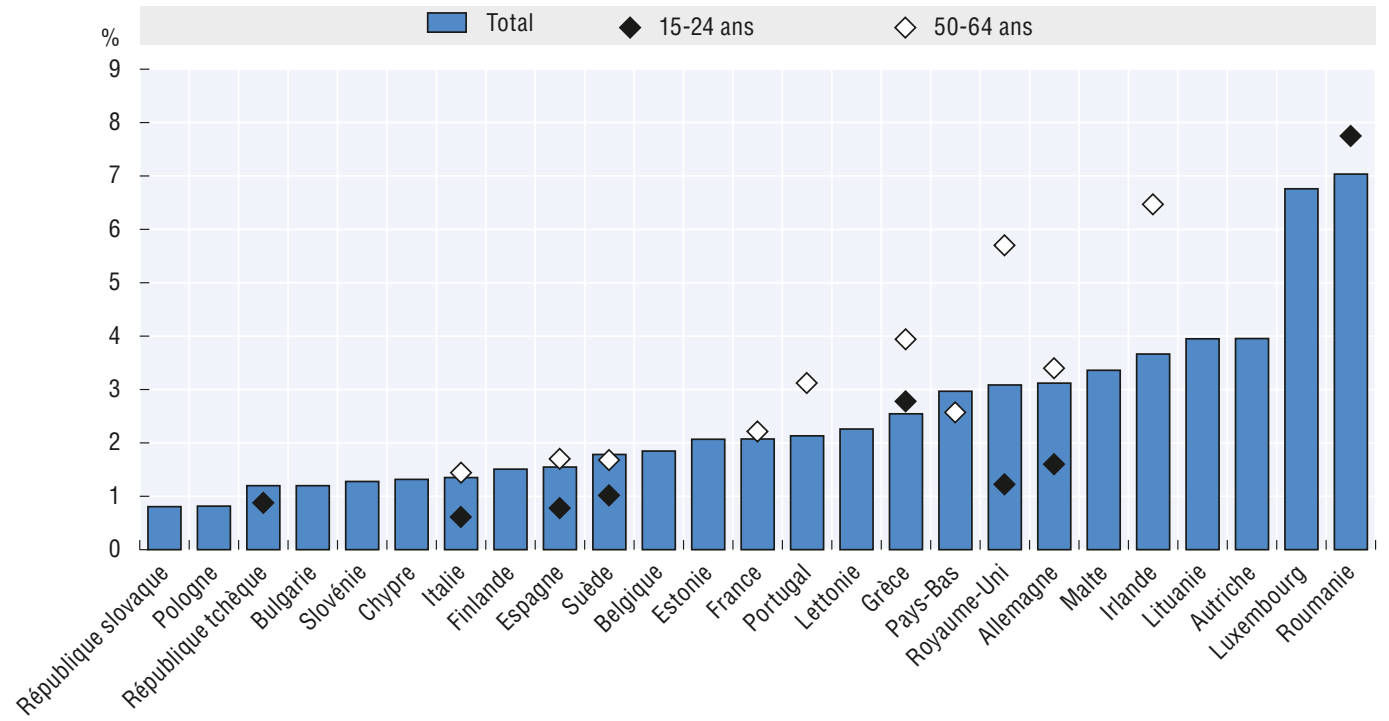


Les chômeurs ont eu davantage tendance à chercher un emploi indépendant après le début de la crise économique (graphiques 5.4 et 5.5) qu'au cours des quatre années précédentes. Globalement, en 2008, 3,6 \% de chômeurs se sont tournés vers une activité indépendante, contre $2,5 \%$ en 2007 et $1,9 \%$ en 2003. Au cœur de la crise en 2008, les proportions d'hommes, de femmes, de jeunes et de seniors au chômage à la recherche d'un travail indépendant ont atteint 4,7 \%, 2,4 \%, 2,9 \% et 3,4 \% respectivement. Entre 2008 et 2013, la proportion de chômeurs à la recherche d'une activité indépendante a baissé pour revenir à son niveau de 2003, alors que le nombre total de chômeurs est passé de 16,7 millions en 2008 à 26,2 millions en 2013. Au cours de cette même période, le nombre de chômeurs à la recherche d'un travail indépendant est resté relativement stable (entre 520000 et 708000 personnes).

\section{Graphique 5.4. Proportion de chômeurs (hommes et femmes) à la recherche d'un travail indépendant dans l'EU-28, 2003-2013}

Pourcentage des 15-64 ans

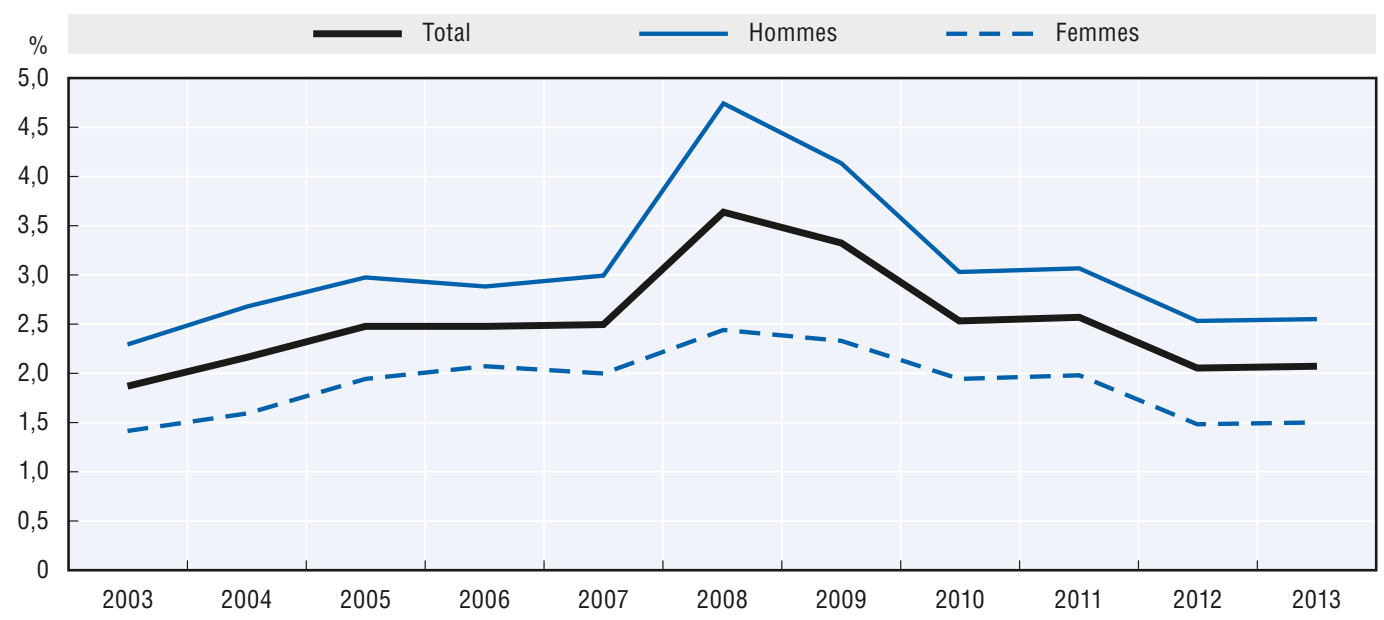

Source: Eurostat (2014), Enquête sur les forces de travail 2003-2013.

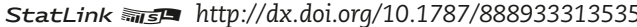

\section{Graphique 5.5. Proportion de jeunes et de seniors sans emploi à la recherche d'un travail indépendant dans l'EU-28, 2003-2013}

Pourcentage des 15-64 ans

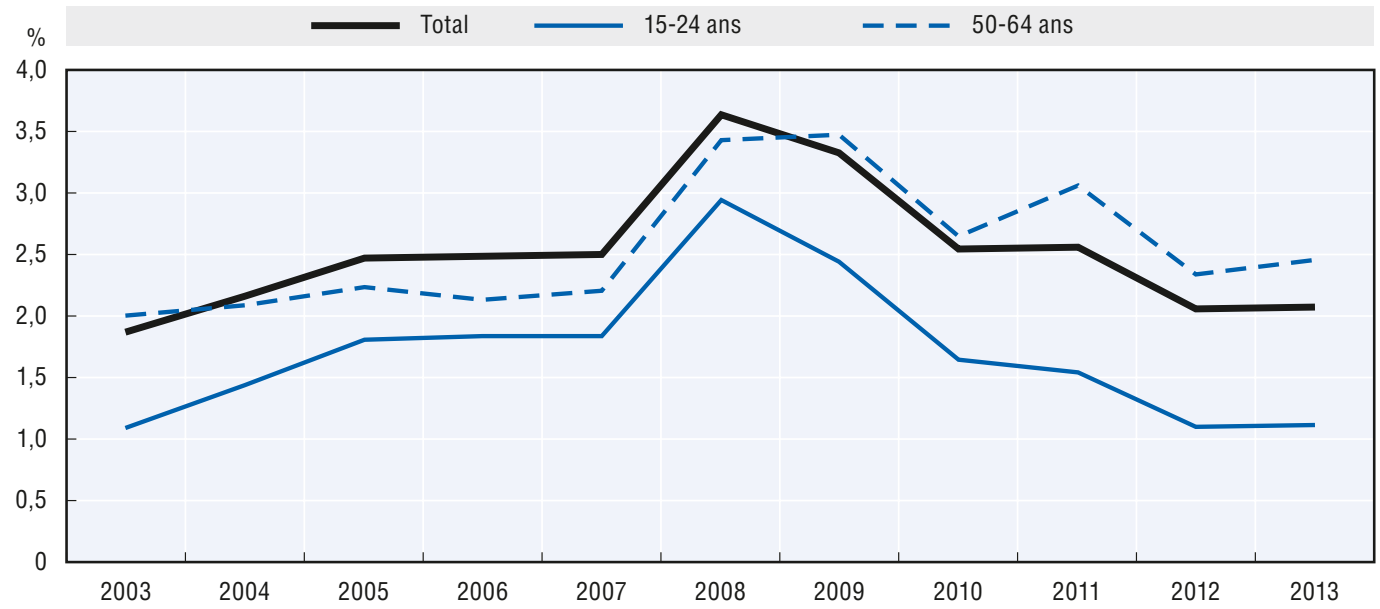

Source: Eurostat (2014), Enquête sur les forces de travail 2003-2013. 


\section{Quitter le chômage pour débuter une activité indépendante}

- 2,7 \% des Européens au chômage en 2012 ont réussi à retrouver un emploi par le biais du travail indépendant en 2013, soit plus de 685000 personnes.

- La proportion de chômeurs débutant une activité indépendante sur une année donnée a tendance à être légèrement supérieure à la proportion de chômeurs à la recherche d'une activité indépendante au cours de l’année précédente.

En 2012, à l'échelle européenne, 2,1 \% des chômeurs ont cherché un emploi indépendant, soit 520000 personnes. Cependant, en observant les chiffres de 2013, il apparaît que 687000 chômeurs ont effectivement trouvé un travail indépendant (2,7 \%) (graphique 5.6). Certaines personnes sans emploi ont donc dû créer leur entreprise alors qu'elles ne l'avaient pas prévu. Cette situation peut s'expliquer par plusieurs raisons, mais les scénarios les plus probables sont la création d'une entreprise par nécessité suite à la fin des droits de chômage ou l'exploitation d'une opportunité qui s'est présentée à certains chômeurs. Les chiffres de chacune de ces catégories sont inconnus.

La proportion de chômeurs ayant retrouvé un travail en tant qu'indépendants est relativement stable. De 2003 à 2013, entre 2,4 \% et 3,4 \% des chômeurs ont trouvé un emploi indépendant chaque année (graphique 5.6). Cette proportion ne semble pas avoir beaucoup évolué avec la crise économique.

\section{Graphique 5.6. Potentiel de travailleurs indépendants chez les chômeurs dans l'EU-28, 2003-2013}

\section{A. Nombre de chômeurs}

Nombre de chômeurs (au cours de l'année t-1) cherchant un travail indépendant

Nombre de chômeurs ayant trouvé un travail indépendant (au cours de l'année t)

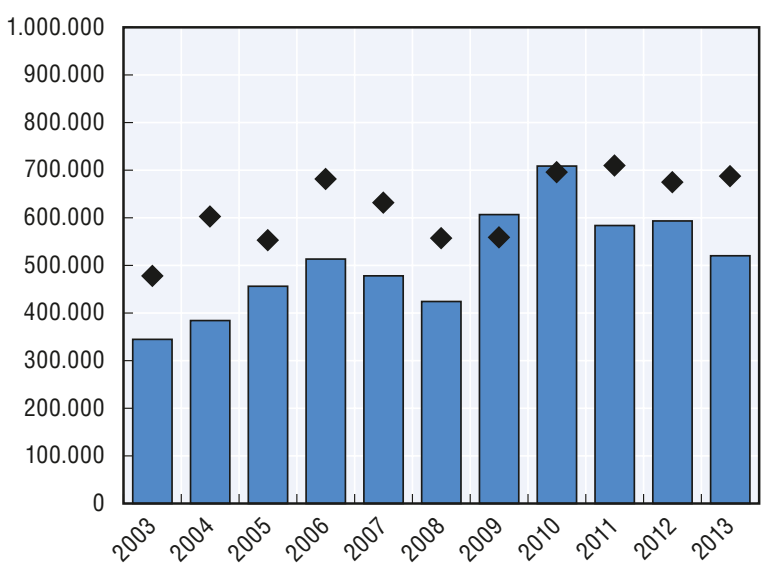

\section{B. Proportion des chômeurs}

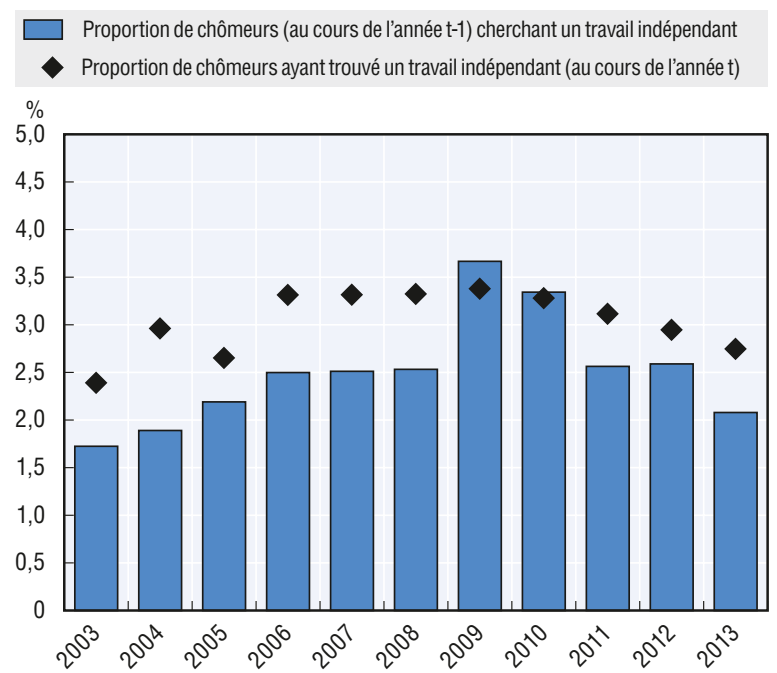

Source: Eurostat, présentations tabulaires spéciales de l'enquête Eurostat sur les forces de travail, 2014.

La proportion de chômeurs devenus indépendants en 2013 varie considérablement d'un État membre à l'autre (graphique 5.7). Elle est comprise entre 0,7 \% aux Pays-Bas et 7,4 \% en Italie. Il semble exister peu de corrélation entre le nombre de chômeurs ayant cherché un travail indépendant et le nombre de chômeurs devenus indépendants. Dans 12 États membres de l'Union européenne, les chômeurs devenus indépendants ont été plus nombreux que les chômeurs ayant cherché à exercer une activité indépendante. Cependant, dans 9 autres États 
membres, les chômeurs ayant cherché un emploi indépendant ont été plus nombreux que les chômeurs effectivement devenus indépendants.

Graphique 5.7. Potentiel de travailleurs indépendants chez les chômeurs, 2013

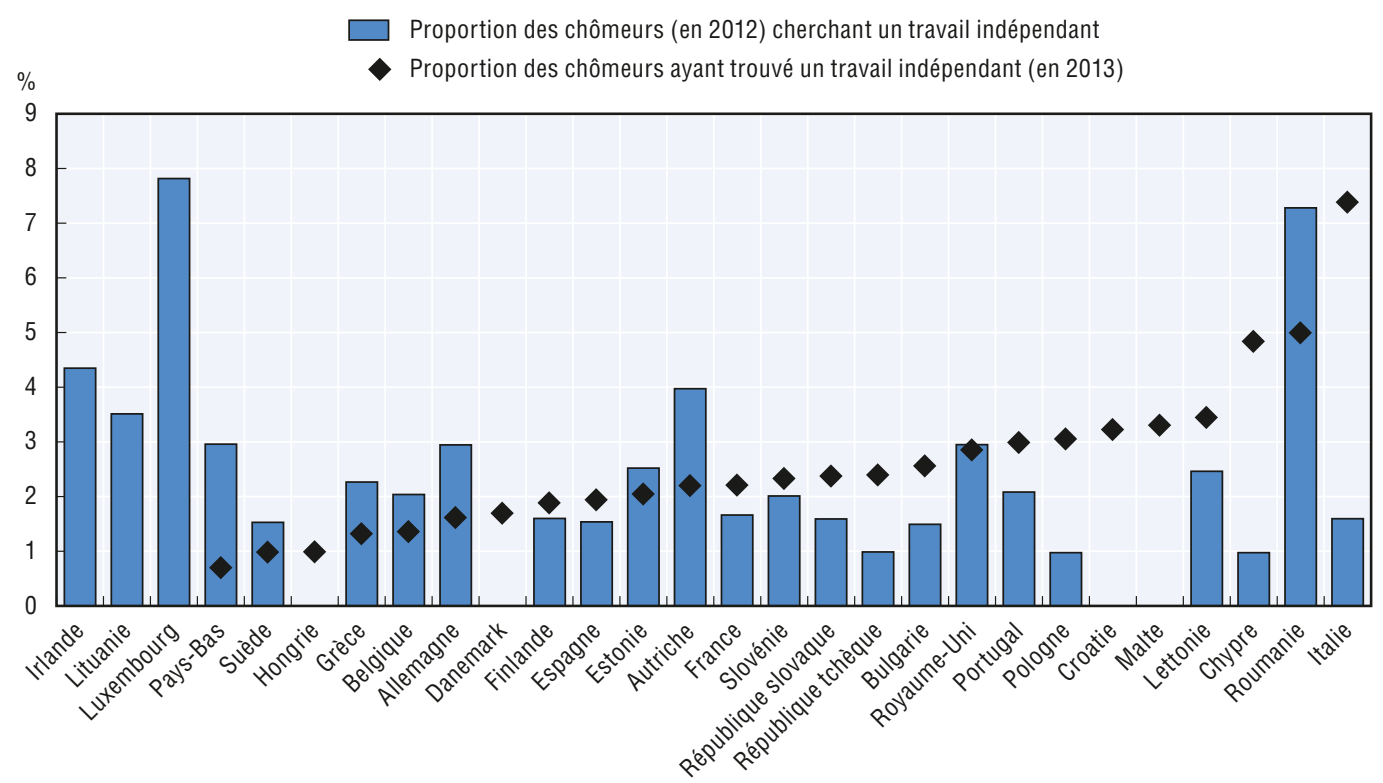

Source: Eurostat, présentations tabulaires spéciales de l'enquête Eurostat sur les forces de travail, 2014.

StatLink inls $h$ ttp://dx.doi.org/10.1787/888933313566

\section{Références}

Eurostat (2014b), Statistiques sur le revenu, l'inclusion sociale et les conditions de vie, http://ec.europa. eu/eurostat/web/lfs/data.

Global Entrepreneurship Monitor (GEM) (2014), Présentations tabulaires spéciales des enquêtes 2009-2013 sur la population adulte, extraites du Global Entrepreneurship Monitor. 


\section{Chapitre 6}

\section{Le travail indépendant et l'entrepreneuriat chez les personnes nées à l'étranger}

Ce chapitre traite du travail indépendant des habitants de l'Union européenne nés en dehors de leur pays de résidence. Il fournit des informations sur le taux de travail indépendant chez les personnes immigrées et la proportion de travailleurs indépendants immigrés qui emploient du personnel. Les données présentées concernent l'ensemble de l'Union européenne et chacun de ses États membres.

Note Turquie/Chypre:

1. Note en bas de page de la Turquie

Les informations figurant dans ce document qui font référence à "Chypre " concernent la partie méridionale de l'Ile. Il n'y a pas d'autorité unique représentant à la fois les Chypriotes turcs et grecs sur l'Ile. La Turquie reconnaît la République Turque de Chypre Nord (RTCN). Jusqu'à ce qu'une solution durable et équitable soit trouvée dans le cadre des Nations Unies, la Turquie maintiendra sa position sur la " question chypriote ".

2. Note en bas de page de tous les États de l'Union européenne membres de l'OCDE et de l'Union européenne La République de Chypre est reconnue par tous les membres des Nations Unies sauf la Turquie. Les informations figurant dans ce document concernent la zone sous le contrôle effectif du gouvernement de la République de Chypre. 


\section{Le travail indépendant chez les personnes nées à l'étranger}

- 6,6 \% des travailleurs indépendants dans l'Union européenne sont nés hors de leur pays de résidence, soit plus de 2 millions de personnes, et 47 \% d'entre eux sont nés hors de l'Union européenne.

- Le taux de travail indépendant des personnes d'origine étrangère est légèrement inférieur à celui des personnes nées dans leur pays de résidence actuel (14,1 \% contre 15,3\%).

- En 2013, les personnes indépendantes d'origine étrangère étaient moins susceptibles d'avoir des employés $(24,7 \%$ contre $28,5 \%$ ).

Sur les 30,6 millions de travailleurs indépendants que comptait l'Union européenne en 2013, 6,6 \% étaient nés hors de leur pays de résidence (2 millions de personnes). Plus précisément, 3,1 \% sont nés dans un autre pays de l'Union européenne que leur pays de résidence actuel et 3,5\% sont nés hors de l'Union européenne (graphique 6.1). La proportion d'indépendants d'origine étrangère varie considérablement d'un État membre à l'autre (de 2,5 \% en Hongrie à 50,5 \% au Luxembourg). Dans huit États membres, les travailleurs indépendants nés dans un autre pays de l'Union européenne que leur pays de résidence actuel sont plus nombreux que ceux nés hors de l'Union européenne, en particulier au Luxembourg. En effet, en 2013, 44,6 \% des travailleurs indépendants au Luxembourg étaient nés dans un autre pays de l'Union européenne. Il s'agit de loin de la plus forte proportion observée parmi tous les pays de l'Union européenne.

\section{Graphique 6.1. Proportion de travailleurs indépendants nés en dehors de leur pays de résidence, 2013}

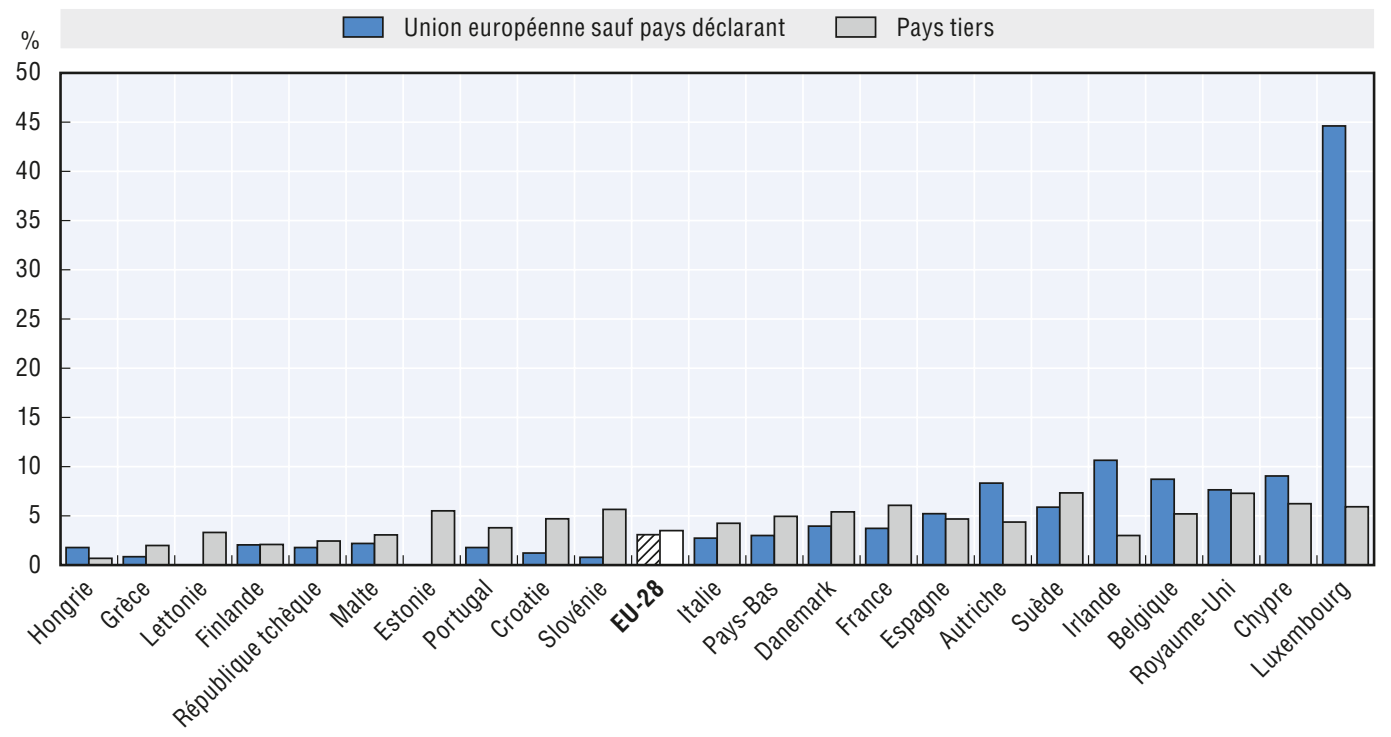


À l'échelle de l'Union européenne, le taux de travail indépendant des personnes d'origine étrangère (c'est-à-dire les personnes nées hors de leur pays de résidence) était de 14,1 \% en 2013 (graphique 6.2). Légèrement plus faible que le taux de travail indépendant des personnes nées dans leur pays de résidence actuel (15,3\%), il était généralement compris entre $10 \%$ et $15 \%$ dans les différents États membres en 2013, à l'exception de l'Estonie (8,3 \%), du Luxembourg (8,6 \%), de la Lettonie (9,1\%), du Danemark (9,3\%), de l'Autriche (9,8\%), du Royaume-Uni (16,7\%), de la République slovaque $(16,8 \%)$, de la République tchèque $(26,7 \%)$ et de la Pologne $(31,3 \%)$. En 2013, le taux de travail indépendant des personnes nées dans leur pays de résidence actuel était supérieur à celui des personnes nées à l'étranger dans tous les États membres, sauf sept.

\section{Graphique 6.2. Taux de travail indépendant des personnes d'origine étrangère par État membre, 2013}

Travail indépendant en pourcentage du taux d'emploi total

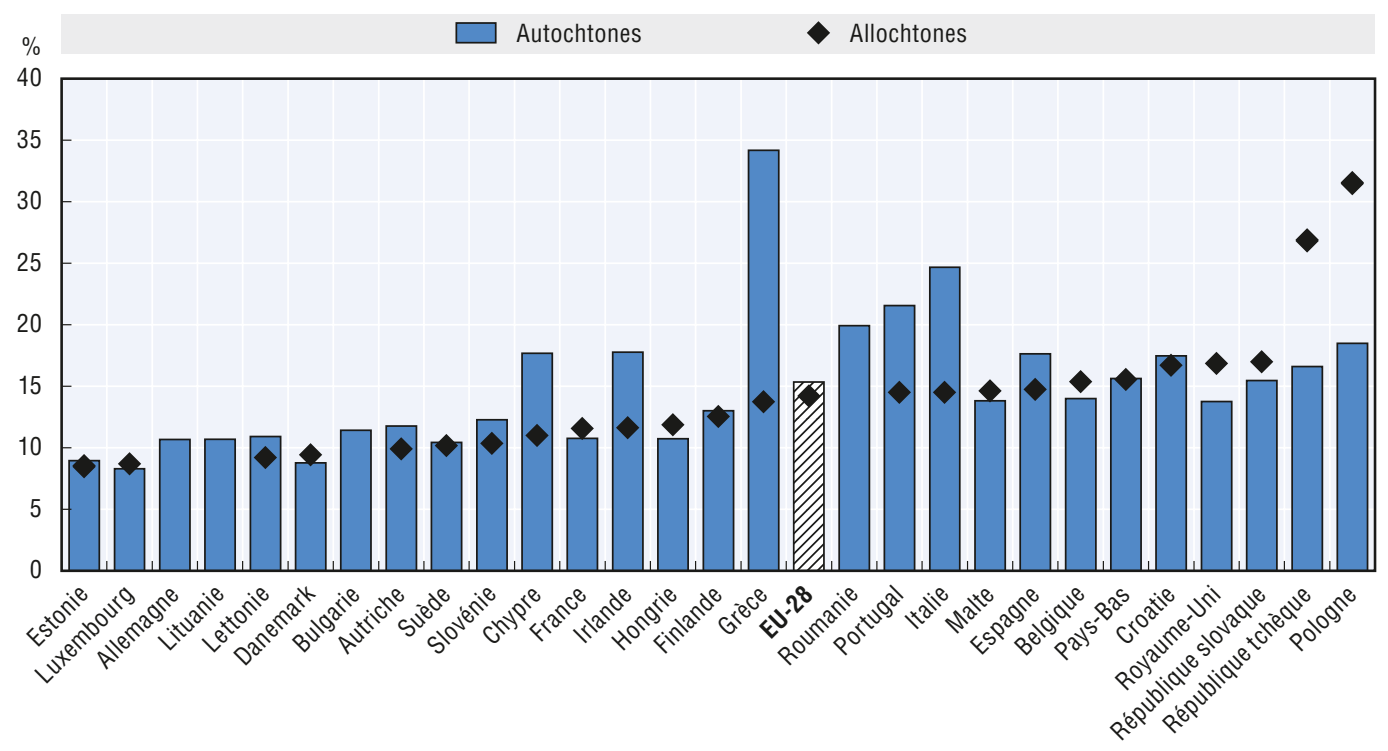

Source: Eurostat (2014), Enquête sur les forces de travail 2003-2013.

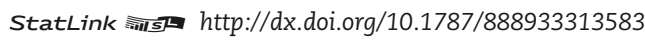

Les travailleurs indépendants d'origine étrangère étaient en 2013 légèrement moins susceptibles d'employer des salariés que les autochtones. À l'échelle de l'Union européenne, $24,7 \%$ des indépendants d'origine étrangère employaient du personnel, contre $28,5 \%$ des indépendants nés dans leur pays de résidence actuel. Au niveau national, la proportion d'indépendants d'origine étrangère employant du personnel était comprise entre 15,6 \% au Royaume-Uni et 53,4 \% en Hongrie. En 2013, les travailleurs indépendants d'origine étrangère étaient plus susceptibles que les indépendants nés dans leur pays de résidence actuel d'avoir des employés dans cinq États membres: la Slovénie, la Suède, la Croatie, la Lettonie et la Hongrie. 


\section{Graphique 6.3. Proportion des travailleurs indépendants d'origine étrangère employant du personnel, 2013}

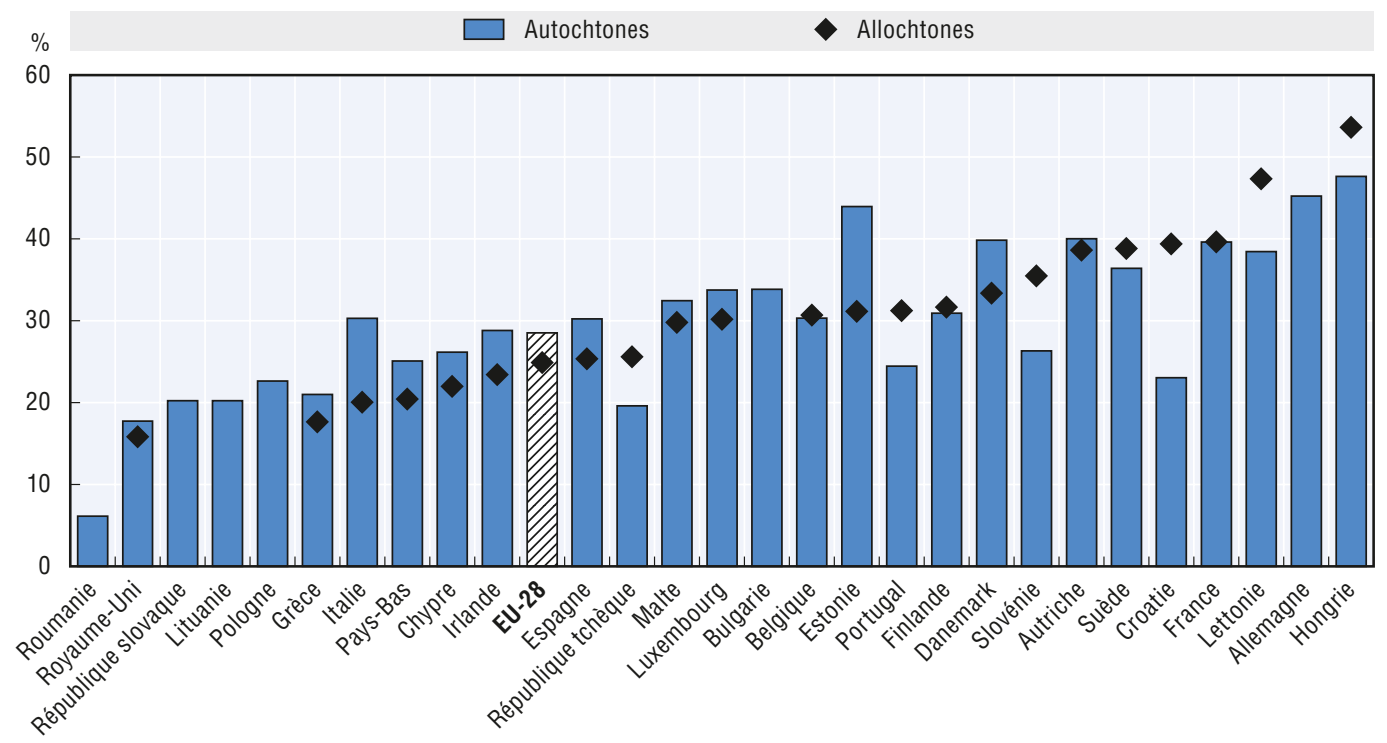

Source: Eurostat (2014), Enquête sur les forces de travail 2003-2013.

StatLink *inाs http://dx.doi.org/10.1787/888933313595

\section{Références}

Eurostat (2014b), Statistiques sur le revenu, l'inclusion sociale et les conditions de vie, http://ec.europa. eu/eurostat/web/lfs/data. 
PARTIE II

\section{Les politiques d'entrepreneuriat inclusif}





\section{Chapitre 7}

\section{Soutenir la croissance des entrepreneurs appartenant à des groupes sous-représentés et défavorisés}

Ce chapitre traite des principaux facteurs de croissance des entreprises créées et gérées par des entrepreneurs femmes, jeunes, seniors, immigrés et issus de minorités ethniques. Il décrit ensuite les mesures politiques clés que les pouvoirs publics peuvent mettre en œuvre pour soutenir la croissance de ces entreprises, qui sont souvent confrontées à des difficultés plus importantes que les entrepreneurs traditionnels. Une attention est également accordée à ces soutiens.

Note Turquie/Chypre:

1. Note en bas de page de la Turquie

Les informations figurant dans ce document qui font référence à " Chypre " concernent la partie méridionale de l'Ile. Il n'y a pas d'autorité unique représentant à la fois les Chypriotes turcs et grecs sur l'Ile. La Turquie reconnaît la République Turque de Chypre Nord (RTCN). Jusqu'à ce qu'une solution durable et équitable soit trouvée dans le cadre des Nations Unies, la Turquie maintiendra sa position sur la " question chypriote".

2. Note en bas de page de tous les États de l'Union européenne membres de l'OCDE et de l'Union européenne La République de Chypre est reconnue par tous les membres des Nations Unies sauf la Turquie. Les informations figurant dans ce document concernent la zone sous le contrôle effectif du gouvernement de la République de Chypre. 


\section{Le potentiel de croissance des entrepreneurs appartenant à des groupes sous-représentés et défavorisés}

- En 2013, environ 22,7 millions de travailleurs indépendants dans l'Union européenne appartenaient à des groupes sous-représentés et défavorisés (comme les femmes, les jeunes, les seniors, les personnes d'origine étrangère, les chômeurs), ce qui représente près de 75 \% de l'ensemble des travailleurs indépendants. Ils étaient presque aussi nombreux que les entrepreneurs traditionnels à employer au moins un salarié (27 \% contre $29 \%$ ).

- En revanche, les femmes et les seniors (50-64 ans) ont eu moins tendance à viser une forte croissance entre 2009 et 2013 dans l'Union européenne. Les jeunes (18-30 ans) étaient légèrement plus susceptibles que les adultes (18-64 ans) de chercher à se développer au cours de cette période.

- Les responsables politiques ne doivent pas partir du principe que les entrepreneurs issus de groupes sous-représentés et défavorisés ne créent que des entreprises unipersonnelles à faible valeur ajoutée.

Sur les 30,6 millions de personnes exerçant une activité indépendante au sein de l'Union européenne en 2013, 9,6 millions étaient des femmes, 774000 des jeunes (15-24 ans), 11,2 millions des seniors (55-64 ans), 687000 étaient chômeurs en 2012 et 3,3 millions étaient des entrepreneurs nés hors de leur pays de résidence. Pris individuellement, ces groupes sont considérés comme étant sous-représentés ou défavorisés au sein de l'entrepreneuriat. Or, collectivement, ils représentent la majorité des travailleurs indépendants de l’Union européenne.

Les entreprises gérées par des personnes issues de ces groupes sont généralement considérées comme des entreprises qui ne contribuent que marginalement à l'économie en termes d'emplois, de valeur ajoutée, ou d'innovation. Des données corroborent ce point de vue. Par exemple, les données indiquent généralement que le taux de croissance des entreprises gérées par des femmes reste inférieur à celui des hommes dans tous les pays de l'OCDE (par exemple, Delmar et Holmquist, 2004). Plus précisément, en Allemagne, seuls $3 \%$ des brevets sont déposés par des femmes (Bundesministerium für Wirtschaft, Familie und Jugend, 2012). De nombreux jeunes exercent dans des secteurs très compétitifs présentant peu d'obstacles à l'entrée et n'ont généralement pas les fonds et l'expérience nécessaires pour créer une entreprise orientée vers la croissance (OCDE/CE, 2012a). En outre, les entreprises gérées par des jeunes présentent un taux de survie faible (van Praag, 2003). Peu d'entrepreneurs seniors gèrent des entreprises à croissance (Eurostat, 2006). En revanche, ils sont nombreux à diriger des entreprises en rapport avec leur passe-temps et qui créent peu de valeur (OCDE/CE, 2012a). De plus, dans toute l'Union européenne, les entreprises gérées par des entrepreneurs immigrés sont concentrées dans des secteurs où peu de qualifications sont nécessaires et où la concurrence est féroce (CEEDR, 2000; Marucci et Montedoro, 2010). Ces résultats sont reflétés dans les analyses nationales. En Italie, par exemple, les entreprises gérées par des immigrés présentent un potentiel de croissance faible parce qu'elles ne sont pas tournées vers des activités innovantes (Di Maria et De Marchi, 2008).

Cependant, même si les entrepreneurs issus de ces groupes font face à des obstacles plus importants à la création de leur entreprise que les entrepreneurs traditionnels dans leur ensemble, il est inopportun de les mettre tous dans le même panier. La population des 
entrepreneurs appartenant à des groupes sous-représentés ou défavorisés est en effet très hétérogène et nombre d'entre eux ont le potentiel nécessaire pour créer une entreprise à forte valeur ajoutée, innovante et orientée vers la croissance. Sur les quelque 22,7 millions de femmes, de jeunes, de seniors, de chômeurs et de personnes d'origine étrangère qui exercent une activité indépendante dans les pays de l'Union européenne (calcul ajusté pour éviter le risque de double comptabilisation), environ 6,2 millions emploient au moins un salarié. Cette proportion n'est que légèrement inférieure à la moyenne des indépendants employant du personnel (27\% contre $29 \%$ ), ce qui prouve que nombre d'entrepreneurs défavorisés sont tout à fait capables de développer une entreprise impliquant plus d'une personne.

En outre, le cliché de l'entrepreneur immigré qui dirige une entreprise à faible valeur ajoutée et à faible croissance est de plus en plus remis en question, car un ensemble d'études croissant met en exergue le grand nombre d'entrepreneurs immigrés hautement qualifiés qui se lancent dans la création d'entreprises (Saxenian, 2002). La distinction entre les entrepreneurs immigrés de première et de deuxième génération est importante à cet égard, car les différences entre ces groupes sont conséquentes en termes de richesses, de maîtrise de la langue et de niveau d'études (Farley et Alba, 2002). De plus, des études ont montré que leur double culture (celle de leur pays d'origine et celle de leur pays d'accueil) constitue un atout, car elle permet de diversifier les domaines au sein desquels ils peuvent chercher une opportunité économique pour développer leur entreprise (Hart et Acs, 2011). Les immigrés ont, par exemple, la capacité d'identifier des opportunités sur d'autres marchés, dans certains cas parce qu'ils ont vécu dans ces pays, ce que les entrepreneurs autochtones n'ayant pas d'expérience à l'étranger ne pourraient pas faire. Des études en Italie ont révélé que le savoir-faire culturel et les connaissances linguistiques des entrepreneurs d'origine étrangère peuvent représenter un atout dans la mise en œuvre de stratégie d'internationalisation (Di Maria et De Marchi, 2008). La capacité des entrepreneurs immigrés de deuxième génération à se positionner sur une plus grande variété de secteurs d'activité que leurs parents est un facteur déterminant de croissance (Ndofor et Priem, 2011).

Par exemple, des données attestent que les entreprises gérées par des jeunes qui survivent présentent souvent un plus grand potentiel de croissance que celles gérées par des entrepreneurs plus âgés. Parmi les entreprises ayant survécu au moins trois ans, celles gérées par des personnes âgées de moins de 30 ans enregistrent un taux de croissance moyen de $206 \%$, soit près du double du taux de croissance des entreprises gérées par des personnes de plus de 40 ans (114 \%) (Eurostat, 2006). En Suède, une étude récente portant sur les entreprises privées à responsabilité limitée suédoises, employant entre 1 et 100 employés entre 2004 et 2008 a révélé que les entreprises gérées par la tranche d'âge des 18-30 ans représentaient la plus grande proportion relative d'entreprises à forte croissance (Efendic et al., 2014). Ces données attestent que les jeunes entrepreneurs constituent un groupe d'entrepreneurs à haut risque, mais qui présentent de très bons résultats en cas de réussite. De toute évidence, les entreprises des autres groupes sous-représentés ou défavorisés sont également nombreuses à présenter un potentiel de croissance.

En ce qui concerne le potentiel de croissance des entrepreneurs appartenant à des groupes sous-représentés ou défavorisés, il n'est pas pertinent d'utiliser la définition classique de l'entreprise à forte croissance comme référence. Selon la définition de l'OCDE, une entreprise à forte croissance est une entreprise dont le taux de croissance moyen annualisé est supérieur à $20 \%$ par an, sur une période de trois années consécutives, et qui compte au moins 10 employés au début de la période de référence. L'impact de ces entreprises sur le développement économique et la création d'emplois est indéniable (Janczak et Bares, 2010). Cependant, dans la plupart des pays de l'OCDE, moins de $4 \%$ des entreprises atteignent ce niveau de croissance (OCDE, 2013), qui ne constitue pas un objectif réaliste pour la plupart des entrepreneurs. Les responsables politiques devraient plutôt aider les entrepreneurs appartenant à des groupes sous-représentés et défavorisés à pérenniser les entreprises ayant le potentiel de créer des emplois. 


\section{Les facteurs de croissance}

- Quatre grands facteurs influencent le degré de croissance des entreprises gérées par des entrepreneurs appartenant à des groupes sous-représentés et défavorisés: i) les intentions de croissance et la motivation de l'entrepreneur; ii) l'accès aux financements; iii) un niveau élevé de compétences entrepreneuriales (par exemple, compétences de direction et de gestion); et iv) l'accès aux réseaux professionnels.

- Les femmes, les immigrés et les seniors ont tendance à viser une croissance moins forte que les autres entrepreneurs et sont plus susceptibles de gérer des entreprises dans des secteurs à faible valeur ajoutée. Les femmes et les seniors sont plus susceptibles que les autres d'occuper un emploi à temps partiel et de gérer des entreprises à but essentiellement non lucratif.

- Les entrepreneurs appartenant à des groupes sous-représentés et défavorisés peuvent avoir des difficultés à obtenir des financements extérieurs, car ils n'ont pas d'historique de crédit ni de garanties. Ils peuvent également subir des discriminations sur les marchés financiers.

- Une partimportante de la population affirme ne pas posséder de compétences entrepreneuriales, notamment les femmes et les jeunes. Chez les jeunes, cette lacune est liée à leur inexpérience du marché de l'emploi et du travail indépendant.

- Les entrepreneurs appartenant à des groupes sous-représentés et défavorisés ont tendance à disposer de réseaux professionnels plus restreints. Par exemple, les femmes entrepreneurs bénéficient généralement de réseaux professionnels moins étendus que les hommes. De nombreux entrepreneurs immigrés possèdent des réseaux relativement restreints, qui peuvent l'être encore plus s'ils maîtrisent mal la langue, mais ils ont l'avantage de pouvoir exploiter leurs réseaux internationaux.

Pour comprendre comment aider les entrepreneurs appartenant à des groupes sousreprésentés et défavorisés à développer leur entreprise, les responsables politiques doivent d'abord comprendre les facteurs qui dopent la croissance de ces entreprises. Des études ont identifié quatre facteurs fondamentaux, indispensables pour créer une entreprise à fort potentiel de croissance: la volonté de se développer et la motivation de l'entrepreneur; les compétences entrepreneuriales; l'accès aux financements; et les réseaux professionnels.

\section{Volonté de croissance et motivation}

Les motivations qui incitent à créer son entreprise sont très diverses. Certains créent leur entreprise pour profiter d'une opportunité économique tandis que d'autres se lancent parce qu'ils n'ont pas d'autre choix sur le marché du travail. D'autres poursuivent des objectifs de nature sociale, plutôt que les seuls profits (entreprises sociales, associations à but non lucratif). Ces motivations peuvent également évoluer. Un entrepreneur qui crée son entreprise parce qu'il ne trouve pas d'emploi salarié peut identifier une opportunité économique pendant la création de son entreprise ou une fois celle-ci créée. De même, une personne ayant choisi de créer son entreprise pour exploiter une opportunité économique peut échouer, mais continuer à exploiter son entreprise parce qu'il s'agit de sa seule source de revenus.

L'intention de l'entrepreneur de développer son entreprise est le meilleur indicateur de croissance (Wiklund et al., 2003). Un entrepreneur doit avoir envie de se développer. Cela suppose d'accepter les risques et les efforts nécessaires pour développer une entreprise, de savoir imposer une orientation claire et d'être suffisamment persévérant dans les efforts entrepris pour se développer (Gundry et Welsch, 2001). De plus, il doit faire preuve de motivation. Cela signifie qu'il peut envisager son avenir à long terme et prendre des mesures stratégiques à court terme pour réaliser son ambition (Baum et al., 1998). Cependant, nombre d'entrepreneurs sont dissuadés par les éventuels risques et répercussions néfastes de cette stratégie, y compris en ce qui concerne le bien-être des employés et la capacité à garder le contrôle sur l'entreprise (Wiklund et al., 2003). 
Les graphiques 7.1 et 7.2 montrent les proportions d'entrepreneurs en cours de création de leur entreprise ou ayant créé leur entreprise récemment qui envisagent d'employer plus de 19 salariés au cours des cinq prochaines années. À l'échelle de l’Union européenne, environ 1 \% des personnes impliquées dans la création d'entreprises envisagent de créer plus de 19 emplois dans les cinq ans suivant la création. Les femmes sont trois fois moins nombreuses que les hommes à envisager d'employer plus de 19 salariés dans les cinq ans à venir (graphique 7.1). Globalement, les seniors (50-64 ans) sont un peu moins enclins que les adultes en âge de travailler à envisager une telle croissance du personnel, même si la proportion varie d'un État membre à l'autre. En revanche, les jeunes (18-30 ans) ont un peu plus tendance que les adultes à espérer un tel niveau d'expansion (graphique 7.2). Il est clair que ces prévisions de croissance sont très élevées. Elles sont toutefois le signe d'un manque relatif de motivation de la part des femmes et des seniors.

\section{Graphique 7.1. Prévisions de croissance chez les femmes entrepreneurs, 2009-2013 (combinés)}

Pourcentage des entrepreneurs engagés dans une activité entrepreneuriale au stade précoce qui prévoient de créer au moins 19 emplois dans les cinq prochaines années

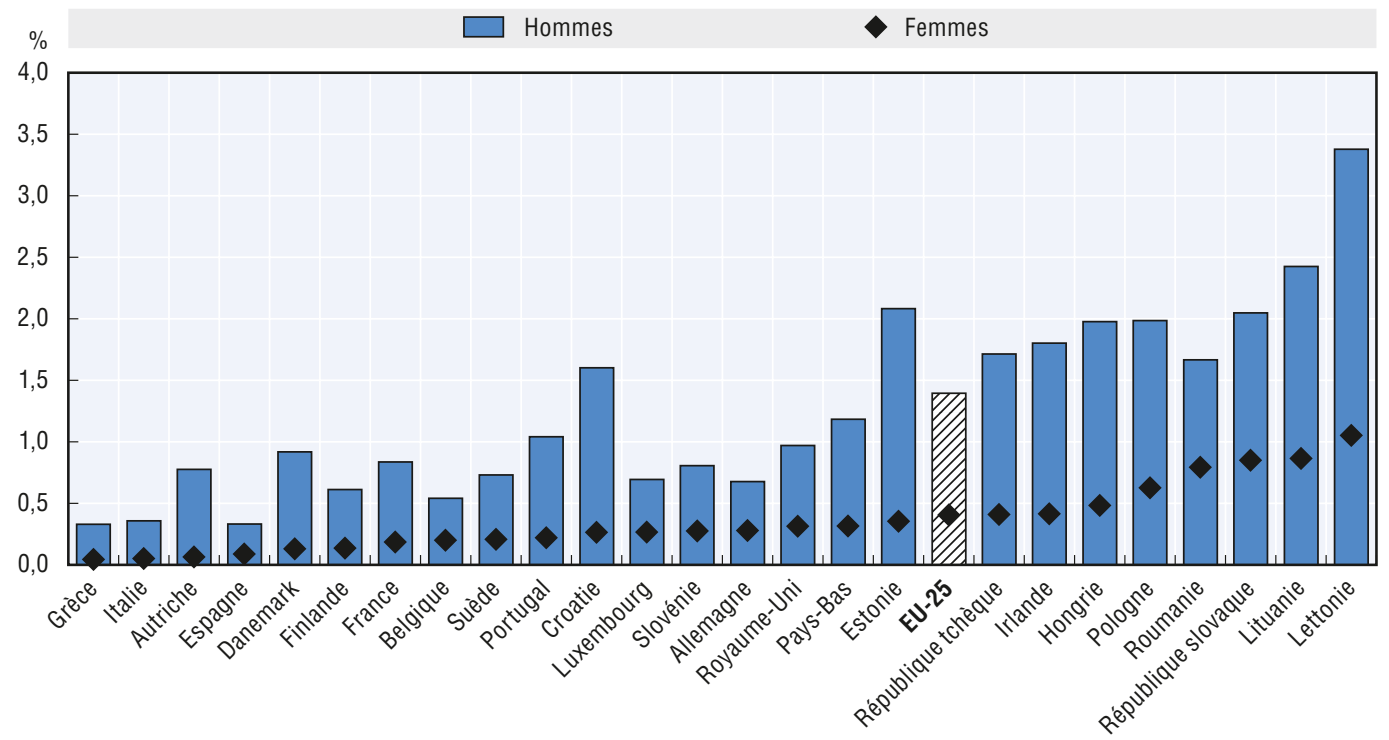

Notes: 1. Les pays de l'Union européenne ayant participé à l'enquête Global Entrepreneurship Monitor pendant cette période sont: la Belgique, la République tchèque, l'Allemagne, l'Estonie, l'Irlande, la Grèce, l'Espagne, la France, la Croatie, l'Italie, la Lettonie, la Lituanie, la Hongrie, les Pays-Bas, l’Autriche, la Pologne, le Portugal, la Roumanie, la Slovénie, la Slovaquie, la Finlande, la Suède et le Royaume-Uni. 2. Les données présentées dans ce graphique ont été combinées: elles cumulent les résultats des enquêtes annuelles portant sur la période 2009-2013. Certains pays n'ont pas pris part aux enquêtes GEM réalisées chaque année, mais ont été inclus dans les graphiques: la République tchèque (2011 et 2013), le Danemark (2009, 2010, 2011, 2012), l'Estonie (2012, 2013), l'Irlande (2010, 2011, 2012, 2013), l'Italie (2009, 2010, 2012, 2013), la Lituanie (2011, 2012, 2013), le Luxembourg (2013), l'Autriche (2012, 2013), la Pologne (2011, 2012, 2013), le Portugal (2010, 2011, 2012, 2013), la Slovaquie (2011, 2012, 2013), et la Suède (2010, 2011, 2012, 2013). 3. L'entrepreneuriat au stade précoce désigne les phases de création ou la gestion d'une entreprise de moins de 42 mois.

Source: Global Entrepreneurship Monitor (GEM) (2014), présentations tabulaires spéciales des enquêtes 2009-2013 sur la population adulte, extraites du Global Entrepreneurship Monitor.

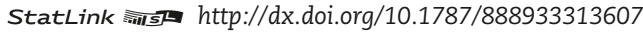

Dans une certaine mesure, les femmes ont des motivations plus diverses que les hommes à l'égard de l'entrepreneuriat (Brush, 1992). Par exemple, les enquêtes menées au sein de l'Union européenne pointent souvent du doigt les discriminations existantes sur le marché du travail comme un puissant moteur en faveur de l'entrepreneuriat féminin. Des données provenant d'Italie indiquent que le travail indépendant des femmes peut parfois être un moyen de répondre au manque d'opportunités d'emploi salarié (Goffi, 2012). Par ailleurs, une méta-analyse menée sur près de 200 articles de revues universitaires sur l'entrepreneuriat féminin publiés entre 2000 
et 2012 montre que les femmes entrepreneurs se heurtent également aux stéréotypes de genre (Ebbers et Halbfas, 2013). Les femmes semblent donc moins enclines que les hommes à créer une entreprise pour exploiter une opportunité et ont moins de chance de gérer une entreprise à croissance que les hommes.

L'enseignement empirique le plus important qui peut être tiré de la comparaison entre les entreprises gérées par des femmes et des hommes est que si, par exemple, la taille ou le chiffre d'affaires moyen dans les différents secteurs varie, il n'existe aucune différence systématique entre leurs performances (Du Rietz et Henrekson, 2000). La structure des secteurs d'activité est donc une des clés pour comprendre les différences entre les entreprises gérées par des femmes et des hommes. En effet, les secteurs ne présentent pas tous les mêmes obstacles à l'entrée, la même intensité capitalistique et les mêmes économies d'échelle, ce qui joue sur la conduite et les performances de l'entreprise. Les femmes peuvent être confrontées à certaines difficultés lorsqu'elles créent et développent des entreprises dans des secteurs à forte valeur ajoutée. Ces obstacles peuvent être de nature économique (par exemple, investissements requis pour la création de l'entreprise), juridique (par exemple, permis, réglementations) ou sociocognitive (par exemple, les clients n'ont pas l'habitude de faire appel à une femme pour acheter une voiture ou de demander une manucure à un homme) (Roithmayr, 2000).

\section{Graphique 7.2. Prévisions de croissance chez les entrepreneurs jeunes et seniors, 2009-2013 (combinés)}

Pourcentage des entrepreneurs engagés dans une activité entrepreneuriale au stade précoce qui prévoient de créer au moins 19 emplois dans les cinq prochaines années

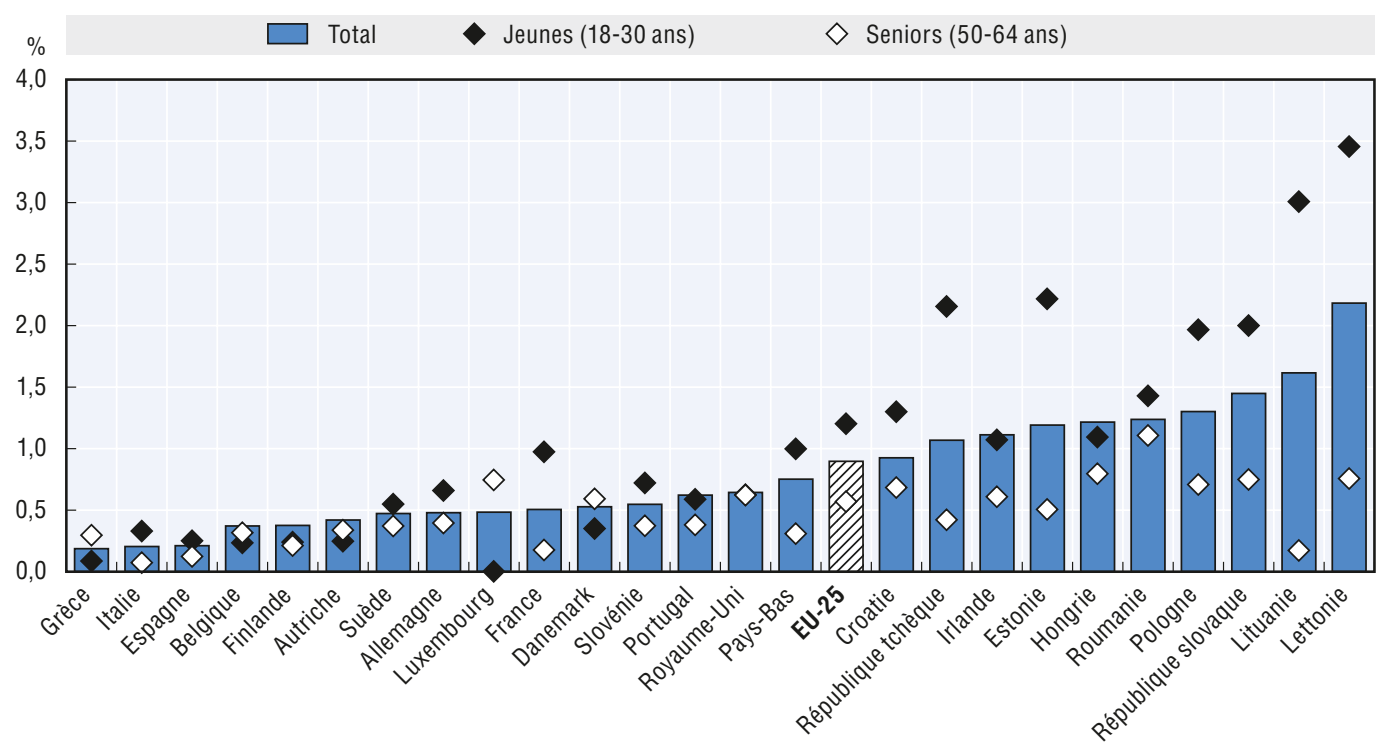

Notes: 1. Les pays de l'Union européenne ayant participé à l'enquête Global Entrepreneurship Monitor pendant cette période sont: la Belgique, la République tchèque, l'Allemagne, l'Estonie, l'Irlande, la Grèce, l'Espagne, la France, la Croatie, l'Italie, la Lettonie, la Lituanie, la Hongrie, les Pays-Bas, l'Autriche, la Pologne, le Portugal, la Roumanie, la Slovénie, la Slovaquie, la Finlande, la Suède et le Royaume-Uni. 2. Les données présentées dans ce graphique ont été combinées: elles cumulent les résultats des enquêtes annuelles portant sur la période 2009-2013. Certains pays n'ont pas pris part aux enquêtes GEM réalisées chaque année, mais ont été inclus dans les graphiques: la République tchèque (2011 et 2013), le Danemark (2009, 2010, 2011, 2012), l'Estonie (2012, 2013), l'Irlande (2010, 2011, 2012, 2013), l'Italie (2009, 2010, 2012, 2013), la Lituanie (2011, 2012, 2013), le Luxembourg (2013), l'Autriche (2012, 2013), la Pologne (2011, 2012, 2013), le Portugal $(2010,2011,2012,2013)$, la Slovaquie $(2011,2012,2013)$, et la Suède $(2010,2011,2012,2013)$. 3. L'entrepreneuriat au stade précoce désigne les phases de création ou la gestion d'une entreprise de moins de 42 mois.

Source: Global Entrepreneurship Monitor (GEM) (2014), présentations tabulaires spéciales des enquêtes 2009-2013 sur la population adulte, extraites du Global Entrepreneurship Monitor.

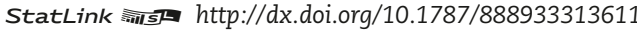


Les motivations personnelles de l'entrepreneur sont souvent à l'origine de l'absence de croissance dans les entreprises gérées par des seniors. Certains d'entre eux exercent un travail indépendant en fin de carrière, car il s'agit d'une solution professionnelle plus flexible qu'un emploi salarié et offre un équilibre intéressant entre vie professionnelle et vie privée (Curran et Blackburn, 2001) ou parce qu'il s'agit d'un moyen de compléter les revenus provenant de la pension de retraite (Folta et al., 2010). Ce choix relève du mode de vie souhaité, et les motivations sont souvent liées à la flexibilité que procure ce type d'emploi. En d'autres termes, les entrepreneurs seniors n'aspirent pas souvent à la croissance, en particulier s'ils souffrent de problèmes de santé. D'autres seniors font le choix du travail indépendant parce qu'ils sont victimes de discrimination sur le marché du travail ou parce qu'ils n'arrivent pas à retrouver un emploi salarié après un licenciement (OCDE/CE, 2012b). Dans ces cas, la création d'une entreprise peut être la seule alternative possible pour ces personnes qui souhaitent réintégrer le monde du travail, et leur idée commerciale ne constitue donc pas forcément une réponse à une opportunité commerciale.

En outre, de nombreuses études paneuropéennes démontrent que les jeunes sont souvent inhibés par leurs craintes et d'autres attitudes négatives. Des études en Italie, par exemple, révèlent que de nombreux jeunes considèrent le travail indépendant comme une «solution de secours" au cas où ils n'arriveraient pas à trouver un emploi salarié (Abburrà, 1998). De plus, les jeunes redoutent fortement l'échec de leur entreprise, la faillite et l'incertitude concernant les revenus (Commission européenne, 2012). Les parents, les proches et les amis peuvent influer sur l'opinion des jeunes vis-à-vis de l'entrepreneuriat en transmettant une image positive ou négative de l'entreprise (Criaco et al., 2014). La famille, notamment, joue un grand rôle dans la formation de l'esprit d'entreprise.

Nombre d'entrepreneurs immigrés ou issus de minorités ethniques créent leur entreprise pour ne pas avoir à accepter un emploi non qualifié (Ndofor et Priem, 2011) ni à subir des discriminations sur le marché du travail. Des études menées en Italie montrent que de nombreuses personnes d'origine étrangère envisagent le travail indépendant comme l'une des seules solutions pour s'élever sur l'échelle sociale (Marucci et Montedoro, 2010). Ces motivations laissent supposer que nombre de ces entrepreneurs sont "contraints» à l'entrepreneuriat et sont donc peu susceptibles de chercher à développer leur entreprise une fois créée.

\section{Accès aux financements}

Les entreprises en développement ont davantage besoin de financements externes que les entreprises sans croissance, qu'il s'agisse d'emprunts ou de capitaux propres (Cassar et Holmes, 2003; Bhaird et Lucey, 2006). Les capitaux d'emprunts sont des prêts accordés à l'entrepreneur qui peuvent provenir de sources informelles (par exemple, les amis ou la famille) ou formelles (par exemple, les banques, autres organismes de prêts). À l'instar des capitaux d'emprunt, les fonds propres peuvent provenir de sources formelles ou informelles. Les capitaux en fonds propres proviennent le plus souvent de l'épargne personnelle des entrepreneurs ou d'investisseurs externes (Le, 1999; Nykvist, 2008; Taylor, 2001) et de sources informelles (par exemple, la famille ou les amis), qui sont bien plus courantes que les fonds propres provenant d'investisseurs formels (par exemple, capital-risque).

En général, les PME en développement connaissent des difficultés pour accéder aux financements pour plusieurs raisons. Premièrement, les entreprises en expansion, notamment les jeunes entreprises en développement, présentent plus de risques que les entreprises stables et bien établies (Coleman, 2004). Deuxièmement, les banques et institutions financières peuvent avoir tendance à octroyer plus facilement des prêts aux grandes multinationales qu'aux petites entreprises en développement. Troisièmement, les coûts de transaction des petits emprunts les rendent moins intéressants pour les institutions financières, car leur rentabilité est réduite. Enfin, les entrepreneurs exploitant de petites entreprises en développement peuvent ne pas 
être capables ou ne pas vouloir fournir les garanties ou les documents comptables exigés par les prêteurs, ce qui rend l'évaluation du niveau de risque du prêt difficile (Ono et Uesugi, 2005).

Les entrepreneurs appartenant à des groupes sous-représentés et défavorisés jugent souvent difficile d'obtenir des financements externes formels du fait de leur absence de garanties et d'antécédents. Par exemple, l'absence d'historique de crédit peut empêcher les jeunes d'obtenir des financements externes. Le CEEDR (2000) montre également que les immigrés dans les pays de l'Union européenne parviennent difficilement à accéder aux financements parce qu'ils n'ont pas ou peu d'historiques de crédit. Les femmes sont également plus susceptibles de rencontrer des problèmes de financement. Par ailleurs, certains seniors peuvent compter sur leur épargne pour financer leur entreprise et ont eu davantage d'opportunités de se constituer un historique de crédit positif.

\section{Compétences entrepreneuriales élevées}

Plus une personne présente un niveau d'études élevé et une expérience professionnelle solide, plus elle est susceptible d'avoir les connaissances et compétences requises pour lancer une entreprise orientée vers la croissance et la faire prospérer. Des études empiriques dans ce domaine ont étudié la façon dont les compétences et l'expérience influent sur la propension de chacun à se lancer dans l'entrepreneuriat (Bates, 1995; Davidsson et Honig, 2003), à renoncer ou à persister en tant qu'entrepreneur (Bates, 1990), à développer son entreprise (Colombo et Grilli, 2005; Wiklund et Shepherd, 2003) ou à générer un retour sur investissement élevé (Honig, 1998).

L'une des clés du succès pour développer une entreprise est la capacité à identifier les opportunités et à les exploiter en mobilisant les ressources nécessaires (Aldrich, 1999). L'expansion d'une entreprise requiert des compétences plus approfondies que la gestion d'une petite entreprise stable. Les principaux domaines dans lesquels les gérants d'une entreprise en développement sont les plus susceptibles d'avoir besoin d'un niveau élevé de compétences sont la gestion des ressources humaines, l'internationalisation, l'accès aux financements et éventuellement l'aide à la recherche et au développement, l'innovation et la gestion de droits de propriété intellectuelle. La difficulté pour les entreprises en développement, notamment celles à forte croissance, consiste à identifier les mécanismes d'aide adaptés et à y accéder en temps utile.

En revanche, comme indiqué aux chapitres 2 et 3, les femmes et les jeunes ont moins tendance que les autres groupes à penser disposer des compétences et connaissances nécessaires pour créer leur entreprise. Les jeunes notamment ont une faible expérience du marché du travail et de l'entrepreneuriat, et sont donc confrontés à certains obstacles pour créer et développer une entreprise orientée vers la croissance. Le CEEDR (2000) révèle également que les immigrés possèdent des compétences entrepreneuriales et commerciales relativement limitées. Par ailleurs, nombre de travailleurs seniors disposent d'une expérience solide sur le marché du travail et parfois également dans le domaine de l'entrepreneuriat. C'est pourquoi ils disposent généralement des nombreux atouts requis pour réussir en tant qu'entrepreneurs.

\section{Réseaux professionnels}

Une fois l'entreprise établie, le réseau de l'entrepreneur s'élargit généralement pour inclure un vivier de contacts susceptibles de devenir des ressources importantes pour l'entreprise (Jack et al., 2008). Selon Drakopoulou Dodd et al. (2014), les entrepreneurs désireux de développer leur entreprise doivent trouver les moyens d'aller au-delà de ce que Hite et Hesterly (2001) appellent les «réseaux fondés sur des liens d'identité forts» et éviter d'être contraints par un lien de dépendance trop important à l'égard de la famille et des amis qui n'ont pas la capacité d'apporter un soutien de qualité (Johannisson et Mønsted, 1997). Le développement de ces réseaux peut inclure des concurrents spécialisés (Lechner et Dowling, 2003). Les relations se diversifient, y compris les relations sociales et économiques. Ces liens sont en effet importants pour la croissance d'une 
entreprise, car les réseaux offrent de nouvelles ressources, y compris des idées, des opportunités, des financements, des collaborateurs et des partenariats (Drakopoulou Dodd, 2012). Considérées dans leur ensemble, ces ressources jouent un rôle très important dans le succès de l'entreprise en termes de revenus et de création d'emplois (par exemple, Jack et Anderson, 2002).

Les entrepreneurs appartenant à des groupes sous-représentés et défavorisés ont toutefois tendance à disposer de réseaux professionnels plus restreints que les autres entrepreneurs (OCDE/Commission européenne, 2015). Par exemple, leurs réseaux professionnels relativement restreints peuvent également entraver la croissance des entreprises gérées par des femmes. Elles ont souvent des réseaux sociaux plus vastes que les hommes (McPherson et al., 2006), mais ceuxci sont en grande partie composés d'amis et de parents (Renzulli et al., 2005). Même s'ils peuvent être un atout pour surmonter les obstacles qui surviennent lors des phases de démarrage de l'entreprise et constituer un soutien concret et affectif (Kim et al., 2013), les réseaux constitués d'amis et de membres de la famille n'apportent pas de nouveaux clients ni de partenaires professionnels. Les jeunes ne s'orientent pas nécessairement plus vers les réseaux sociaux que vers les réseaux professionnels, mais ils ont moins eu l'occasion de développer ce dernier type de relations. De plus, des études réalisées dans toute l’Union européenne démontrent que les personnes immigrées rencontrent des difficultés pour étendre leur réseau au-delà de leurs communautés, car elles maîtrisent mal la langue locale (CEEDR, 2000). Par ailleurs, les seniors qui créent une entreprise dans un domaine lié à leur expérience professionnelle peuvent compter sur des réseaux professionnels étendus pour mobiliser les ressources humaines et financières nécessaires.

\section{Politiques en faveur de la croissance des entrepreneurs appartenant à des groupes sous-représentés et défavorisés}

- Il est important que les responsables politiques sensibilisent davantage au potentiel que représente l'entrepreneuriat des groupes appartenant à des groupes défavorisés et sousreprésentés ainsi qu'aux compétences nécessaires à la croissance. Cette sensibilisation peut passer par la promotion de modèles, la récompense et la célébration de la réussite et la formation à l'entrepreneuriat.

- Les entreprises en expansion ont un besoin pressant de financements. Les responsables politiques peuvent soutenir les entrepreneurs appartenant à des groupes sous-représentés et défavorisés en facilitant leur accès au microcrédit et au capital de croissance. Ils peuvent également soutenir le développement d'autres formes de financement comme le créditbail, la prise de participation d'investisseurs providentiels au capital, la finance solidaire, le financement participatif et le prêt entre particuliers. Les entrepreneurs peuvent également suivre une formation financière pour apprendre à identifier les sources appropriées de financement et à y accéder.

- Les compétences requises pour gérer une entreprise en expansion sont légèrement différentes de celles nécessaires pour la phase de démarrage. Les compétences en direction, gestion et finances occupent une place bien plus importante. Les responsables politiques peuvent aider les entrepreneurs appartenant à des groupes sous-représentés et défavorisés à acquérir ces compétences au moyen de programmes de formation, de coaching et de mentorat.

- Les réseaux professionnels peuvent également être importants pour stimuler et soutenir la croissance grâce à la pression positive des pairs et à la mise à disposition de ressources. Les responsables politiques peuvent également aider les entrepreneurs appartenant à des groupes sous-représentés et défavorisés à développer leurs réseaux professionnels par le biais de programmes formels de mise en réseau. 


\section{Décupler les motivations pour la croissance}

L'un des principaux défis des responsables politiques est de donner envie aux entrepreneurs appartenant à des groupes sous-représentés et défavorisés de développer leur entreprise et de leur donner la confiance pour y parvenir, ce qui implique d'accroître la qualité moyenne des start-up de ces groupes en termes de valeur ajoutée, d'emploi et d'innovation, et de soutenir leur croissance. Deux facteurs doivent être pris en compte: la volonté et la motivation pour la croissance. La volonté de se développer est souvent sur un trait de caractère latent. En revanche, la motivation évolue au gré des interactions sociales. Les efforts politiques visant à soutenir la croissance des entrepreneurs doivent donc se focaliser sur les entrepreneurs faisant preuve d'une volonté de se développer, car si cette envie est absente au début, elle a peu de chance de se manifester par la suite (Delmar et Wiklund, 2008). D'autre part, la motivation se construit souvent par le jeu des interactions sociales. Ainsi, le fait d'être entouré de personnes très motivées peut renforcer la motivation d'un futur entrepreneur (Autio et al., 2013; Baum et Locke, 2004; Davidsson, 1989).

Trois approches sont généralement adoptées par les responsables politiques pour renforcer la motivation de se développer. Premièrement, le fait de faire appel à des modèles qui ont développé leur activité peut inspirer les entrepreneurs grâce à leurs expériences (Autio et al., 2013; Samuelson, 2004). Ces modèles de réussite peuvent particulièrement aider les femmes entrepreneurs à surmonter les stéréotypes de genre traditionnels (Ahl, 2006). Ils sont souvent utilisés dans le cadre des programmes de promotion de l'entrepreneuriat en général ou d'un mécanisme ou événement particulier. Ils peuvent également être intégrés à des programmes de formation, de coaching et de mentorat. Pour accroître la motivation du public cible, celui-ci doit pouvoir s'identifier à la personne présentée en modèle et à son expérience. Cet aspect est particulièrement important pour les entrepreneurs appartenant à des groupes sous-représentés ou défavorisés qui peuvent avoir plus de mal à s'identifier à un entrepreneur traditionnel, car le contexte de réussite peut être complètement différent. Il est donc nécessaire de présenter des exemples de réussite représentatifs de la population dans son ensemble, et des publics cibles en particulier. Par exemple, si le public cible est constitué d'entrepreneurs potentiels ayant un handicap, ils seront probablement plus inspirés par le récit de succès qu'ont connu des entrepreneurs présentant eux-mêmes une forme de handicap.

Deuxièmement, les responsables politiques peuvent ériger en exemple et récompenser des entrepreneurs ayant réussi, par exemple en leur remettant des prix de l'entrepreneuriat. Même s'il est peu probable que la perspective de recevoir un prix soit un moyen très efficace de soutenir la croissance des entreprises, la promotion de l'événement et des lauréats constitue un autre moyen de diffuser les modèles de réussite qui peuvent inspirer et aider les entrepreneurs potentiels à croire en eux et en leur capacité à réussir.

Enfin et surtout, les programmes de formation et d'éducation à l'entrepreneuriat peuvent avoir une influence positive sur la motivation pour la croissance. En plus de leur expliquer les actions à même de générer de la croissance, les éducateurs et les formateurs peuvent donner aux entrepreneurs une meilleure image d'eux-mêmes et une plus grande confiance en eux en formulant des commentaires tout au long du programme. Il est important d'offrir un soutien moral et des encouragements aux entrepreneurs appartenant à des groupes sous-représentés ou défavorisés qui peuvent manquer de confiance en eux et de réseaux personnels. Un autre facteur de réussite des programmes de formation et d'éducation à l'entrepreneuriat est le recours à des exercices pratiques qui permettent de démontrer aux bénéficiaires qu'ils sont capables d'élaborer et de réaliser leurs plans de croissance (De Clercq et Arenius, 2006).

"Going for Growth» en Irlande est un bon exemple de programme public qui combine ces trois approches. Ce programme propose aux femmes entrepreneurs de participer à des groupes de soutien composés de pairs et dirigés par des femmes entrepreneurs ayant réussi. Les chefs de groupe jouent le rôle de modèle et de mentor en partageant leurs expériences et en exerçant une 
pression positive sur les membres du groupe afin qu'ils atteignent leurs objectifs. Ces groupes permettent également de mettre en place un soutien par les pairs et un apprentissage mutuel puisque les membres de ces groupes partagent également leurs expériences et leurs difficultés. Ce soutien repose sur des réunions mensuelles où les femmes travaillent ensemble sur leurs objectifs de croissance à atteindre et le calendrier de leurs échéances. En plus de ces réunions de groupe, les bénéficiaires peuvent participer à des ateliers pour améliorer leurs compétences entrepreneuriales.

\section{Améliorer l'accès aux financements}

L'un des besoins les plus pressants des entrepreneurs qui cherchent à développer leur entreprise est l'accès aux financements nécessaires. Les difficultés liées au développement d'une entreprise sont légèrement différentes de celles de la phase de démarrage, mais les réponses politiques possibles sont semblables. Les responsables politiques peuvent remédier à ces difficultés d'accès aux financements en mettant en place plusieurs mécanismes de prêts ou de financement sur fonds propres du côté de l'offre et en renforçant les connaissances financières du côté de la demande pour que les entrepreneurs soient mieux dotés pour solliciter et obtenir des financements externes. Ils doivent cependant veiller à adapter le soutien financier au parcours de l'entreprise, car celles qui enregistrent une croissance stable n'ont pas les mêmes exigences que les entreprises ayant une croissance irrégulière (Claveau et al., 2013).

\section{Prêt bancaire et microcrédit}

Les responsables politiques peuvent soutenir directement les entrepreneurs appartenant à des groupes sous-représentés ou défavorisés en leur accordant des prêts ou des subventions. Bien qu'elles soient principalement destinées à la phase de création de l'entreprise, ces mesures peuvent être efficaces, car elles contribuent à créer dès le départ des entreprises orientées vers la croissance. Par exemple, elles permettent de réaliser des investissements de départ suffisants dans le capital physique, la formation et le développement de leur capital intellectuel. Des subventions et prêts peuvent être également être octroyés dans un second temps pour soutenir les investissements nécessaires aux phases postérieures au démarrage. Ces aides directes sont souvent gérées par des organismes de microcrédit.

L'offre de garanties de crédit publiques peut également faciliter l'accès au crédit, tant au démarrage que durant les phases d'expansion ultérieures, notamment lorsque les banques sont réticentes à octroyer un prêt en raison du risque perçu et de l'absence de garanties. Cette technique est mise en place indirectement par le biais des banques, ou d'autres établissements financiers, et présente l'avantage d'exploiter leur expertise dans l'octroi et la gestion des prêts et de partager le risque entre les secteurs public et privé.

Pour soutenir efficacement le crédit, il est primordial de disposer d'un bon mécanisme de sélection des entrepreneurs et des projets éligibles à un soutien financier. L'expérience de la Street Microfinance Organisation au Royaume-Uni témoigne que la taille et la qualité du réseau professionnel de l'entrepreneur sont des critères de sélection importants dans l'octroi de prêts aux entreprises en expansion (Forster, 2004). Le Seed Money Fund, dans la province autonome de Trente en Italie, qui fournit des capitaux aux entreprises jeunes et nouvelles, et notamment aux sociétés innovantes gérées par des femmes et des jeunes, constitue un bon exemple de mécanisme de microcrédit imposant des critères de sélection stricts (encadré 7.1). Un autre exemple instructif mené en Grèce est présenté à la troisième partie de cet ouvrage. Ce projet octroie des microcrédits à des jeunes qui créent une entreprise innovante en ayant recours à une procédure de sélection qui comprend une phase d'évaluation par un comité spécialisé.

Pour qu'ils puissent accéder aux financements leur permettant de développer leur entreprise, les entrepreneurs issus de groupes sous-représentés et défavorisés doivent également bénéficier d'une formation et d'un coaching pour s'assurer qu'ils disposent des compétences nécessaires 
pour faire bon usage des financements (OCDE/Commission européenne, 2014). De nombreuses études réalisées dans toute l'Union européenne étayent ces conclusions. Les évaluations de la Street Microfinance Organisation au Royaume-Uni montrent, par exemple, que les taux de réussite augmentent lorsque les entrepreneurs bénéficient d'une formation et de coaching, en particulier dans le domaine de la gestion des risques (Forster, 2004).

\section{Encadré 7.1. Seed Money Fund, province autonome de Trente, Italie}

Description du programme: le Seed Money Fund est un fonds (lancé à la fin de 2009) qui promeut la diffusion d'initiatives professionnelles dans des domaines innovants ou à la pointe de la technologie en prenant en charge une partie des coûts de création de l'entreprise. La priorité est accordée aux femmes et aux jeunes entrepreneurs, ainsi qu'aux retombées dans le domaine universitaire et de la recherche.

Contexte: même s'il reste plus faible que dans la plupart des autres régions italiennes, le taux de chômage des jeunes a fortement augmenté dans la province de Trente. Le gouvernement de la province souhaite également réduire les inégalités sociales subies par les femmes, les personnes immigrées et d'autres groupes. De plus, à l'instar de l'économie nationale, l'économie provinciale a connu une faible croissance depuis le début de la crise.

Problème abordé: le Seed Money Fund vise à promouvoir l'inclusion sociale et la croissance économique en proposant des financements à des entreprises innovantes présentant un bon potentiel de croissance et en soutenant les projets de jeunes et de femmes. Ces fonds sont destinés à financer les analyses sectorielles et de marché, la préparation des plans d'affaires, le mentorat et les autres coûts de création d'une entreprise innovante.

Approche: des appels à projets ont été publiés par le Trentino Suiluppo, l'agence de développement économique locale qui évalue l'éligibilité des différentes candidatures. Ces appels sont ouverts aux nouvelles entreprises, ou très récentes, situées dans la province de Trente. Un comité mis en place par le Trentino Sviluppo évalue ensuite les candidatures, sur la base d'un ensemble de critères prédéfinis qui privilégient la durabilité et l'innovation. De plus, d'autres appels à projets peuvent concerner des objectifs de financement spécifiques. Par exemple, ce fonds a lancé des appels pour les femmes et les jeunes entrepreneurs. Le montant de l'aide s'élève jusqu'à 100000 euros, ou 150000 euros si les frais de mentorat sont compris. Ce fonds a fait partie du programme opérationnel du Fonds européen de développement régional 2007-2013, qui finance les investissements des entreprises (en particulier les PME). Au cours de cette période, les financements provenaient à $30 \%$ de l'Union européenne, $30 \%$ de la province de Trente et $40 \%$ du gouvernement italien.

Impact: en 2009, 62 candidatures ont été déposées (55 ont été considérées comme admissibles et 23 ont été financées). Étant donné le fort intérêt suscité, le gouvernement de la province a doublé le financement prévu initialement pour atteindre 2,17 millions d'euros. Sur les 79 candidatures reçues en 2011, 40 ont obtenu un financement. L'enveloppe globale s'est élevée à 4,5 millions. Aucune évaluation ex post n'a encore été réalisée. Les prochains appels à projets devraient en prévoir une.

Facteurs de réussite: afin d'accroître son impact, le programme a fait l'objet de certains ajustements à l'occasion de l'appel à projets de 2013. Les types de projets innovants susceptibles d'être soutenus ont notamment été élargis. Des projets d'entreprises peuvent être financés dans les domaines de l'innovation technologique (budget de 2 millions d'euros) mais aussi de l'innovation sociale: bien-être, culture, éducation, tourisme et protection environnementale, gestion des communications et de l'information, économie verte (2 millions d'euros). Cette prise en charge élargie doit renforcer les synergies avec le puissant secteur coopératif local et développer le potentiel d'inclusion sociale et de création d'emplois du fonds. Il est intéressant de noter que l'appel à projets a également soutenu la diffusion de la connaissance et de l'information sur l'entrepreneuriat dans le cadre de l'enseignement supérieur et de la formation continue (par le biais de bourses d'études pour les jeunes diplômés, les étudiants et les chercheurs pour promouvoir des idées entrepreneuriales, et de comptes de formation individuels), ce qui devrait accroître l'implication des jeunes dans des entreprises en croissance. L'appel incluait également des politiques axées sur la demande: 3 millions d'euros ont été alloués à l'émission de chèques services afin de créer des opportunités économiques pour les nouvelles entreprises opérant dans le secteur du bien-être.

Pour en savoir plus, veuillez consulter: Trentino Sviluppo (2014), «Fondo Seed Money», http://www.trentinosviluppo. it/it/Principale/Diventa_imprenditore/Gli_strumenti/Seed_Money/Seed_Money.aspx, Agenzia del Lavoro (2013), Interventi di politica del Lavoro Rivolti al Giovani, Trente. 


\section{Crédit-bail}

Le crédit-bail est un autre mécanisme de financement par l'emprunt auquel les entreprises en développement ont souvent recours, généralement pour acheter des équipements. Des solutions alternatives de financement par l'emprunt comme le crédit-bail sont proposées aux entrepreneurs issus de groupes sous-représentés et défavorisés qui ont plus tendance à avoir des difficultés à obtenir des emprunts auprès des banques commerciales. Des mesures politiques peuvent aider à créer des mécanismes de crédit-bail ou à orienter les entrepreneurs appartenant à des groupes sous-représentés et défavorisés vers les mécanismes privés existants, par exemple, au moyen d'informations, de conseils et de mentorat.

Actuellement, il existe peu d'exemples de mécanismes de crédit-bail soutenus par les pouvoirs publics alors que leur potentiel à combler les déficits de financement semble important. En Bulgarie, le Job Opportunities through Business Support (JOBS) est un exemple de programme dont l'objectif est de soutenir la croissance des personnes à faibles revenus qui ne peuvent pas solliciter de prêts bancaires et qui gèrent déjà leur petite ou microentreprise, ou qui ont l'intention d'en créer une. Ses interventions ciblent les zones rurales enregistrant un taux de chômage élevé et une forte proportion de minorités ethniques (par exemple, les Roms). Ce projet subordonne l'octroi du crédit-bail au suivi d'un programme de formation en finances et gestion d'entreprises d'une durée de 20 heures. Ce mécanisme est disponible dans 42 centres d'affaires et 10 couveuses d'entreprises créés au niveau local par les agences pour l'emploi locales, les municipalités et d'autres organisations publiques et privées. Ces centres et couveuses ont le statut juridique d'associations à but non lucratif et sont responsables de l'achat des équipements en crédit-bail, de la formation en finances et des cours de développement d'entreprise. Entre 2000 et 2008, 1985 entreprises ont bénéficié d'un crédit-bail pour un montant total de 10,4 millions d'euros. Grâce à ce mécanisme, près de 53500 personnes ont bénéficié d'une formation et 34660 ont trouvé un emploi stable.

\section{Prise de participation au capital}

Un type de financement courant sur fonds propres pour les entreprises en croissance provient des investisseurs providentiels. Ces investisseurs privés sont des personnes disposant de fonds personnels importants qui choisissent d'investir dans des start-up et des entreprises en développement dans le but de générer des profits à moyen ou long terme. Généralement, ces investissements sont compris entre 25000 et 500000 euros, mais peuvent atteindre des sommes bien plus importantes si plusieurs de ces investisseurs mettent en commun leur apport, par le biais de réseaux, de clubs ou de consortiums. Ces investisseurs providentiels soutiennent souvent les entreprises dans lesquelles ils ont placé leur investissement par d'autres moyens, notamment en leur prodiguant des conseils et en leur donnant accès à leurs réseaux professionnels.

Ce type de financement concerne généralement les entreprises à forte croissance, mais peut également aider des entrepreneurs appartenant à des groupes sous-représentés et défavorisés. À l'échelle de l'Union européenne, le marché des investisseurs providentiels est estimé à environ 5 milliards d'euros, dont les plus importants sont le Royaume-Uni, la France, l'Espagne, la Finlande et l'Allemagne (EBAN, 2012). Ces investissements ciblent les secteurs orientés vers la croissance (Levratto et Tessier, 2014). À l'échelle de l'Union européenne, 70 \% des investissements providentiels sont toutefois destinés aux secteurs des technologies de la communication et de l'information et des biotechnologies tandis que moins de $10 \%$ d'entre eux bénéficient au secteur des biens de consommation, des services et de la vente au détail. Cette situation explique pourquoi les entrepreneurs appartenant à des groupes sous-représentés et défavorisés ne bénéficient qu'à la marge de ces investissements. Par exemple, les entreprises détenues par des femmes sont bien moins susceptibles d'exercer dans les secteurs orientés vers la croissance (voir chapitre 2) que les hommes. De plus, relativement peu d'investisseurs providentiels sont issus de groupes sous-représentés et défavorisés, ce qui contribue au faible niveau d'investissements privés obtenus par les entrepreneurs appartenant à ces groupes. 
Les responsables politiques dans l'Union européenne peuvent soutenir les investissements providentiels consacrés aux entreprises gérées par des entrepreneurs appartenant à des groupes sous-représentés et défavorisés par plusieurs biais. Premièrement, ils peuvent créer des réseaux d'investisseurs providentiels orientés vers les groupes cibles de l'inclusion sociale en subventionnant les coûts de création et de fonctionnement de ces réseaux. Cette pratique est très courante parmi les réseaux d'investisseurs providentiels qui participent au capital des entreprises gérées par des femmes. Deuxièmement, les responsables politiques peuvent proposer des programmes de formation aux entrepreneurs pour renforcer leur aptitude à recevoir de tels investissements. Au Royaume-Uni, une étude portant sur les entreprises qui ont échoué à obtenir un tel investissement indique trois principaux motifs de refus principaux motifs de refus: i) une faiblesse de l'entrepreneur ou de l'équipe de direction, ii) un marketing peu développé; et iii) des prévisions et des projections financières erronées (Mason et Kwok, 2010). Ces trois aspects peuvent constituer les thèmes à aborder lors des formations de préparation aux investissements. Troisièmement, les pouvoirs publics peuvent prévoir des allégements fiscaux pour encourager les investisseurs providentiels, notamment ceux qui investissent auprès d'entrepreneurs appartenant à des groupes sous-représentés et défavorisés. Quatrièmement, les pouvoirs publics peuvent investir conjointement avec ces investisseurs providentiels dans le cadre de projets d'entrepreneuriat inclusif. Cinquièmement, ils peuvent également faciliter et améliorer la mise en relation des investisseurs et des entrepreneurs appartenant à des groupes sous-représentés et défavorisés.

La finance solidaire est une autre approche de la prise de participation au capital. Il s'agit d'une forme de financement social qui a autant pour objectif de générer des profits financiers que d'avoir un impact social ou environnemental positif. Par exemple, les fonds d'investissement solidaire servent d'intermédiaires entre les investisseurs et les entrepreneurs en encourageant l'investissement des instruments de placement traditionnels (comptes d'épargne et d'assurance-vie, fonds d'investissement) dans des entreprises ayant un impact social. L'organisme français Autonomie et Solidarité est un exemple de finance solidaire (encadré 7.2).

\section{Financement participatif}

Le financement participatif est une forme de financement de plus en plus répandue, qui permet de collecter de petites sommes auprès d'un grand nombre de personnes, plutôt que d'une seule grande institution financière. Par rapport aux autres formes de financement, le financement participatif présente les avantages suivants pour les entrepreneurs visant la croissance: évaluation moins formelle et minutieuse des propositions de l'entreprise; suivi limité de l'utilisation des fonds; et faibles coûts fixes (notamment de personnel et de locaux) des portails de financement participatif.

Il existe quatre grandes catégories de financement participatif: les donations, les récompenses (par exemple, l'investisseur reçoit une récompense d'une valeur inférieure à sa participation), l'emprunt et la prise de participation (De Buysere et al., 2012). Le financement participatif peut toutefois combiner plusieurs catégories. Pour les trois premières catégories de financement participatif, en plus des profits, les financeurs sont souvent motivés par des objectifs sociaux et affectifs, ce qui rend ce type de financement particulièrement intéressant pour l'entrepreneuriat inclusif.

Même si ce marché est relativement nouveau et en développement, le rôle que peuvent jouer les pouvoirs publics se fait jour. Tout d'abord, le financement participatif devrait être davantage réglementé, car ces plateformes font l'objet de peu de contrôle notamment en ce qui concerne la viabilité des projets financés. Les informations disponibles sont limitées et les projets pourraient bénéficier d'une présentation plus structurée afin que les investisseurs puissent prendre des décisions éclairées.

Deuxièmement, les responsables politiques peuvent sensibiliser davantage à ce type de financement et améliorer les informations existantes à ce sujet. L'éducation financière du côté de l'offre comme de la demande du marché peut contribuer à aider les investisseurs et les entrepreneurs à mieux comprendre le potentiel du financement participatif. Les formations et conseils destinés aux entrepreneurs appartenant à des groupes sous-représentés et défavorisés devraient porter sur les questions de gestion de l'emprunt et, si le financement participatif repose sur une prise de participation, il faut informer sur le rôle de l'équité externe dans le cadre de la gestion entrepreneuriale. 


\section{Encadré 7.2. Autonomie et Solidarité - société de capital-risque, France}

Description: Autonomie et Solidarité est une société de capital-risque à capital variable créée en 1990 dans la région Nord - Pas-de-Calais, en France. Ce fonds d'investissement compte parmi ses actionnaires des municipalités et des collectivités territoriales. Son objectif est d'aider les demandeurs d'emploi à créer et développer des entreprises et d'investir dans des entreprises qui cherchent à créer des emplois destinés aux personnes menacées d'exclusion sociale.

Contexte: ces dernières années, le secteur minier a été confronté à de nombreuses difficultés sur le plan social et de l'emploi. Le taux de pauvreté a dépassé 19 \% en 2010 et le taux de chômage était de $14 \%$ au premier trimestre 2013. Sur les quelque 4 millions d'habitants de la région, 288000 étaient bénéficiaires d'une aide au revenu à la fin de 2012 (par exemple, revenu minimum, allocations de handicap).

Problème abordé: Autonomie et Solidarité lutte contre la pauvreté en soutenant la création d'entreprises comme moyen d'acquérir une indépendance économique et de se réinsérer socialement.

Approche: Autonomie et Solidarité est une société de capital-risque dont le capital provient de l'épargne solidaire des actionnaires, qui souscrivent des actions valant 77 euros chacune. Ce fonds acquiert des parts dans des entreprises (dans la limite de $25 \%$ de prise de participation) poursuivant des objectifs sociaux. Pour être éligibles, les entreprises doivent avoir créé au moins six emplois par an pendant trois années consécutives et employer des salariés appartenant à des groupes défavorisés. Autonomie et Solidarité dispense également aux entreprises des conseils stratégiques et des formations en gestion en faisant appel à des mentors. Le mentor est chargé de soutenir et de suivre les progrès de l'entreprise. Ce soutien est mis à disposition pendant cinq ans. Toute plus-value perçue par le fonds est réinvestie pour financer de nouveaux projets ou pour compenser les pertes d'autres projets. Les actionnaires ne perçoivent pas de dividendes.

La procédure de sélection débute par un diagnostic de la viabilité du projet. Si l'évaluation est jugée positive, les produits commercialisés, les stratégies adoptées, les motivations et le plan d'affaires de l'entreprise sont examinés de façon approfondie. En fonction des résultats de cette évaluation, des conditions de financement sont proposées.

Impact: à la fin de juin 2012, Autonomie et Solidarité disposait d'un capital d'environ 8,5 millions d'euros, rassemblait 2357 actionnaires, comptait plus de 200 participations au capital et 9,6 millions d'euros d'engagements cumulés (3,4 millions d'euros en capital, 4,9 millions en comptes courants et 1,2 million d'euros en prêts participatifs). Selon le rapport publié par Autonomie et Solidarité, plus de 2000 emplois ont pu être créés par les entreprises et projets qui ont été financés.

Facteurs de réussite: Autonomie et Solidarité compte trois principaux facteurs de réussite. Le premier est l'application d'un régime fiscal favorable aux investisseurs, qui prévoit des allégements de l'impôt sur la fortune, à hauteur de $50 \%$ du montant de l'investissement, dans la limite de 20000 euros. Cet allégement a pour but d'inciter à investir dans le fonds. Le deuxième facteur concerne l'implication d'une association à but non lucratif qui offre services de conseil et coaching aux entrepreneurs naissants en plus d'une prise de participation au capital. Cette combinaison d'aides de nature financière et non financière garantit l'adéquation des projets avec les objectifs de l'association. Le troisième facteur est la concrétisation d'une réflexion et d'une action stratégique sur le long terme. Depuis sa création, ses opérations ciblent des objectifs clairs et simples (promouvoir l'inclusion sociale et lutter contre la pauvreté par le biais de l'entrepreneuriat). Les actionnaires et les entreprises bénéficiaires disposent ainsi d'informations claires et cohérentes sur leurs droits et obligations liés à leur participation.

\section{Prêt entre particuliers}

Le prêt entre particuliers fonctionne sur le même principe que le prêt participatif. Ce type de prêt intervient directement entre deux personnes, la plupart du temps par le biais d'une plateforme en ligne. Il peut être particulièrement bien adapté pour soutenir l'entrepreneuriat orienté vers la croissance des groupes appartenant à des groupes défavorisés et sousreprésentés, car il permet aux entrepreneurs qui ne peuvent pas solliciter de prêts bancaires 
d'accéder à des financements. De plus, les garanties exigées sont plus limitées que dans le cadre des mécanismes formels de financement. Les taux d'intérêt appliqués à ce type de transaction sont plus élevés que ceux des prêts bancaires, et il est courant que ces prêts entre particuliers soient basés sur des prêts subordonnés, c'est-à-dire des prêts qui ne peuvent être remboursés en cas de liquidation qu'une fois que les créanciers privilégiés l'ont été. Le marché des prêts entre particuliers est estimé à 20 millions d'euros par mois en Europe (De Buysere et al., 2012).

Les pouvoirs publics ont un rôle important à jouer dans la régulation de ces marchés, à savoir améliorer la disponibilité des informations sur le sujet et pour former les prêteurs et les emprunteurs aux avantages, coûts et risques de ce type de financement. Les responsables politiques peuvent soutenir ce mécanisme au profit de l'entrepreneuriat inclusif en créant des incitations fiscales pour les investisseurs et des plateformes destinées à des groupes ou des domaines cibles. Ils peuvent également contribuer à la mise en relation des investisseurs et des entrepreneurs.

\section{Éducation financière}

Comme pour les autres types de financement, l'une des clés du succès est l'éducation financière dispensée aux entrepreneurs appartenant à des groupes sous-représentés et défavorisés. Elle peut faire l'objet de cours distincts ou s'inscrire dans le cadre d'une offre de financement globale. Plusieurs des programmes abordés ci-dessus incluent une formation financière et un accès aux financements. La formation financière doit toutefois couvrir l'ensemble des sources de financement disponibles et les grands principes de gestion financière, et ne pas traiter uniquement des conditions pour faire bon usage du type de financement spécifique proposé par le programme comprenant cette formation financière. Les programmes d'éducation financière doivent également figurer dans les programmes de formation générale à l'entrepreneuriat et doivent insister et influer sur les attitudes et comportements, plutôt que seulement approfondir les connaissances. Il est également important de proposer une formation de qualité au développement des compétences financières, dispensée par des formateurs qualifiés. Les responsables politiques peuvent également encourager la formation financière du personnel des banques et établissements financiers. Il est important notamment qu'il emploie un langage simple (OCDE, 2005).

\section{Renforcer les compétences entrepreneuriales}

Les entrepreneurs appartenant à des groupes sous-représentés et défavorisés peuvent renforcer leurs compétences entrepreneuriales en combinant une formation générale à l'entrepreneuriat, axée sur la promotion de l'entrepreneuriat pour tous, et une formation à la création d'entreprises plus ciblée destinée aux entrepreneurs potentiels. La formation à l'entrepreneuriat doit être adaptée aux besoins des participants, étant donné que les différentes catégories de population, comme les jeunes (Moberg, 2011) et les personnes immigrées (Lofstrom, 2004) ont des besoins en formation différents. De récentes études recommandent que les programmes de formation destinés aux jeunes portent sur les compétences non cognitives, comme le travail d'équipe, l'autorégulation et la définition d'objectifs de plus en plus ambitieux (Rosendahl et al., 2012). La formation donne souvent de meilleurs résultats lorsqu'elle est associée à d'autres formes de soutien. Par exemple, une évaluation de huit programmes suédois de politique active du marché du travail révèle que les programmes les plus performants sont ceux qui combinent formation et expérience pratique (Carling et Richardson, 2001). Le programme NEnA en Allemagne constitue également un bon exemple de formation destinée aux femmes scientifiques qui cherchent des débouchés commerciaux à leurs recherches (encadré 7.3) 


\section{Encadré 7.3. NEnA, Allemagne}

Description: ce mécanisme dispense des programmes de formation, de coaching et de mentorat aux femmes scientifiques qui opèrent dans le secteur des nanotechnologies et souhaitent créer leur entreprise. Après examen de leurs compétences et de leur potentiel de création d'entreprises, une équipe interdisciplinaire de participants est formée et chargée d'élaborer des projets d'entreprises au cours du programme.

Problème abordé: les scientifiques travaillant dans la recherche fondamentale se sentent souvent très éloignés de l'entrepreneuriat et de l'économie et pensent qu'il est difficile de créer une entreprise. C'est particulièrement vrai chez les femmes scientifiques, qui ont tendance à bénéficier d'une visibilité publique moindre, à disposer de réseaux plus restreints et à moins se lancer dans la création d'une entreprise que leurs homologues masculins.

Approche: pendant la période 2006-2010, le projet a été géré par le ministère fédéral allemand de l'éducation et de la recherche (BMBF) avec un consortium national d'universités, dans le cadre de l'initiative de perfectionnement professionnel nano4women. Des universités l'ont ensuite repris et financé lorsque d'autres soutiens financiers ont pu être trouvés. Par exemple, le projet est toujours en cours à l'institut de physique l'université Martin-Luther de Halle-Wittenberg, avec le soutien du Land fédéral de Saxe-Anhalt. Au total, 525000 euros ont été investis par le BMBF entre 2006 et 2010. Ses coûts annuels de fonctionnement de près de 100000 euros ont ensuite été pris en charge par le ministère régional. Ce programme n'a pas bénéficié de financements européens.

Le projet de l'institut de physique l'université Martin-Luther de Halle-Wittenberg consiste à proposer une formation d'une semaine dans une école de commerce à des femmes scientifiques ayant une proposition de recherches présentant un intérêt pratique. La procédure stricte d'examen et de sélection (qui comprend un examen des réalisations et des motivations ainsi qu'un questionnaire sur le potentiel entrepreneurial) permet de créer un groupe de participants à fort potentiel, qui bénéficie ensuite d'interventions sur le développement personnel et le renforcement des compétences techniques, d'un coaching individuel. Après cette formation d'une semaine, les partenaires locaux du projet poursuivent (normalement) leurs activités de coaching et de conseil. Impact: quelque 100 participants (étudiants en master, doctorants ou post-doctorants) de 50 universités et instituts de recherche allemands ont participé à ce programme fédéral. Une étude ex post a permis de montrer que $92 \%$ des participants se sont sentis encouragés par le NEnA à créer leur entreprise et que $75 \%$ souhaitent créer leur entreprise à la suite de l'identification d'une opportunité économique. Toujours selon cette étude, sur 23 équipes/idées, 11 projets ont été concrétisés par au moins un des participants en vue de créer une entreprise $(9$ demandes de fonds de promotion impliquant l'élaboration d'un plan d'affaires) ou de la développer (deux équipes avaient déjà créé leur entreprise avant de suivre le programme).

Facteurs de réussite: ce programme met en lumière deux facteurs principaux de succès. Premièrement, des agents (membres de facultés et agents de promotion de l'entrepreneuriat) doivent être recrutés dans les différents instituts de recherche et universités pour mobiliser des participants. Le deuxième facteur de réussite est la participation de formatrices, de coaches et accompagnatrices qualifiées et motivantes qui servent de modèle.

La prestation de services d'aide au développement des entreprises après leur création (comme le mentorat, le coaching et les couveuses d'entreprises) est un moyen supplémentaire de soutenir l'acquisition de compétences qui renforceront le potentiel de croissance des entrepreneurs appartenant à des groupes sous-représentés et défavorisés. Des études menées par le Business Link Scheme au Royaume-Uni et le service danois de conseil et de préparation encadrée ont permis de mettre en exergue les retombées positives de ces programmes (Lundström et al., 2013; Rotger et al., 2012). En ce qui concerne les interventions intensives et personnalisées (c'est-à-dire le mentorat, le coaching, les conseils et les couveuses d'entreprises), les responsables politiques devraient s'efforcer de structurer leur prestation par les acteurs 
locaux, qui sont plus susceptibles de faciliter le développement de compétences et la mise en relation avec les acteurs concernés (Huggins et Williams, 2009).

\section{Construire des réseaux professionnels}

Pendant la phase de démarrage d'entreprises et une fois établie, les réseaux constituent une ressource importante pour collecter des informations et des idées; instaurer des relations avec les partenaires, fournisseurs et clients; identifier des opportunités et des marchés; trouver et attirer les bons collaborateurs et financiers (Kim et al., 2013). Les responsables politiques doivent donc faciliter les interactions entre les entrepreneurs et la communauté des affaires au moyen de rencontres en tête-à-tête et d'événements, ou d'espaces en ligne. Les acteurs locaux sont souvent les personnes les plus à même d'y parvenir, car ils sont déjà en contact avec les acteurs concernés (Huggins et Williams, 2009). En Espagne, par exemple, le projet Woman Emprende (encadré 7.4) crée des réseaux de femmes entrepreneurs qui participent au programme de couveuses d'entreprises de l'université de Saint-Jacques-de-Compostelle.

\section{Encadré 7.4. Woman Emprende, Espagne}

Description du programme: Woman Emprende vise à créer des réseaux comprenant le personnel féminin et les étudiantes en commerce de l'université de Saint-Jacques-de-Compostelle, y compris celles de la couveuse d'entreprises de l'université.

Contexte: une participation réussie à un programme de couveuses d'entreprises accroît le potentiel de croissance d'une jeune entreprise. Pourtant, malgré l'amélioration du niveau général d'études, les entreprises détenues et gérées par des femmes restent sous-représentées parmi les entreprises du secteur de la connaissance (Scott, 2009).

Problème abordé: depuis 1999, la ville de Saint-Jacques-de-Compostelle accompagne l'université locale dans le développement d'entreprises technologiques innovantes, issues de travaux de R \& D. Grâce à ce programme, plus de 120 entreprises ont été créées entre 1999 et 2008, dont $92 \%$ ont survécu jusqu'en 2009. Cependant, le nombre de femmes exerçant dans ces entreprises reste limité alors que les femmes représentent plus de $70 \%$ de la population estudiantine de l'université de Saint-Jacques-de-Compostelle.

Approche: Woman Emprende soutient toutes les étapes de la création d'entreprises détenues par des femmes à l'aide du programme de couveuses d'entreprises Uninova de l'université (http://www.uninova.org/ga/default.asp) et de la société de capital-risque de l'université, Unirisco (http://www.unirisco.com/). L'élément central de ce programme est la plateforme INNOVATIA 8.3 qui permet de sélectionner, d'accompagner et de mettre en relation les femmes entrepreneurs.

Impact: si l'objectif du programme Woman Emprende, de renforcer la présence des femmes au sein du programme de couveuses d'entreprises pour qu'elle soit proportionnée au nombre d'étudiantes, reste encore à atteindre, il a déjà permis de créer plusieurs entreprises gérées par des femmes. Par exemple, la société GalChimia a été créée par quatre doctorantes en chimie. Elle est aujourd'hui le leader national de la chimie organique synthétique.

Facteurs de réussite: ce programme est le fruit d'une collaboration bien établie entre les autorités locales du développement, l'université et le monde des affaires.

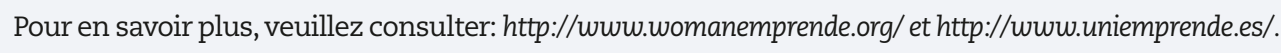




\section{Mettre en place des programmes de soutien à la croissance}

- Étant donné le faible nombre de participants potentiels aux programmes de soutien à la croissance réservés aux entrepreneurs appartenant à des groupes défavorisés et sousreprésentés, il est souvent plus approprié de proposer un soutien en ayant recours aux programmes traditionnels existants. Des mécanismes d'information et de sensibilisation aux programmes traditionnels seront toutefois nécessaires pour ces groupes.

- Des programmes ciblés peuvent également être mis en place afin de promouvoir la croissance des entreprises auprès des jeunes, des femmes, des seniors, des immigrés et d'autres groupes cibles spécifiques. Le cas échéant, il est indispensable d'établir des passerelles entre ces aides complémentaires personnalisées et les programmes traditionnels.

- Les participants aux programmes de soutien à la croissance, notamment les entrepreneurs issus des groupes sous-représentés et défavorisés, devraient être sélectionnés en fonction de la volonté exprimée de se développer.

- Tous les programmes généraux d'aide à la création d'entreprises destinés aux entrepreneurs sous-représentés et défavorisés devraient veiller autant que possible à susciter l'envie de se développer et à faciliter l'accès aux financements de croissance, l'acquisition de compétences entrepreneuriales approfondies, y compris en gestion et en direction, et la création de réseaux professionnels plus solides parmi les entrepreneurs désireux de se développer.

\section{Identifier les entrepreneurs à fort potentiel de croissance}

Les politiques publiques qui visent à soutenir la croissance des entreprises ont plus de chances d'être efficaces si elles ciblent les entrepreneurs manifestant une volonté de se développer. Il convient alors de soutenir la traduction de cette volonté d'expansion en motivation et de faciliter l'acquisition des ressources importantes en la matière (par exemple, financements, compétences et réseaux). Les entrepreneurs désireux de se développer peuvent être identifiés au moyen d'entretiens et d'enquêtes. S'il est impossible de toucher toutes les personnes ayant la volonté de se développer, il est probable que ceux qui demandent à bénéficier des programmes de soutien à la croissance souhaitent également se développer. Les bénéficiaires des programmes de formation à l'entrepreneuriat ou d'aide à la création d'entreprises les plus motivés pourraient également être repérés et soutenus si le personnel opérationnel de ces programmes y prêtait attention ou était chargé de les identifier. Par ailleurs, il n'est pas opportun d'encourager les nouveaux entrepreneurs et propriétaires d'entreprises établies à se développer sans les sélectionner au préalable, car de nombreux entrepreneurs souhaitent simplement subvenir à leurs besoins.

\section{Établir des passerelles avec les programmes traditionnels}

Comme évoqué par l'OCDE/la Commission européenne (2013), il existe diverses approches politiques pour soutenir les entrepreneurs appartenant à des groupes défavorisés et sous-représentés: accès aux programmes traditionnels proposés aux autres groupes; activités de sensibilisation et de promotion ciblées afin d'intégrer les groupes sous-représentés et défavorisés aux services traditionnels auxquels ils ne pourraient avoir accès autrement; actions personnalisées pour les groupes sous-représentés et défavorisés par le biais des programmes et des agences traditionnels; et création d'agences de soutien spécialisées.

Le soutien des agences spécialisées est généralement le plus efficace, car le public cible est plus restreint. De plus, il est généralement axé sur les besoins des entreprises plutôt que sur les caractéristiques personnelles des entrepreneurs. Il est donc plus harmonisé que l'aide à la création d'entreprises. Cependant, les entrepreneurs appartenant à des groupes sous-représentés et défavorisés participent peu aux programmes classiques de soutien à la croissance. Les raisons en sont multiples: i) la participation volontaire des bénéficiaires qui connaissent les programmes traditionnels d'aide à la croissance, savent y accéder et comment en profiter réduit les chances de candidature des entrepreneurs appartenant à 
des groupes sous-représentés et défavorisés; et ii) les divers critères de sélection et d'éligibilité ont tendance à écarter ces groupes.

Lorsque les entrepreneurs appartenant à des groupes sous-représentés et défavorisés ont moins tendance à solliciter les programmes d'aide classiques, des mesures de sensibilisation devraient être mises en place pour informer ces groupes de l'existence de ces programmes. Par exemple, l'initiative Mingo Migrant Enterprises en Autriche fait appel à des conseillers appartenant à des minorités ethniques, ce qui a effectivement permis de faciliter l'accès des immigrés aux services d'aide traditionnels. Des programmes de proximité sont également mis en place afin d'atteindre les bénéficiaires potentiels par le biais de campagnes médiatiques en langues minoritaires, dans la presse et lors de divers événements.

Dans certains cas, le nombre de participants peut toutefois justifier la mise en place de programmes de soutien à la croissance pour certains groupes. De plus, tous les programmes généraux d'aide à la création d'entreprises destinés aux entrepreneurs sous-représentés doivent s'intéresser aux principaux facteurs de croissance des entreprises et veiller ainsi autant que possible à susciter l'envie de se développer et à faciliter l'accès aux financements pour se développer, l'acquisition de compétences entrepreneuriales approfondies, y compris en gestion et en direction, et la création de réseaux professionnels plus solides parmi les entrepreneurs désireux de se développer.

\section{Conclusions et recommandations politiques}

La plupart des entrepreneurs créent leur entreprise dans des secteurs qu'ils connaissent et dans lesquels ils ont déjà une expérience professionnelle. Or, cette situation mène à la création d'un grand nombre d'entreprises dans les mêmes secteurs présentant peu d'obstacles à l'entrée, en particulier pour les entrepreneurs appartenant à des groupes sous-représentés et défavorisés, qui disposent souvent d'un faible niveau de compétences, d'un accès limité aux financements et de réseaux restreints (OCDE/Commission européenne, 2013). La concurrence fait donc rage sur les marchés, réduisant ainsi les marges des entrepreneurs au profit des consommateurs, qui disposent eux-mêmes de revenus faibles et représentent donc un potentiel de croissance limité pour les nouveaux entrepreneurs (Camerer et Lovallo, 1999). Les opportunités les plus intéressantes résident donc dans les secteurs qui n'ont pas encore été exploités à leur plein potentiel par d'autres entreprises (Evans, 1989). Choisir ces secteurs d'activité accroît les chances de créer une entreprise pérenne qui génère un chiffre d'affaires élevé et présente un potentiel de croissance. Cela augmente également les chances de retombées positives sur l'économie locale, comme la création d'emplois.

Les politiques peuvent avoir une incidence sur le nombre d'entrepreneurs appartenant à des groupes sous-représentés et défavorisés qui développent leur activité. À cet égard, les responsables et acteurs politiques qui cherchent à soutenir la croissance doivent tout d'abord identifier les entrepreneurs établis et potentiels ayant une véritable volonté de se développer, mais qui manquent des ressources nécessaires pour y parvenir (notamment, la motivation, les financements, les compétences et les réseaux), puis les aider à combler ces lacunes. D'un point de vue pratique, cette sélection est bien plus facile à mettre en place que d'essayer de motiver ou d'inciter des personnes peu enclines à prendre des risques ou des entrepreneurs privilégiant leur qualité de vie à se développer.

\section{Principales recommandations politiques}

- Sélectionner les bénéficiaires des programmes d'aide à la croissance en fonction des motivations exprimées.

- Faire appel à des modèles de réussite issus des groupes cibles des politiques en faveur de l'entrepreneuriat inclusif pour encourager d'autres entrepreneurs à se développer et à réussir.

- Intégrer les compétences requises pour le développement de l'entreprise aux programmes de formation à l'entrepreneuriat, en particulier des compétences en direction, gestion et finances. 
- Utiliser les relations individuelles comme le mentorat et le coaching pour motiver et soutenir les entrepreneurs appartenant à des groupes sous-représentés et défavorisés qui cherchent à développer leur entreprise.

- Favoriser l'accès aux financements de croissance, notamment l'emprunt et la prise de participation au capital. Mettre en place des fonds spéciaux pour les entreprises en expansion et mettre en relation les investisseurs providentiels et les entrepreneurs appartenant à des groupes sous-représentés et défavorisés dans le cadre d'événements de mise en réseau.

- Développer des réseaux professionnels dans le cadre de programmes structurés pour aider les entrepreneurs à renforcer leur accès aux ressources. Si la création de réseaux au sein des groupes cibles est utile pour renforcer la solidarité entre eux, il est également important de favoriser les liens avec la communauté des entrepreneurs traditionnels pour optimiser l'accès aux ressources et aux connaissances.

- S'assurer que les programmes traditionnels de soutien à la croissance des entreprises sont accessibles aux entrepreneurs appartenant à des groupes sous-représentés et défavorisés et que ces derniers bénéficient de services d'information et de sensibilisation ciblés. Créer des passerelles entre les initiatives de soutien à la croissance des entreprises destinées aux groupes sous-représentés et défavorisés spécifiques et les aides complémentaires disponibles dans le cadre des programmes traditionnels.

- Veiller à susciter l'envie de se développer et à faciliter l'accès aux financements de croissance, l'acquisition de compétences entrepreneuriales approfondies, y compris en gestion et en direction, et la création de réseaux professionnels plus solides parmi les entrepreneurs désireux de se développer qui participent aux programmes d'aide traditionnels destinés aux groupes sousreprésentés et défavorisés.

\section{Références}

Abburrà, L. (1998), «Creare nuove imprese di successo in aree a rischio di declino. Un'indagine empirica tra letteratura economica e politiche pubbliche», Economia \& Lavoro, n² 2, p. 49-72.

Agenzia del Lavoro (2013), Interventi di politica del Lavoro Rivolti al Giovani, Trento.

Ahl, H. (2006), «Why research on women entrepreneurs needs new directions», Entrepreneurship Theory and Practice, Vol. 30, n 5, pp. 595-621.

Aldrich, H. (1999), Organizations Evolving, Sage Publications, Londres.

Autio, E, S. Pathak, K. Wennberg (2013), "Consequences of cultural practices for entrepreneurial behaviors», Journal of International Business Studies, Vol. 44, n 4, p. 334-362.

Bates, T., «Entrepreneur Human Capital Inputs and Small Business Longevity», The Review of Economics and Statistics, vol. 72, n 4, pp. 551-559.

Bates, T. (1995), «Self-employment entry across industry groups», Journal of Business Venturing, Vol. 10, $n^{\circ} 2$, p. $143-156$.

Baum, R. et E. Locke (2004), «The Relationship of Entrepreneurial Traits, Skill, and Motivation to Subsequent Venture Growth", Journal of Applied Psychology, Vol. 89, n 4, p. 587-598.

Baum, R., E. Locke, S. Kirkpatrick (1998), «À longitudinal study of the relation of vision and vision communication to venture growth in entrepreneurial firms", Journal of Applied Psychology, Vol. 83, n 1, p. 43-54.

Bhaird, C. et B. Lucey (2006), «An Explanatory Cross-Sectional study of the capital structures of Irish SMEs», document présenté lors du International Conference on the Financing of SMEs au CSME, Warwick Business School.

Brush, C. G., «Research on women business owners: Past trends, a new perspective and future directions», Entrepreneurship Theory \& Practice, Vol. 16, n 4, p. 5-30.

Bundesministerium für Wirtschaft, Familie und Jugend (2012), Mittelstandsbericht 2012, Vienne, BWFJ.

Camerer, C. et D. Lovallo (1999), "Overconfidence and Excess Entry: An Experimental Approach», American Economic Review, Vol. 89, n 1, p. 306-318. 
Carling, K. et K. Richardson (2001), «The Relative Efficiency of Labor Market Programs: Swedish Experience from the 1990's», Labour Economics, Vol. 11, n³ 3, p. 335-354.

Cassar, G. et S. Holmes (2003), «Capital Structure and the financing of SMEs: Australian evidence», Accounting and Finance, Vol. 43, p. 123-147.

CEEDR (Centre for Enterprise and Economic Development Research) (2000), «Young entrepreneurs, women entrepreneurs, co-entrepreneurs and ethnic minority entrepreneurs in the European Union and central and eastern Europe», Bruxelles, Commission européenne, DG Entreprise, http://ec.europa.eu/enterprise/ newsroom/cf/_getdocument.cfm?doc_id=4095.

Claveau, N., M. Perez et I. Prim-Allaz (2013), «Vers une différenciation des trajectoires de forte croissance (FC continue vs FC discontinue)", Revue internationale P.M.E., Vol. 26, n 1, p. 117-139.

Coleman, S. (2004), «The Liability of newness and small firm access to debt capital: Is there a link?», document présenté lors de l'Annual Conference of the Academy of Entrepreneurial Finance, 29 avril 2004, Washington D.C.

Colombo, M. et L. Grilli (2005), «Founders' human capital and the growth of new technology-based firms: A competence-based view", Research Policy, Vol. 34, n 6, p. 795-816.

Commission européenne (2012), «Entrepreneurship in the EU and beyond», Flash Eurobaromètre 354, disponible à l'adresse: ec.europa.eu/public_opinion/flash/fl_354_en.pdf.

Criaco, G., F. Chirico, P. Sieger, T. Minola et K. Wennberg (2014), «Entrepreneurial parents as a double-edged sword for offspring's entrepreneurial intentions: A social comparison perspective», document de travail, Jönköping International Business School.

Curran, J. et R. Blackburn (2001), "Older people and the enterprise society: age and self-employment propensities», Work, Employment and Society, Vol. 15, n 4, p. 889-902.

Davidsson, P. (1989), "Continued entrepreneurship and small firm growth». Economic Research Institute Stockholm School of Economics, Ekonomiska forskningsinstitutet vid Handelshögsk, (EFI), Stockholm.

Davidsson P, et B. Honig (2003), «The role of social and human capital among nascent entrepreneurs» Journal of Business Venturing, Vol. 18, n 3, p. 301-331.

De Buysere, K., O. Gajda, R. Kleverlaan et D. Mar (2012), «A Framework for European Crowdfunding», http:// www.crowdfundingframework.eu.

De Clercq D, et P. Arenius (2006), "The role of knowledge in business start-up activity», International Small Business Journal, Vol. 24, $n^{\circ}$ 4, p. 339-358.

Delmar, F., et C. Holmquist (2004), "Women's entrepreneurship: issues and policies», Actes de la 2ème conférence des ministres en charge des PME «Promotion de l'entrepreneuriat et des PME innovantes dans l'économie mondiale » de l'Organisation de coopération et de développement économique (OCDE), Istanbul, Turquie

Delmar, F. et J. Wiklund (2008), «The effect of small business managers' growth motivation on firm growth: À longitudinal study", Entrepreneurship Theory and Practice, Vol. 32, n³, p. 437-457.

Di Maria, E. et V. De Marchi (2008), «Competitività, imprenditorialità e immigrazione», Il caso del Veneto, argomenti, $n^{\circ} 24$.

Drakopoulou Dodd, S. (2012), «Network approaches and embeddedness», Perspectives on Entrepreneurship: A Course Text, Mole, K et Ram, M (eds., 2012), Palgrave Macmillan, Londres

Drakopoulou Dodd, S., S. Jack et A. Anderson (2014), «The Role Of Networking In The Growth Processes Of Family Firms: An International Study», Family Entrepreneurship, Fayolle, ed., (à paraître).

Du Rietz A. et M. Henrekson (2000), «Testing the female underperformance hypothesis», Small Business Economics, Vol. 14, n 1, p. 1-10.

EBAN (2012), «European Angel Investment Overview: 2012», disponible sur: http://www.eban.org/wp-content/ uploads/2013/07/EBAN-Angel-Investment-Overview-2012.pdf.

Ebbers, I. et B. Halbfas (2013), «Beteiligung von Frauen am Gründungsgeschehen: diskursanalytische Verortung in der akademischen Entrepreneurship Education", document présenté lors du G-Forum, 17.

Efendic, N., F. Andersson et K. Wennberg (2014), «Growth in Immigrant-run Businesses», document présenté lors du Symposium Uddevalla 2014.

Eurostat (2006), «The profile of the successful entrepreneur - Results of the survey Factors for Success», Statistics in Focus 29/2006. 
Evans. M. (1989), «Immigrant Entrepreneurship: Effects of Ethnic Market Size and Isolated Labor Pool», American Sociological Review, Vol. 54, n 6, p. 950.

Farley, R. et R. Alba (2002), «The New Second Generation in the United States», International Migration Review, Vol. 36, p. 669-701.

Folta, T. B., F. Delmar et K. Wennberg (2010), «Hybrid Entrepreneurship», Management Science, Vol. 56, $\mathrm{n}^{\circ} 2$, p. 253-269.

Forster, S. (Ed.) (2004), Street UK: A microfinance organisation. Lessons learned from its first three years' operations. Street (UK) Foundation, soutenu par la Fondation Calouste Gulbenkian et le Réseau européen de la microfinance.

Global Entrepreneurship Monitor (GEM) (2014), Présentations tabulaires spéciales des enquêtes 2009-2013 sur la population adulte, extraites du Global Entrepreneurship Monitor.

Goffi, G. (2012), «Donne e lavoro in Italia e nelle Marche. Il punto sulle difficoltà e sulle prospettive», Economia Marche Journal of Applied Economics, Vol. XXXI, n² 2, décembre.

Gundry, L. et H. Welsch (2001), «The ambitious entrepreneur: High growth strategies of women-owned enterprises", Journal of Business Venturing, Vol. 16, n 5, p. 453-470.

Hart, D. et Z. Acs (2011), «High-Tech Immigrant Entrepreneurship in the United States», Economic Development Quarterly, Vol. 25, n², p. 116-127.

Hite, J. et W. Hesterly (2001), «The evolution of firm networks: From emergence to early growth of the firm», Strategic Management Journal, Vol. 22, n 3, p. 275-286.

Honig, B. (1998), «What determines success? Examining the human, financial, and social capital of Jamaican microentrepreneurs", Journal of Business Venturing, vol. 13(5), p. 371-394.

Huggins, R. et N. Williams (2009), «Enterprise and public policy: a review of Labor government intervention in the United Kingdom», Environment and planning. C, Government and policy, Vol. 27, n 1, p. 19.

Jack, S. et A. Anderson (2002), «The effects of embeddedness on the entrepreneurial process», Journal of Business Venturing, Vol. 17, n 5, p. 467-487.

Jack, S., S. Dodd et A. Anderson (2008), «Change and the development of entrepreneurial networks over time: a processual perspective», Entrepreneurship and Regional Development, Vol. 20, n² 2, p. 125-159.

Janczak, S. et F. Bares (2010), «High Growth SMEs: The Evolution of the Gazelles and Some Evidence from the Field», J.A.-Bombardier Chair of Entrepreneurship, document de travail n²010-01.

Johannisson, B. et M. Mønsted (1997), «Contextualizing Entrepreneurial Networking», International Journal of Management and Organization, Vol. 27, n 3, p. 109-137.

Kim, P., K. Longest et H. Aldrich (2013), «Can You Lend Me a Hand? Task-Role Alignment of Social Support for Aspiring Business Owners", Work and Occupations.

Le, A. (1999), «Empirical Studies of Self-Employment», Journal of Economic Surveys, vol. 13(4), p. 381.

Lechner, C. et M. Dowling (2003), «Firm networks: External relationships as sources for the growth and competitiveness of entrepreneurial firms", Entrepreneurship and Regional Development, Vol. 15, n 1, p. 1-26.

Levratto, N. et L. Tessier (2014), «La croissance des PME est-elle favorisée par les Business Angels? Une analyse à partir du cas français en 2008 et 2009", Communication au 12ème CIFEPME, Agadir, 29-31 octobre 2014.

Lofstrom, M. (2004), Labor market assimilation and the self-employment decision of immigrant entrepreneurs, Springer, New York.

Lundström A, P. Vikström, M. Fink, H. Crijns, P. Głodek, D. Storey et A. Kroksgård (2013), «Measuring the Costs and Coverage of SME and Entrepreneurship Policy: A Pioneering Study», Entrepreneurship Theory and Practice, Vol. 38, n 4, p. 941-957.

Marucci, M. et C Montedoro (2010), «L'integrazione degli immigrati tra politiche attive del lavoro e politiche sociali: esperienze ed eccellenze in quattro regioni italiane», Strumenti ISFOL, numéro 6 - septembre.

Mason, C. et J. Kwok (2010), «Investment Readiness Programmes and Access to Finance: A Critical Review of Design Issues», Local Economy, Vol. 25, n 4, p. 269-92.

McPherson, M., L. Smith-Lovin et M. Brashears (2006), «Social isolation in America: Changes in core discussion networks over two decades", American Sociological Review, Vol. 71, n 3, p. 353-375.

Moberg, K. (2011), «Evaluating content dimensions in entrepreneurship education», disponible à l'adresse SSRN suivante: $h$ ttp://ssrn.com/abstract=1969852. 
Ndofor, H. et R. Priem (2011), «Immigrant Entrepreneurs, the Ethnic Enclave Strategy, and Venture Performance», Journal of Management, Vol. 37, n 3, p. 790-818.

Nykvist, J. (2008), «Entrepreneurship and Liquidity Constraints: Evidence from Sweden», The Scandinavian Journal of Economics, Vol. 110, n 1, p. 23-43.

OCDE (2013), Panorama de l'entrepreneuriat, Publications OCDE, Paris. DOI: 10.1787/22266941.

OCDE, Les principes et les bonnes pratiques relatifs à la sensibilisation et l'éducation financières, Publications OCDE, Paris, 2005.

OCDE/Commission européenne (2012a), «Synthèse sur les réseaux d'entrepreneuriat inclusif - Activité entrepreneuriale en Europe», Union européenne, Luxembourg, disponible à l'adresse suivante: http:// ec.europa.eu/social/main.jsp?catId=738\&langId=en\&pubId=7751.

OCDE/Commission européenne (2014), Pallier la pénurie d'entrepreneurs 2014: politiques d'entrepreneuriat inclusif en Europe. DOI: 10.1787/9789264213593-fr.

OCDE/Commission européenne (2013), Pallier la pénurie d'entrepreneurs: politiques d'entrepreneuriat inclusif en Europe. DOI: $10.1787 / 9789264188211-\mathrm{fr}$.

OCDE/Commission européenne (2012a), Synthèse sur l'entrepreneuriat des jeunes, Union européenne, Luxembourg, disponible à l'adresse suivante: http://ec.europa.eu/social/main.jsp?catId=738\&langId=fr\& pubId $=6501$.

OCDE/Commission européenne (2012b), Synthèse sur l'entrepreneuriat des seniors, Union européenne, Luxembourg, disponible à l'adresse suivante: http://ec.europa.eu/social/main.jsp?catId=738\&langId=fr\& pubId $=7342$.

Ono, A. et I. Uesugi (2005), «The role of collateral and personal guarantees in relationship lending: evidence from Japan's small business loan market», document présenté lors de l'International Conference on Financing of SMEs in Developed Countries, CSME, Warwick Business School.

Renzulli, L.A.et H.E. Aldrich (2005), «Who can you turn to? Tie activation within core business discussion networks", Social Forces, Vol. 84, n² 1, pp. 323-341.

Roithmayr, D. (2000), «Barriers to Entry: A Market Lock -In Model of Discrimination», Virginia Law Review, Vol. 8, $\mathrm{n}^{\circ}$ 4, p. 727-799.

Rosendahl, H., R. Sloof et M. van Praag (2012), «The effect of early entrepreneurship education: Evidence from a randomized field experiment», IZA Discussion Paper No. 6512, disponible à l'adresse: http://ftp.iza.org/ dp6512.pdf.

Rotger, G., M. Gørtz et D. Storey (2012), «Assessing the effectiveness of guided preparation for new venture creation and performance: A meta-analytical review", Journal of Business Venturing, vol. 27, n 4, p. 506-521.

Samuelsson, M. (2004), Creating new ventures: a longitudinal investigation of the nascent venturing process, Jönköping International Business School: Jönköping.

Saxenian, A. (2002), «Silicon Valley's New Immigrant High-Growth Entrepreneurs», Economic Development Quarterly, Vol. 16, n 1, p. 20-31.

Scott, G. (2009), «Towards an Urban Agenda for the Economic Downturn», The URBACT Tribune, novembre.

Taylor, M. (2001), «Self-employment and windfall gains in Britain: Evidence from panel data», Economica, vol. 68, p. 539-565.

Trentino Sviluppo (2014), «Fondo Seed money», http://www.trentinosviluppo.it/it/Principale/Diventa_ imprenditore/Gli_strumenti/Seed_Money/Seed_Money.aspx.

Uniemprende (2014), «Universidade de Santiago de Compostela», http://www.uniemprende.es/.

van Praag, M. (2003), «Business survival and success of young small business owners», Small Business Economics, Vol. 21, n 1, p. 1-17.

Wiklund, J., P. Davidsson et F. Delmar (2003), «What do they think and feel about growth? An expectancy-value approach to small business managers' attitudes toward growth», Entrepreneurship Theory and Practice, Vol. 27, n³, p. 247-270.

Wiklund, J. et D. Shepherd (2003), «Knowledge-based resources, entrepreneurial orientation, and the performance of small and medium-sized businesses», Strategic Management Journal, Vol. 24, p. 1307-1314.

Women Emprende (2014), «Universidade de Santiago de Compostela», http://www.womanemprende.org/. 


\section{Chapitre 8}

\section{Mécanismes de coaching et de mentorat efficaces pour les entrepreneurs appartenant à des groupes sous-représentés et défavorisés}

Ce chapitre définit le coaching et le mentorat et présente les avantages de ces soutiens pour les entrepreneurs appartenant à des groupes sous-représentés et défavorisés. Il décrit les différentes approches politiques qui peuvent être utilisées pour proposer des services de coaching et de mentorat aux entrepreneurs établis et potentiels appartenant à des groupes défavorisés ou sous-représentés et fournit des exemples. Il traite également des éléments à prendre en compte lors de la conception et de la mise en œuure de mécanismes efficaces de coaching et de mentorat pour soutenir les entrepreneurs établis et potentiels appartenant à des groupes sous-représentés et défavorisés. Ce chapitre présente également un ensemble de recommandations politiques.

Note Turquie/Chypre:

1. Note en bas de page de la Turquie

Les informations figurant dans ce document qui font référence à " Chypre " concernent la partie méridionale de l'Ile. Il n'y a pas d'autorité unique représentant à la fois les Chypriotes turcs et grecs sur l'Ile. La Turquie reconnaît la République Turque de Chypre Nord (RTCN). Jusqu'à ce qu'une solution durable et équitable soit trouvée dans le cadre des Nations Unies, la Turquie maintiendra sa position sur la " question chypriote".

2. Note en bas de page de tous les États de l'Union européenne membres de l'OCDE et de l'Union européenne La République de Chypre est reconnue par tous les membres des Nations Unies sauf la Turquie. Les informations figurant dans ce document concernent la zone sous le contrôle effectif du gouvernement de la République de Chypre. 


\section{Nature et définition du coaching et du mentorat}

- Le coaching (ou accompagnement individualisé) consiste généralement en une relation de courte durée entre deux individus, destinée à développer les compétences d'un entrepreneur. Le coach est chargé de la réalisation des objectifs à court terme et de guider son élève vers ces objectifs. L'élève est chargé de produire des idées et des solutions, de prendre des mesures pour atteindre les objectifs et de faire part de ses progrès.

- Le mentorat se fonde sur une relation professionnelle où une personne expérimentée (le mentor) aide une autre (l'élève) à approfondir ses compétences et ses connaissances. Le mentorat s'organise généralement sur une période plus longue que le coaching et porte souvent plus particulièrement sur le développement personnel.

- Le mentorat et le coaching se distinguent principalement par le fait que le coaching se concentre davantage sur des questions plus spécifiques que le mentorat. Le coaching est également plus susceptible d'être proposé dans le cadre de programmes intégrés d'aide à l'entrepreneuriat.

Le coaching et le mentorat sont des services de conseil qui peuvent être mis en place dans divers contextes personnels et professionnels, y compris au profit des personnes qui envisagent de créer une entreprise ou l'ont déjà fait. Ce type de soutien revêt généralement la forme d'une relation personnelle entre deux individus, même s'il existe des exemples de coaching de groupe (par exemple, collaboration entre un entrepreneur expérimenté et un groupe d'entrepreneurs bénéficiaires, qu'ils soient nouveaux ou établis, ou entre plusieurs coaches et un entrepreneur) (D'abate et al., 2003). Pour que ce dispositif soit efficace, il est indispensable d'instaurer une relation de confiance solide entre les personnes impliquées (CREME, 2013). Dans le cas particulier d'entrepreneurs appartenant à des groupes sous-représentés et défavorisés, il peut être nécessaire d'imposer des critères spécifiques pour le recrutement des coaches et des mentors, comme le fait de comprendre les difficultés rencontrées.

Le coaching et le mentorat sont des formes de soutien étroitement corrélées qui peuvent être utilisées pour promouvoir l'entrepreneuriat. Le tableau 8.1 présente les composants de ces relations sur lesquels tout le monde s'accorde et leurs principales différences.

Dans le contexte de l'entrepreneuriat, le coaching peut être envisagé comme une relation personnelle entre un entrepreneur expérimenté (le coach) et un entrepreneur moins expérimenté ou qui cherche à surmonter une difficulté particulière (l'élève). Dans ce cadre, le coach travaille avec l'élève pour définir et atteindre des objectifs ou cibles spécifiques. En d'autres termes, le coaching repose sur une relation interpersonnelle étroite, qui permet à l'élève d'apprendre et de développer son potentiel dans un contexte de changement (Audet et Couteret, 2012). Il oblige souvent le coach à encourager l'élève à se dépasser et à aller au-delà de ses capacités sur des points précis et quantifiables en le soutenant, en lui fournissant les ressources nécessaires et en le responsabilisant (Edgcomb et Malm, 2002). Le coaching porte souvent sur des difficultés liées à l'entreprise. Les coaches travaillent avec l'élève à la conception d'un programme répondant à ses besoins, en général dans le cadre de rencontres structurées, au cours desquelles le coach lui apporte son aide et élabore des activités de suivi en complément, notamment des travaux pratiques (St-Jean et Audet, 2009). 
Tableau 8.1. Composants clés des services de coaching et de mentorat destinés aux entrepreneurs

\begin{tabular}{|c|c|c|}
\hline & Coaching & Mentorat \\
\hline \multicolumn{3}{|l|}{ Structure } \\
\hline Mission & $\begin{array}{l}\text { Soutenir un entrepreneur sur une difficulté particulière } \\
\text { en lien avec son entreprise. Priorité au développement } \\
\text { de l'entreprise. }\end{array}$ & $\begin{array}{l}\text { Soutenir un entrepreneur dans son développement } \\
\text { personnel. Le mentorat se concentre plus sur les } \\
\text { difficultés de l'entrepreneur que sur celles de son } \\
\text { entreprise. }\end{array}$ \\
\hline Forme & Conseils sur le processus & Conseils sur la situation \\
\hline Tâche & $\begin{array}{l}\text { Soutenir les entrepreneurs par le biais d'un service de } \\
\text { conseil structuré. }\end{array}$ & $\begin{array}{l}\text { Faire appel à son expérience personnelle pour aider des } \\
\text { entrepreneurs à comprendre les conséquences de leurs } \\
\text { actions et à résoudre les problèmes. }\end{array}$ \\
\hline \multicolumn{3}{|l|}{ Processus } \\
\hline Lien avec le contenu du programme & Fort & Faible \\
\hline Lieu de rencontre & Neutre & Neutre \\
\hline Résolution des problèmes & Conseils & $\begin{array}{l}\text { Suggestions spécifiques pour aider les entrepreneurs à } \\
\text { comprendre les conséquences et les résultats }\end{array}$ \\
\hline Évaluation des opportunités ou des idées & Non & Non \\
\hline Rôle opérationnel & Non & Non \\
\hline Confidentialité & Accord oral & Accord oral \\
\hline Mise en réseau & Facilitateur & Facilitateur (plus actif qu'un coach) \\
\hline \multicolumn{3}{|l|}{ Relations } \\
\hline Cadre & Rencontres programmées et structurées & Rencontres moins structurées \\
\hline Rencontres & Individuelles ou collectives & Individuelles ou collectives \\
\hline Initiative & En fonction du calendrier & En fonction de la demande \\
\hline Travaux pratiques & Oui — partie intégrante du processus & Non - ne fait pas partie intégrante du processus \\
\hline Documentation & Oui - partie intégrante du processus & Non - ne fait pas partie intégrante du processus \\
\hline Suivi & Oui — partie intégrante du processus & Non - ne fait pas partie intégrante du processus \\
\hline \multicolumn{3}{|l|}{ Profil du coach et du mentor } \\
\hline Éducation et expérience & Expertise sur une difficulté particulière & $\begin{array}{l}\text { Généralement ancien entrepreneur. Aucune compétence } \\
\text { sectorielle requise }\end{array}$ \\
\hline Implication & Élevée & Élevée \\
\hline Intégrité & Élevée & Élevée \\
\hline Aptitudes sociales & Élevées et crédibles & Élevées et crédibles \\
\hline Rôle (déontologique) & Neutre et indépendant & Neutre et indépendant \\
\hline
\end{tabular}

Source: Adapté de Klofsten et Öberg (2008).

Même si le mentorat repose également sur une relation personnelle, généralement entre un entrepreneur expérimenté (le mentor) et un entrepreneur ayant moins d'expérience (l'élève), le mentorat est considéré comme un soutien d'ordre plus général, qui porte surtout sur le développement personnel de l'entrepreneur, et non sur son entreprise. Le mentor conseille et oriente, sert de baromètre pour évaluer de nouvelles idées, stimule et encourage l'entrepreneur. Il fait donc plus office de moteur ou de guide que de formateur (St-Jean, 2012). Un des objectifs primordiaux du mentorat est de renforcer la résilience de l'entrepreneur en lui apportant du réconfort, en particulier dans les moments de doute (St-Jean et Audet, 2009).

Le coaching et le mentorat peuvent être considérés comme une forme de soutien consultatif qui peut varier en intensité, du conseil de base occasionnel au soutien pratique direct. Ces soutiens sont particulièrement bien adaptés aux entrepreneurs appartenant à des groupes sous-représentés et défavorisés, car ils ont plus tendance à manquer de certaines compétences entrepreneuriales et de réseaux professionnels que les autres groupes d'entrepreneurs (OCDE/CE, 2013).

Il existe deux différences majeures entre le mentorat et le coaching. Premièrement, le coaching a tendance à se concentrer davantage sur des problèmes spécifiques de développement de l'entreprise que le mentorat. C'est pourquoi la nature et le contenu du soutien qu'offre le coaching sont fondamentalement différents. Les objectifs sont nettement plus concrets et le coach a la charge de concevoir une stratégie personnalisée pour aider l'élève à atteindre ses objectifs. Celle-ci peut comporter des exercices et des travaux pratiques. 
La seconde différence importante tient au fait que le coaching est plus susceptible d'être intégré à d'autres formes d'aide au développement des entreprises (par exemple, aides financières ou prêts). L'aide financière est souvent conditionnée au suivi d'un coaching..

\section{Avantages du mentorat et du coaching}

- Le coaching et le mentorat encouragent l'apprentissage pratique et la capacité d'acquisition des connaissances chez les entrepreneurs.

- Ils contribuent également à renforcer leur confiance, leur motivation et les aident à acquérir un ensemble de compétences entrepreneuriales.

- Ils vont même jusqu'à améliorer l'accès aux ressources (financement, par exemple) ainsi qu'aux fournisseurs et aux clients.

- Ces avantages sont susceptibles d'avoir une incidence sur la création et la survie des entreprises, le chiffre d'affaires et la création d'emplois.

Lorsqu'ils sont confrontés à un problème au sein de leur entreprise, les entrepreneurs et travailleurs indépendants demandent souvent conseils à leurs pairs et à des collègues dignes de confiance. Cette source de conseils informelle est importante et existera toujours, mais les programmes formels de coaching et de mentorat peuvent élargir les compétences des entrepreneurs et leur offrir une approche plus structurée qui anticipe leurs besoins (une approche plus proactive que réactive) et améliorer ainsi la qualité des conseils fournis.

Le coaching et le mentorat par les pairs peuvent être très efficaces dans l'apprentissage pratique des entrepreneurs. Cet apprentissage informel passe par la résolution quotidienne des problèmes de l'entreprise plutôt que par le biais d'une formation formelle (par exemple, ateliers et séminaires). Il est généralement admis et reconnu que l'apprentissage informel est plus important que l'apprentissage formel dans le processus de formation des entrepreneurs (Rae et Carswell, 2001; Corbett, 2005; Cope, 2005). Ils jouent donc un rôle très important en aidant les entrepreneurs à acquérir un savoir-faire dans le cadre de leurs activités quotidiennes avec l'aide de coaches et de mentors dignes de confiance (Vygotsky, 1978).

Le mentorat et le coaching peuvent également renforcer la capacité des entrepreneurs à absorber des connaissances, c'est-à-dire à les acquérir, les assimiler, les transformer et les exploiter (Newey et Zahra, 2009). Les mentors et les coaches peuvent notamment les aider à comprendre quand et comment réagir par rapport aux informations et aux connaissances en leur possession, et ainsi renforcer leur apprentissage de l'entrepreneuriat. Concrètement, il s'agit d'aider l'entrepreneur bénéficiaire à gérer les problèmes de son entreprise et à comprendre les enseignements et les opportunités qui en découlent.

Il est plus difficile de trouver des coaches et mentors compétents et dignes de confiance pour les entrepreneurs appartenant à des groupes défavorisés et sous-représentés que pour les entrepreneurs traditionnels, car ils possèdent des réseaux plus restreints, ils font davantage l'objet de discriminations et ont moins confiance en eux (Vickers et al., 2009). Les initiatives de mentorat et de coaching jouent donc un rôle particulièrement important en aidant les entrepreneurs appartenant à des groupes sousreprésentés et défavorisés à surmonter les principales difficultés auxquelles ils sont confrontés, à renforcer leur confiance en eux, leur donner envie de créer et d'exploiter une entreprise pérenne, à développer leurs réseaux et à gérer une entreprise. Ces avantages peuvent être en grande partie perçus comme un épanouissement personnel des entrepreneurs établis et potentiels.

Les autres avantages concernent l'entreprise qu'ils dirigent: meilleur accès aux ressources, meilleur positionnement concurrentiel, performances accrues de l'entreprise, meilleure gestion des ressources humaines, etc. Plusieurs études ont identifié les nombreux avantages des interventions de coaching et de mentorat destinées aux entrepreneurs appartenant à des groupes sous-représentés et défavorisés. Ils sont résumés dans le tableau 8.2. 


\section{Tableau 8.2. Résumé des avantages des services de coaching et de mentorat} destinés aux entrepreneurs sous-représentés et défavorisés

\begin{tabular}{ll}
\hline Avantages pour l'entrepreneur & Avantages pour l'entreprise \\
\hline $\begin{array}{l}\text { Confiance en soi accrue } \\
\text { Plus grande capacité d'adaptation }\end{array}$ & $\begin{array}{l}\text { Meilleur accès aux ressources (par exemple, financement, conseils) } \\
\text { Meilleures opportunités d'apprentissage }\end{array}$ \\
$\begin{array}{l}\text { Durabilité et performances accrues de l'entreprise (par exemple, chiffre } \\
\text { d'affaires, rentabilité et emploi) }\end{array}$ \\
$\begin{array}{l}\text { Acquisition de nouvelles compétences } \\
\text { Meilleure aptitude à gérer l'entreprise }\end{array}$ \\
Définition et réalisation des objectifs \\
Motivation accrue
\end{tabular}

Source: CREME (2013); St-Jean et Audet, (2009); Shahidi (2012).

\section{Approches politiques du coaching et du mentorat pour les entrepreneurs appartenant à des groupes sous-représentés et défavorisés}

- Le mentorat est l'une des formes de soutien les plus fréquemment proposées aux entrepreneurs issus de groupes sous-représentés et défavorisés. Il est souvent dispensé en partenariat avec des chambres de commerce, des organisations non gouvernementales ou des entreprises locales.

- Les programmes de coaching sont plus formels et plus intensifs. Généralement, les coaches évaluent les besoins ou réalisent un diagnostic de l'entreprise et organisent des discussions formelles pour répondre à ces besoins.

- Les programmes de mentorat et de coaching font souvent appel à des mentors bénévoles. L'identification, la sélection et la préparation des mentors et des coaches ainsi que le processus formel d'appariement des entrepreneurs font partie des aspects essentiels des programmes de coaching.

- Le coaching et le mentorat par les pairs ont démontré une certaine efficacité. Les responsables politiques peuvent s'appuyer sur le soutien par les pairs et sur la relation de confiance instaurée pour rendre les aides destinées aux entrepreneurs appartenant à des groupes sous-représentés et défavorisés plus attractives.

- L'utilisation de moyens de communication en ligne (par exemple, visioconférences et messagerie instantanée) permet d'accroître la portée du coaching et du mentorat, en particulier dans les zones rurales.

- Il est également indispensable de fournir une formation aux coaches et mentors pour garantir un service de qualité. Même si les mentors et les coaches font preuve d'un niveau de compétences entrepreneuriales élevé, ils peuvent avoir besoin d'une formation pour mieux communiquer et comprendre les difficultés spécifiques aux entrepreneurs appartenant à des groupes sousreprésentés et défavorisés.

\section{Programmes de mentorat}

Même si le coaching et le mentorat sont étroitement liés, les politiques publiques actuelles de l'Union européenne reposent davantage sur le mentorat que sur le coaching. Ce choix semble lié en grande partie aux frais réduits de mise en place et de gestion des programmes de mentorat, qui ont tendance à être moins structurés et intensifs que les programmes de coaching.

Les programmes de mentorat de l'Union européenne destinés aux entrepreneurs appartenant à des groupes sous-représentés et défavorisés sont souvent mis en œuvre par des mentors bénévoles, qui sont des entrepreneurs recrutés au sein de la communauté locale 
ou des cadres supérieurs dans le secteur des services financiers et professionnels, comme la comptabilité et la banque. Le succès de cette approche dépend toutefois de la disponibilité en nombre suffisant d'anciens entrepreneurs ou d'entrepreneurs établis et expérimentés qui disposent de l'expérience et des compétences nécessaires pour constituer une équipe de sélection et/ou de formation des mentors.

Les mentors sont généralement assignés aux bénéficiaires selon un mécanisme formel d'appariement. Celui-ci a pour but de faciliter le premier contact entre les mentors et les élèves, mais le déroulement et la fréquence des rencontres ultérieures sont laissés au libre choix des deux parties. Ce fonctionnement, assez flexible, permet de répondre au mieux à la diversité des besoins des différents entrepreneurs. Les rencontres sont souvent organisées en face à face, mais elles peuvent également prendre la forme de table ronde réunissant plusieurs duos de mentors et élèves. Cette solution peut permettre aux mentors d'économiser leur temps et d'utiliser efficacement les ressources, notamment s'ils sont gérants d'une entreprise établie et ne peuvent pas consacrer beaucoup de temps à plusieurs relations individualisées. Cette flexibilité peut inciter les mentors à participer à ces programmes. Le projet irlandais «Going for Growth", qui recrute comme mentors bénévoles des dirigeants d'entreprises prospères, est un bon exemple de mentorat de groupe. Les mentors de ce projet organisent des séances collectives mensuelles au cours desquelles les femmes peuvent partager leurs expériences et discuter de leurs difficultés communes.

Les rencontres entre les mentors et les élèves ont généralement lieu en face à face. Quelques programmes organisent toutefois des rencontres virtuelles via internet. (La question du coaching et du mentorat en ligne est traitée en détail plus loin dans ce chapitre.) Les interactions évoluent au fur et à mesure que la relation s'approfondit entre le mentor et l'élève. Les échanges peuvent avoir lieu par courrier électronique et téléphone et les mentors peuvent informer ou orienter leurs élèves sans avoir à les rencontrer physiquement. Si la relation débute donc généralement par une rencontre physique en face à face, les supports de communication et de contact peuvent évoluer au fil du temps en fonction des besoins respectifs des mentors et de leurs élèves.

Les relations du mentorat sont définies formellement lors des premières phases afin de s'assurer que le mentor et l'élève nourrissent des attentes compatibles. Les deux parties de ce duo précisent souvent leurs objectifs et leurs responsabilités par écrit. Les attentes des deux parties peuvent être stipulées dans le cadre d'un contrat précisant les obligations de l'entrepreneur et du mentor. Ce processus peut également inclure une évaluation formelle des besoins en compétences pour faciliter la définition des objectifs de cette relation. Cette approche est celle adoptée par le programme 45+ en France (encadré 8.1).

Le mentorat est souvent mis en œuvre en partenariat avec les chambres de commerce ou d'autres organisations non gouvernementales locales. Cette approche permet d'accroître la portée auprès des groupes d'entrepreneurs sous-représentés et défavorisés en tirant profit des relations de confiance qu'ils ont tissées avec la communauté locale. Par exemple, l'Unioncamere Piemonte, la chambre de commerce de la région italienne du Piémont, organise un programme de mentorat et de formation pour les femmes entrepreneurs dans le cadre d'un mémorandum d'entente avec le ministère de l'industrie. Malgré sa portée restreinte, ce programme est utile aux mentors comme aux élèves et devrait être étendu à d'autres régions (Regione Piemonte, 2010). 


\section{Encadré 8.1. Programme 45+, France}

Description: le programme 45+ a pour objectif de promouvoir et de faciliter la création d'entreprises par des personnes de plus de 45 ans qui sont retraitées, proches de l'âge de la retraite ou sans emploi. Ce projet a été lancé par Initiative France et AG2R La Mondiale. Il propose plusieurs types de soutien dans le cadre d'un programme intégré, notamment des formations, des services de mentorat, une aide à l'élaboration du plan d'affaires et des aides à la création d'entreprise.

Problème abordé: nombre de seniors, y compris ceux à la retraite ou proches de l'âge de la retraite, sont très qualifiés, compétents et disposent des ressources financières (épargne) requises pour créer et gérer une entreprise, mais les compétences et l'expérience entrepreneuriales leur font défaut. C'est pourquoi les banques et les organisations de soutien aux entreprises dissuadent souvent les seniors de mettre leur projet d'entreprise à exécution alors qu'ils auraient le potentiel nécessaire s'ils n'avaient pas ces lacunes.

En France, le taux de participation des plus de 50 ans au marché du travail (35\%) est assez faible par rapport aux autres pays de l'Union européenne (Eurostat, Enquête sur les forces de travail, 2013). La création d'entreprises est considérée comme l'un des moyens de les réintégrer sur le marché du travail. Selon l'Agence pour la création d'entreprises (APCE), 17 \% des personnes âgées de plus de 50 ans envisagent la création de leur entreprise comme une phase de transition entre le salariat et la retraite. De plus, des enquêtes de l'APCE montrent que $64 \%$ des plus de 50 ans considèrent le travail indépendant comme un bon moyen de compléter leur retraite. Ces enquêtes révèlent également que les seniors demandent de l'aide pour surmonter les obstacles à la création d'entreprises, notamment le manque de capital de démarrage et la complexité de formalités administratives.

Approche: ce programme offre une combinaison de mesures d'aide adaptées aux besoins de chaque participant. Le processus commence par une évaluation des compétences personnelles, suivie d'une évaluation des biens financiers personnels (par exemple, revenus, immobilier, polices d'assurance) et des besoins. Ce programme propose également des ateliers de créativité pour aider les participants à développer leur idée d'entreprise et à approfondir leur plan d'affaires. Une formation personnalisée leur est ensuite proposée pour combler le manque de compétences et de connaissances de chaque participant. Durant la phase de création de l'entreprise, l'entrepreneur peut avoir accès à des ordinateurs et participer à des séminaires sur les nouvelles technologies. De plus, dès l'entreprise créée, des cours de perfectionnement ou de remise à niveau en gestion des ressources humaines, comptabilité et financement d'entreprise sont proposés. Le mentorat est également l'un des éléments clés de ce programme. Il doit notamment aider les nouveaux entrepreneurs à utiliser efficacement les aides financières mises à leur disposition dans le cadre de ce programme.

Impact: ce programme a été lancé en septembre 2013 dans le but de mener à bien quatre projets pilotes avant la fin de l'année 2014. Des données seront collectées sur son efficacité afin de définir la future orientation du programme.

Facteurs de réussite: la participation d'une institution financière, AG2R, est un élément essentiel de la réussite de ce programme. Elle apporte aux projets de création d'entreprises le soutien financier permettant de compléter le mentorat. La société AG2R s'est engagée avec force dans ce programme, car la responsabilité sociale fait partie de sa stratégie d'entreprise. 
Un autre exemple est celui du Centre Ergani dans le nord de la Grèce. Créé en 1991, il a pour objectif de lutter contre l'exclusion des femmes du marché du travail, notamment par le biais du travail indépendant. Ce centre propose un programme de mentorat aux femmes qui souhaitent créer leur entreprise, notamment des coopératives sociales. Les mentors sont des entrepreneurs bénévoles expérimentés qui souhaitent aider les élèves dans leur développement personnel. Le programme de mentorat du centre s'organise en six étapes: la publication du programme; la sélection, la préparation et la formation des mentors; la sélection et la formation des élèves; l'appariement des mentors et des élèves; l'approfondissement de la relation; et l'évaluation et la diffusion des résultats du projet.

Il existe également plusieurs exemples de mentorat d'entreprises qui soutiennent les entrepreneurs. En Italie, un programme lancé par ENEL fait appel à des cadres expérimentés de grandes entreprises privées et du secteur public dans les régions de Latium, de Sardaigne, du Piémont et des Pouilles pour aider les femmes à renforcer leurs compétences en gestion d'entreprise. Un autre exemple de mentorat d'entreprises est celui mis en œuvre par la Lloyds Bank au Royaume-Uni, qui propose un programme de mentorat aux entrepreneurs, notamment ceux issus de minorités ethniques, en partenariat avec le réseau Enterprise and Diversity Alliance.

Enfin, il existe plusieurs exemples de réseaux paneuropéens de mentors comme l'European Network of Mentors for Women Entrepreneurs (Réseau européen de mentors pour femmes entrepreneurs). Ce réseau a pour objectif de mettre en relation des mentors avec des femmes entrepreneurs par le biais de points de contacts nationaux (Commission européenne, 2014, http://ec.europa.eu/growth/smes/promoting-entrepreneurship/we-work-for/women/support-networks/ index_en.htm).

Les données concernant l'efficacité des programmes de mentorat sur les résultats obtenus auprès des entrepreneurs doivent être interprétées avec prudence. En effet, l'impact du mentorat par rapport aux autres formes d'aide proposées est difficile à isoler. Il est également souvent subjectif et compliqué à mesurer, étant donné que les résultats incluent ou concernent des changements comportementaux. De plus, des difficultés méthodologiques, notamment dans la sélection des échantillons, ne permettent pas de comparer les différences de performances et/ ou de participation. Néanmoins, des données suggèrent que les programmes de mentorat, s'ils sont conçus soigneusement, peuvent être des interventions efficaces.

Il est prouvé que les mentors sont efficaces dans différents contextes professionnels, en particulier auprès des groupes confrontés à des difficultés sur le marché du travail, comme les jeunes, les femmes et les personnes issues des minorités ethniques (Clutterbuck et Ragins, 2002; St-Jean, 2010). Dans le cadre de la création d'entreprises et du travail indépendant, un tel corpus de données est inexistant. Toutefois, des exemples de programmes à succès ayant eu un impact positif sur les participants sont disponibles. Dans la plupart des cas, les bénéfices du programme de mentorat se manifestent lors des premières phases de développement de l'entreprise.

En ce qui concerne les jeunes, des données attestent de l'efficacité du projet de mentorat du Prince's Trust Youth Business Scotland (PTYBS). Le mentorat n'est que l'un des éléments de ce programme intégré qui propose également une aide financière aux entrepreneurs âgés de moins de 30 ans. Des évaluations indiquent que ce projet a contribué à la création de 155 start-up qui n'auraient pas vu le jour autrement et facilité la création ou le développement de 416 autres jeunes entreprises (DTZ, 2007). Même si l'impact du mentorat est difficile à isoler, on estime qu'il a joué un rôle important dans ces résultats.

Les mentors ont également eu un rôle précieux dans le processus d'apprentissage de l'entrepreneuriat des femmes (Sullivan, 2000; St-Jean, 2010). Certaines études de cas montrent que le mentorat permet aux femmes de prendre plus de recul par rapport à leur projet d'entreprise pour la prise de décisions et d'avoir accès à des réseaux professionnels, notamment à des investisseurs (Ncube et Washburn, 2010). De plus, il a été montré que le manque de mentors 
pour les femmes peut inhiber leur développement (Carsrud et al., 1987). Le mentorat de groupe par les pairs est également efficace, mais moins que le mentorat individuel (Davis, 2011).

Le mentorat a prouvé son utilité auprès des entrepreneurs issus de minorités ethniques. Des données provenant d'Italie indiquent que des entrepreneurs issus de minorités ethniques ont pu renforcer leurs liens avec les réseaux locaux (Fondazione Sussidiarietà, 2014). En France, des données suggèrent que le soutien apporté par les mentors et les conseillers en entreprise doit être adapté aux besoins en fonction du modèle entrepreneurial, mais que le mentorat peut favoriser l'intégration des entrepreneurs immigrés dans la société (Tisserant, 2003).

Les données mentionnées ci-dessus et d'autres études dans ce domaine ont permis d'identifier plusieurs facteurs clés de réussite du mentorat:

- La relation de mentorat est fondée sur une participation à double sens. Les élèves doivent participer activement et être francs avec leur mentor (St-Jean, 2012).

- Le niveau d'implication de l'élève est un facteur de réussite crucial. Des recherches montrent que l'implication et la volonté d'évoluer de l'élève jouent un rôle considérable sur le résultat de la relation (Audet et Couteret, 2012).

- En outre, même si le temps qu'il peut consacrer au mentorat est limité, le mentor doit s'investir dans la relation pour que les objectifs puissent être atteints (Sullivan, 2000).

- Le processus d'appariement entre le mentor et l'élève est crucial pour que la relation soit fructueuse. Il est important que le mentor puisse répondre aux besoins de l'élève et que le niveau d'interactions corresponde aux attentes des deux parties. Le mentor peut être tenté de trop intervenir et entraver alors le processus d'apprentissage de l'élève.

- Un mentorat efficace repose sur une confiance mutuelle (St-Jean, 2012). Un manque de confiance peut limiter les résultats du dispositif.

- Dans certaines circonstances, une relation de dépendance peut s'instaurer si le mentor s'implique trop dans les activités de l'élève et nuire à l'autonomie que celui-ci doit acquérir (Cull, 2006). et

- L'accessibilité du mentor (c'est-à-dire le lieu de rencontre) a une incidence sur l'efficacité de la relation (Davis, 2011).

\section{Programmes de coaching}

Comme pour les programmes de mentorat, les coaches sont dans la plupart des cas des entrepreneurs bénévoles qui ont une expérience du travail indépendant. L’identification, la sélection et la préparation des coaches font partie des aspects stratégiques des programmes de coaching. Les programmes de coaching visent alors à faciliter la mise en relation entre les coaches et les bénéficiaires et à offrir un cadre à cette relation. Généralement, les besoins des élèves sont évalués pour identifier les domaines d'action. Comme pour le mentorat, le coaching définit des objectifs et prévoit le déroulement de la relation. La fréquence des rencontres, généralement des rencontres en face à face, est déterminée par le coach et l'élève. Un exemple de programme allemand de coaching destiné aux personnes handicapées est présenté à l'encadré 8.2. D'autres exemples sont disponibles dans les notes de pays consacrées à la Croatie, à Chypre et au Luxembourg à la partie III de cet ouvrage. 


\section{Encadré 8.2. EnterAbility, Allemagne}

Description: EnterAbility est un projet qui promeut l'insertion des personnes handicapées sur le marché du travail par le biais du travail indépendant. Il informe sur la création d'entreprises et propose des services de coaching, de mentorat, de conseil en entreprise et d'orientation vers d'autres services d'aide au développement des entreprises. Il est mis en œuvre par iq Consult en coopération avec Aktion Mensch.

Problème abordé: du fait de leur handicap et des discriminations des employeurs, les personnes handicapées doivent faire face à de nombreuses difficultés pour s'insérer sur le marché du travail. Le travail indépendant constitue donc une voie alternative pour intégrer un emploi, car il offre à l'entrepreneur la possibilité d'avoir la maîtrise de son temps et de ses conditions de travail.

Approche: les personnes handicapées qui sont au chômage ou qui risquent de perdre leur emploi remplissent les conditions de participation à ce programme d'aide. Les candidats doivent avoir un projet d'entreprise précis qu'ils développeront avec les conseillers du programme afin d'améliorer sa viabilité. Un coaching est proposé pour aider l'entrepreneur pendant et après le démarrage de son entreprise. Le programme comporte également une offre d'outils ou de services d'aide aux personnes handicapées pour les aider à acquérir le capital d'investissement.

Le budget de ce programme pour la période de 2004 à 2008 était de 1046775 euros. Sur ce total, 730384 euros provenaient de fonds publics, 71000 euros d'iq Consult, 163787 euros de l'association des personnes handicapées et 81604 euros d'autres fondations.

Impact: 420 personnes ont bénéficié d'une aide pour développer leur idée d'entreprise et 109 ont créé leur entreprise. Sur les 109 entreprises créées, 79 \% étaient toujours en activité à la fin de 2008, 35 \% ont survécu au moins trois ans et 61 \% au moins deux ans. Outre leur propre emploi, ces entrepreneurs ont permis de créer six postes à plein temps, cinq postes à temps partiel, trois petits emplois et un contrat de travail pour sept autres personnes. En moyenne, ces entreprises enregistrent un revenu mensuel de 923 euros. Même si les enquêtes de suivi indiquent que $33 \%$ des entreprises auraient été créées sans l'intervention de ce programme, il est estimé que chaque euro investi a permis de générer un rendement social de 3,9 euros.

Facteurs de réussite: ce projet compte trois facteurs de réussite. Premièrement, la qualité et le dévouement du personnel et des coaches qui apportent leur aide aux entreprises, mais également un soutien personnel et moral. Deuxièmement, une relation de collaboration étroite entre les pouvoirs publics et les partenaires du projet, qui ont élaboré ensemble des interventions ciblées de soutien. Enfin, un objectif clairement défini, un groupe cible et une zone d'intervention suffisamment étendue pour atteindre un nombre suffisant de participants potentiels.

Les programmes de coaching peuvent également être adaptés en fonction des préférences des groupes sociaux ciblés. Par exemple, des données provenant d'Allemagne montrent que les seniors préfèrent une relation de coaching plus formelle que les jeunes (Nietschke, 2010). Les seniors attendent de leur coaches qu'ils soient ponctuels, professionnels, sensibles à leurs perceptions des risques et capables de leur fournir des informations détaillées, tandis que les jeunes entrepreneurs voient cette relation de façon plus décontractée (Nietschke, 2010). D'autres données mettent en évidence une préférence marquée chez les femmes immigrées pour un coach qui maîtrise leur langue maternelle (Wagner, 2011).

Des recherches en Allemagne montrent que le coaching peut être utile aux nouveaux entrepreneurs sortant d'une période de chômage. Comparés aux personnes n'ayant pas participé, les bénéficiaires du programme Gründercoaching étaient nettement plus susceptibles de continuer à exercer leur activité indépendante 24 mois (+ $6 \%$ ) et 46 mois (+ $4 \%$ ) après l'immatriculation de leur entreprise (Caliendo et al., 2014). Au fil du temps, la taille de l'entreprise et leurs recettes ont également augmenté plus fortement au sein du groupe de bénéficiaires. Les femmes ayant participé à ce programme ont été nettement plus satisfaites de leur vie et de leur situation 
professionnelle que les femmes n'en ayant pas bénéficié. Cette observation n'est en revanche pas valable pour les hommes. Le coaching a toutefois été plus efficace auprès des jeunes que des seniors. De plus, le coaching ne semble pas avoir eu d'effets notables sur les entrepreneurs immigrés.

Les facteurs de réussite du coaching sont presque identiques à ceux identifiés dans la partie précédente pour le mentorat. Les bénéficiaires doivent être activement impliqués dans la relation, être ouverts aux suggestions et aux changements. La relation de confiance entre le coach et l'élève est particulièrement importante pour les entrepreneurs appartenant à des groupes défavorisés. Les élèves doivent également avoir envie d'utiliser cette aide et être ouverts au changement (Audet et Couteret, 2012).

\section{Coaching et mentorat par les pairs}

Le coaching et le mentorat par les pairs reposent davantage sur une relation de soutien entre pairs que sur une relation entre entrepreneurs novices et expérimentés. Le coaching et le mentorat par les pairs présentent notamment l'avantage de gagner plus facilement la confiance des entrepreneurs appartenant à des groupes sous-représentés et défavorisés. Les bénéficiaires ont en effet plus tendance à considérer que leurs pairs comprennent leurs besoins et savent y répondre. Ils sont donc plus susceptibles d'accepter de participer à des programmes de soutien par les pairs. Cet aspect revêt une importance particulière pour les groupes sous-représentés et défavorisés comme les entrepreneurs immigrés et issus de minorité ethnique dont le taux de participation aux programmes d'aide publics est faible (Ram et Smallbone, 2003). Même s'ils offrent peut-être moins de conseils basés sur une expérience entrepreneuriale bien établie, le coaching et le mentorat par les pairs comportent de nombreux avantages, comme l'accès à des solutions innovantes, une multiplicité de points de vue sur une question, la construction d'un capital social et un soutien moral (Kutzhanova et al., 2009).

Le 12/8 Group au Royaume-Uni constitue un bon exemple de programme de mentorat par les pairs (encadré 8.3). La viabilité de ce modèle repose sur le degré élevé d'engagement et de motivation de ses membres. Les organismes du secteur public n'interviennent pas toujours directement, mais peuvent les encourager et leur apporter l'appui initial qui leur permettra de se développer.

Des données indiquent que le coaching et le mentorat par les pairs peuvent être efficaces pour les travailleurs indépendants, en particulier les femmes et les groupes minoritaires (par exemple, Ensher et Murphy, 1997). Le coaching par les pairs peut également être efficace chez les entrepreneurs seniors. Les seniors qui souhaitent créer leur entreprise ont souvent des relations difficiles avec leurs coaches, car ces derniers ne comprennent pas la réalité des seniors. Le coaching par les pairs peut contribuer à éviter cette situation, car de nombreux seniors ont une grande expérience de l'entrepreneuriat à proposer et une bonne compréhension des problèmes des autres seniors 


\section{Encadré 8.3. 12/8 Group, Royaume-Uni}

Description: le 12/8 Group est une initiative de mentorat d'entreprises par les pairs gérée par et pour des entreprises afrocaribéennes dans la région britannique des West Midlands.

Problème abordé: il vise à encourager non seulement le développement des entreprises déjà présentes dans le réseau de mentorat, mais aussi celui des personnes qui cherchent à créer leur propre entreprise et à développer leur communauté locale.

Approche: tirant son nom de la date de sa création, le 12 août 2004, le 12/8 Group est une initiative de mentorat d'entreprises par les pairs. Il a débuté avec six entrepreneurs d'origine afrocaribéenne orientés vers la croissance, qui se sont entraidés en vue d'élaborer leur plan d'affaires et de contribuer à l'économie locale de leur communauté. À partir de 2009, le programme a également fait appel à des mentors issus de grandes entreprises du secteur privé. Les membres se réunissent tous les mois pour définir des objectifs professionnels, personnels et communautaires et passer en revue les progrès accomplis (CREME, 2013).

Impact: un rapport d'étude de cas a mis en évidence les avantages suivants pour les entrepreneurs et leur entreprise:

- meilleure stratégie de pénétration de nouveaux marchés;

- confiance accrue pour le développement de nouveaux produits et la conquête de nouveaux marchés;

- davantage d'échanges commerciaux entre les membres;

- acquisition de nouvelles compétences;

- meilleure connaissance des sources de financement.

En outre, les membres du 12/8 Group ont participé à de nouveaux projets avec leur communauté locale. Ils ont notamment soutenu de nouvelles entreprises et collaboré avec des jeunes vulnérables (CREME, 2012). Certains membres ont également endossé le rôle de mentor personnel de nouveaux entrepreneurs.

Facteurs de réussite: ce projet relativement peu coûteux repose essentiellement sur des mentors bénévoles et la responsabilité sociale des entreprises locales. Il a collaboré notamment avec une grande entreprise de la région dont il a pu utiliser les ressources.

Les autres facteurs de réussite de cette initiative sont le niveau élevé de confiance et de respect entre les membres; l'absence de contrainte de temps, qui permet d'instaurer une vraie relation de confiance; une forte motivation des membres; l'appropriation de l'initiative par les participants; une présidence tournante; et une implication constante dans l'examen des réalisations (CREME, 2013).

Pour en savoir plus, veuillez consulter: Enterprise \& Diversity Alliance (EDA) (2012), «Effective Business Mentoring and CSR: Promoting Growth and the Big Society, A Case Study of the 12/8 Group", disponible à l'adresse suivante: http://mentorsme.co.uk/images/uploads2/Case_Study_Mentoring_-_Branded_u_2.pdf.

\section{Coaching et mentorat en ligne}

Le fondement du coaching et du mentorat réside dans la relation de confiance personnelle qui s'instaure avec l'élève. On pourrait penser qu'il est plus difficile d'instaurer (efficacement) ce type de relation en ligne. Or, une étude consacrée au potentiel du soutien en ligne des femmes entrepreneurs montre que les coaches/mentors et leurs élèves ont tiré des avantages de la relation en ligne (Fielden et Hunt, 2011). Ils ont pu notamment profiter d'un soutien moral et immatériel et d'une perception différente de la situation, qui a pu contribuer à la résolution de leurs problèmes (Fielden et Hunt, 2011). Le financement public de programmes en ligne devrait donc être envisagé. Cette aide pourrait consister à fournir une plateforme, élaborer des procédures opérationnelles, recruter des mentors, des coaches et des participants issus de groupes sous-représentés et défavorisés et veiller à la bonne conduite de toutes les parties. 
La simplicité des communications en ligne peut également être exploitée dans le cadre de programmes de coaching et de mentorat prévoyant des entretiens en face à face.

Le Mentor Eget Företag, en Suède est un exemple de programme (encadré 8.4) qui prévoit, entre autres, un soutien en ligne (mais qui ne fonctionne pas exclusivement en ligne).

\section{Encadré 8.4. Mentor Eget Företag, Suède}

Description: ce programme propose aux nouveaux entrepreneurs et aux personnes souhaitant créer une entreprise en Suède un accès en ligne gratuit à un mentor pendant une durée d'un an. Lancé en 2006, il a été élaboré et mis en œuvre par le NyföretagarCentrum, qui représente un réseau national d'agences d'aide aux entreprises de Suède.

Problème abordé: le programme propose un service de mentorat aux nouveaux entrepreneurs, qui ne seraient autrement pas en mesure d'en bénéficier. L'utilisation de services en ligne facilite l'accès des bénéficiaires ruraux et la communication entre le mentor et l'élève.

Approche: les mentors sont des bénévoles, qui ne perçoivent aucune rémunération. Pour être recrutés, ils doivent jouir d'une certaine réputation et être connus au sein de leur profession. Après avoir procédé aux entretiens, un responsable local met en relation les mentors et les élèves et veille à ce que leur collaboration soit effective. Le bénéficiaire est le moteur de la relation. C'est lui qui fait appel au mentor quand il a besoin de conseils. La seconde étape importante est la signature d'un contrat confirmant l'engagement des deux parties. Même si la relation se déroule en ligne, le mentor et le bénéficiaire peuvent se rencontrer au moins une fois par mois lors d'événements de mise en réseau d'une durée de deux heures.

Le programme a une portée nationale et ne cible pas spécialement les groupes défavorisés ou sous-représentés, mais son suivi concerne:

- le nombre de mentors/bénéficiaires du programme;

- le sexe, l'âge des bénéficiaires et la proportion de participants d'origine étrangère; et

- le secteur d'activité des élèves (commerce, services, industrie/artisanat).

Impact: le programme fait valoir que les mentors aident les entrepreneurs à créer plus rapidement leur entreprise et à améliorer leurs performances, notamment leur rentabilité. Selon l'Institute for Growth Policy Studies, le taux de survie des entreprises participantes est supérieur à celui des autres nouvelles entreprises.

Facteurs de réussite: les facteurs de réussite de ce programme reposent sur la procédure d'admission qui garantit un appariement pertinent entre le mentor et les élèves. La procédure structurée d'admission comprend un entretien avec tous les élèves et les mentors au cours duquel le responsable du programme fait connaissance avec les futurs participants. Cette procédure augmente les chances d'instaurer rapidement une relation de confiance productive.

Pour en savoir plus, veuillez consulter: Mentor Eget Företag (2014), http://www.mentoregetforetag.se

\section{Formation des coaches et des mentors}

Les mentors et les coaches sont généralement recrutés en raison de la réussite de leur entreprise. Ils disposent d'une expérience et de connaissances utiles, mais cela n'implique pas nécessairement qu'ils possèdent également les compétences communicationnelles et relationnelles qui leur permettront d'instaurer la relation d'empathie nécessaire avec l'élève (Cope et Watts, 2004). Il faut faire appel à divers styles de communication, notamment la persuasion et l'encouragement des entrepreneurs novices pour qu'ils développent leur projet et construisent leur identité entrepreneuriale (Lefebvre et Redien-Collot, 2013). De plus, en tant qu'entrepreneurs, ils sont habitués à disposer d'un degré élevé d'autonomie et de liberté dans leurs décisions et jugements. Toutefois, dans une relation de coaching ou de mentorat, le but est de laisser l'élève prendre les décisions tout en lui fournissant des informations et des conseils pertinents. 
Une autre difficulté à laquelle les mentors et les coaches peuvent être confrontés est la nécessité de faire preuve de compétences différentes pour soutenir les entrepreneurs en phase de démarrage et lors de phases ultérieures de développement. Le mentor peut endosser cinq rôles différents: coach, coordinateur, défenseur, superviseur et organisateur. Les exigences à son égard peuvent varier au fil du temps. Une autre difficulté consiste à identifier le moment opportun pour réduire l'intensité du soutien et encourager la prise d'indépendance (Cull, 2006).

Les coaches et mentors travaillant avec des entrepreneurs appartenant à des groupes défavorisés ou sous-représentés devront sûrement interagir différemment qu'avec les entrepreneurs traditionnels Par exemple, dans le cas d'entrepreneurs handicapés, il est important que le mentor ou le coach comprenne leur handicap (Wood et al., 2012). Le coach ou le mentor devra recevoir une formation s'il n'est pas issu du même milieu que l'élève.

Étant donné ces difficultés, les responsables politiques doivent prévoir au moins une formation de base pour les coaches et mentors dans le cadre des programmes publics d'aide. L'objectif est de sensibiliser les coaches et les mentors aux besoins des clients et de les aider à communiquer efficacement. Des données provenant de Grèce montrent que la formation des coaches et des mentors permet également de renforcer leur propre confiance en eux et dans leur capacité à aider d'autres entrepreneurs (Sarri, 2011). Des séances de formation et de préparation peuvent être prescrites durant la conception des programmes de mentorat et de coaching, mais une formation "juste à temps» des mentors est plus efficace qu'une formation obligatoire, car elle tient compte de la nature de l'apprentissage entrepreneurial (Sullivan, 2000). Il est donc nécessaire de garder à l'esprit que la formation des coaches et des mentors doit être flexible et ajustée dans le temps.

\section{Clés pour concevoir des programmes de coaching et de mentorat efficaces pour les entrepreneurs appartenant à des groupes sous-représentés et défavorisés}

- Une des clés du succès du coaching et du mentorat réside dans le bon appariement du mentor ou le coach et de l'élève. La plupart des services de coaching et de mentorat utilisent un mécanisme formel d'appariement qui tient compte des caractéristiques de la personne et de l'entreprise.

- La relation débute souvent par une rencontre en face à face, mais elle peut évoluer selon les besoins de chaque partie. Cette flexibilité renforce l'attrait de ce soutien aussi bien pour les coaches et les mentors que pour les élèves.

- Il est nécessaire de définir un ensemble d'objectifs dès le début et de suivre les progrès accomplis au regard de ces objectifs.

- Le coaching et le mentorat doivent avoir une durée déterminée. Cette limite dans le temps évite d'instaurer une relation de dépendance.

- Les coaches et les mentors doivent être formés et une procédure d'admission doit être adoptée. 
Une relation de coaching et de mentorat efficace doit généralement passer par les étapes clés suivantes: recherche de coaches et de mentors; préparation des coaches et des mentors; appariement des coaches et mentors avec les entrepreneurs établis et potentiels souhaitant recevoir une aide; définition des objectifs et procédures opérationnelles par les parties concernées; et prestation des services de soutien. Les études et la documentation montrent que plusieurs facteurs influencent la réussite du programme à chacune de ses étapes, comme suit:

\section{Recherche de mentors et de coaches}

- Constituer un vivier de mentors et de coaches potentiels capables de travailler avec des entrepreneurs appartenant à des groupes sous-représentés et défavorisés: Les organismes du secteur public jouent un rôle important en recrutant des mentors et des coaches, souvent bénévoles, pour créer une base de ressources pour l'étape suivante de l'appariement. La constitution d'un vivier de mentors et de coaches issus des mêmes groupes de population que les entrepreneurs ciblés présente des avantages. Une procédure de recrutement actif doit donc être mise en place au sein de ces groupes. Les coaches et mentors peuvent également être issus d'entreprises locales.

- Proposer une incitation financière aux mentors et aux coaches: des programmes proposent aux coaches et aux mentors une rémunération symbolique (Regione Piemonte et Unioncamere Piemonte, 2010), mais elle est rarement nécessaire. Nombre d'entrepreneurs ayant réussi sont enthousiastes à l'idée de partager leur expérience avec leur communauté, en particulier s'ils proviennent eux-mêmes d'un groupe sous-représenté ou défavorisé.

- Recruter des mentors et des coaches: les mentors et les coaches doivent être recrutés non seulement pour leur expérience et leurs compétences, mais aussi pour leur envie d'aider d'autres entrepreneurs, leur capacité à communiquer et leur volonté d'aider les entrepreneurs à prendre leurs propres décisions.

\section{Préparation des mentors et des coaches}

- Former les mentors et les coaches: les relations de coaching et de mentorat exigent des compétences et un savoir-faire spécifiques de la part du coach ou du mentor. Il doit notamment posséder des techniques de communication particulières et une capacité d'écoute et de partage des connaissances tout en sachant encourager l'indépendance et l'apprentissage du bénéficiaire (Clutterbuck, 2004). Les formations des coaches et des mentors sont généralement bien accueillies (Sarri, 2011).

- Prévoir une phase d'initiation pour l'entrepreneur: les entrepreneurs doivent s'engager à participer au programme et être ouverts au changement et au mentorat (Audet et Couteret, 2012). Les programmes efficaces comportent donc souvent une phase d'initiation pour s'assurer que le bénéficiaire est prêt à s'impliquer.

\section{Appariement des coaches et mentors avec les entrepreneurs désireux de recevoir une aide}

- Avoir recours à un processus d'appariement structuré: la plupart des programmes de coaching et de mentorat comportent un processus d'appariement structuré tenant compte des critères comme le secteur d'activité de l'entreprise soutenue, le sexe et l'origine ethnique des entrepreneurs soutenus, ou d'autres éléments comme le niveau de développement de l'entreprise. Le processus d'appariement ne garantit pas une relation fructueuse, mais permet de réduire les risques de relation conflictuelle. 


\section{Définition des objectifs et procédures}

- Définir des objectifs: la définition d'objectifs et de cibles dès le début de la relation de coaching et de mentorat (une fois le duo défini) présente l'avantage de fixer des attentes réalistes et d'éviter les déceptions (Sullivan, 2000). Les organismes du secteur public ou les exécutants peuvent souhaiter formaliser cette étape en signant un accord ou un contrat.

- Limiter la relation dans le temps: il est souhaitable de limiter le mentorat ou le coaching dans le temps, à un ou deux ans par exemple. Cette condition permet d'éviter une relation de dépendance entre le mentor ou le coach et l'entrepreneur bénéficiaire (Cull, 2006).

\section{Prestation des services de soutien}

- Créer des programmes ciblés pour les groupes défavorisés et sous-représentés: des données indiquent que les entrepreneurs appartenant à des groupes défavorisés et sous-représentés peuvent bénéficier de programmes ciblés et spécifiques. Le programme de mentorat destiné aux femmes mis en œuvre par le Centre Ergani démontre que les femmes entrepreneurs peuvent bénéficier de l'aide du secteur public dans le recrutement de mentors (Davis, 2011). De plus, les entrepreneurs issus de minorités ethniques sont plus susceptibles de participer à des programmes s'ils peuvent s'identifier à leurs mentors et coaches (CREME, 2013). Une assistance appropriée pourrait néanmoins leur être proposée dans le cadre des programmes nationaux traditionnels dès lors qu'ils prévoient un suivi de l'inclusion des différents groupes sociaux cibles tels que les femmes et les entrepreneurs appartenant à une minorité ethnique (ou immigrés) et des mesures pour remédier à ce manque de participation.

- Proposer un soutien en ligne: les rencontres en face à face avec les entrepreneurs bénéficiaires représentent une part importante des programmes de coaching et de mentorat. Grâce à sa structure et son rythme assez flexibles, le soutien en ligne peut toutefois offrir des opportunités de communication supplémentaires. En dehors de ces communications en ligne avec les mentors et coaches, diverses aides devraient être proposées en ligne (par exemple, plans d'affaires pro forma, sources d'information et de conseil, accès à des sources de financement et de conseil sur le marketing, la croissance, les réglementations commerciales et entrepreneuriales et autres services d'aide au développement des entreprises).

- Construire des communautés entrepreneuriales: ces programmes de mentorat et de coaching ont pour effet de créer des réseaux professionnels. Ces derniers sont la conséquence naturelle $\mathrm{du}$ processus de recrutement d'anciens entrepreneurs et d'entrepreneurs établis comme mentors et coaches. Cependant, ces réseaux peuvent se développer dans le temps à mesure que les bénéficiaires des programmes murissent, évoluent jusqu'à devenir eux-mêmes des membres à part entière du réseau. Les programmes de mentorat et de coaching contribuent donc, dans une certaine mesure, au développement de la communauté entrepreneuriale au sens large au sein des groupes sous-représentés et défavorisés. Il est également possible que les bénéficiaires de ces initiatives soient ensuite eux-mêmes recrutés en tant que coaches ou mentors.

- Suivre les progrès: il est utile d'organiser régulièrement des rencontres avec les participants du programme afin d'évaluer les progrès accomplis et l'efficacité des relations. 


\section{Encadré 8.5. Le mentorat et le coaching doivent-ils être gratuits?}

La plupart des exemples de programmes de mentorat et de coaching financés par des fonds publics font appel à des coaches et mentors bénévoles, ce qui permet de réduire les coûts de fonctionnement au minimum. Généralement, les seuls coûts sont ceux de fonctionnement, pour la formation des coaches et des mentors, la communication (par exemple, publicité et promotion) et le suivi (par exemple, enquêtes et évaluations). La plupart des programmes de coaching et de mentorat destinés aux entrepreneurs sous-représentés et défavorisés dans l'Union européenne sont gratuits pour les participants.

En revanche, hors de l'Union européenne, il existe des programmes qui facturent l'accès à leurs services aux participants. Par exemple, le programme de mentorat «New Zealand's Business Mentors» mis en œuvre en Nouvelle Zélande prévoit des frais d'inscription. Le programme néo-zélandais compte plus de 1900 mentors entrepreneurs bénévoles et a bénéficié à plus de 67000 entreprises néo-zélandaises depuis sa création, en 1991. Les entrepreneurs qui souhaitent participer au programme doivent s'acquitter de frais d'inscription de 150 dollars néo-zélandais (NZD) (environ 93 euros). Le service de mentorat est dispensé gratuitement après l'inscription, mais ce soutien est limité à deux ans. Les mentors sont recrutés par les agences régionales de développement économique, qui se chargent de les apparier avec des entrepreneurs et de leur fournir une formation formelle et une accréditation (Business Mentors New Zealand, 2014). De même, le réseau de mentorat Réseau $M$ au Canada demande aux participants de s'acquitter d'une cotisation annuelle peu élevée, qui leur donne accès au service de mentorat. Dans certains cas, il existe une dispense de frais d'adhésion (St-Jean, 2012).

Chaque approche comporte des avantages. Les services proposés gratuitement sont nettement plus attractifs pour les participants et peuvent garantir un taux élevé de participation. Cependant, il peut également être avantageux de proposer des services payants (à bas coût), même si les mentors sont bénévoles. L'acquittement de frais d'inscription ou d'adhésion annuelle permet de garantir l'implication de l'entrepreneur, qui est l'un des gages de réussite de ces services. Ces frais peuvent également permettre de réduire le coût des programmes financés par des fonds publics.

\section{Conclusions et recommandations politiques}

Le coaching et le mentorat peuvent contribuer efficacement à augmenter les chances de réussite des entrepreneurs appartenant à des groupes sous-représentés et défavorisés. Ils peuvent aider les entrepreneurs à se former, à prendre de meilleures décisions concernant l'expansion de leur entreprise, à développer leurs réseaux et à bénéficier d'un meilleur accès aux ressources et aux marchés. Les coaches et les mentors peuvent également participer plus activement aux réseaux entrepreneuriaux locaux.

Les avantages des interventions de mentorat et de coaching résident dans la capacité du coach ou du mentor à transmettre ses connaissances à l'entrepreneur bénéficiaire et, surtout, à lui donner les moyens d'optimiser son apprentissage. L'efficacité de ces interventions repose également sur une relation personnelle et dynamique qui doit mûrir et évoluer au fil du temps et qui impose des obligations aux deux parties. Les coaches et les mentors doivent être capables d'intervenir de façon compétente et opportune, tandis que les bénéficiaires doivent être ouverts au conseil et impliqués dans la relation. Les programmes de mentorat et de coaching soutenus par les pouvoirs publics doivent être conçus avec soin, en particulier concernant la sélection et le recrutement et la formation des coaches et des mentors et le processus d'appariement utilisé pour les associer à des bénéficiaires.

Un groupe d'entrepreneurs et de professionnels talentueux pouvant être recrutés comme coaches et mentors devrait également être constitué. Il convient de souligner à cet égard que les entrepreneurs établis ont souvent envie d'aider leur communauté d'entrepreneurs et que les entreprises locales peuvent également être un vivier important de coaches et de mentors. 
Il n'existe cependant pas toujours un groupe suffisant d'entrepreneurs établis capables de comprendre les problématiques des entrepreneurs appartenant à des groupes sous-représentés et défavorisés. Dans ces circonstances, la formation d'entrepreneurs ou d'autres professionnels traditionnels comme coaches et mentors peut parfois suffire à leur faire comprendre les grandes difficultés auxquelles ces bénéficiaires issus de groupes sous-représentés et défavorisés sont confrontés.

\section{Principales recommandations politiques}

- Prévoir une étape préparatoire ou une initiation pour les entrepreneurs bénéficiaires afin de les aider à définir des attentes réalistes et à comprendre l'importance de leur engagement dans la relation.

- Utiliser un processus d'appariement entre coaches/mentors et entrepreneurs fondé sur des critères clairement définis tels que le sexe, l'origine ethnique et le secteur d'activité.

- Limiter le coaching et le mentorat à une durée d'un à deux ans pour ne pas mettre en place une relation de dépendance entre le mentor et le bénéficiaire.

- S'assurer que les objectifs de la relation de mentorat ou de coaching sont clairement définis dès le début.

- Offrir un soutien complémentaire à la relation de mentorat et de coaching (par exemple, sources d'information en ligne).

- Fournir une formation aux mentors et coaches qui: i) comprend une composante psychosociale pour sensibiliser aux problèmes et défis spécifiques auxquels les entrepreneurs défavorisés et sous-représentés sont confrontés; et ii) contribue à améliorer leurs compétences en communication.

\section{Références}

Audet, J. et P. Couteret (2012), "Coaching the entrepreneur: features and success factors», Journal of Small Business and Enterprise Development, Vol. 19, n 3, p. 515-531.

Business Mentors New Zealand (2014), http://www.businessmentors.org.nz.

Caliendo, M., A. Kritikos, S. Künn, C. Loersch, H. Schröder et H. Schütz, (2014), «Evaluation der Programme Gründercoaching und Gründercoaching Deutschland - Gründungen aus der Arbeitslosigkeit», IZA Research Report $n^{\circ}$ 61, Potsdam.

Cancedda, A. (2008), Linee guida sulla leadership femminile nel mondo del lavoro, Febbraio.

Carsrud, A., C. Gaglio et K. Olm (1987), «Entrepreneurs-Mentors, Networks and Successful New Venture Development: An Exploratory Study", American Journal of Small Business, p. 13-18.

Clutterbuck, D. et B. Ragins (2002), Mentoring and Diversity: An International Perspective, Oxford, Butterworth-Heinemann.

Clutterbuck, D. (2004), «Everyone Needs a Mentor: Fostering talent in your organisation», London, Chartered Institute of Personnel and Development.

Commission européenne (2014), «Support networks for women», disponible à l'adresse: http://ec.europa. eu/growth/smes/promoting-entrepreneurship/we-work-for/women/support-networks/index_en.htm.

Cope, J. (2005), «Toward a dynamic learning perspective of entrepreneurship», Entrepreneurship Theory and Practice, Vol. 29, n 4, p. 373-98.

Cope, J. et G. Watts (2000), «Learning by doing -An exploration of experience, critical incidents and reflection in entrepreneurial learning", International Journal of Entrepreneurial Behaviour \& Research, Vol. 6, No, 3, pp 104-124.

Corbett, A. (2005), «Experiential learning within the process of opportunity identification and exploitation", Entrepreneurship Theory and Practice, Vol. 29, n 4, p. 473-492. 
CREME (Centre for Research in Ethnic Minority Entrepreneurship) (2013), «Enterprise Mentoring and Diversity: A Case Study of the joint approach of Lloyds Banking Group and the Enterprise and Diversity Alliance», Centre for Research in Ethnic Minority Entrepreneurship, Birmingham Business School, Birmingham, University of Birmingham.

Cull, J. (2006), «Mentoring Young Entrepreneurs: What leads to success?», International Journal of Evidence Based Coaching and Mentoring, Vol. 4, n 2, p. 8-18.

D’abate, C., E. Eddy et S. Tannenbaum (2003), «What's in a Name? A Literature-Based Approach to Understanding Mentoring, Coaching, and Other Constructs That Describe Developmental Interactions", Human Resource Development Review, Vol. 2, n 4, p. 360-384.

Davis, A. (2011), «Rural and urban women entrepreneurs: A comparison of service needs and delivery methods priorities", International Journal of Business Science and Applied Management, Vol. 6, $\mathrm{n}^{\circ} 2$, p. 1-16.

DTZ Consulting and Research (2007), «Prince's Scottish Youth Business Trust (PSYBT) Evaluation of Impact and Strategic Contribution", Revised Final Report, Scottish Enterprise, Glasgow.

Edgcomb, E. et E. Malm (2002), «Consulting, Coaching and Mentoring for Microentrepreneurs: Best Practice Guide», Vol. 4, Washington, USA.

Ensher, E. et S. Murphy (1997), «Effects of Race, Gender, Perceived Similarity, and Contact on Mentor Relationships» Journal of Vocational Behavior, Vol. 50, n³, p. 460-481.

Enterprise \& Diversity Alliance (EDA) (2012), «Effective Business Mentoring and CSR: Promoting Growth and the Big Society, A Case Study of the 12/8 Group", disponible à l'adresse suivante: http:// mentorsme.co.uk/images/uploads2/Case_Study_-_Mentoring_-_Branded_u_2.pdf.

Ergani Center (2014), http://ergani.gr/en/ergani/dsen.aspx, consulté le 22 août 2014.

Eurostat (2013), Emploi et chômage (Enquête sur les forces de travail), disponible sur: http://ec.europa. eu/eurostat/web/lfs/data.

Fielden, S. et C. Hunt (2011), «Online coaching: An alternative source of social support for female entrepreneurs during venture creation", International Small Business Journal, Vol. 29, n 4, p. 345-359.

Fondazione Sussidiarietà (2014), "Studio relativo all'imprenditorialità delle comunità immigrate e agli strumenti di supporto ai migranti per la creazione di impresa, report finale», OP.II.4FESR 2007-2013 CIG 0382556F2E, disponible à l'adresse suivante: http://www.retepariopportunita.it/Rete_ Pari_Opportunita/UserFiles/programmazione_2007_2013/reportFondSUSS.pdf.

Klofsten, M. et S. Öberg (2008), «Coaching versus mentoring: Are there any differences?», disponible à l'adresse suivante: http://www.inoverzum.eu/files/Tomaz_Cerne/coacing_us._mentoring.pdf.

Kutzhanova, N., T. S. Lyons et G. A. Lichtenstein (2009), «Skill-Based Development of Entrepreneurs and the Role of Personal and Peer Group Coaching in Enterprise Development», Economic Development Quarterly, Vol. 23, p. 193-210.

Lefebvre, M. et R. Redien-Collot (2013), «How to Do Things with Words': The Discursive Dimension of Experiential Learning in Entrepreneurial Mentoring Dyads», Journal of Small Business Management, Vol. 51, n³, p. 370-393.

Mentor Eget Företag (2014), http://www.mentoregetforetag.se.

Ncube, L. et M. Washburn (2010), «Strategic Collaboration and Mentoring Women Entrepreneurs: A case study", Academy of Entrepreneurship Journal, Vol. 16, n 1, p. 71-93.

Newey, L. et S. Zahra (2009), «The Evolving Firm: How Dynamic and Operating Capabilities Interact to Enable Entrepreneurship", British Journal of Management, Vol. 20, p. 81-100.

Nietschke, A. (2010), Ältere Gründerinnen und Gründer — Was zeichnet sie aus? Welche Unterstützung benötigen sie?, Düsseldorf: RKW Kompetenzzentrum.

OCDE/Commission européenne (2013), Pallier la pénurie d'entrepreneurs: politiques d'entrepreneuriat inclusif en Europe, Publications OCDE, Paris. 10.1787/9789264188167-fr..

Rae, D. et M. Carswell (2001), «Towards a conceptual understanding of entrepreneurial learning», Journal of Small Business and Enterprise Development, Vol. 8, n 2, p. 150-158.

Ram, M. et D. Smallbone (2003), «Policies to Support Ethnic Minority Enterprise:The English experience», Entrepreneurship and Regional Development, Vol. 15, n² 2, p. 151-166.

Regione Piemonte et Unioncamere Piemonte (2010), Piccole impresse, grandi imprenditrici '09, Regione Piemonte - Unioncamere Piemonte. 
Sarri, K. (2011), «Mentoring female entrepreneurs: a mentors' training intervention evaluation», Journal of European Industrial Training, Vol. 35, n 7, p. 721-741.

Shahidi, N. (2012), «Les jeunes entrepreneurs nécessitent-ils un accompagnement particulier? Le cas français", Journal of Small business and Entrepreneurship, Vol. 25, n 1, p. 57-74.

St-Jean, E. (2012), «Mentoring as professional development for novice entrepreneurs: maximizing the learning", International Journal of Training and Development, Vol. 16, n³ 3, p. 200-216.

St-Jean, E. (2010), «Les fonctions du mentor de l'entrepreneur novice» Revue de l'entrepreneuriat, Vol. 9, $\mathrm{n}^{\circ}$ 2, p. 34-55.

St-Jean, E. et J. Audet (2009), «The role of mentoring in the learning development of the novice entrepreneur», International Entrepreneurship Management Journal, Vol. 8, p. 119-140.

Sullivan, R. (2000), «Entrepreneurial Learning and Mentoring», International Journal of Entrepreneurial Behaviour and Research, Vol. 6, n 3, p. 160-175.

Tisserant, P. (2003), «L'entrepreneuriat immigré: contribution à l'étude de l'aide à la création d'entreprises par les personnes d'origine étrangère», document de travail, Laboratoire ETIC, université de Metz.

Vickers, I., F. Lyon et D. North (2009), «Removing Barriers to Enterprise through Targeted Support For Disadvantaged Groups», ISBE Conference, novembre, Liverpool.

Vygotsky, L. (1978), Mind and society: The development of higher psychological processes, Cambridge, MA, Princeton University Press.

Wagner, M. (2011), «Gründungen von Personen mit Migrationshintergrund: Implikationen von Enklaveneffekten für die Gründungsförderung», In: Block, J., H. Brockmann, K. Kohn, T. Staak, et K. Ullrich, Gründungsförderung in Theorie und Praxis, Frankfurt am Main: KfW Bankengruppe et Förderkreis Gründungs-Forschung e. V., p. 207-221.

Wood, G., M. Davidson et S. Fielden (2012), Minorities in Entrepreneurship: An International Review, Cheltenham, Edward Elgar. 
PARTIE III

\section{Profils des pays: exemples de politiques et données clés sur l'entrepreneuriat inclusif}

Ce chapitre présente une pratique politique instructive issue de chacun des 28 États membres de l'Union européenne et, pour chaque pays, un ensemble de graphiques qui mesurent des indicateurs clés en matière d'entrepreneuriat et de travail indépendant dans les groupes sous-représentés et défavorisés à l'aune des moyennes de l’Union européenne.

Note Turquie/Chypre:

1. Note en bas de page de la Turquie

Les informations figurant dans ce document qui font référence à " Chypre " concernent la partie méridionale de l'Ile. Il n'y a pas d'autorité unique représentant à la fois les Chypriotes turcs et grecs sur l'Ile. La Turquie reconnaît la République Turque de Chypre Nord (RTCN). Jusqu'à ce qu'une solution durable et équitable soit trouvée dans le cadre des Nations Unies, la Turquie maintiendra sa position sur la "question chypriote".

2. Note en bas de page de tous les États de l'Union européenne membres de l'OCDE et de l'Union européenne La République de Chypre est reconnue par tous les membres des Nations Unies sauf la Turquie. Les informations figurant dans ce document concernent la zone sous le contrôle effectif du gouvernement de la République de Chypre. 
$\mathrm{C}$ chapitre décrit brièvement des politiques instructives qui encouragent l'entrepreneuriat inclusif dans chaque État membre de l'Union européenne. Le tableau 9.1 les répertorie toutes. Les descriptions fournies visent à aider les décideurs nationaux, régionaux et locaux à réfléchir aux méthodes qui s'offrent à eux pour relever les difficultés communes rencontrées pour soutenir l'entrepreneuriat inclusif dans l'Union européenne. Chaque description donne un bref aperçu des activités principales de la mesure politique, ainsi que des informations sur ses incidences et des points à prendre en considération pour la bonne mise en œuvre de ce type d'intervention.

Toutes les descriptions des exemples instructifs sont assorties d'un même ensemble de données propres à chaque pays, qui mesurent des indicateurs clés à l'aune de la moyenne de l'Union européenne et dans le temps. Ces données contribuent à présenter l'ampleur du défi et son évolution récente. Les notes des pays comportent trois diagrammes présentant des indicateurs majeurs en termes d'économie et d'entrepreneuriat, pour replacer la mesure politique décrite dans son contexte.

Le diagramme A présente l'évolution du taux de chômage du pays et montre comment il varie entre les différents groupes sociaux. Ces taux sont donnés pour la période 2000-2013 afin d'illustrer l'évolution à moyen terme et l'impact de la crise économique mondiale.

Le diagramme B présente le taux de travail indépendant en 2013 pour différents groupes de population par rapport à la moyenne de l'Union européenne. Le taux de travail indépendant équivaut au ratio du nombre de personnes exerçant un travail indépendant par rapport au nombre total de personnes salariées dans chaque groupe cible.

Le diagramme $C$ illustre l'évolution et les tendances du taux de travail indépendant pour différents groupes de population entre 2000 et 2013. Il indique comment le niveau relatif de l'activité indépendante a évolué pour chaque groupe cible, y compris l'impact de la crise économique.

Deux autres tableaux sont fournis pour les États membres de l'Union européenne qui ont participé aux enquêtes sur la population adulte menées par le Global Entrepreneurship Monitor (GEM) pendant au moins un an entre 2009 et 2013. Ces pays sont: la Belgique, la République tchèque, le Danemark, l'Allemagne, l'Estonie, l'Irlande, la Grèce, l'Espagne, la France, la Croatie, l'Italie, la Lettonie, la Lituanie, le Luxembourg, la Hongrie, les Pays-Bas, l'Autriche, la Pologne, le Portugal, la Roumanie, la Slovénie, la Slovaquie, la Finlande, la Suède et le Royaume-Uni (EU-24).

Le diagramme $\mathrm{D}$ présente le taux d'activité entrepreneuriale totale à un stade précoce (TEA) pour la période 2009-2013 (combinés) par sexe et par âge pour chaque pays. Ces données sont mises en balance avec la moyenne des pays de l'Union européenne qui ont participé à l'enquête du GEM. Pour de plus amples informations sur les données du GEM et sur le taux de TEA, nous vous renvoyons au guide de lecture proposé au début de cet ouvrage.

Le diagramme E présente la proportion de personnes impliquées dans une activité entrepreneuriale à un stade précoce qui envisagent de créer plus de 19 emplois dans les cinq ans. Ces données sont présentées par sexe et par âge pour chaque pays à l'aune de la moyenne de l'Union européenne. Afin d'accroître la taille de l'échantillon, les données sont rassemblées (c'est-à-dire combinées) pour la période 2009-2013. 
Tableau 9.1. Inventaire des mesures politiques décrites

\begin{tabular}{|c|c|c|c|c|}
\hline Pays & Nom du programme & Approche & $\begin{array}{l}\text { Groupe cible couvert par le } \\
\text { programme }\end{array}$ & $\begin{array}{l}\text { Financement } \\
\text { de l'Union } \\
\text { européenne }\end{array}$ \\
\hline Autriche & Microcrédit (Mikrokredit) & Microcrédit & Chômeurs & \\
\hline Belgique & $\begin{array}{l}\text { Hazo vzw: soutenir les entrepreneurs handicapés et leur } \\
\text { entreprise }\end{array}$ & $\begin{array}{l}\text { Conseil, information, } \\
\text { représentation }\end{array}$ & Personnes handicapées & \\
\hline Bulgarie & Réseau d'aide au développement des entreprises & Recherche, formation, conseil & Jeunes & \\
\hline Croatie & $\begin{array}{l}\text { Activity and Creativity Through Ideas and Ventures = } \\
\text { Employment (ACTIVE) }\end{array}$ & Éducation, mentorat, concours & Jeunes & FSE \\
\hline Chypre & $\begin{array}{l}\text { Agrotoepixeirein: renforcer l'entrepreneuriat des jeunes et } \\
\text { des femmes dans les zones rurales }\end{array}$ & $\begin{array}{l}\text { Conseil, mentorat, information, } \\
\text { mise en réseau }\end{array}$ & Jeunes & Interreg \\
\hline République tchèque & $\begin{array}{l}\text { Aide au travail indépendant des personnes souffrant de } \\
\text { problèmes de santé }\end{array}$ & Formation et conseil & Personnes handicapées & FSE \\
\hline Danemark & Igangz & $\begin{array}{l}\text { Éducation } \\
\text { Formation d'enseignants }\end{array}$ & Jeunes & \\
\hline Estonie & StartSmart! & Ateliers et séminaires & Jeunes & \\
\hline Finlande & $\begin{array}{l}\text { Atelier d'aide à la création d'entreprises destiné aux } \\
\text { moins de } 30 \text { ans }\end{array}$ & Formation et ateliers & Jeunes & \\
\hline France & Ouvrir les portes de la banque aux jeunes entrepreneurs & Financement, formation & Jeunes & \\
\hline Allemagne & $\begin{array}{l}\text { Agence nationale d'activités et de services d'aide à la } \\
\text { création d'entreprises par des femmes }\end{array}$ & Approche intégrée & Femmes & FSE \\
\hline Grèce & Entrepreneuriat innovant des jeunes & Financement & Jeunes & \\
\hline Hongrie & Snétberger Music Talent Centre & Soutien intégré & Jeunes Roms & \\
\hline Irlande & Female Entrepreneurship Strategy & Approche intégrée & Femmes & \\
\hline Italie & Couveuse d'entreprises «FabriQ» & Approche intégrée & Entreprise sociale & FEDER \\
\hline Lettonie & $\begin{array}{l}\text { Mesures d'encouragement à l'innovation et à la création } \\
\text { d'entreprise }\end{array}$ & Mentorat, concours, séminaires & Jeunes & \\
\hline Lituanie & Aide au travail indépendant & Financement & $\begin{array}{l}\text { Chômeurs } \\
\text { Personnes handicapées }\end{array}$ & \\
\hline Luxembourg & Programme de mentorat d'entreprise & Mentorat & Immigrés & \\
\hline Malte & Projet My WoW & Éducation & Jeunes & \\
\hline Pays-Bas & Bbz: aide à la prise de décision pour les entrepreneurs & Approche intégrée & Chômeurs & FSE \\
\hline Pologne & $\begin{array}{l}\text { Wings for business: un atelier pour l'entrepreneuriat des } \\
\text { personnes handicapées }\end{array}$ & Approche intégrée & Personnes handicapées & FEINPT \\
\hline Portugal & Promotion de l'entrepreneuriat des immigrés & Formation, conseil & Immigrés & FSE \\
\hline Roumanie & Fem.RRom & Approche intégrée & Femmes roms & \\
\hline République slovaque & Contribution financière au travail indépendant & Formation, financement & Chômeurs & \\
\hline Slovénie & $\begin{array}{l}\mathrm{P} 2 \mathrm{P} \text { - Les femmes entrepreneurs pour l'égalité des } \\
\text { chances entrepreneuriales des femmes }\end{array}$ & $\begin{array}{l}\text { Formation, information, conseil, } \\
\text { mise en réseau }\end{array}$ & Femmes & FSE \\
\hline Espagne & Réseau de coopération de femmes entrepreneurs & Mise en réseau, formation & Femmes & \\
\hline Suède & Inkubator 55+ & Approche intégrée & Seniors & \\
\hline Royaume-Uni & Buy Sunderland First & $\begin{array}{l}\text { Aide à la procédure de passation } \\
\text { de marchés publics }\end{array}$ & Zones défavorisées & \\
\hline
\end{tabular}

Note: ERDF - FEDER: Fonds européen de développement régional; FSE: Fonds social européen; FEINPT: Fonds européen d'intégration des ressortissants des pays tiers; Interreg: initiative visant à soutenir la coopération entre les régions de l'Union européenne financée par le Fonds européen de développement régional (FEDER). 


\section{Autriche: Der Mikrokredit («Microcrédit»)}

Cette note de pays présente brièvement un programme de microcrédit dont l'objectif est d'aider les chômeurs ou les personnes qui risquent de perdre leur emploi à créer leur entreprise. Elle comprend également des données clés relatives à l'entrepreneuriat inclusif en Autriche.

Description: ce programme aide les personnes au chômage, ou qui risquent de perdre leur emploi, à créer ou à maintenir leur travail indépendant en leur accordant un microcrédit, en les formant et en les conseillant. Il est financé par le ministère du travail, des affaires sociales et de la protection des consommateurs et par des banques privées. Il est mis en œuvre et géré par ÖSB Consulting $\mathrm{GmbH}$ en coopération avec l'Austria Wirtschaftsservice $\mathrm{GmbH}$ (banque publique de développement détenue à 100 \% par la République d'Autriche), l’Erste Bank, Sparkassen et CARE.

Problème abordé: les difficultés d'accès aux financements constituent un obstacle majeur à la création ou au maintien du travail indépendant des chômeurs. Ce programme les aide durant la phase de démarrage de leur activité et facilite leur accès aux crédits et aux financements sans qu'ils aient besoin de garanties. Pour garantir l'intérêt du programme et éviter les effets d'aubaine, le candidat doit avoir des difficultés à accéder au marché classique du crédit.

Approche: les candidats éligibles doivent être sans emploi, avoir une idée d'entreprise réaliste, viable et pérenne et participer à l'Unternehmensgründungsprogramm (UGP) (programme d'aide à la création d'entreprise) du service autrichien de l'emploi. Les personnes menacées par le chômage ou la pauvreté, les travailleurs atypiques et les personnes défavorisées peuvent également y participer. Le dépôt des candidatures s'effectue en ligne. Les conseillers d'ÖSB Consulting $\mathrm{GmbH}$ les aident à préparer leur candidature, y compris à réunir tous les documents exigés (p.ex. plan d'affaires et de financement), par téléphone, courrier électronique ou en personne. Lorsque l'engagement de crédit est accordé par les banques en coopération avec le ministère, le bénéficiaire continue à bénéficier d'un accompagnement par courrier électronique, par téléphone ou en personne de la part des conseillers. Le microcrédit peut être utilisé pour tous les types d'investissements et ressources de fonctionnement. Les banques octroient des crédits d'un montant maximal de 12500 euros et concluent des partenariats d'entreprise à hauteur de 25000 euros maximum. La durée maximale du crédit est de cinq ans, avec un délai de grâce de six à neuf mois. Un taux d'intérêt fixe est garanti pour toute la durée du crédit (3 points de pourcentage au-dessus du taux Euribor à 3 mois). Il n'y a pas de frais de traitement. Le programme a été lancé en mai 2010 par le ministère fédéral du travail, des affaires sociales et de la protection des consommateurs. Il s'agissait initialement d'une mesure pilote testée uniquement dans la ville de Vienne et en Styrie. En 2011, le programme a été étendu à toutes les provinces fédérales d'Autriche. Au cours de ses quatre premières années d'existence, le volume total des emprunts s'est élevé à environ 3,3 millions d'euros.

Impact: une évaluation (Oberholzner, 2013) montre que ce programme a un véritable impact sur l'augmentation des taux de travail indépendant et de création d'entreprise. Environ 90 \% des candidats acceptés étaient toujours travailleurs indépendants au moment de l'enquête (printemps 2013). Le manque de connaissance du secteur d'activité a été la principale cause d'échec des $10 \%$ restants. En moyenne, les entreprises qui ont été soutenues ont créé 0,4 poste de travail. Un cinquième des participants a indiqué qu'ils auraient créé leur entreprise sans l'obtention de ce microcrédit et demandé un soutien financier à leur famille ou leurs amis.

Facteurs de réussite: il s'agit du premier programme de microcrédit mené en Autriche. Le soutien individuel, les conseils et l'assistance (en personne, par téléphone et par courrier électronique) à toutes les étapes du programme semblent être les principaux facteurs de réussite.

Référence: Oberholzner, T. (2013), «Evaluierung des Programms 'Der Mikrokredit'», Austrian Institute for SME Research. 


\section{Données clés relatives à l'entrepreneuriat inclusif}

\section{Graphique 10.1. Données relatives à l'entrepreneuriat et au travail indépendant en Autriche}

Diagramme A. Taux de chômage, 2000-13

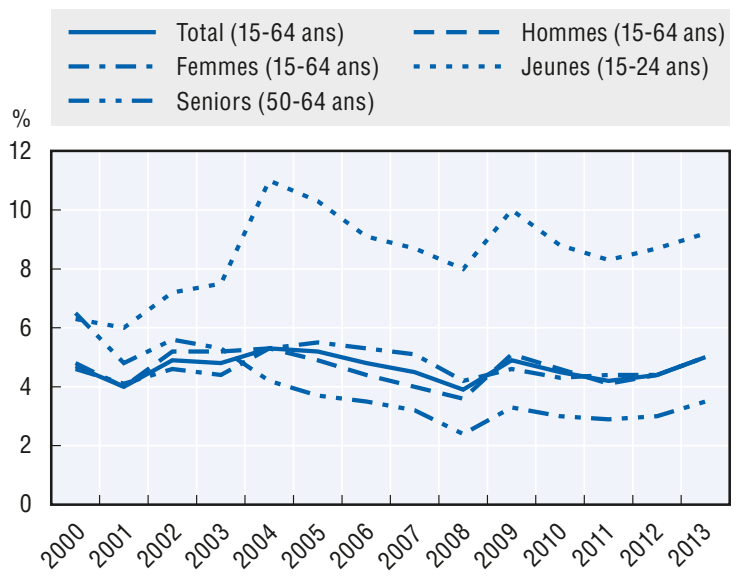

Diagramme C. Taux de travail indépendant, 2000-2013

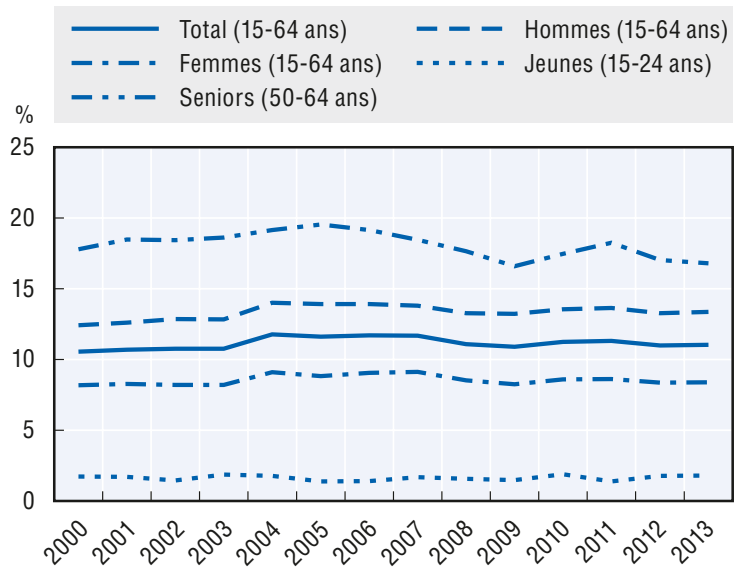

Diagramme E. Nombre total des entrepreneurs au stade précoce qui envisagent de créer plus de 19 emplois dans les 5 ans, 2009-2013 (combinés)

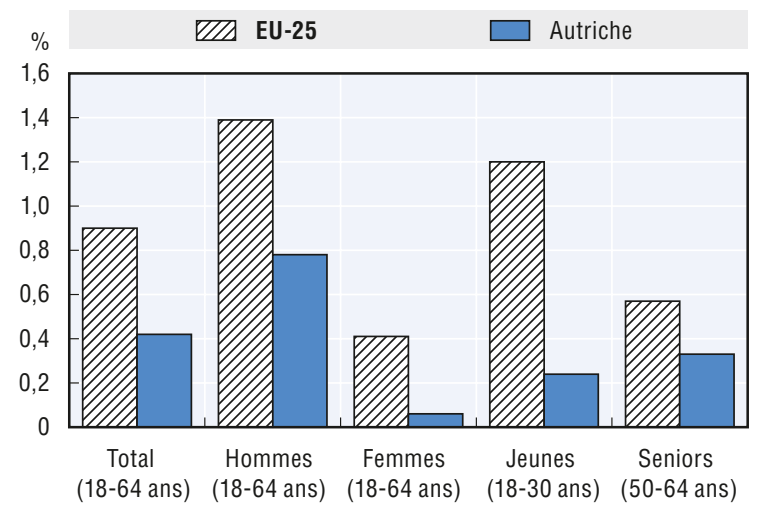

Diagramme B. Taux de travail indépendant, 2013

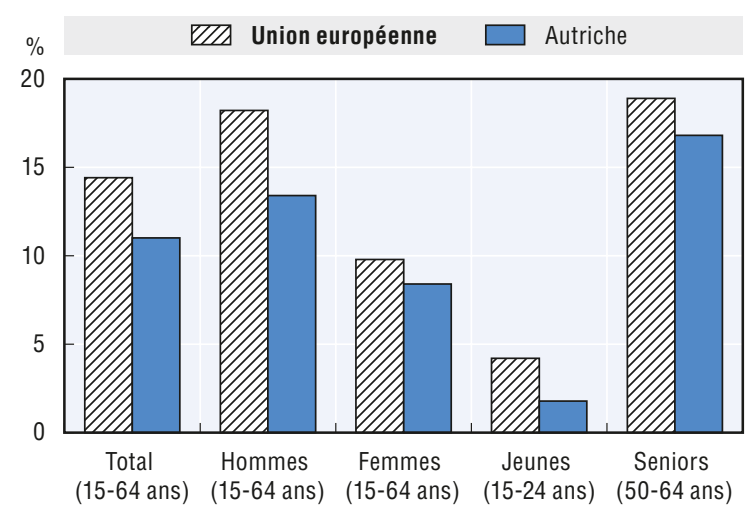

Diagramme D. Indice de l'activité entrepreneuriale totale au stade précoce 2009-2013 (combinés)

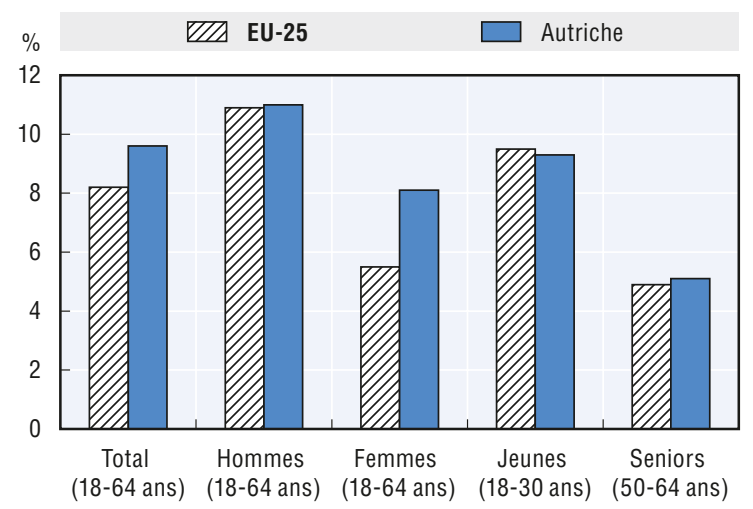

Sources: Diagramme A. Eurostat, Eurostat, Enquête sur les forces de travail, 2000-2013; diagramme B. Eurostat, Enquête sur les forces de travail. 2013; Diagramme C. Eurostat, Enquête sur les forces de travail, 2000-2013; Diagramme D. Présentation tabulaire spéciale de l'enquête sur la population adulte du Global Entrepreneurship Monitor, 2009-2013; Diagramme E. Présentation tabulaire spéciale de l'enquête sur la population adulte du Global Entrepreneurship Monitor, 2009-2013. 


\section{Belgique: Hazo vzw}

Cette note de pays présente brièvement une association à but non lucratif qui aide les entrepreneurs handicapés. Elle comprend également des données clés relatives à l'entrepreneuriat inclusif en Belgique.

Description: Hazo uzw est une association à but non lucratif basée en Flandre, Belgique. Elle a pour mission d'aider les entrepreneurs handicapés à développer une entreprise durable.

Problème abordé: les activités de Hazo uzw se fondent sur l'article 27 de la Convention des Nations unies relative aux droits des personnes handicapées, qui stipule que les États doivent prendre les mesures appropriées pour que les personnes handicapées puissent créer et conserver leur entreprise. Plus de 20000 entrepreneurs en Flandre souffrent d'une infirmité physique ou d'une maladie chronique. Les difficultés auxquelles certains entrepreneurs handicapés peuvent être confrontés incluent l'incapacité de travailler à plein temps, le besoin d'assistance pour les activités professionnelles élémentaires, le manque de lieux de travail aménagés et le manque d'accès aux crédits d'entreprise des banques ou des institutions financières.

Approche: Hazo uzw a pour objectif d'aider les personnes handicapées qui cherchent à créer une entreprise et qui ont besoin de modèles, d'information et de soutien ainsi que les entrepreneurs qui gèrent déjà leur propre entreprise et ont besoin d'aide pour poursuivre leurs activités. L'association a mis en place les activités suivantes pour répondre aux problèmes de la population cible: 1. Conseils de pairs: séances supervisées durant lesquelles les entrepreneurs handicapés s'entraident dans le cadre de conversations structurées. Ces séances peuvent prendre la forme de conseils, de partage d'expériences et de questions/réponses. Elles sont proposées ponctuellement et sont complétées par des conférences d'intervenants externes sur un large choix de sujets relatifs à la gestion d'entreprise. 2. Aide individuelle complémentaire de professionnels, notamment conseils personnalisés et/ou orientation vers des services spécifiques. 3. Site Internet contenant des informations actualisées pour les entrepreneurs handicapés. 4. Publication régulière d'un bulletin d'information sur des sujets d'actualité relatifs au handicap et à l'entrepreneuriat. 5. Orientation vers des services et organisations spécialisés en entrepreneuriat et handicap. 6. Lobbying et représentation au niveau politique, sur la base d'enquêtes régulières, d'échanges informels d'expériences avec les entrepreneurs handicapés et des recherches. 7. Activités d'information destinées aux personnes handicapées et au grand public sur le potentiel d'entrepreneuriat, les difficultés auxquelles les personnes handicapées sont confrontées et les services de Hazo uzw (par exemple, conférences, communiqués de presse, articles de presse et participation à des salons). Tous les types d'aides dispensés par Hazo vzw sont gratuits. L'association est financée par l'Agentschap Ondernemen (l'Agence pour l'entrepreneuriat) du gouvernement régional flamand (subvention annuelle de 100000 euros) et les dons volontaires de particuliers.

Impact: bien que relativement récente, l'initiative Hazo uzw a déjà conseillé et soutenu individuellement 80 personnes. Le bulletin d'information compte environ 500 abonnés.

Facteurs de réussite: Hazo uzw illustre les avantages d'une approche intégrée aux problèmes des entrepreneurs handicapés. Il est également important que l'initiative soutienne les entrepreneurs handicapés sur le long terme, car leurs difficultés sont multiples et longues à régler. 


\section{Données clés relatives à l'entrepreneuriat inclusif}

\section{Graphique 11.1. Données relatives à l'entrepreneuriat et au travail indépendant en Belgique}

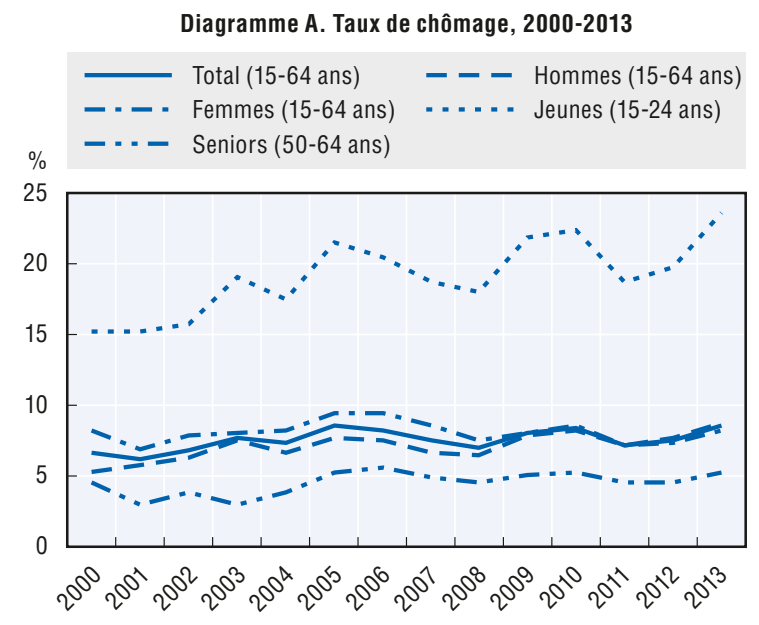

Diagramme B. Taux de travail indépendant, 2013
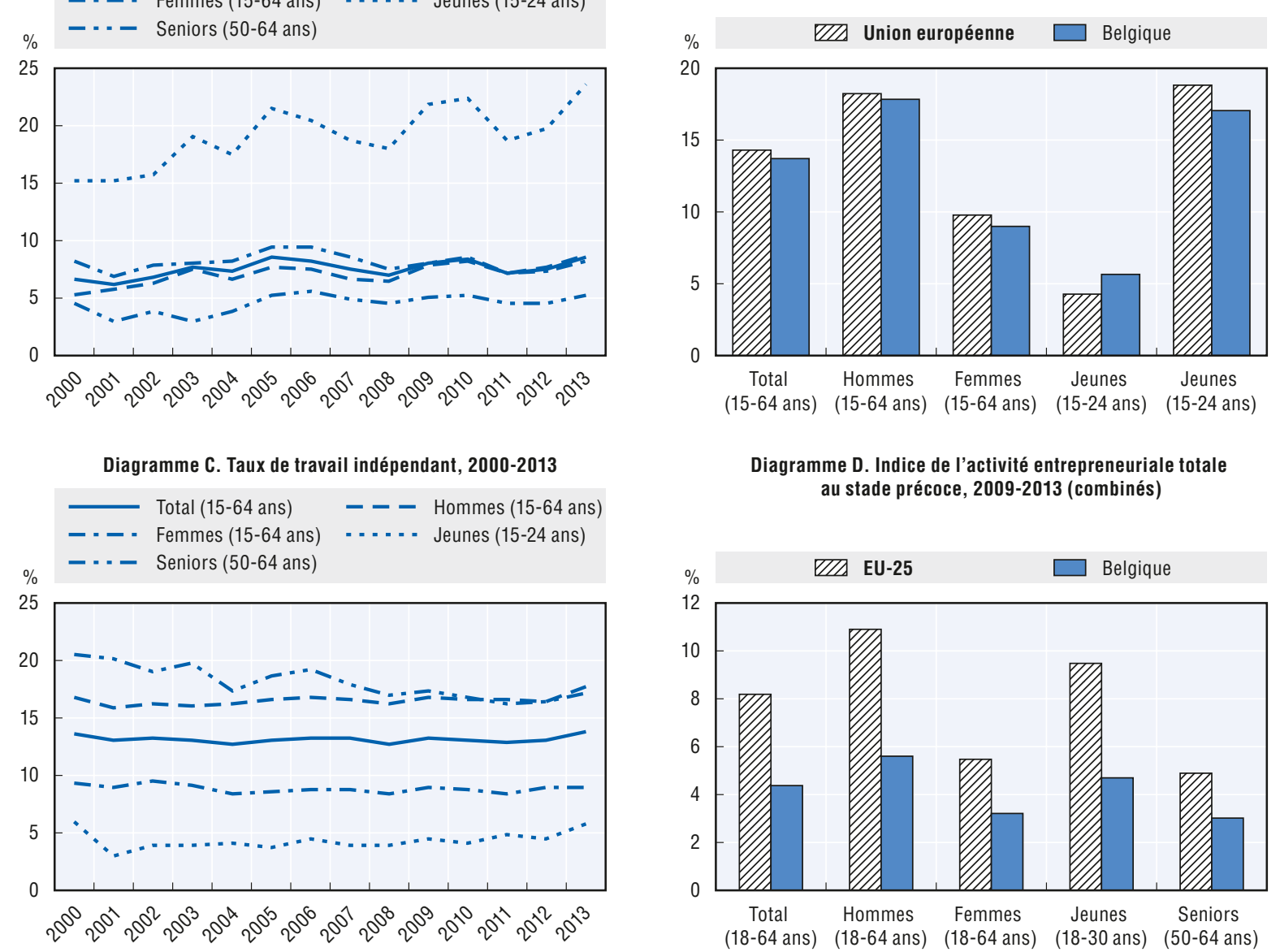

Diagramme E. Nombre total des entrepreneurs au stade précoce qui envisagent de créer plus de 19 emplois dans les 5 ans, 2009-2013 (combinés)

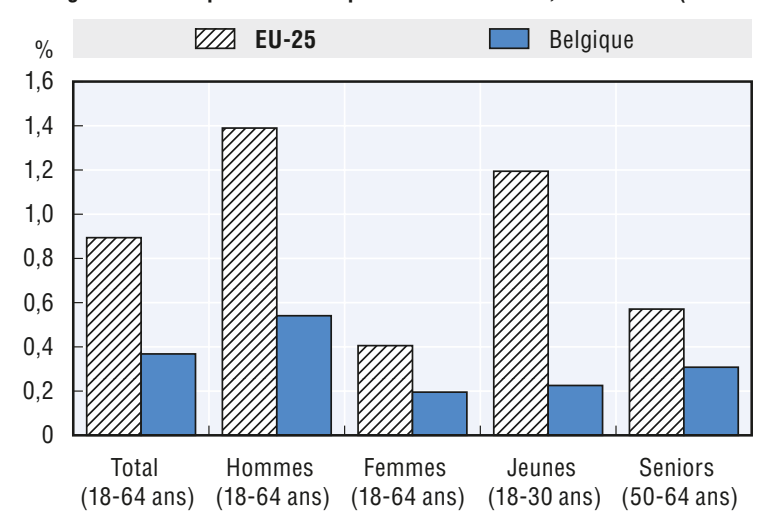

Sources: Diagramme A. Eurostat, Enquête sur les forces de travail, 2000-2013; Diagramme B. Eurostat, Enquête sur les forces de travail, 2013; Diagramme C. Eurostat, Enquête sur les forces de travail, 2000-2013; Diagramme D. Présentation tabulaire spéciale de l'enquête sur la population adulte du Global Entrepreneurship Monitor, 2009-2013; Diagramme E. Présentations tabulaires spéciales de l'enquête sur la population adulte du Global Entrepreneurship Monitor, 2009-2013.. 


\section{Bulgarie: Entrepreneurship Development Network (EDN)}

Cette note de pays présente brièvement un réseau d'organisations qui fournit aux jeunes un programme intégré d'aide à l'entrepreneuriat. Elle comprend également des données clés relatives à l'entrepreneuriat inclusif en Bulgarie.

Description:l'EDN propose auxjeunes etétudiants à l'université un programme d'aide intégré afin de les aider à définir l'orientation de leur entreprise et contribuer à renforcer leur capacité à créer leur entreprise. Ce programme est le fruit d'une coopération de longue date (plus de 13 ans) entre trois organisations basées à Sofia - l'Institut pour le développement entrepreneurial (IED) de l'université d'économie nationale et mondiale, la Chaire de l'entrepreneuriat et la BAMDE (Bulgarian Association for Management Development and Entrepreneurship) - et un organisme de jeunesse créé récemment, le Club of Young Innovative Entrepreneur (CYIE).

Problème abordé: la Bulgarie enregistre un taux de travail indépendant des jeunes de 15 à 24 ans de 4,5\%, inférieur à la moyenne de l'Union européenne et des pays environnants. Cependant, $74,3 \%$ des jeunes en Bulgarie souhaiteraient exercer une activité indépendante. Ce pourcentage est le plus élevé des pays de l’Union européenne et est nettement supérieur à la moyenne de l'Union européenne (42,8 \%) (Eurobaromètre, 2011). Ce faible taux de travail indépendant s'explique par plusieurs facteurs, notamment le manque de compétences et d'expérience entrepreneuriales, la difficulté d'accès aux ressources d'entreprise, l'émigration et une culture entrepreneuriale faible.

Approche: ce réseau utilise une approche intégrée pour aider les jeunes ayant un potentiel entrepreneurial. Ce soutien comprend une aide à la recherche, des formations et des conseils pour la préparation du plan d'affaires, un programme de mentorat pour jeunes talents prometteurs par des experts renommés, la fourniture d'un capital de démarrage en coopération avec des institutions de financement et une aide spécialisée pour le renforcement des compétences non techniques dont les jeunes entrepreneurs ont besoin pour réussir dans un environnement international multiculturel. Il s'agit, plus particulièrement, de la formation de jeunes entrepreneurs potentiels à l'entrepreneuriat (par exemple, élaboration de plans d'affaires, immatriculation de l'entreprise, stratégies d'entreprise, reprise de l'affaire familiale), ainsi que des services de conseil et de mentorat dispensés par des entrepreneurs expérimentés aux entrepreneurs potentiels ayant une idée d'entreprise viable. Le développement de ce réseau se fonde sur des recherches relatives à l'entrepreneuriat et aux PME, l'organisation de conférences et d'ateliers internationaux ainsi que sur la préparation et la mise en œuvre de projets nationaux et internationaux auxquels participent ces étudiants prometteurs. C'est grâce à une coopération sur le long terme et aux efforts coordonnés et constants d'un vaste réseau rassemblant des acteurs nationaux et internationaux qu'il a été possible de développer cette gamme d'activités diversifiées mais reliées sur le thème de l'entrepreneuriat. Ce réseau fait appel à plusieurs sources de financement. Essentiellement autofinancé (BAMDE, IED et CYIE), il bénéficie de fonds publics (CE), des fonds du projet et, dans une moindre mesure, de parrainages (de banques notamment).

Impact: depuis son lancement, 280 étudiants ont suivi une spécialisation en entrepreneuriat, tandis que quelque 2500 autres ont participé à un cours facultatif d'introduction à l'entrepreneuriat. Plus de 130 jeunes ayant réussi ce cursus ont ensuite créé leur propre entreprise. L'impact à long terme de cette initiative devrait être encore plus important, puisque ces étudiants pourraient avoir envie de créer leur entreprise ultérieurement.

Facteurs de réussite: ce projet repose sur l'existence de réseaux de longue date pour instiller une culture entrepreneuriale au sein du milieu universitaire et soutenir les créations d'entreprise. Ses principaux facteurs de succès sont la présence d'entrepreneurs issus du monde universitaire qui jouent un rôle de moteur, ainsi que le partage d'expériences et la coopération internationale entre les acteurs concernés.

Référence: Eurobaromètre (2011), "Youth on the move», rapport analytique, Eurobaromètre Flash, $\mathrm{n}^{\circ} 319 \mathrm{~b}$. 


\section{Données clés relatives à l'entrepreneuriat inclusif}

\section{Graphique 12.1. Données relatives à l'entrepreneuriat et au travail indépendant en Bulgarie}

Diagramme A. Taux de chômage, 2000-2013

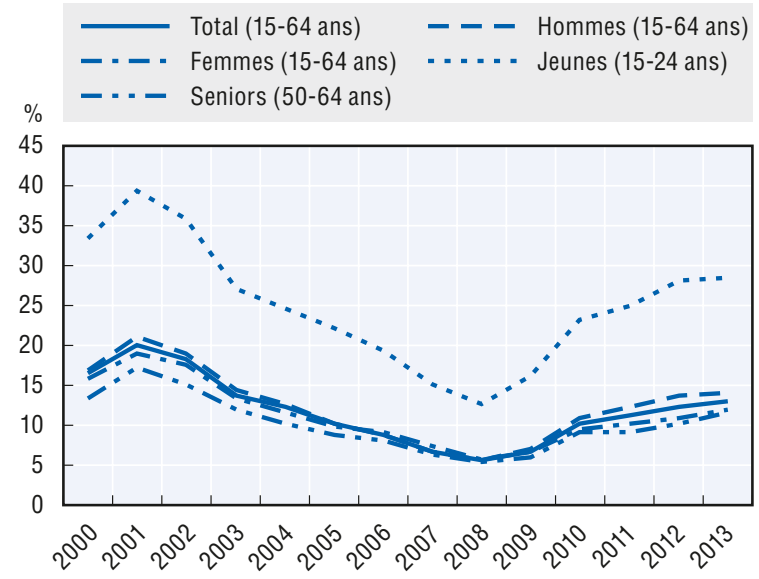

Diagramme C. Taux de travail indépendant, 2000-2013

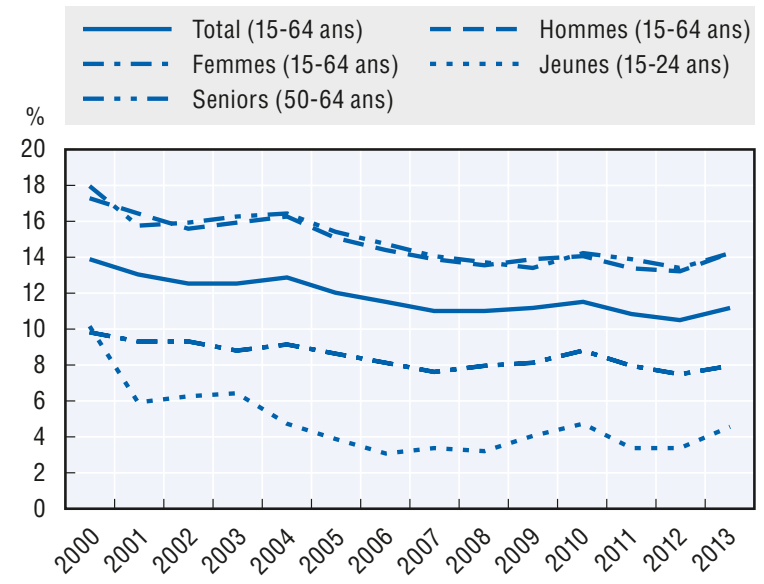

Diagramme B. Taux de travail indépendant, 2013

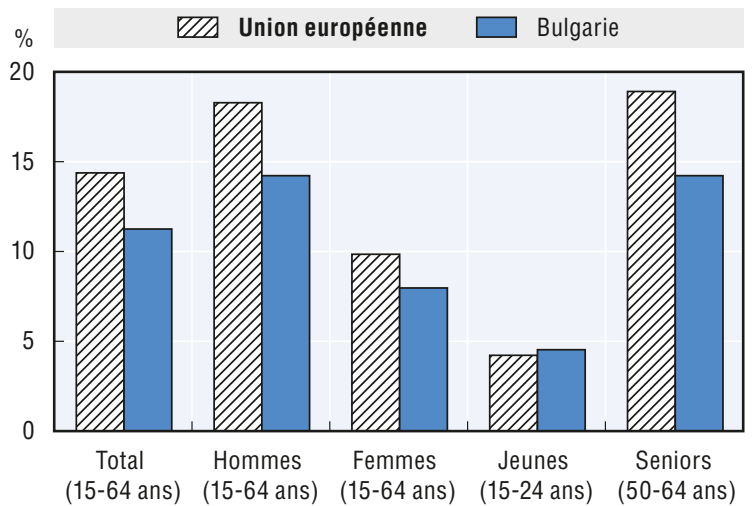

Sources: Diagramme A. Eurostat, Enquête sur les forces de travail, 2000-2013; Diagramme B. Eurostat, Enquête sur les forces de travail, 2013; Diagramme C. Eurostat, Enquête sur les forces de travail, 2000-2013. 


\section{Croatie: projet A.C.T.I.V.E. (Activity and Creativity Through Ideas and Ventures = Employment)}

Cette note de pays présente brièvement un programme de soutien aux étudiants et jeunes chômeurs, proposant des formations à l'entrepreneuriat, des conseils et des services de couveuse d'entreprises. Elle comprend également des données clés relatives à l'entrepreneuriat inclusif en Croatie.

Description: ce projet cible les étudiants d'université et les élèves de terminale et les jeunes chômeurs sans expérience professionnelle. Il propose des formations à l'entrepreneuriat, des activités permettant de développer la confiance en soi, des conseils pour développer une idée d'entreprise et des services de couveuse d'entreprises. L'université J.J. Strossmayer d'Osijek supervise le projet et met en œuvre les activités en collaboration avec les partenaires locaux.

Problème abordé: la Croatie souffre d'un taux de chômage des jeunes très élevé. Les données de l'étude du Global Entrepreneurship Monitor (GEM) indiquent toutefois que la culture entrepreneuriale est sous-développée en Croatie. Seuls 17,6 \% des habitants ont identifié des opportunités entrepreneuriales en 2013, contre $44,4 \%$ en 2008 . De plus, les formations à l'entrepreneuriat ne sont pas encore répandues dans le système éducatif formel.

Approche: le projet combine plusieurs activités destinées à promouvoir l'entrepreneuriat auprès des lycéens, étudiants d'universités et jeunes chômeurs dans le comitat d'Osijek-Baranja. Parmi ses principales activités, figure la formation à l'entrepreneuriat, composée de modules sur l'identification d'opportunités entrepreneuriales, la création d'une entreprise ou d'une activité indépendante, le travail indépendant sur le marché du travail et l'entrepreneuriat social. De plus, le programme a mis en place un club de débat sur des sujets liés au monde du travail et de l'entreprise; un concours des meilleures idées d'entreprise; une couveuse offrant des locaux et des services de conseil, de mentorat et de soutien administratif aux jeunes; et des opportunités de mise en réseau via la participation à des forums d'entreprise. Ces activités s'accompagnent d'une campagne publique destinée à promouvoir l'entrepreneuriat et à faire connaître les aides proposées dans le cadre du projet. Le projet a été créé il y a moins d'un an pour un coût total de 222719 euros. Le Fonds social européen le finance à 87,5 \%.

Impact: au cours du premier trimestre d'activité, six ateliers rassemblant des étudiants et des jeunes chômeurs sans expérience professionnelle ont eu lieu. Les deux lycées participants au projet ont organisé 18 ateliers. De plus, dix ateliers d'information ont eu lieu pour attirer les étudiants. À la fin du premier trimestre, 112 des 201 participants aux ateliers d'information ont intégré la formation à l'entrepreneuriat (57 élèves de terminale, 28 étudiants universitaires et 27 jeunes chômeurs sans expérience professionnelle).

Facteurs de réussite: le succès de ce programme repose sur la coopération entre les diverses parties prenantes, qui apportent leur expertise et leurs services pour lutter contre les divers facteurs du chômage (psychologiques, sociaux, économiques et politiques). 


\section{Données clés relatives à l'entrepreneuriat inclusif}

\section{Graphique 13.1. Données relatives à l'entrepreneuriat et au travail indépendant en Croatie}

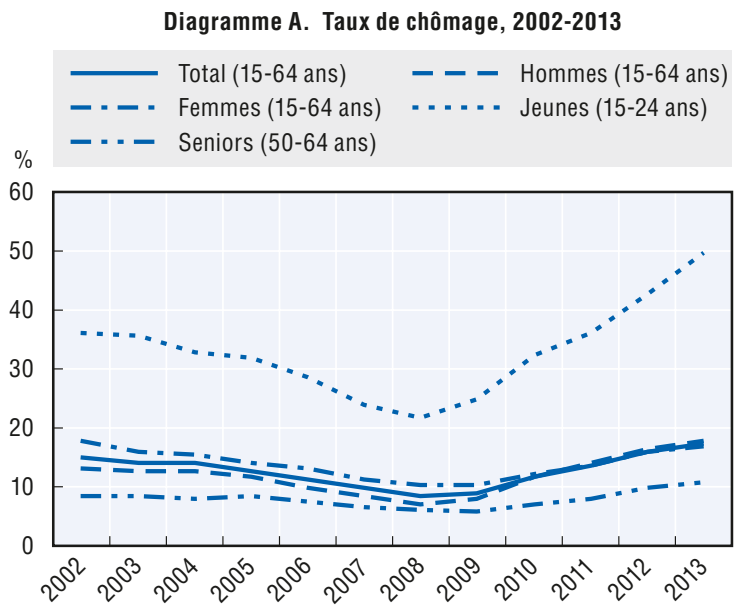

Diagramme B. Taux de travail indépendant, 2013
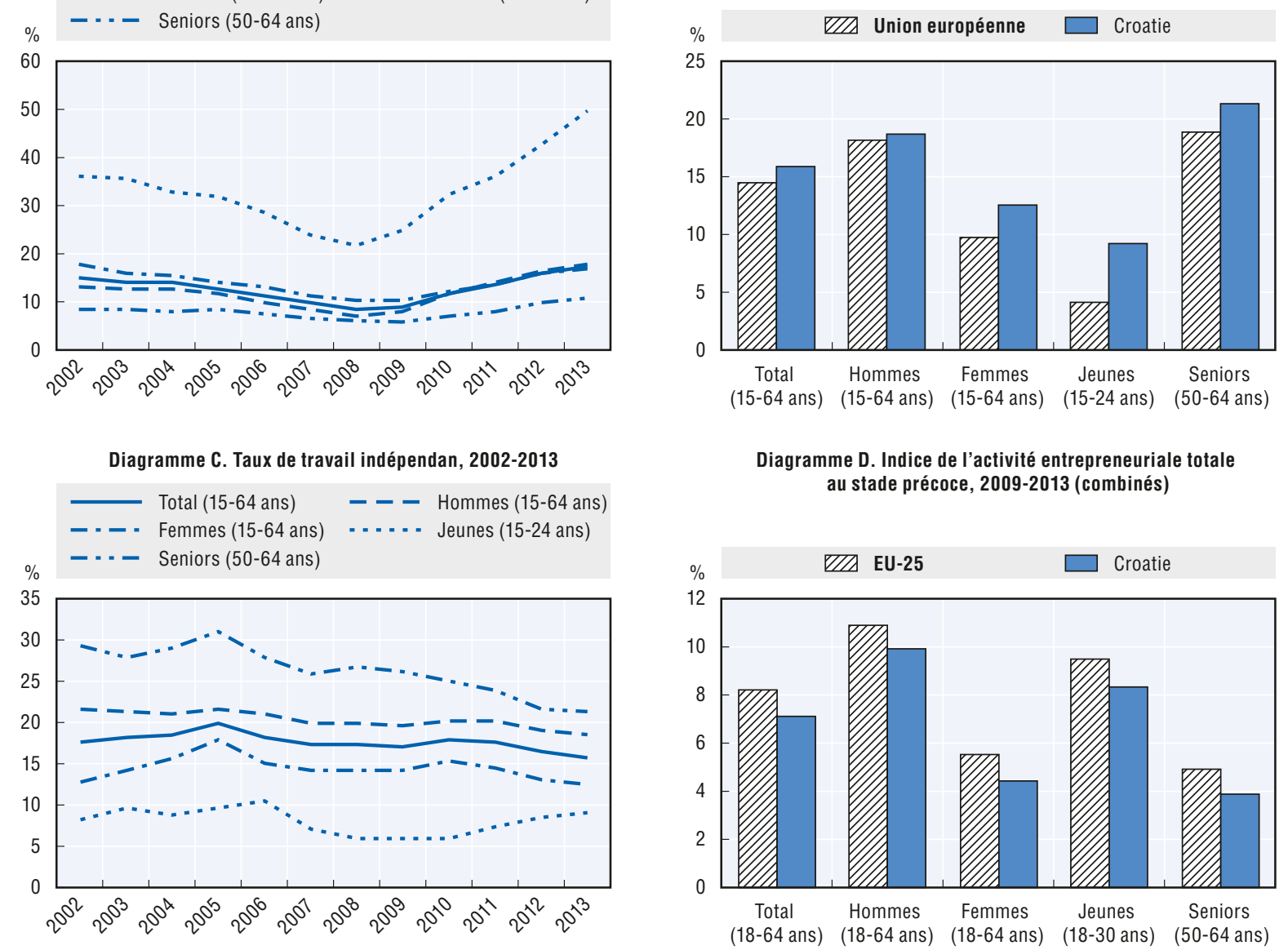

Diagramme E. Nombre total des entrepreneurs au stade précoce qui envisagent de créer plus de 19 emplois dans les 5 ans, 2009-2013 (combinés)

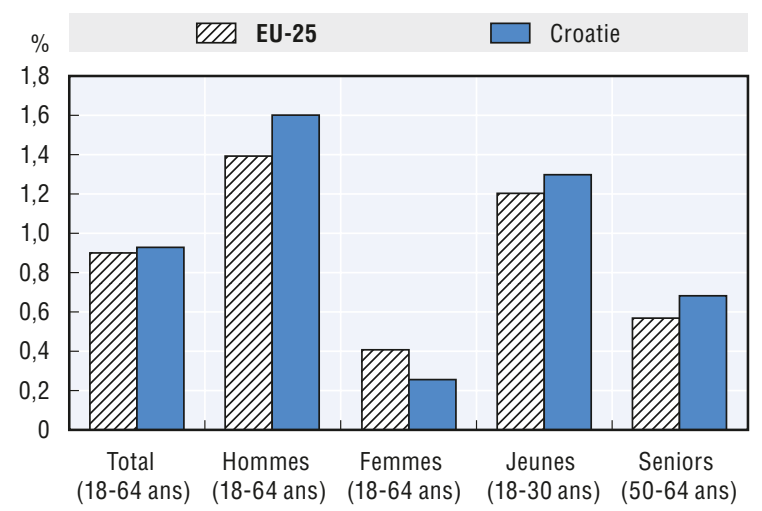

Sources: Diagramme A. Eurostat, Enquête sur les forces de travail, 2002-2013; Diagramme B. Eurostat, Enquête sur les forces de travail, 2013; Diagramme C. Eurostat, Enquête sur les forces de travail, 2002-2013; Diagramme D. Présentation tabulaire spéciale de l'enquête sur la population adulte du Global Entrepreneurship Monitor, 2009-2013; Diagramme E. Présentations tabulaires spéciales de l'enquête sur la population adulte du Global Entrepreneurship Monitor, 2009-2013. 


\section{Chypre: Agrotoepixeirein: renforcer l'entrepreneuriat des jeunes et des femmes dans les zones rurales}

Cette note de pays présente brièvement un programme de développement de l'entrepreneuriat rural destiné aux femmes et aux jeunes. Elle comprend également des données clés relatives à l'entrepreneuriat inclusif à Chypre.

Description: Agrotoepixeirein (qui signifie «entrepreneuriat rural») est un programme qui met l'accent sur la promotion de l'entrepreneuriat des femmes et des jeunes dans les zones rurales. Le projet, mis en œuvre entre janvier 2012 et juin 2013, était géré par l'Agence de développement du district de Larnaca, en coopération avec la chambre de commerce locale.

Problème abordé: le taux de chômage des jeunes de 15-24 ans est passé de 9 \% en 2008 à plus de $40 \%$ en 2013 (Commission européenne, 2014). Celui des femmes a également augmenté, passant de 4,3\% en 2008 à 15,2 \% en 2013. Les taux d'entrepreneuriat des femmes et des jeunes sont inférieurs à ceux de la population générale. De plus, ces publics rencontrent plus de difficultés à créer leur entreprise et à accéder aux financements, et manquent souvent de compétences entrepreneuriales (Nearchou-Ellinas et Kountouris, 2004). Les zones rurales sont davantage affectées.

Approche: l'objectif de ce projet était de renforcer l'entrepreneuriat rural dans les secteurs clés (traditionnels), comme le tourisme rural, l'agriculture, l'élevage et la fabrication de produits alimentaires locaux traditionnels. La priorité a été accordée aux femmes et aux jeunes entrepreneurs. Le soutien fourni visait à augmenter le nombre de créations d'entreprises, améliorer l'environnement des affaires et renforcer la compétitivité des entreprises existantes. Il a revêtu différentes formes, comme des services de mentorat, de conseil en entreprise et d'information sur les possibilités de financement, des audits technologiques, des opportunités de mise en réseau, un partage des meilleures pratiques et des exemples de réussites, ainsi que des formations de perfectionnement en entrepreneuriat (par exemple, rédaction de plans d'affaires). Ce soutien a été conçu après un diagnostic approfondi des besoins des microentrepreneurs originaires des zones rurales chypriotes.

Impact: Agrotoepixeirin a reçu 223 candidatures dont 84 ont été retenues. Ce programme de soutien, proposant notamment une formation et du mentorat, a aidé 84 entrepreneurs ruraux (jeunes et femmes) à créer leur entreprise. Il a également contribué à l'élaboration de 40 plans d'affaires et d'audits technologiques. Il a donné naissance à un réseau de nouveaux entrepreneurs apiculteurs et à la première coopérative de femmes chypriotes («Traditional Sweet Memories»). Trois bureaux d'aide à l'entrepreneuriat rural, une boîte à outils destinée aux entrepreneurs et des services de conseil individuels et collectifs ont également été créés.

Facteurs de réussite: la formation et le mentorat ont joué un rôle essentiel dans l'incitation à l'entrepreneuriat des femmes et des jeunes. Il était également important de refléter la nature de l'économie rurale en soutenant la création d'entreprises dans l'artisanat, le micro-artisanat et dans d'autres secteurs.

Références: Commission européenne (2014), "Chypre doit mieux préparer ses jeunes au marché du travail», disponible à l'adresse suivante: http://europa.eu/rapid/press-release_IP-14-284_ fr.htm.

Lina Nearchou-Ellinas, I.et S. Kountouris, (2004), «Women entrepreneurs in Cyprus: a new dynamic in Cyprus economy», Women In Management Review, Vol. 19, n 6, p. 325-332. 


\section{Données clés relatives à l'entrepreneuriat inclusif}

\section{Graphique 14.1. Données relatives à l'entrepreneuriat et au travail indépendant à Chypre}

Diagramme A. Taux de chômage, 2000-2013

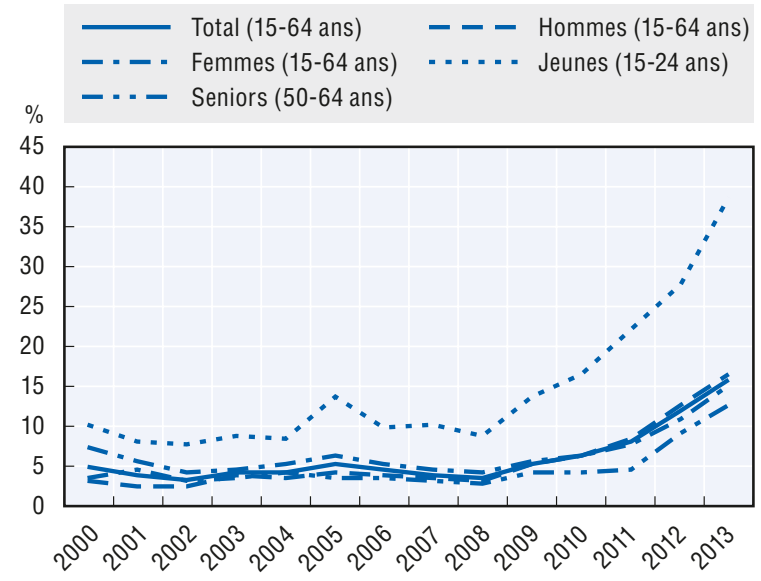

Diagramme C. Taux de travail indépendant, 2000-2013

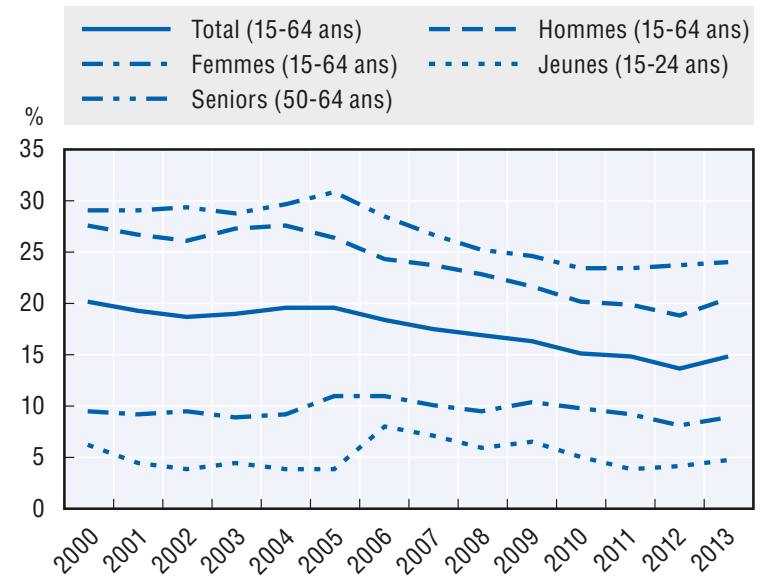

Diagramme B. Taux de travail indépendant, 2013

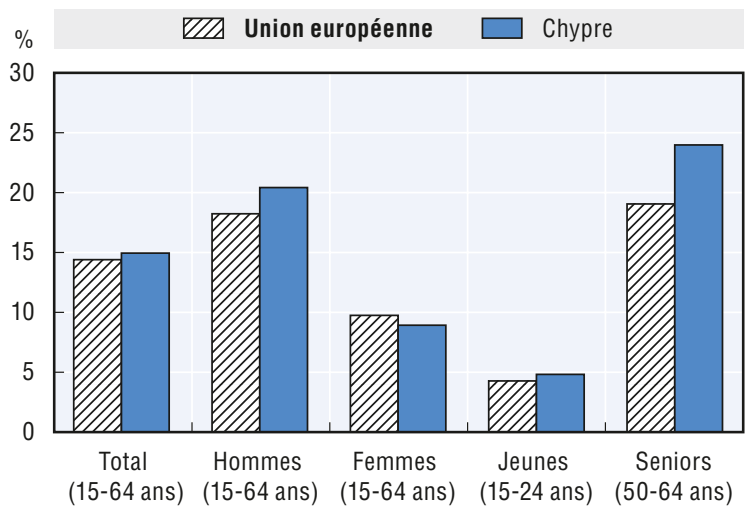

Sources: Diagramme A. Eurostat, Enquête sur les forces de travail, 2000-2013; Diagramme B. Eurostat, Enquête sur les forces de travail, 2013; Diagramme C. Eurostat, Enquête sur les forces de travail, 2000-2013. 


\section{République tchèque: aide au travail indépendant des personnes souffrant de problèmes de santé en Bohême centrale}

Cette note de pays présente brièvement un programme d'aide à l'entrepreneuriat des personnes souffrant de problèmes de santé. Elle comprend également des données clés relatives à l'entrepreneuriat inclusif en République tchèque.

Description: ce projet vise à aider les personnes atteintes de "maladies de civilisation»: problèmes cardiovasculaires, tumeurs, maladies endocriniennes, troubles de l'alimentation et toxicomanie. Il les informe et partage l'expérience d'autres entrepreneurs afin de les aider à créer leur propre entreprise et améliorer leur situation professionnelle. L'approche adoptée est un programme d'aide intégré alliant formations à l'entrepreneuriat et services de conseil en entreprise et d'orientation en vue de soutenir la création d'entreprises ou la recherche d'emploi. Ce projet a été mis en œuvre du $1^{\text {er }}$ septembre 2011 au 31 août 2013.

Problème abordé: ce projet avait pour objectif d'aider les personnes atteintes de handicaps les plus courants en République tchèque, car elles sont davantage touchées par le chômage que la population générale. Les personnes souffrant de problèmes de santé peuvent posséder un savoir-faire et une expérience professionnelle solide, mais avoir perdu leur emploi à cause de leur maladie. Or, souvent, elles pourraient continuer à travailler avec la mise en place d'un soutien et d'aménagements liés à leur état de santé. Ce projet remédie aux obstacles que rencontrent souvent ces personnes: performances professionnelles altérées par l'état de santé; problèmes de transport pour se rendre au travail (par exemple, utilisation d'un fauteuil roulant); discrimination des employeurs; et difficultés de retour à l'emploi après un arrêt de travail.

Approche: initialement, le projet était destiné aux participants recrutés auprès d'agences pour l'emploi, puis il a été étendu aux personnes envoyées par des associations spécialisées dans ces maladies spécifiques. Le projet ciblait les personnes malades au chômage ou menacées de perdre leur emploi. Ce projet comportait cinq composantes: un diagnostic personnalisé (série d'entretiens individuels aboutissant à l'élaboration d'un plan de développement personnel); des séances de motivation (pour renforcer la confiance en soi et la motivation par l'apprentissage de compétences transmissibles); une formation agréée sur les fondamentaux de l'entreprise (formation intensive de reconversion à plein temps d'une durée de 120 heures portant sur les aptitudes clés pour gérer une entreprise); une formation en ligne sur «les fondamentaux de l'entreprise pour les personnes handicapées»; et une aide à l'élaboration du projet individuel et des consultations. Le budget de ce projet s'est élevé à 4828123 CZK (environ 179000 euros), financé à 85 \% environ par le Fonds social européen au titre du programme opérationnel pour l'emploi et le développement des ressources humaines.

Impact: le projet a permis d'aider 168 bénéficiaires âgés de 21 à 68 ans, dont 61 ont trouvé un emploi: 24 personnes ont créé leur entreprise et 37 sont devenues travailleurs indépendants. Ces chiffres relativement bas s'expliquent par les difficultés de retour du groupe cible à l'emploi.

Facteurs de réussite: ce projet montre qu'il est possible d'atteindre et de soutenir un groupe cible qui est souvent négligé. Il doit son efficacité aux consultations et à l'analyse approfondies des problèmes auxquels les participants sont confrontés, qui ont permis d'élaborer des plans de développement personnels. 


\section{Données clés relatives à l'entrepreneuriat inclusif}

\section{Graphique 15.1. Données relatives à l'entrepreneuriat et au travail indépendant en République tchèque}

Diagramme A. Taux de chômage, 2000-2013
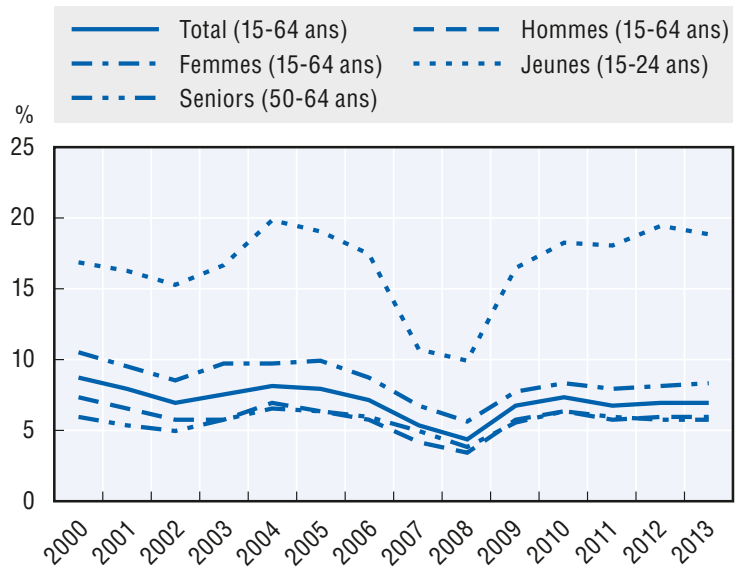

Diagramme C. Taux de travail indépendant, 2000-2013

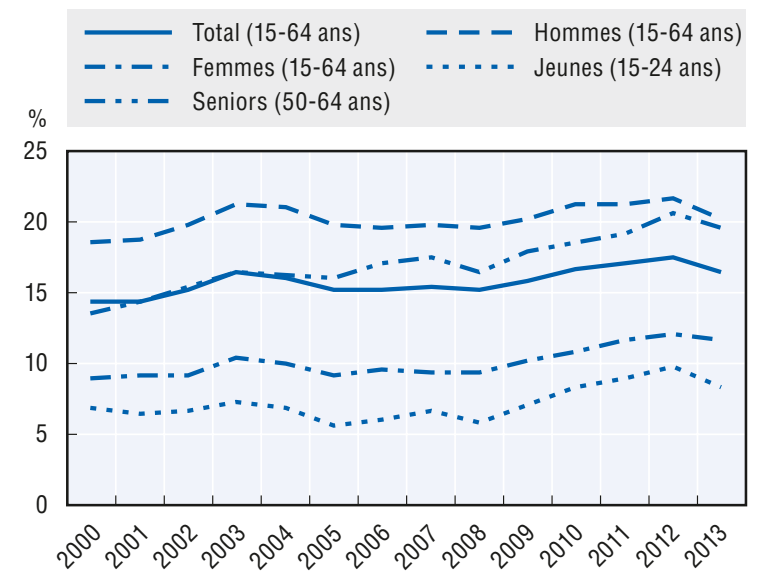

Diagramme E. Nombre total des entrepreneurs au stade précoce qui envisagent de créer plus de 19 emplois dans les 5 ans, 2009-2013 (combinés)

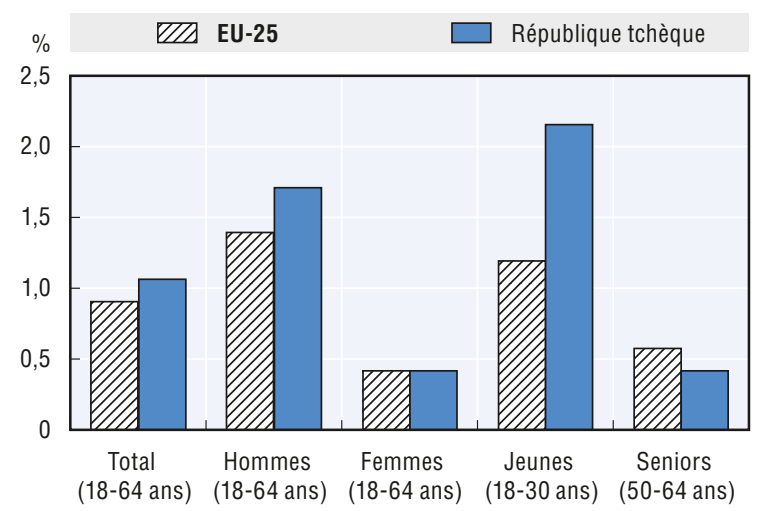

Diagramme B. Taux de travail indépendant, 2013

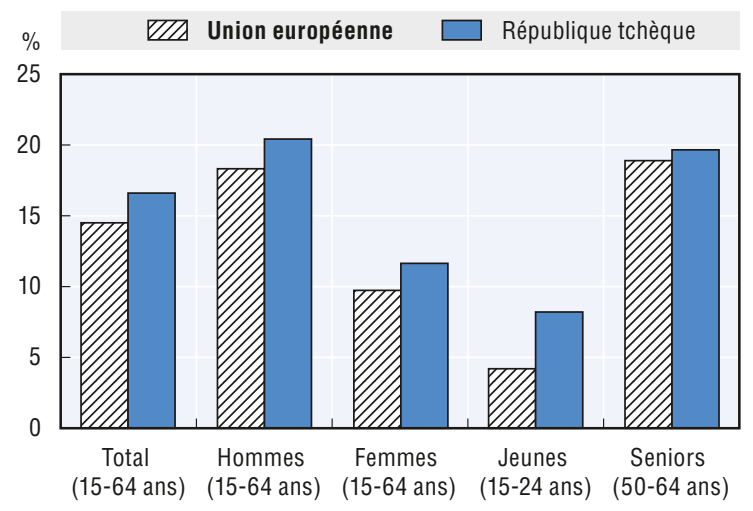

Diagramme D. Indice de l'activité entrepreneuriale totale au stade précoce, 2009-2013 (combinés)

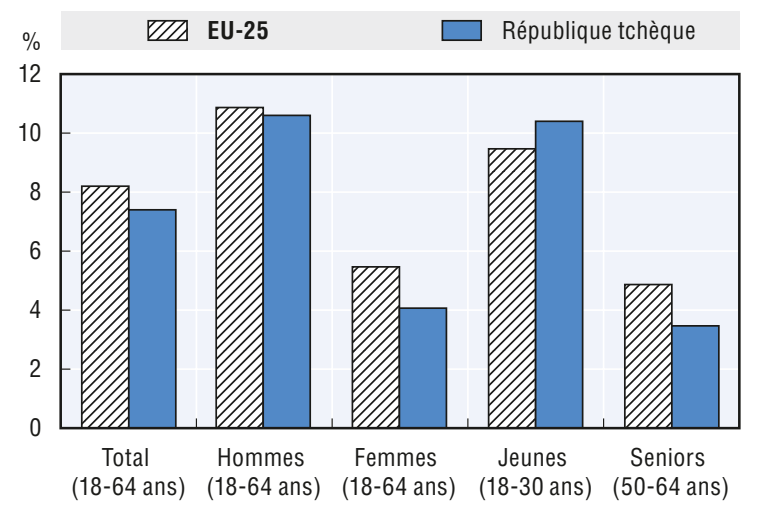

Sources: Diagramme A. Eurostat, Enquête sur les forces de travail, 2000-2013; Diagramme B. Eurostat, Enquête sur les forces de travail, 2013; Diagramme C. Eurostat, Enquête sur les forces de travail, 2000-2013; Diagramme D. Présentation tabulaire spéciale de l'enquête sur la population adulte du Global Entrepreneurship Monitor, 2009-2013; Diagramme E. Présentations tabulaires spéciales de l'enquête sur la population adulte du Global Entrepreneurship Monitor, 2009-2013.. 


\section{Danemark: Igangz}

Cette note de pays présente brièvement un programme d'aide à l'entrepreneuriat des jeunes, qui combine une aide au secteur éducatif et une couveuse pour l'innovation et la croissance. Elle comprend également des données clés relatives à l'entrepreneuriat inclusif au Danemark.

Description: le projet Igangz a pour objectif de créer des conditions favorables à la croissance dans la région du Jutland du Nord en soutenant la formation à l'entrepreneuriat et en mettant en place une couveuse pour la croissance et l'innovation afin d'aider les étudiants des établissements d'enseignement participants à développer et mûrir leur idée d'entreprise. Cette initiative est financée par la région du Jutland du Nord à hauteur de 4,4 millions de couronnes danoises (DKK) (600 000 euros). La région prend en charge $75 \%$ des coûts et les neuf établissements d'enseignement participants, les $25 \%$ restants.

Problème abordé: le Jutland du Nord est la plus petite des cinq régions danoises en termes de population, avec seulement 580000 habitants en 2013. C'est également la seule région du pays où la population devrait baisser d'ici à $2030(-0,4 \%)$ alors que la population nationale devrait augmenter de $6 \%$. Nombre de jeunes, en particulier ceux disposant d'un niveau élevé d'études, quittent la région pour poursuivre leurs études et/ou chercher un emploi ailleurs, généralement dans les grandes villes. Le taux de chômage des jeunes dans la région est supérieur à la moyenne nationale. Le Jutland du Nord compte également peu d'entreprises dites «à croissance» (entreprises qui comptent plus de cinq salariés après deux ans d'activité et qui enregistrent une croissance moyenne de plus de $20 \%$ ), 3,4 \% contre une moyenne nationale de 6,4 \%.

Approche: Igangz a débuté en novembre 2013. Il aide les établissements d'enseignement de tous niveaux à mettre en place une formation à l'entrepreneuriat en proposant une formation des enseignants à l'enseignement de l'entrepreneuriat et à l'élaboration des supports pédagogiques; l'organisation de semaines thématiques innovantes dans des écoles de commerce; et des programmes pédagogiques interétablissements. Igangz propose également une couveuse où les étudiants peuvent réserver un espace, et où leur sont fournis gratuitement une assistance et des services de conseil Cette couveuse compte 18 postes de travail pour les étudiants et héberge également un "café des entrepreneurs" pour favoriser les rencontres entre étudiants. Les étudiants peuvent également consulter des mentors ou participer aux ateliers, aux programmes de formation et aux conférences organisés régulièrement dans les locaux de la couveuse. Cette dernière fait également office de centre de ressources pour le personnel des établissements d'enseignement participants et d'agent de liaison avec les autres programmes d'innovation et d'entrepreneuriat dans la région du Jutland du Nord.

Impact: la couveuse du programme Igangz a permis de créer 14 entreprises (avril 2014). De plus, 45 autres étudiants ont utilisé les équipements du programme, mais leur plan ou leur idée d'entreprise n'était pas suffisamment abouti(e) à cette date pour utiliser la couveuse. Dans le cadre du programme "Career Hub» (programme-cadre finançant cette initiative), les enseignants des établissements participants ont bénéficié d'une formation sur l'innovation et l'entrepreneuriat. En 2013, trois formations ont eu lieu, entre 25 et 30 personnes y ont participé. À chaque fois, le programme a organisé plusieurs semaines thématiques et a participé à plusieurs salons et autres événements.

Facteurs de réussite: ce projet démontre l'intérêt d'une coopération entre établissements d'enseignement. Son principal facteur de réussite a été de veiller à ce que tous les établissements d'enseignement participants soient impliqués et travaillent activement à sensibiliser les étudiants à l'entrepreneuriat et à l'innovation. Dans le cadre de ce programme, c'est le cofinancement des établissements d'enseignement et la participation active de tous les participants à l'élaboration et à l'organisation des activités et des mesures du programme qui ont permis d'y parvenir. 


\section{Données clés relatives à l'entrepreneuriat inclusif}

\section{Graphique 16.1. Données relatives à l'entrepreneuriat et au travail indépendant au Danemark}

\section{Diagramme A. Taux de chômage, 2000-2013}

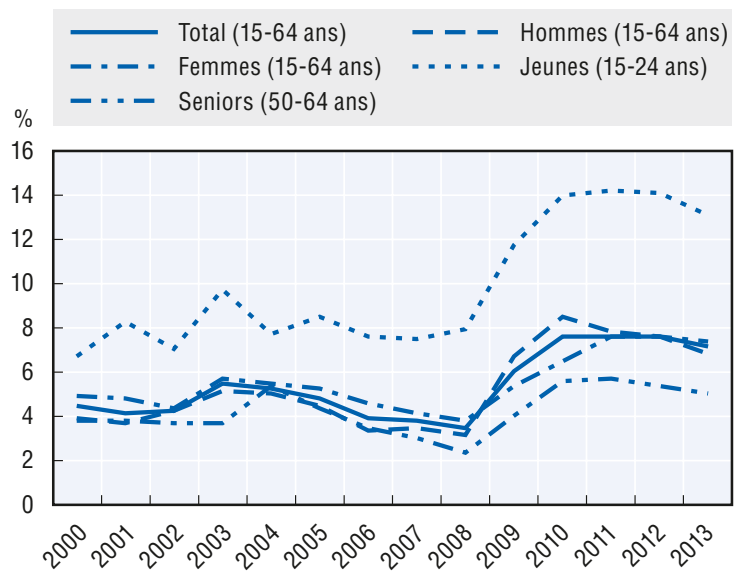

Diagramme C. Taux de travail indépendant, 2000-2013

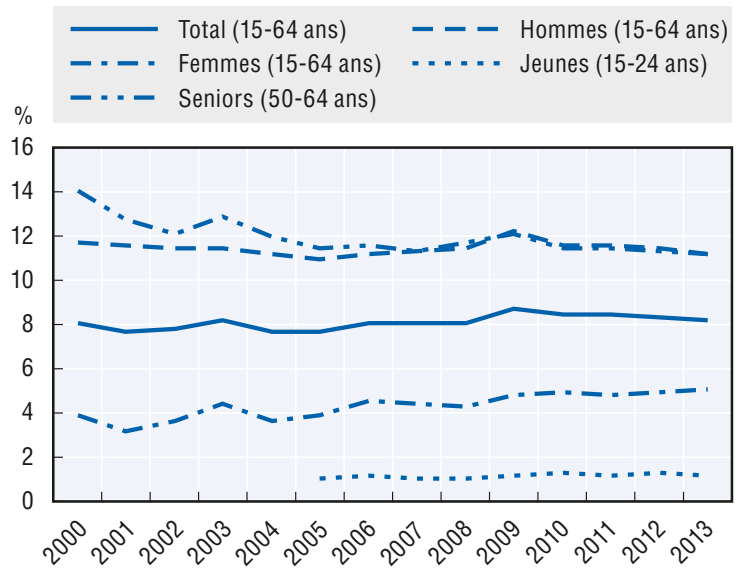

Diagramme E. Nombre total des entrepreneurs au stade précoce qui envisagent de créer plus de 19 emplois dans les 5 ans, 2009-2013 (combinés)

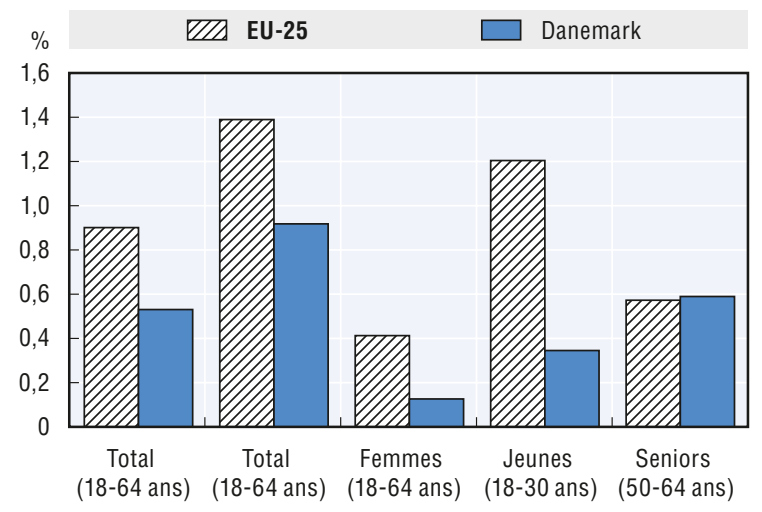

Diagramme B. Taux de travail indépendant, 2013

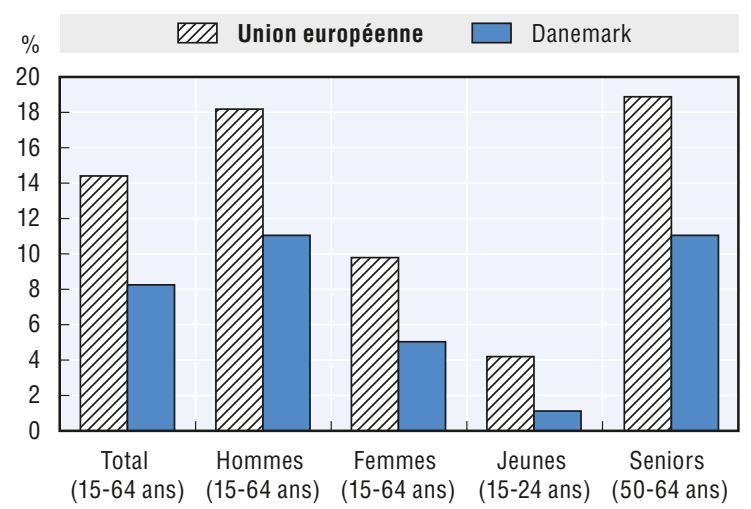

Diagramme D. Indice de l'activité entrepreneuriale totale au stade précoce, 2009-2013 (combinés)

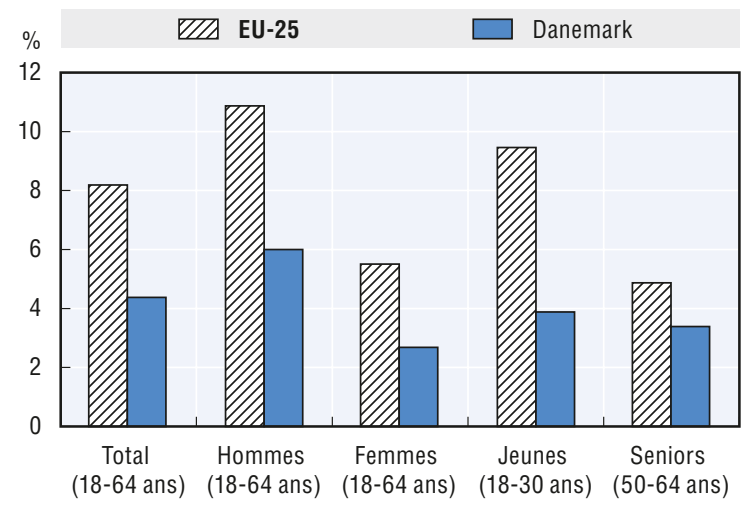

Sources: Diagramme A. Eurostat, Enquête sur les forces de travail, 2000-2013; Diagramme B. Eurostat, Enquête sur les forces de travail, 2013; Diagramme C. Eurostat, Enquête sur les forces de travail, 2000-2013; Diagramme D. Présentation tabulaire spéciale de l'enquête sur la population adulte du Global Entrepreneurship Monitor, 2009-2013; Diagramme E. Présentations tabulaires spéciales de l'enquête sur la population adulte du Global Entrepreneurship Monitor, 2009-2013. 


\section{Estonie: StartSmart!}

Cette note de pays présente brièvement un programme mis en œuvre conjointement avec la Finlande pour soutenir les jeunes dans les entreprises de croissance présentant un potentiel de développement à l'international. Elle comprend également des données clés relatives à l'entrepreneuriat inclusif en Estonie.

Description: «StartSmart!» est un projet finno-estonien et le slogan de nombreuses activités destinées aux jeunes ayant l'esprit d'entreprise (18-30 ans) en Estonie et en Finlande et dont l'ambition est de créer une entreprise de croissance ayant un potentiel de développement vers l'international. Ce projet est dirigé par cinq organisations partenaires (quatre estoniennes et une finlandaise). Plus de 50 partenaires ont également participé à l'organisation d'événements en lien avec ce projet.

Problème abordé: selon des études menées dans les deux pays, seule une faible proportion de jeunes s'oriente vers l'entrepreneuriat plutôt que vers le salariat. Les deux pays considèrent l'entrepreneuriat technologique et l'internationalisation comme des priorités, mais les jeunes manquent souvent de confiance en eux pour voir «les choses en grand». Ce projet a donc pour objectif de stimuler l'esprit d'entreprise et la coopération transfrontalière.

Approche: le projet a duré 32 mois (de mai 2011 à décembre 2013). Son objectif était rendre l'entrepreneuriat attractif aux yeux des jeunes. Il visait également à transmettre le savoir-faire nécessaire à la création et au développement d'une entreprise à l'international. Les activités et tâches étaient réparties entre les partenaires en fonction de leurs compétences et de leurs atouts (par exemple, organisation d'événements, communication, réseaux disponibles et gestion de projet). Des séminaires et ateliers thématiques ont été organisés sur une très grande variété de sujets, du séminaire d'initiation intitulé «Wantepreneur2Entepreneur» jusqu'à la conférence de clôture portant sur les leçons à tirer. La participation aux 15 séminaires était ouverte à tous sans restriction, tandis que les ateliers étaient réservés aux équipes ayant déjà une idée d'entreprise. Sous réserve des places disponibles, d'autres participants se sont joints aux équipes sur place. Les séminaires étaient suivis d'événements de mise en réseau et de lancement d'idées. Tous les événements de ce programme ont bénéficié d'une couverture médiatique et ont été retransmis en vidéo sur internet. Le but était d'inspirer également les personnes n'ayant pas pu y participer en personne. Des formations ont également été dispensées sur des thèmes particuliers, comme l'entrepreneuriat social et les technologies de la santé. Les participants ont été deux fois plus nombreux que prévu. Le budget total de ce projet s'est élevé à 889000 euros, dont 77,08 \% ont été financés par le Fonds européen de développement rural (programme opérationnel Interreg IVA Baltique centrale 2007-2013).

Impact: «StartSmart!» a attiré 1395 participants d'Estonie et de Finlande et quelque 437 équipes ont participé aux ateliers et développé leur idée d'entreprise. Globalement, 89 nouvelles idées d'entreprise ont été présentées à la communauté des jeunes entrepreneurs lors des événements de lancement d'idées et 12 entreprises ont été créées. La diffusion en direct des événements a permis d'élargir l'audience, puisque 81000 personnes ont pu les visionner sur internet et les 278 présentations postées sur YouTube ont été vues 20874 fois. Tous les participants ayant rempli le questionnaire de satisfaction ont indiqué que les événements leur avaient permis de nouer des contacts.

Facteurs de réussite: ce projet met en lumière l'intérêt de l'utilisation optimale des réseaux sociaux (par exemple, Facebook, Twitter, YouTube, Mailchimp, diffusion des événements sur internet) et la publicité pour élargir l'audience et accroître la participation à ses activités. Les autres facteurs de réussite notables sont: la priorité accordée à la mise en réseau; l'expérience et l'innovation entrepreneuriales; les activités de communication des partenaires du projet; et l'implication d'autres organisations de promotion de l'entrepreneuriat du pays dans les activités et événements et leur utilisation des canaux de communication. 


\section{Données clés relatives à l'entrepreneuriat inclusif}

\section{Graphique 17.1. Données relatives à l'entrepreneuriat et au travail indépendant en Estonie}

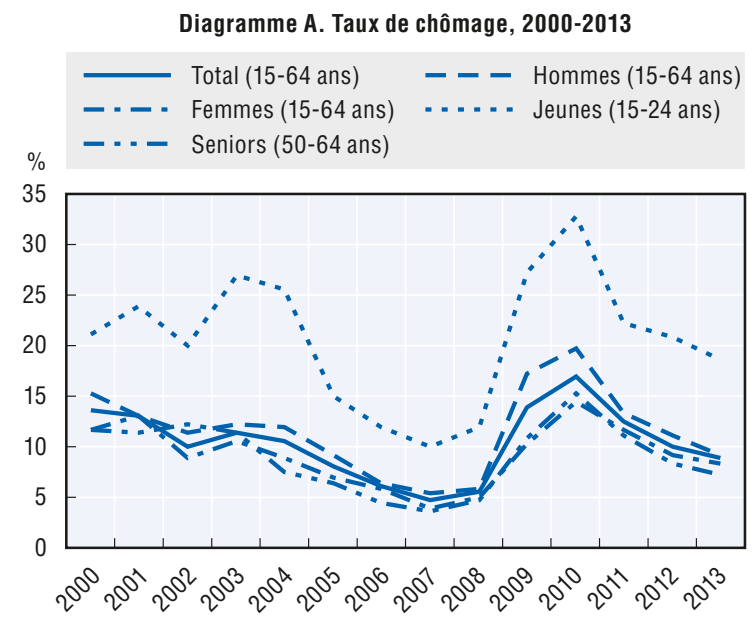

Diagramme B. Taux de travail indépendant, 2013
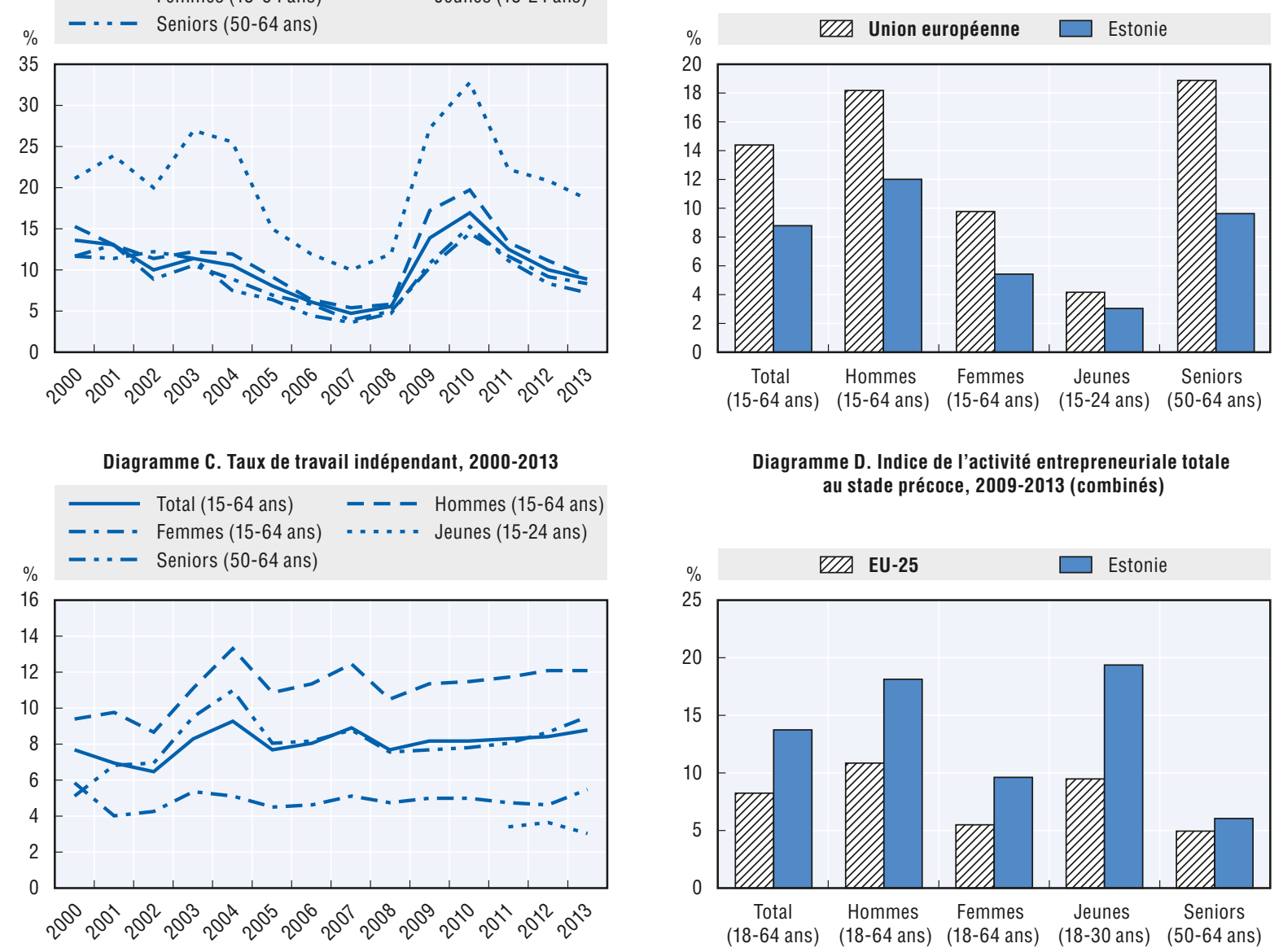

Diagramme D. Indice de l'activité entrepreneuriale totale au stade précoce, 2009-2013 (combinés)

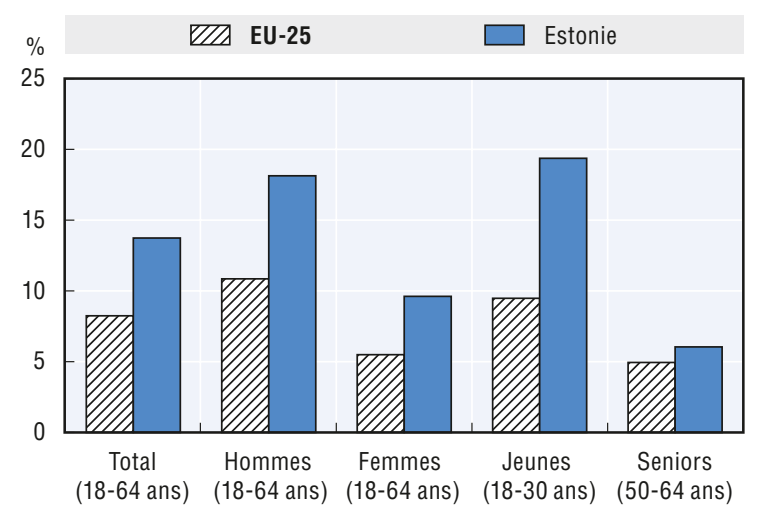

Diagramme E. Nombre total des entrepreneurs au stade précoce qui envisagent de créer plus de 19 emplois dans les 5 ans, 2009-2013 (combinés)

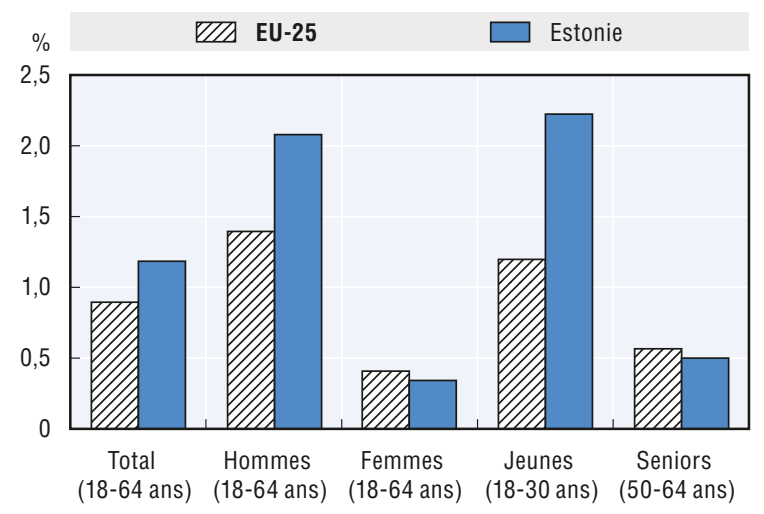

Sources: Diagramme A. Eurostat, Enquête sur les forces de travail, 2000-2013; Diagramme B. Eurostat, Enquête sur les forces de travail, 2013; Diagramme C. Eurostat, Enquête sur les forces de travail, 2000-2013; Diagramme D. Présentation tabulaire spéciale de l'enquête sur la population adulte du Global Entrepreneurship Monitor, 2009-2013; Diagramme E. Présentations tabulaires spéciales de l'enquête sur la population adulte du Global Entrepreneurship Monitor, 2009-2013. 


\section{Finlande: Atelier d'aide à la création d'entreprises destiné aux moins de 30 ans}

Cette note de pays présente brièvement un programme de formation qui aide les jeunes à développer une idée d'entreprise. Elle comprend également des données clés relatives à l'entrepreneuriat inclusif en Finlande.

Description: l'atelier de création d'entreprises propose un programme de formation sur le développement d'idées d'entreprise, puis du plan d'affaires. Cet atelier est destiné aux jeunes âgés de moins de 30 ans qui sont au chômage ou risquent de perdre leur emploi. La participation à ce programme donne droit à une aide financière au titre de la création d'entreprises de la part du gouvernement d'une durée maximale de 18 mois (accordée par tranche de 6 mois et dont le renouvellement est conditionné aux performances de l'entreprise au cours de la tranche précédente). Il vise à soutenir l'entrepreneur dans ses dépenses personnelles (plutôt que professionnelles) au cours des phases de démarrage de l'entreprise. Ce projet est actuellement mis en œuvre à l'échelle régionale, mais il est prévu qu'il soit élargi à tout le pays. Cet atelier sur la création d'entreprises est financé par le ministère de l'emploi et de l'économie par le biais des agences régionales pour l'emploi et l'entreprise, et mis en œuvre par le Small Business Centre de l'université Aalto de Helsinki.

Problème abordé: les jeunes chômeurs ont davantage de difficultés à créer leur entreprise que la population générale du fait de leur manque de compétences entrepreneuriales, d'épargne et, dans une moindre mesure, d'expérience professionnelle. Cet atelier sur la création d'entreprises vise à lever ces obstacles grâce à un programme intensif de mentorat destiné à renforcer leurs compétences entrepreneuriales et leur efficacité personnelle en mettant l'accent sur la création d'opportunités de mise en réseau et sur la confiance en soi.

Approche: cet atelier a eu lieu pour la première fois à l'automne 2013, puis une nouvelle session a été organisée au printemps 2014. Lors de la deuxième session, 131 personnes ont déposé une candidature, 60 ont passé un entretien, 30 ont été sélectionnées pour participer à la formation initiale de deux semaines et 20 personnes ont suivi l'atelier d'approfondissement d'une durée de six semaines. Les critères de sélection incluaient le niveau et la qualité de la participation à la formation, la faisabilité du projet d'entreprise et la crédibilité du désir de créer une entreprise peu de temps après la formation. La formation initiale d'une durée de deux semaines portait sur les motivations entrepreneuriales et le développement d'idées d'entreprises, tandis que l'atelier d'approfondissement d'une durée de six semaines visait à aider les participants à développer une idée d'entreprise réaliste pour laquelle ils pourraient solliciter une aide financière au titre de la création d'entreprise. Ce programme intensif a été complété par six journées thématiques organisées sur une période de six mois au cours desquels les participants ont bénéficié d'une formation approfondie sur des sujets spécifiques comme la création d'une boutique en ligne, l'image de marque ou la commercialisation.

Impact: un questionnaire d'une page, distribué aux neuf participants le dernier jour de la formation, lors de la première session, a révélé que six d'entre eux avaient déjà créé leur entreprise, et que deux autres en avaient l'intention dans les six mois à venir (le dernier participant n'ayant pas encore décidé). Selon les réponses des participants ayant déjà créé leur entreprise, quatre d'entre eux n'auraient pas créé d'entreprise sans l'aide de ce programme. Sur les neuf participants ayant répondu, seul un a indiqué que le principal avantage de cette formation était le sentiment d'appartenir à une communauté, tandis que tous les autres ont évoqué la teneur du programme (prévisions financières, commercialisation, ventes, etc.).

Facteurs de réussite: l'un des principaux facteurs de réussite de ce projet est l'implication des formateurs, qui est allée bien au-delà d'un enseignement magistral pour donner envie aux participants de s'engager dans la voie de l'entrepreneuriat. L'octroi des financements a été optimisé grâce à une sélection stricte des participants, ce qui a eu également un impact sur la dynamique du groupe. 


\section{Données clés relatives à l'entrepreneuriat inclusif}

\section{Graphique 18.1. Données relatives à l'entrepreneuriat et au travail indépendant en Finlande}

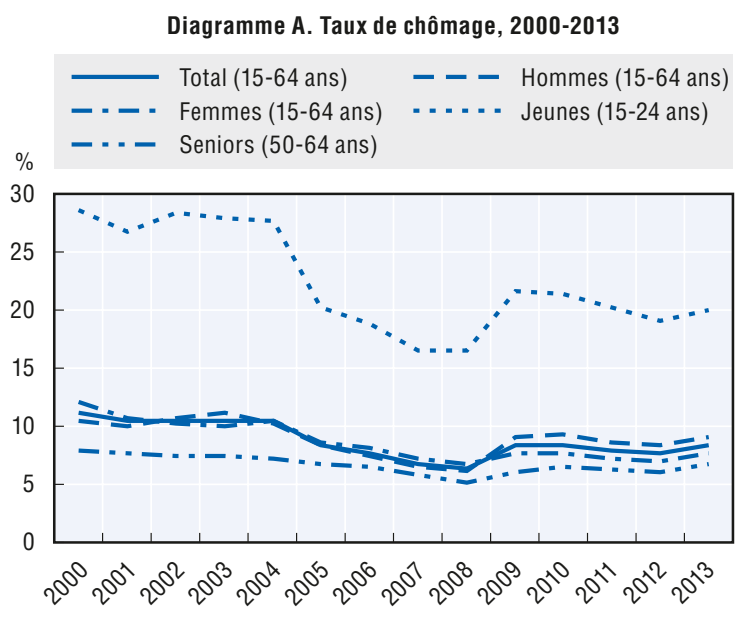

Diagramme B. Taux de travail indépendant, 2013
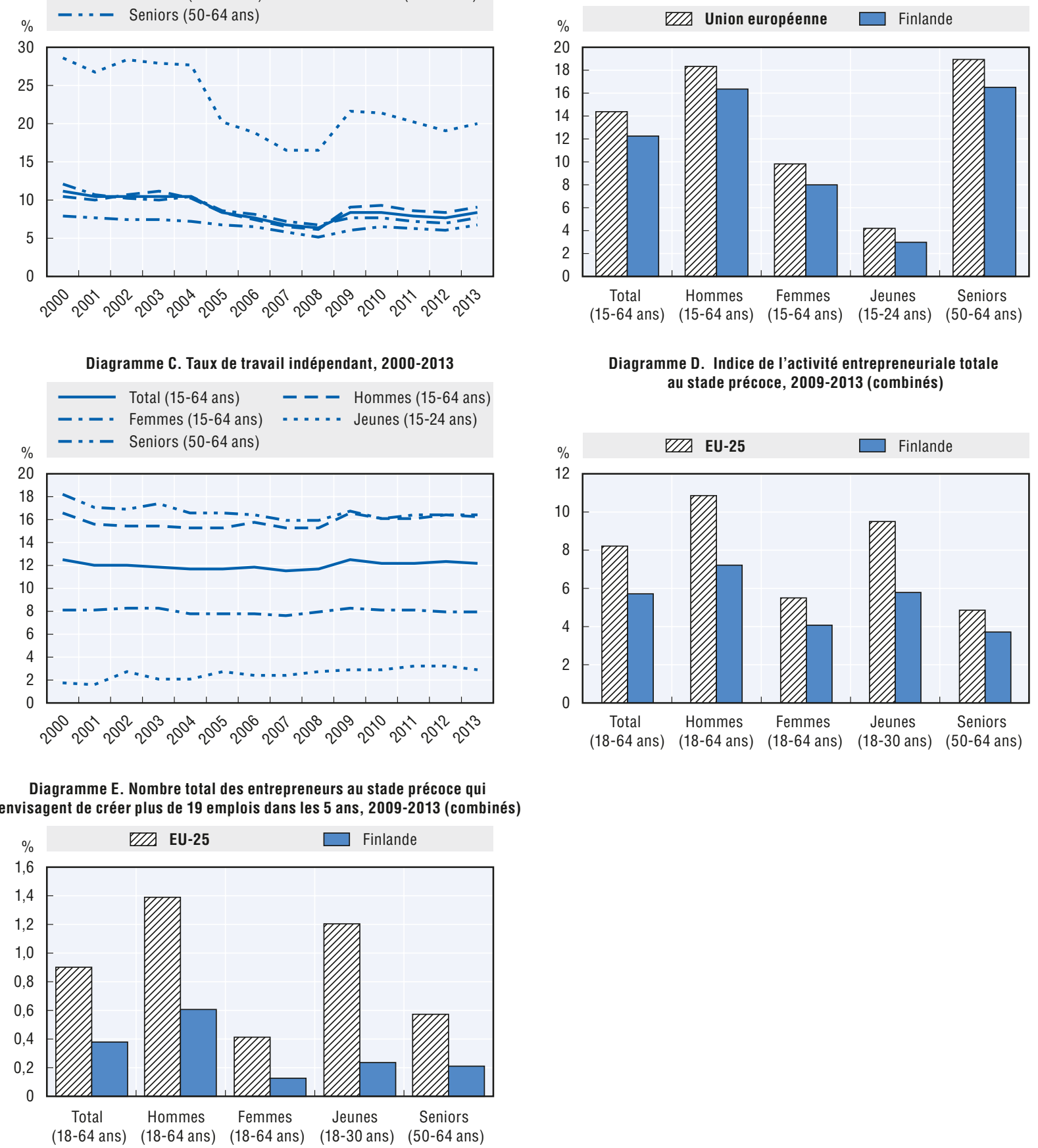

Sources: Diagramme A. Eurostat, Enquête sur les forces de travail, 2000-2013; Diagramme B. Eurostat, Enquête sur les forces de travail, 2013; Diagramme C. Eurostat, Enquête sur les forces de travail, 2000-2013; Diagramme D. Présentation tabulaire spéciale de l'enquête sur la population adulte du Global Entrepreneurship Monitor, 2009-2013; Diagramme E. Présentations tabulaires spéciales de l'enquête sur la population adulte du Global Entrepreneurship Monitor, 2009-2013. 


\section{France: ouvrir les portes de la banque aux jeunes entrepreneurs}

Cette note de pays présente brièvement un programme de soutien aux jeunes entrepreneurs dans leurs recherches de financements. Elle comprend également des données clés relatives à l'entrepreneuriat inclusif en France.

Description: ce projet géré par France Active vise à préparer les jeunes entrepreneurs à chercher et à négocier des aides à la création d'entreprise. Il complète d'autres initiatives d'aide à l'entrepreneuriat grâce à deux instruments supplémentaires: une formation d'une journée pour aider les entrepreneurs à préparer leur rendez-vous à la banque avec leur chargé de clientèle et une "prime» de 2000 euros (en complément des autres aides comme un prêt ou une garantie). Les jeunes entrepreneurs, en majorité âgés de moins de 26 ans, sont le groupe cible de ce projet.

Problème abordé: l'enquête SINE (génération 2006 trois ans après), conduite par l'Institut national de la statistique et des études économiques (INSEE), révèle que les deux principaux obstacles à l'entrepreneuriat indiqués par les jeunes Français ont été les difficultés à remplir les formalités administratives (40\% des jeunes de moins de 30 ans, contre $36 \%$ des 30-40 ans) et la crainte de ne pas obtenir de financement approprié (19\% des moins de 30 ans). Ces difficultés de financement sont dues à leur faible niveau d'épargne, à leur manque d'expérience et de formation et à la faiblesse de leurs réseaux.

Approche: entre mai et décembre 2011, 70 jeunes entrepreneurs ayant un projet de création d'entreprises ont été sélectionnés (par les agents des 4 caisses locales participant au projet pilote) pour participer à la formation destinée à les aider à traiter avec les banques. Cinquante d'entre eux ont bénéficié de la prime de 2000 euros et d'une garantie pour leur prêt. La prime devait quant à elle contribuer au capital de l'entreprise (fonds propre). Sur les 20 projets non éligibles à la prime, le comité de sélection n'a rejeté que trois demandes de financement, les 17 autres ayant été abandonnés à la phase d'amorçage. Ce projet a été financé par le ministère de la jeunesse, par le biais de France Active et des caisses locales.

Impact: les jeunes entrepreneurs participant à ce projet disposaient déjà d'un projet d'entreprise et recherchaient des financements. Toutefois, selon les entretiens menés auprès des entrepreneurs et des banques, la formation d'une journée sur la négociation de prêts bancaires a augmenté leurs chances de réussite et amélioré l'image des jeunes entrepreneurs. Grâce à la prime qui leur a permis de combler le manque de financement initial et d'augmenter le niveau de capitaux propres, les banques étaient plus rassurées, et donc moins réticentes à leur octroyer un prêt. Cette plus grande autonomie financière permet également de proposer ou de solliciter des crédits plus conséquents. Cette intervention aide ainsi les jeunes entrepreneurs à couvrir les coûts de lancement de leur entreprise.

Facteurs de réussite: la prime de ce programme semble avoir joué un rôle essentiel, car elle a été un gage de qualité aux yeux des institutions bancaires et a aidé les entrepreneurs à atteindre le seuil clé de $20 \%$ de fonds propres. 


\section{Données clés relatives à l'entrepreneuriat inclusif}

\section{Graphique 19.1. Données relatives à l'entrepreneuriat et au travail indépendant en France}

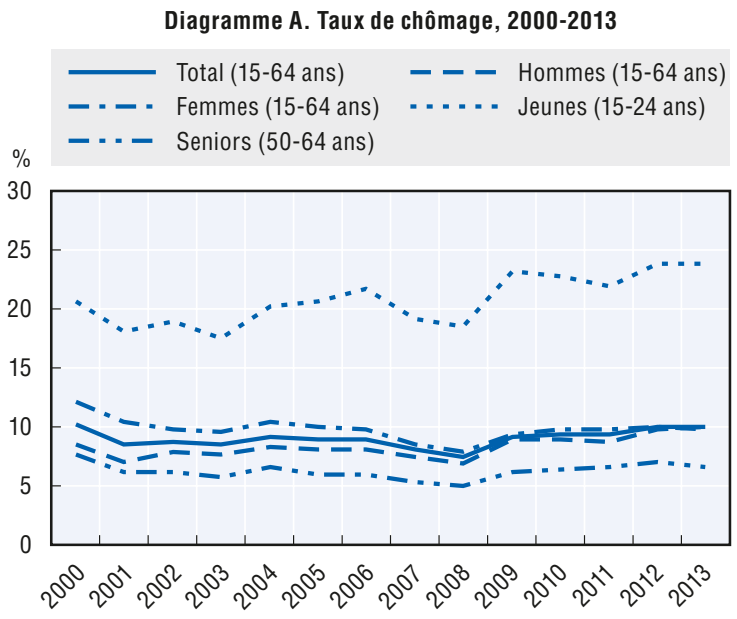

Diagramme B. Taux de travail indépendant, 2013

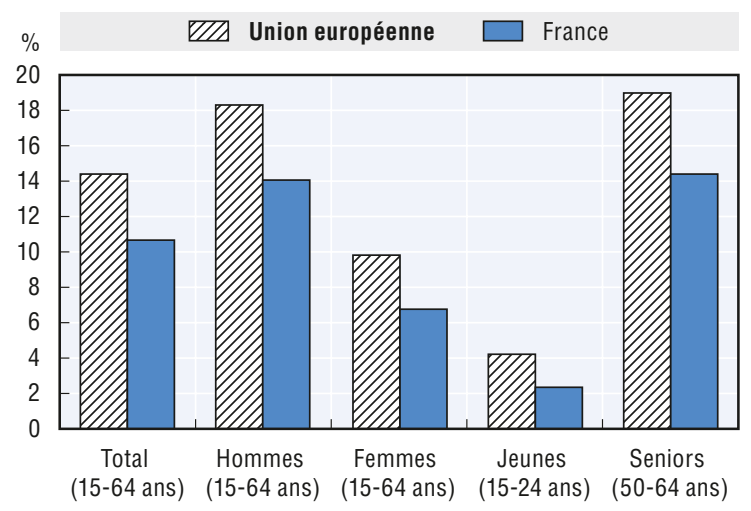

Diagramme C. Taux de travail indépendant, 2000-2013

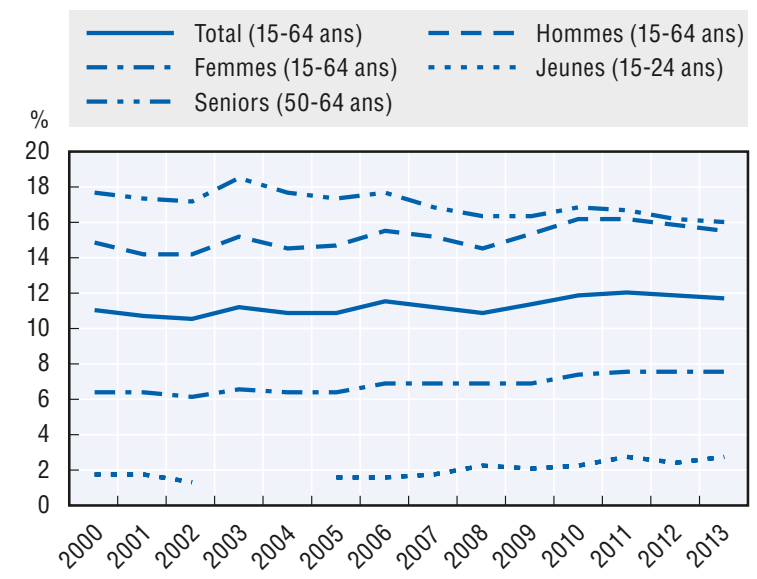

Diagramme D. Indice de l'activité entrepreneuriale totale au stade précoce, 2009-13 (combinés)

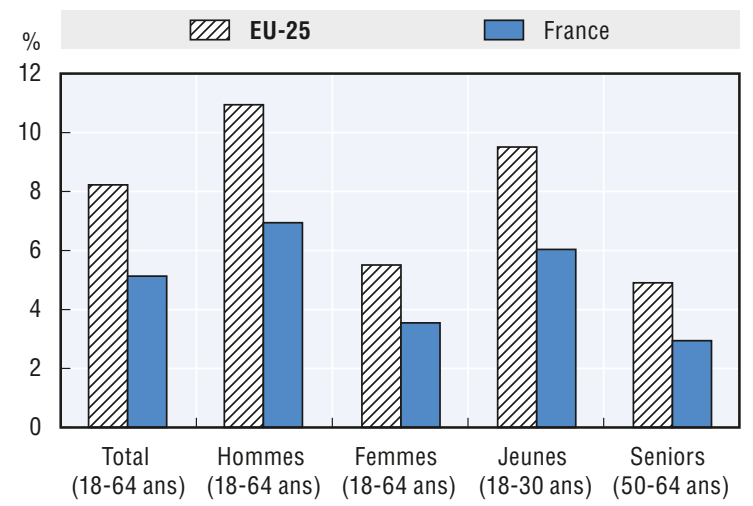

Diagramme E. Nombre total des entrepreneurs au stade précoce qui envisagent de créer plus de 19 emplois dans les 5 ans, 2009-2013 (combinés)

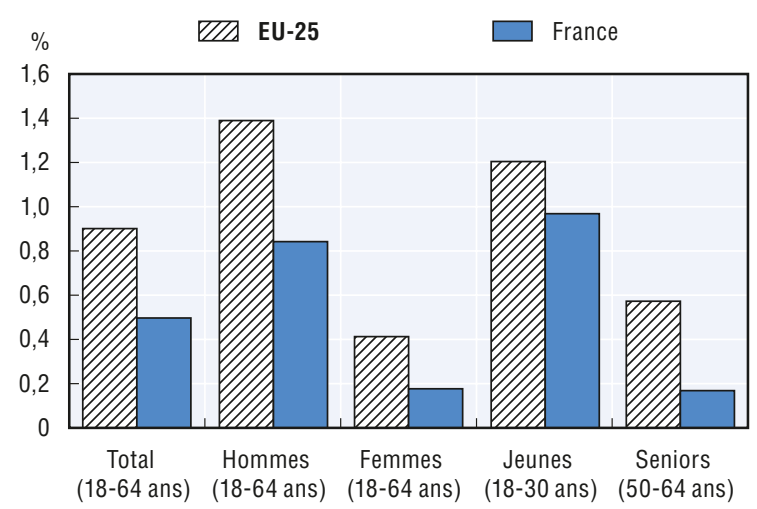

Sources: Diagramme A. Eurostat, Enquête sur les forces de travail, 2000-2013; Diagramme B. Eurostat, Enquête sur les forces de travail, 2013; Diagramme C. Eurostat, Enquête sur les forces de travail, 2000-2013; Diagramme D. Présentation tabulaire spéciale de l'enquête sur la population adulte du Global Entrepreneurship Monitor, 2009-2013; Diagramme E. Présentations tabulaires spéciales de l'enquête sur la population adulte du Global Entrepreneurship Monitor, 2009-2013. 


\section{Allemagne: Bundesweite Gründerinnenagentur (BGA) (Agence nationale d'activités et de services d'aide à la création d'entreprises par des femmes)}

Cette note de pays présente brièvement un programme national et une institution qui soutiennent les femmes entrepreneurs. Elle comprend également des données clés relatives à l'entrepreneuriat inclusif en Allemagne.

Description: lancé en 2004, le Bundesweite Gründerinnenagentur (BGA) est un guichet unique de services d'information et d'aide réservé aux femmes entrepreneurs dans l'ensemble du pays. Le BGA s'adresse aux créatrices d'entreprise et aux femmes entrepreneurs, aux réseaux privés et publics concernés, aux intermédiaires dans les organismes publics et les entreprises, ainsi qu'aux chercheurs universitaires et aux médias. Les activités du BGA sont gérées par un comité de pilotage composé de représentants des ministères fédéraux et du siège du BGA. Le BGA conçoit et coordonne les initiatives conjointes et les politiques en faveur des femmes entrepreneurs, et communique son expérience et son savoir-faire pour alimenter le processus politique.

Problème abordé: les femmes entrepreneurs se distinguent par leur approche et leur motivation, leur parcours professionnel et leur carrière, leur accès au capital financier, leurs objectifs pour l'entreprise, etc. De ce fait, les politiques publiques traditionnelles d'aide aux entreprises peuvent parfois ne pas répondre aux besoins des femmes entrepreneurs. De plus, les femmes sont souvent confrontées à d'autres difficultés comme le manque de solutions de garde d'enfants.

Approche: en tant que premier et unique centre national de services et de savoirfaire pour les femmes entrepreneurs d'Allemagne, le BGA développe et propose une grande variété d'activités et de services conçus spécialement pour aider les femmes entrepreneurs, notamment des services d'information, de conseil, de mentorat et de coaching, de mise en réseau et de formation à l'entrepreneuriat. Le portail internet du BGA est une plateforme centrale d'échange et d'information. Il contient trois répertoires nationaux de prestataires de services de conseils spécialisés pour les femmes (plus de 500 noms) et consultants spécialisés dans l'entrepreneuriat des femmes (environ 1200 noms) et de réseaux et de centres d'affaires de femmes entrepreneurs (plus de 300). De plus, chaque année, le calendrier des événements en ligne compte environ 400 formations et événements (par exemple, congrès et salons professionnels). L'organisation faîtière et son siège sont situés à Stuttgart. Elle pilote, coordonne et centralise les services d'information et de conseil. Des bureaux régionaux ont été ouverts dans les 16 États fédéraux d'Allemagne. Ils élaborent et coordonnent les activités d'aide aux femmes entrepreneurs au niveau des Länder et servent de points de contact pour les acteurs locaux et régionaux. Globalement, le BGA a permis de mettre en place un réseau rassemblant plus de 2000 partenaires, notamment des consultants spécialisés, des femmes entrepreneurs, des centres d'affaires de femmes, des institutions publiques et professionnelles.

Impact: l'impact du BGA sur le nombre de femmes entrepreneurs ne peut pas être mesuré avec précision, car la création d'entreprises est influencée par un grand nombre de facteurs. Cependant, quelques chiffres peuvent donner une idée de sa portée: son site internet a reçu 21 millions de visites, les 40 publications du BGA ont été diffusées à 260000 exemplaires, 6000 séances initiales de conseils et de consultations ont été organisées, le BGA a été cité 5300 fois dans les médias et 1700 événements ont été organisés et dirigés par le BGA.

Facteurs de réussite: l'impact du BGA sur l'entrepreneuriat des femmes est lié à sa grande visibilité et à sa gamme très diversifiée de services et d'activités. Le BGA est généralement reconnu comme étant le porte-parole et l'organe central de coordination des politiques destinées aux femmes entrepreneurs. La structure de l'organisation est également un canal de communication très efficace pour développer de nouveaux programmes et collecter des données sur des besoins spécifiques. 


\section{Données clés relatives à l'entrepreneuriat inclusif}

\section{Graphique 20.1. Données relatives à l'entrepreneuriat et au travail indépendant en Allemagne}

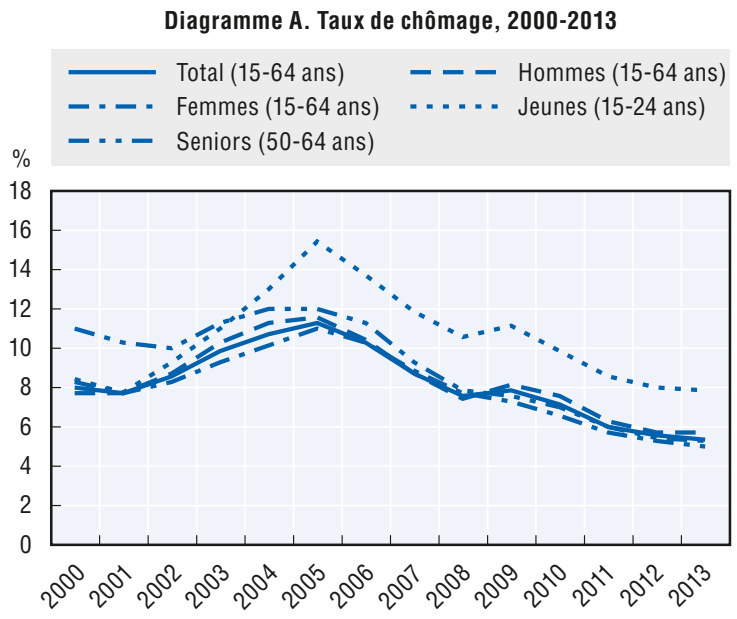

Diagramme B. Taux de travail indépendant, 2013

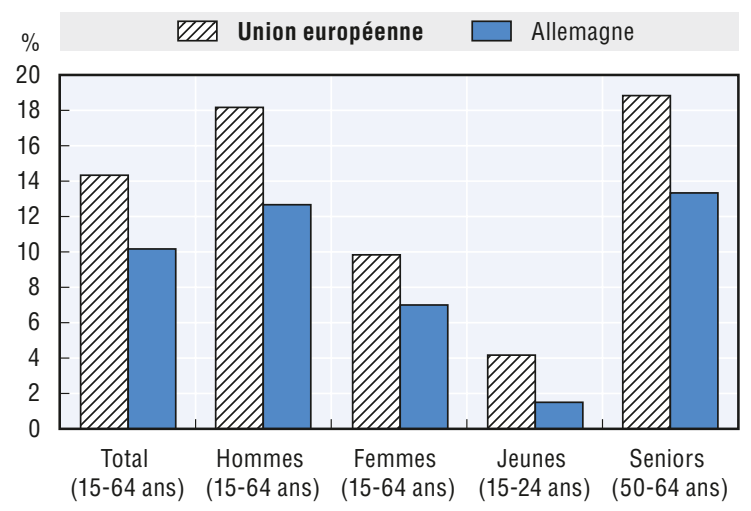

Diagramme C. Taux de travail indépendant, 2000-2013

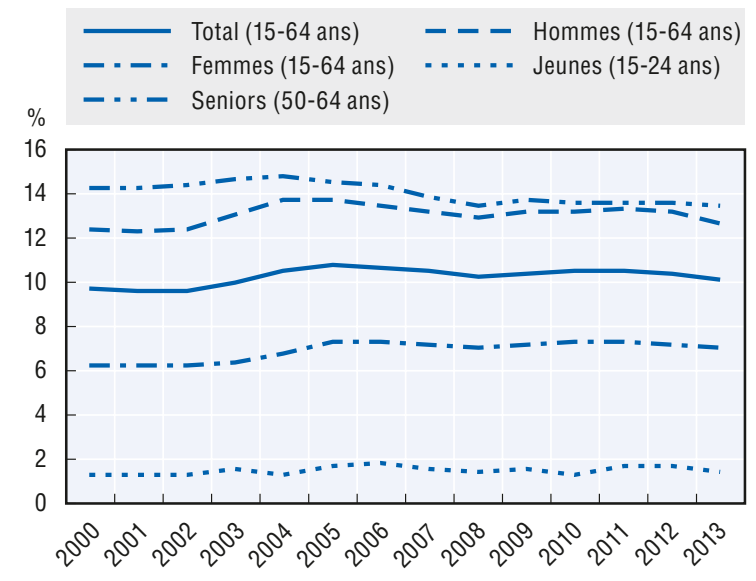

Diagramme D. Indice de l'activité entrepreneuriale totale au stade précoce, 2009-2013 (combinés)

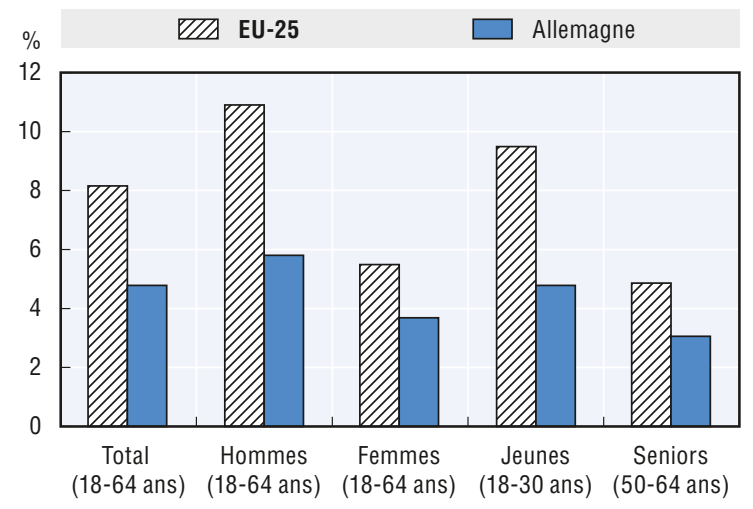

Diagramme E. Nombre total des entrepreneurs au stade précoce qui envisagent de créer plus de 19 emplois dans les 5 ans, 2009-2013 (combinés)

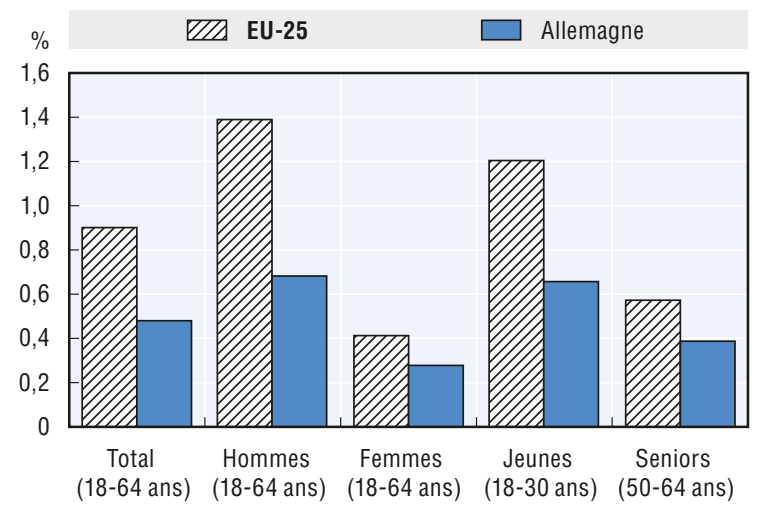

Sources: Diagramme A. Eurostat, Enquête sur les forces de travail, 2000-2013; Diagramme B. Eurostat, Enquête sur les forces de travail, 2013; Diagramme C. Eurostat, Enquête sur les forces de travail, 2000-2013; Diagramme D. Présentation tabulaire spéciale de l'enquête sur la population adulte du Global Entrepreneurship Monitor, 2009-2013; Diagramme E. Présentations tabulaires spéciales de l'enquête sur la population adulte du Global Entrepreneurship Monitor, 2009-2013. 


\section{Grèce: entrepreneuriat innovant des jeunes}

Cette note de pays présente brièvement un programme de soutien financier et de formation destiné aux jeunes qui créent une entreprise innovante. Elle comprend également des données clés relatives à l'entrepreneuriat inclusif en Grèce.

Description: ce programme s'intitule «promotion de l'emploi indépendant pour les nouveaux entrepreneurs et de la création de nouvelles entreprises orientées vers l'innovation». Il vise à encourager le travail indépendant par l'octroi d'une aide financière aux jeunes chômeurs âgés de 18 à 35 ans ayant décidé de créer une entreprise innovante. Tous les jeunes âgés de 18 à 35 ans au chômage peuvent participer à ce programme à condition d'être inscrits comme demandeurs d'emploi, d'avoir élaboré un projet personnel et de participer à un colloque sur l'entrepreneuriat à l'agence publique pour l'emploi. L'instance chargée du programme est Manpower Employment Organization (OAED), la principale agence de placement en Grèce.

Problème abordé: les jeunes (15-24 ans) ont été touchés de façon disproportionnée par la grave récession qui frappe la Grèce actuellement. Leur taux de chômage était de 60 \% en 2013 . Le travail indépendant peut contribuer à intégrer plus de jeunes sur le marché de l'emploi, $50 \%$ des adultes déclarant préférer un emploi indépendant au salariat (CE, 2013). Les jeunes rencontrent toutefois des difficultés pour trouver des financements. Par exemple, la proportion de refus de demandes de prêt bancaire déposées par des PME est plus élevée en Grèce (37 \%) que dans l'ensemble de l'Union européenne (15\%). Plusieurs programmes de prêts et de subventions ont été créés pour remédier à ce problème, mais ils se sont concentrés sur les secteurs à faible valeur ajoutée (par exemple restaurants, bars, traiteurs, vente au détail de vêtements et/ou de chaussures). Les nouvelles entreprises innovantes doivent davantage exploiter les opportunités potentielles des secteurs du tourisme, de l'agroalimentaire et des technologies de l'information et de la communication (TIC).

Approche: ce programme vise à offrir un soutien financier aux nouvelles entreprises innovantes créées par de jeunes chômeurs. Après le dépôt d'une demande de subvention, un comité d'évaluation examine l'éligibilité de la candidature de l'entrepreneur sur la base de la qualité du plan d'affaires, de la pertinence des qualifications et de l'expérience professionnelle du candidat, du degré d'innovation de sa proposition d'entreprise et du montant de sa propre contribution. Chaque candidat sélectionné reçoit une subvention de 10000 euros, versée en trois fois sur 12 mois, pour l'aider à créer son entreprise. Le programme a bénéficié d'un budget de 20 millions d'euros, en partie cofinancé par le programme opérationnel pour le développement des ressources humaines 2007-2013 du FSE.

Impact: l'initiative a été lancée en décembre 2013 et n'a pas encore été évaluée. Une évaluation d'un programme similaire (OAED, 2009) a permis de conclure que les entreprises ayant bénéficié de cette subvention présentent de meilleurs taux de survie que les autres (environ 90 \% sur trois ans). L'accent mis sur les activités innovantes devrait limiter les effets de substitution associés aux activités traditionnelles des programmes précédents.

Facteurs de réussite: la conception de ce programme s'appuie sur les enseignements tirés des résultats des évaluations des programmes précédents, notamment la décision de mettre l'accent sur l'aide aux entreprises innovantes.

Références: Commission européenne (2013), "Small Business Act (SBA) — Fiche technique 2013: Grèce", disponible en anglais à l'adresse suivante: http://ec.europa.eu/enterprise/policies/sme/ facts-figures-analysis/performance-review/files/countries-sheets/2013/greece_en.pdf.

OAED (2009), Evaluation of the New Liberal Professionals Programme (NEE) of 2004, Athènes. 


\section{Données clés relatives à l'entrepreneuriat inclusif}

\section{Graphique 21.1. Données relatives à l'entrepreneuriat et au travail indépendant en Grèce}
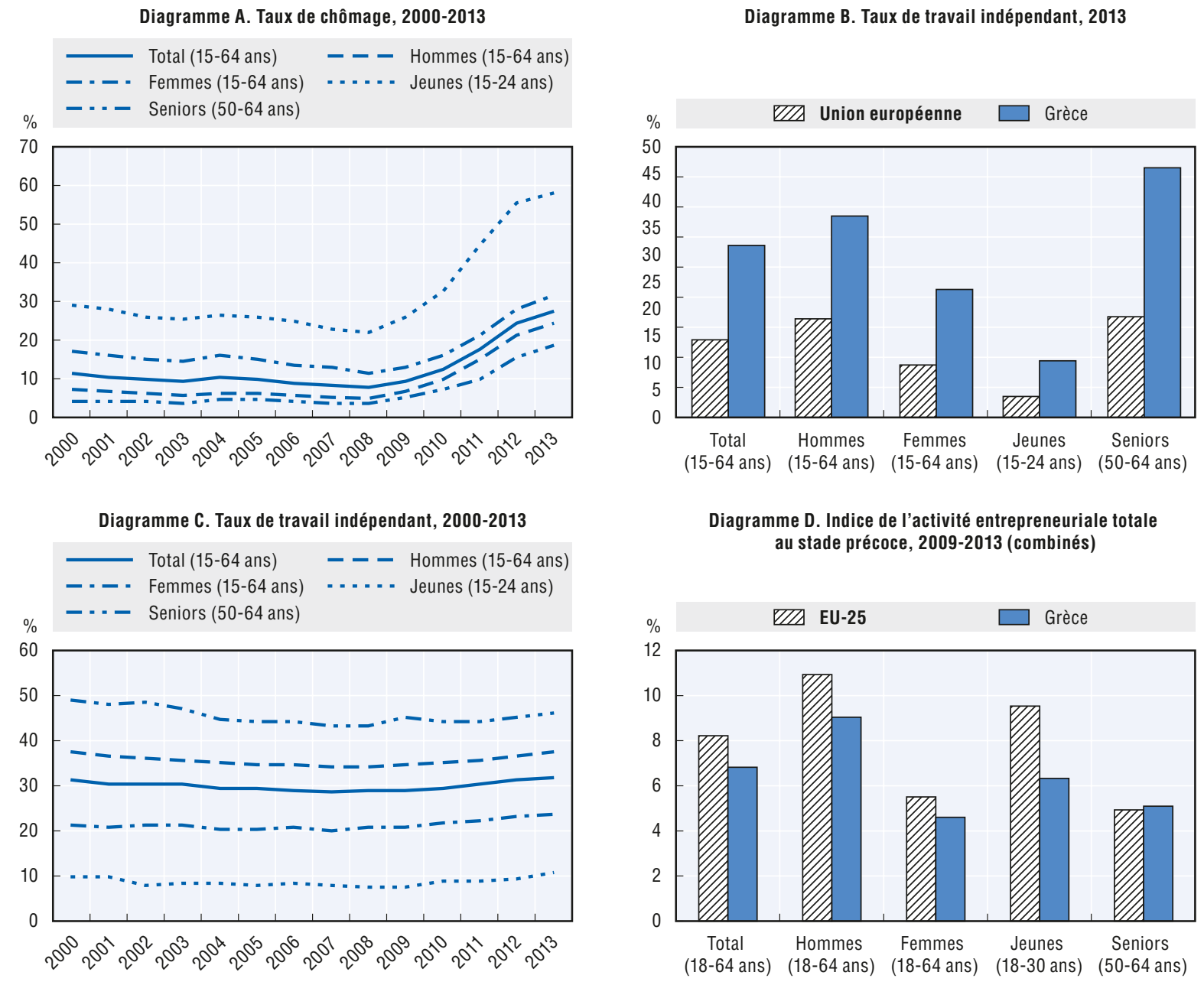

\section{Diagramme D. Indice de l'activité entrepreneuriale totale au stade précoce, 2009-2013 (combinés)}

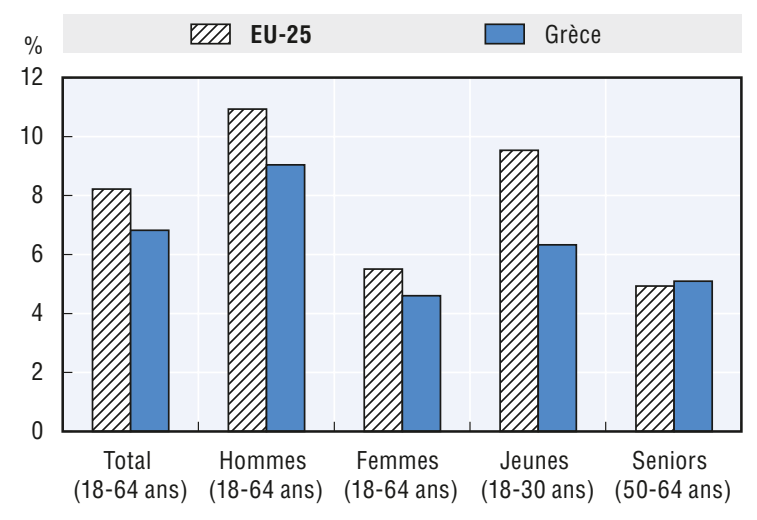

Diagramme E. Nombre total des entrepreneurs au stade précoce qui envisagent de créer plus de 19 emplois dans les 5 ans, 2009-2013 (combinés)

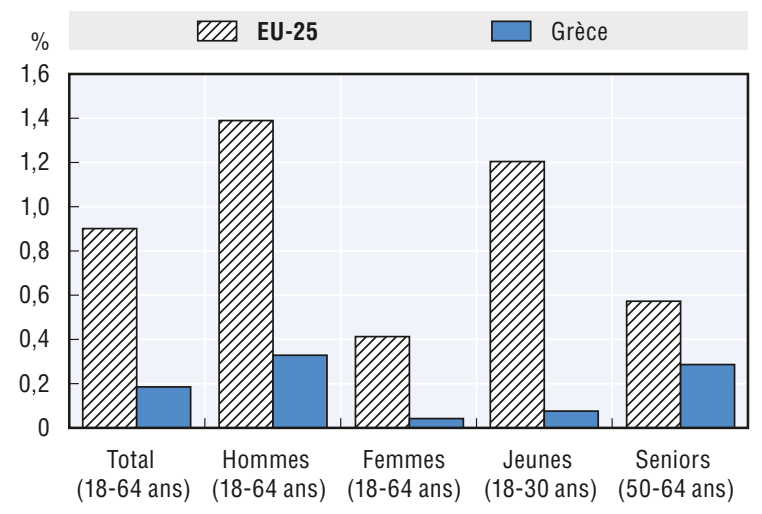

Sources: Diagramme A. Eurostat, Enquête sur les forces de travail, 2000-2013; Diagramme B. Eurostat, Enquête sur les forces de travail, 2013; Diagramme C. Eurostat, Enquête sur les forces de travail, 2000-2013; Diagramme D. Présentation tabulaire spéciale de l'enquête sur la population adulte du Global Entrepreneurship Monitor, 2009-2013; Diagramme E. Présentations tabulaires spéciales de l'enquête sur la population adulte du Global Entrepreneurship Monitor, 2009-2013. 


\section{Hongrie: centre musical Snétberger}

Cette note de pays présente brièvement un programme qui encourage les jeunes roms à devenir des musiciens professionnels indépendants. Elle comprend également des données clés relatives à l'entrepreneuriat inclusif en Hongrie.

Description: le centre musical Snétberger a été fondé en 2011 par un musicien de jazz d'origine rom pour promouvoir l'intégration économique et sociale des jeunes défavorisés en Hongrie et notamment, mais non exclusivement, des jeunes roms, grâce à l'enseignement de la musique et au mentorat. Ses principaux objectifs sont d'améliorer l'estime de soi et les compétences des participants, et de les aider à débuter leur vie professionnelle, y compris au travers de l'emploi indépendant.

Problème abordé: en 2012, 11,5 \% des jeunes Hongrois étaient en décrochage scolaire tandis que $35 \%$ des élèves du primaire, $30 \%$ des élèves de l'enseignement professionnel et près de $10 \%$ des élèves du secondaire étaient considérés comme issus d'un milieu défavorisé (MPT, 2013). Ces taux sont nettement plus élevés que ceux des pays voisins. La situation des Roms est particulièrement difficile. Les jeunes de ce groupe connaissent de grandes difficultés pour accéder à l'enseignement secondaire et supérieur et à l'emploi.

Approche: le centre propose des services de mentorat, d'aide par les pairs et d'orientation professionnelle ainsi qu'un cursus d'études en musique classique. À cette occasion, chaque participant a bénéficié d'une formation, d'un soutien par les pairs et d'un mentor personnel. En 2013, le centre comptait 6 mentors, tous diplômés en enseignement, sociologie ou travail social. Les mentors sont notamment chargés d'animer des camps d'une durée de 6 semaines dans différentes régions du pays. En 2011, 68 personnes ont participé au premier camp organisé à Felsőőrs (village à l'ouest de la Hongrie). Le centre fournit également des services de mentorat et un soutien aux anciens élèves en diffusant des informations sur les évolutions de carrière (par exemple, informations sur les salaires, opportunités de représentations scéniques) et organise régulièrement des concerts. Il est prévu qu'un grand nombre de participants deviennent des travailleurs indépendants, car la plupart des musiciens exercent sous ce statut. Le centre envisage de créer un centre d'orientation professionnelle et un studio d'enregistrement. Le budget total de ce programme depuis sa fondation (coûts du bâtiment compris) s'élève à 1,2 milliard de forints (HUF) (3,9 millions d'euros).

Impact: les camps ont accueilli quelque 213 participants depuis 2011 et le centre est toujours en contact avec 90 anciens élèves. Il a contribué à organiser plus de 100 concerts pour les participants lors d'événements nationaux ou internationaux. Les enquêtes de satisfaction menées auprès des participants montrent qu'une proportion importante est satisfaite de la structure du programme et du cursus proposé.

Facteurs de réussite: le centre musical Snétberger est une initiative unique en son genre qui fait appel à la musique comme médium pour offrir des services de mentorat nécessaires au développement de l'estime de soi et de la confiance en soi. Le suivi après la fin du programme est important. Il permet de transformer les compétences et la confiance acquises en débouchés professionnels dans le salariat et le travail indépendant.

Référence: Magyar Pedagógiai Társaság — MPT (2013), Fehér könyv az oktatásról («Livre blanc sur l'éducation»), Budapest, Haza és Haladás megbízásából készült tanulmánykötet. 


\section{Données clés relatives à l'entrepreneuriat inclusif}

\section{Graphique 22.1. Données relatives à l'entrepreneuriat et au travail indépendant en Hongrie}

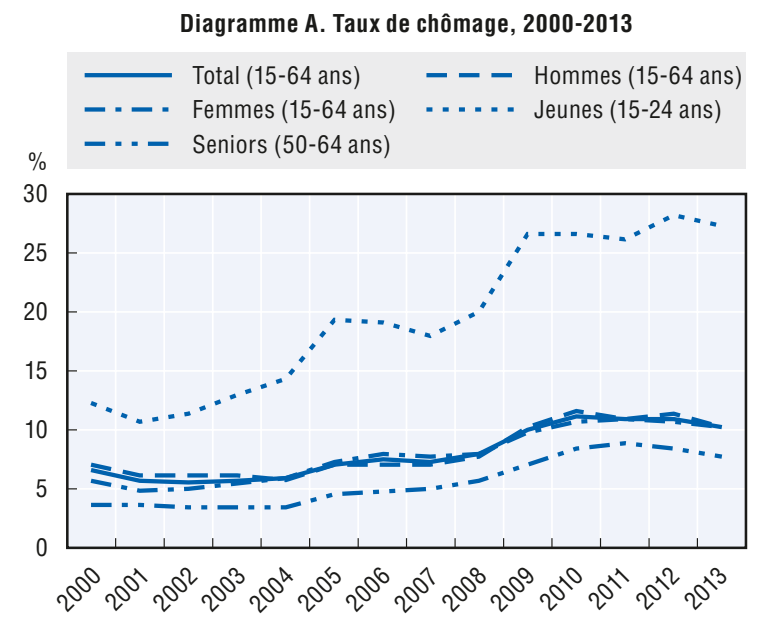

Diagramme B. Taux de travail indépendant, 2013
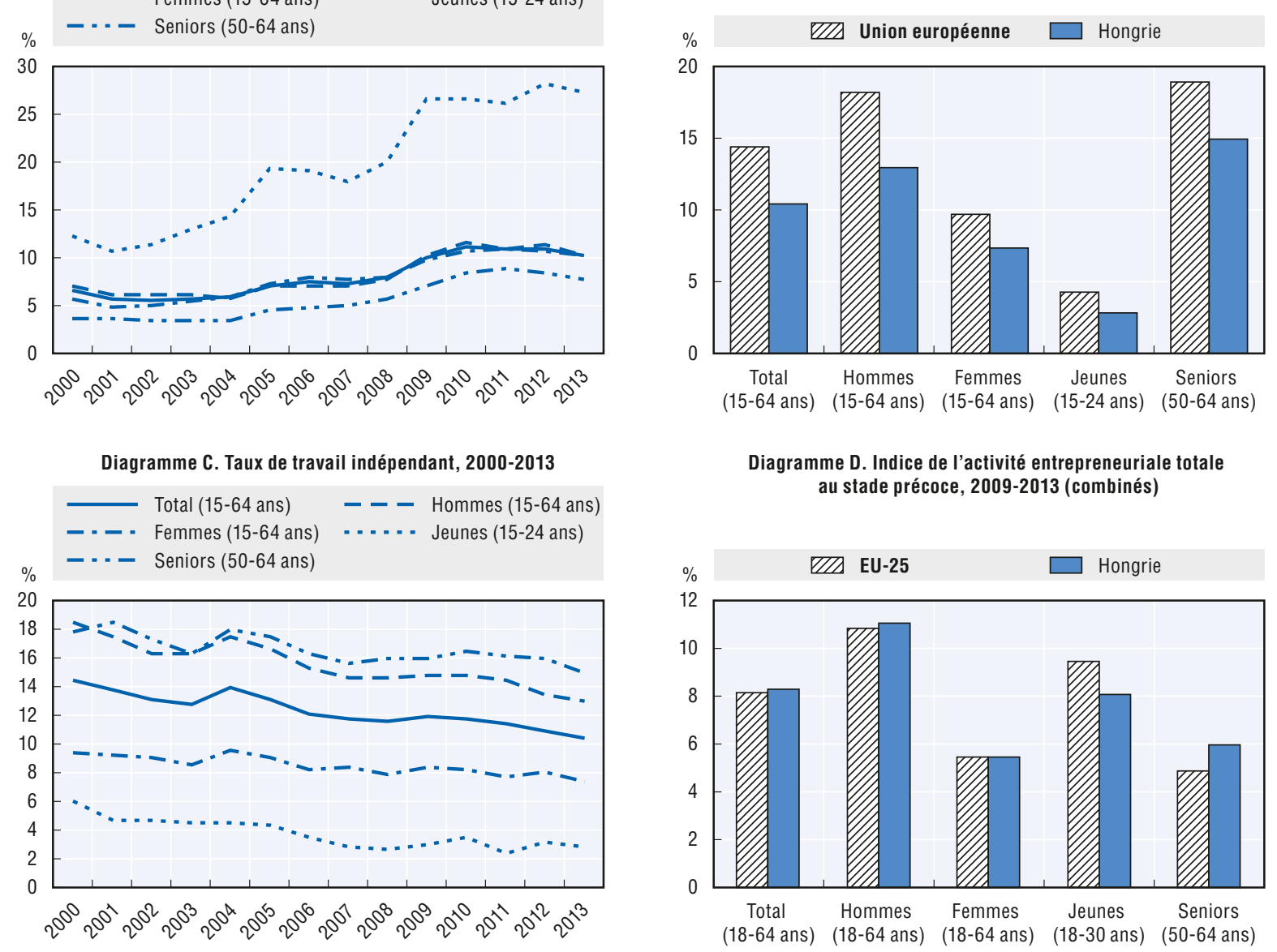

Diagramme E. Nombre total des entrepreneurs au stade précoce qui envisagent de créer plus de 19 emplois dans les 5 ans, 2009-2013 (combinés)

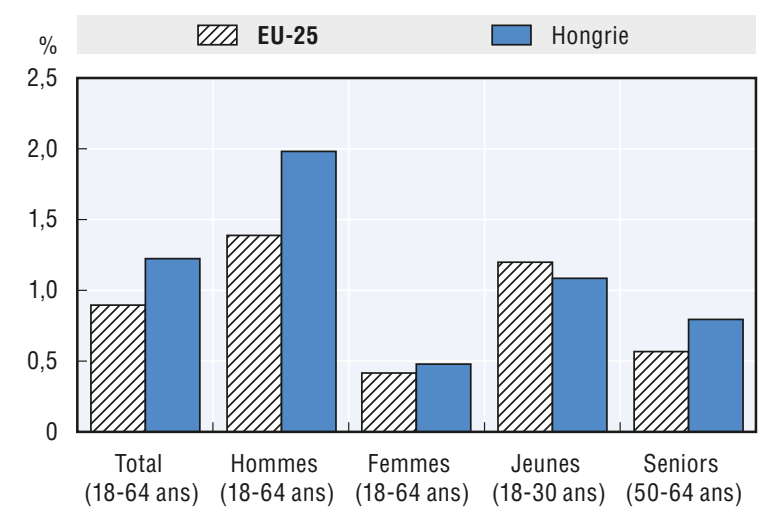

Sources: Diagramme A. Eurostat, Enquête sur les forces de travail, 2000-2013; Diagramme B. Eurostat, Enquête sur les forces de travail, 2013; Diagramme C. Eurostat, Enquête sur les forces de travail, 2000-2013; Diagramme D. Présentation tabulaire spéciale de l'enquête sur la population adulte du Global Entrepreneurship Monitor, 2009-2013; Diagramme E. Présentations tabulaires spéciales de l'enquête sur la population adulte du Global Entrepreneurship Monitor, 2009-2013. 


\section{Irlande: Enterprise Ireland Female Entrepreneurship Strategy}

Cette note de pays présente brièvement un programme qui aide les femmes à créer des entreprises à fort potentiel tournées vers l'international. Elle comprend également des données clés relatives à l'entrepreneuriat inclusif en Irlande.

Description: Enterprise Ireland (EI) travaille en partenariat avec des entreprises irlandaises pour les aider à démarrer, croître, innover et se développer sur les marchés mondiaux. EI aide également les entrepreneurs à créer des entreprises à fort potentiel et orientées vers l'international, appelées les «start-up à fort potentiel» (High Potential Start-Up, HPSU), et s'est engagé en 2012 à mettre en œuvre une stratégie intégrée visant à encourager les femmes à créer des HPSU. Cette stratégie comporte un programme de recherche sur les entraves à la création d'entreprises à fort potentiel par des femmes, une campagne globale de communication et marketing pour sensibiliser les femmes, la désignation d'un responsable de l'initiative, la définition d'objectifs clairs et l'octroi de financements dédiés aux start-up créées par des femmes par voie de concours.

Problème abordé: les entreprises dirigées par des femmes ne représentent que $7 \%$ des nouvelles HPSU dans lesquelles EI a investi en 2012. EI a créé la Female Entrepreneurship Unit dans l'objectif de multiplier par deux cette proportion. Les principales difficultés des femmes entrepreneurs identifiées par incluent l'absence de modèles, de grandes difficultés d'accès aux financements, une faible tolérance au risque, un manque de confiance en soi, un manque d'opportunités de mise en réseau entre femmes et un manque de connaissances techniques.

Approche: la stratégie d'EI porte à la fois sur le développement personnel et les opportunités de mise en réseau. Plusieurs initiatives ont été lancées, notamment la création de fonds dédiés pour soutenir le personnel des entreprises dirigées par une femme; l'identification et la promotion de modèles; le parrainage d'événements et de prix; le soutien aux anciens et nouveaux réseaux; la création d'une page internet ambitieuse consacrée aux femmes sur le site professionnel d'EI. Il a également cofinancé quatre programmes de développement axés sur l'optimisation des capacités des entreprises dirigées par des femmes, notamment «Going for Growth", qui a entamé son sixième cycle et a été conçu pour aider les femmes entrepreneurs ambitieuses à atteindre leurs objectifs de croissance par le biais d'un soutien par les pairs. EI a alloué un budget annuel de 1 million d'euros à la mise en œuvre de cette stratégie en faveur de l'entrepreneuriat des femmes

Impact: la part des investissements d'EI dans des entreprises dirigées par des femmes s'élevait à 14 \% en 2013, soit le double de celui de l'année précédente. Pour 2014, des éléments indiquent déjà que le nombre de HPSU innovantes dirigées par des femmes et soutenues par l'EI atteindra l'objectif de 15 \% défini pour l'année. L'objectif est porté à 20 \% pour l'année 2016.

Facteurs de réussite: l'identification de cette priorité et la définition d'objectifs clairs et mesurables a permis à EI de renforcer son soutien aux HPSU dirigées par des femmes. De plus, il était indispensable non seulement d'augmenter le nombre de créations d'entreprises par des femmes, mais également de contribuer à ce que les femmes aient plus d'ambition en tant qu'entrepreneurs. 


\section{Données clés relatives à l'entrepreneuriat inclusif}

\section{Graphique 23.1. Données relatives à l'entrepreneuriat et au travail indépendant en Irlande}

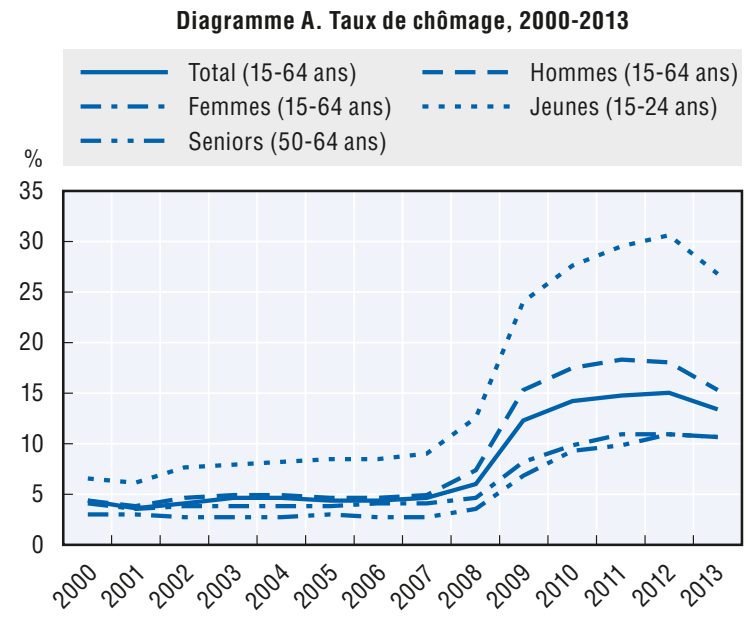

Diagramme B. Taux de travail indépendant, 2013
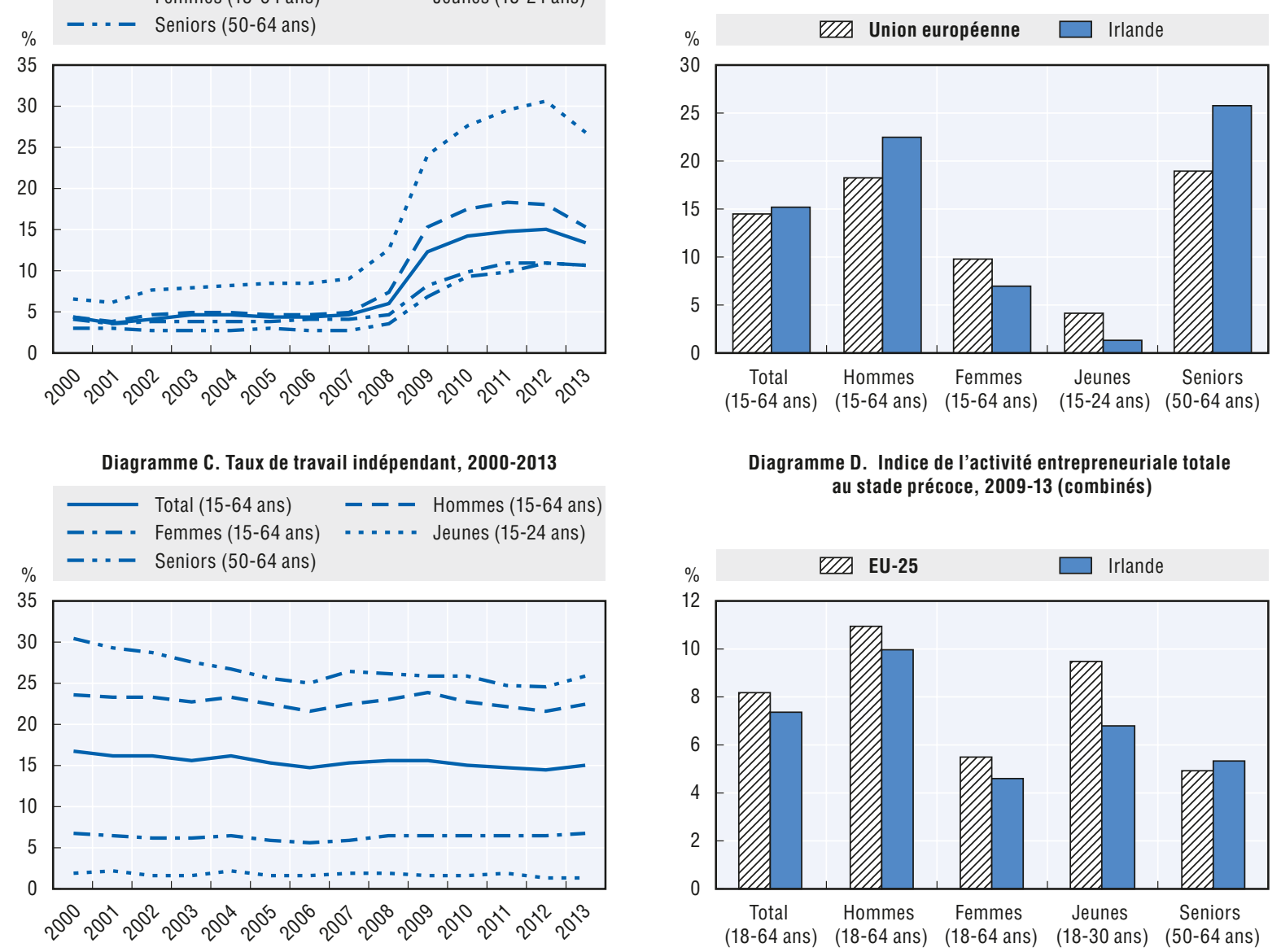

Diagramme D. Indice de l'activité entrepreneuriale totale au stade précoce, 2009-13 (combinés)

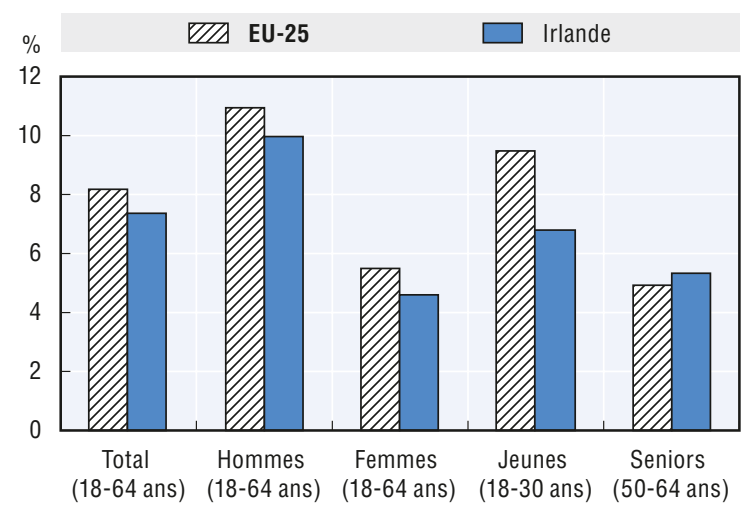

Diagramme E. Nombre total des entrepreneurs au stade précoce qui envisagent de créer plus de 19 emplois dans les 5 ans, 2009-2013 (combinés)

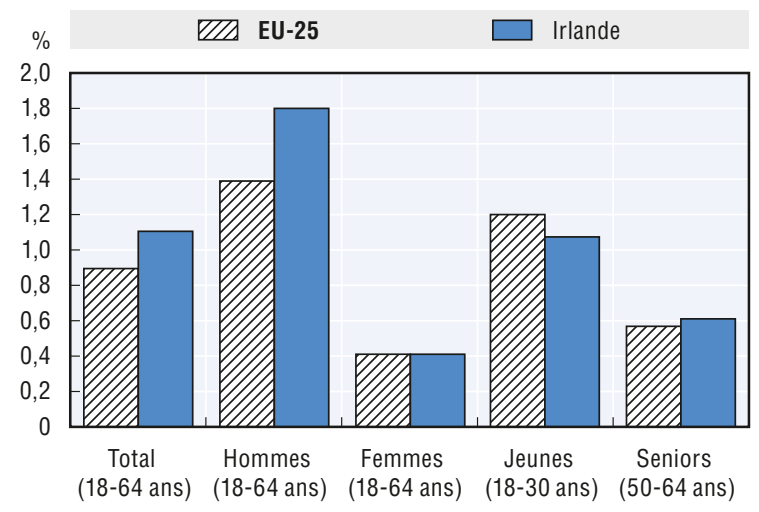

Sources: Diagramme A. Eurostat, Enquête sur les forces de travail, 2000-2013; Diagramme B. Eurostat, Enquête sur les forces de travail, 2013; Diagramme C. Eurostat, Enquête sur les forces de travail, 2000-2013; Diagramme D. Présentation tabulaire spéciale de l'enquête sur la population adulte du Global Entrepreneurship Monitor, 2009-2013; Diagramme E. Présentations tabulaires spéciales de l'enquête sur la population adulte du Global Entrepreneurship Monitor, 2009-2013. 


\section{Italie: couveuse d'entreprises sociales «FabriQ"}

Cette note de pays présente brièvement une couveuse d'entreprises sociales innovantes. Elle comprend également des données clés relatives à l'entrepreneuriat inclusif en Italie.

Description: FabriQ est une couveuse pour l'innovation sociale financée par la municipalité de Milan. Elle est gérée par la fondation Giacomo Brodolini, un centre de recherche privé à but non lucratif, et Impact Hub Milan, une entreprise privée de coworking et d'incubation. Ce projet a pour objectif de soutenir les nouveaux entrepreneurs à créer leur entreprise dans le secteur de l'économie sociale.

Problème abordé: Milan est une ville riche et dynamique, dont plusieurs quartiers périphériques sont néanmoins confrontés à de forts taux d'exclusion sociale. Les entreprises sociales peuvent offrir aux habitants, en particulier aux jeunes, la possibilité de remédier à la pénurie d'emplois dans ces quartiers en créant leur propre entreprise.

Approche: FabriQ s'est donné pour objectif de soutenir l'innovation en mettant les équipements et les services de la couveuse d'entreprises à la disposition des nouveaux ou futurs entrepreneurs dans les secteurs social, environnemental et culturel. FabriQ a reçu 240000 euros de la municipalité de Milan pour équiper la couveuse de $650 \mathrm{~m}^{2}$. Un ensemble complet de services leur est proposé: élaboration de plans d'affaires, services de coaching et de mentorat, services administratifs, espaces de travail partagés et formation à l'entrepreneuriat, notamment social. Cette couveuse peut accueillir jusqu'à 15 nouvelles entreprises pendant une durée maximale d'un an. Parallèlement, des subventions sont octroyées afin de financer jusqu'à $50 \%$ de l'investissement de départ requis (la subvention moyenne était de 28000 euros en 2014 et le montant total des subventions s'est élevé à 140000 euros). Pour accéder à la couveuse et recevoir une subvention, les entreprises doivent répondre à un appel à propositions ayant pour vocation de soutenir de nouveaux projets d'entreprises sociales. En 2014, 50 candidatures ont été soumises et six projets ont été retenus. L’idée est que les entreprises restent membres du réseau, même après avoir quitté la couveuse. FabriQ vise également à développer une culture entrepreneuriale en travaillant avec des jeunes et des étudiants. La couveuse exige un certain niveau d'autonomie financière en faisant payer ses services.

Impact: la couveuse prévoyait d'accueillir entre 12 et 15 entreprises avant la fin de l'année 2014, pour une durée moyenne comprise entre 6 et 12 mois.

Facteurs de réussite: ce projet démontre qu'une approche traditionnelle de l'aide aux entreprises (c'est-à-dire l'incubation) peut être appliquée aux modèles émergents d'entreprise (c'est-à-dire les entreprises sociales). Le succès à long terme de la couveuse dépendra de la mobilisation et de l'expertise de tous les partenaires compétents et de la poursuite des relations avec les entreprises créées. 


\section{Données clés relatives à l'entrepreneuriat inclusif}

\section{Graphique 24.1. Données relatives à l'entrepreneuriat et au travail indépendant en Italie}
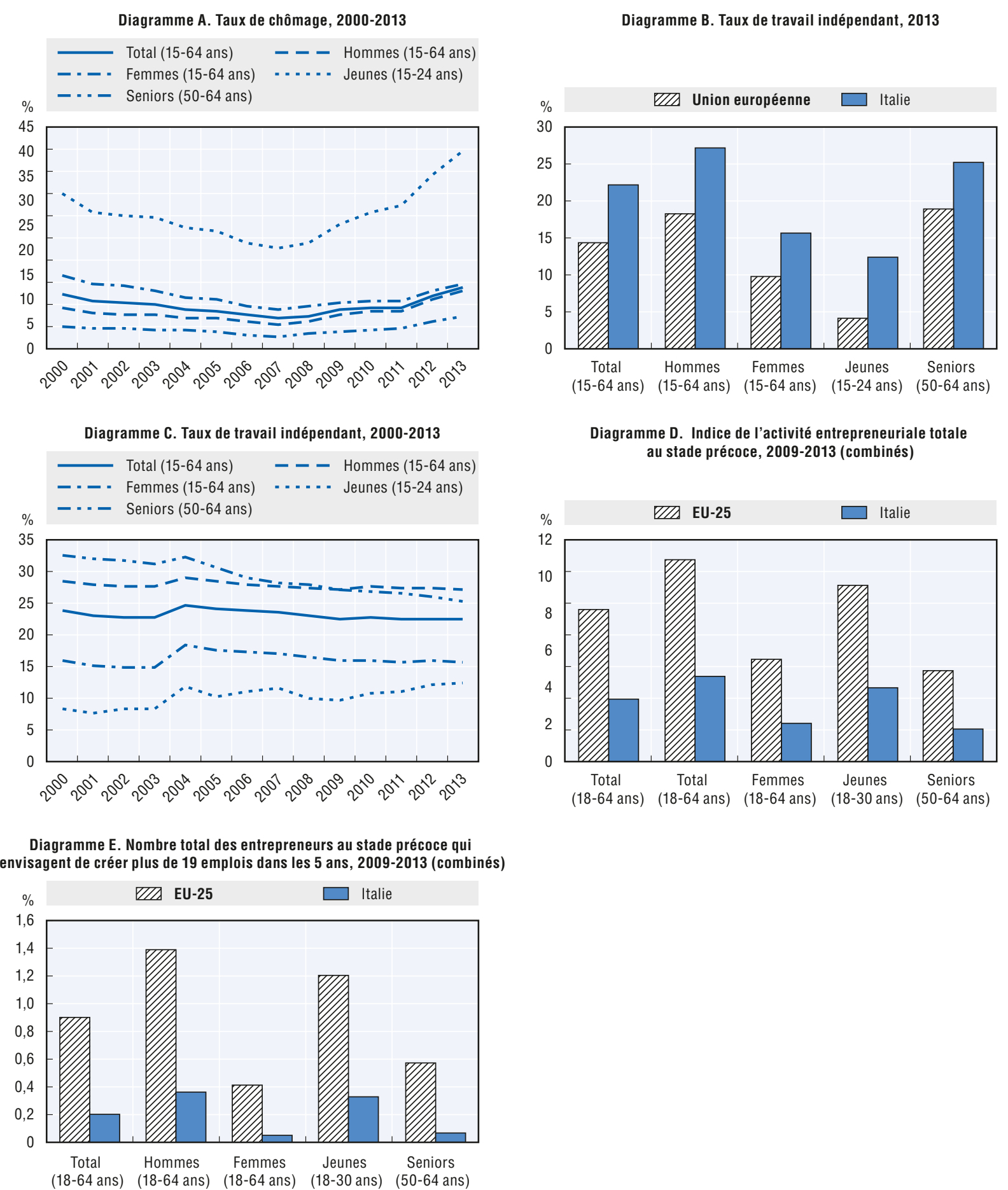

Sources: Diagramme A. Eurostat, Enquête sur les forces de travail, 2000-2013; Diagramme B. Eurostat, Enquête sur les forces de travail, 2013; Diagramme C. Eurostat, Enquête sur les forces de travail, 2000-2013; Diagramme D. Présentation tabulaire spéciale de l'enquête sur la population adulte du Global Entrepreneurship Monitor, 2009-2013; Diagramme E. Présentations tabulaires spéciales de l'enquête sur la population adulte du Global Entrepreneurship Monitor, 2009-2013. 


\section{Lettonie: mesures d'encouragement en faveur de l'innovation et de la création d'entreprises chez les jeunes}

Cette note de pays présente brièvement un ensemble d'activités visant à encourager l'entrepreneuriat chez les jeunes. Elle comprend également des données clés relatives à l'entrepreneuriat inclusif en Lettonie.

Description: ce programme prévoit une série de mesures d'encouragement en faveur de l'innovation et de la création d'entreprises en Lettonie, notamment (mais pas exclusivement) auprès des jeunes. Les principales activités de ce programme consistent à former les enseignants à l'entrepreneuriat et à diffuser des informations sur l'entrepreneuriat et les meilleures pratiques auprès des jeunes. Ces activités sont mises en œuvre par l'Agence de développement et d'investissement de Lettonie (LIAA).

Problème abordé: la Lettonie enregistre l'un des taux de chômage des jeunes les plus élevés de l'Union européenne. Il s'élevait à près de 25 \% chez les 15-24 ans en 2013. La création d'entreprises est l'un des canaux que les jeunes peuvent utiliser pour entrer sur le marché du travail, mais leur manque de compétences et de motivation entrepreneuriales reste un frein.

Approche: parmi les activités de ce programme figurent des mesures destinées à renforcer la capacité du personnel à enseigner et encourager l'entrepreneuriat (par exemple, formation pratique et sensibilisation des enseignants à certaines questions). La promotion de l'entrepreneuriat auprès des jeunes passe également par un programme de mentorat organisé en coopération avec une ONG travaillant avec des femmes entrepreneurs; un concours de plans d'affaires; des séminaires de formation à l'entrepreneuriat; des visites scolaires dans des entreprises; des séminaires d'information destinés aux jeunes; et des expositions itinérantes avec un «bus de l'innovation». En outre, le programme élabore et diffuse des supports d'information et de promotion (émissions, vidéos, etc.) afin de promouvoir les attitudes positives face à l'entrepreneuriat auprès du grand public. Le budget total de ce programme s'élève à 2,9 millions d'euros. Il est financé à 85 \% par le Fonds européen de développement régional.

Impact: en 2010, 15 personnes ont participé au programme de mentorat, 490 plans d'affaires ont été reçus dans le cadre du concours, 65 personnes ont assisté au séminaire de deux jours sur la production de nouvelles idées, 25 visites d'entreprises ont été organisées, 162 personnes ont participé aux séminaires d'information destinés aux jeunes et 484 aux expositions itinérantes. L'objectif pour l'année 2013 était d'atteindre le chiffre de 2250 participants.

Facteurs de réussite: ce programme propose une grande variété d'activités d'information et de promotion de l'innovation destinées aux jeunes. Son succès est lié à la vaste couverture médiatique et aux actions menées pour couvrir toutes les régions du pays. Les obstacles sont les coûts administratifs du programme et la difficulté à évaluer son impact direct. 


\section{Données clés relatives à l'entrepreneuriat inclusif}

\section{Graphique 25.1. Données relatives à l'entrepreneuriat et au travail indépendant en Lettonie}

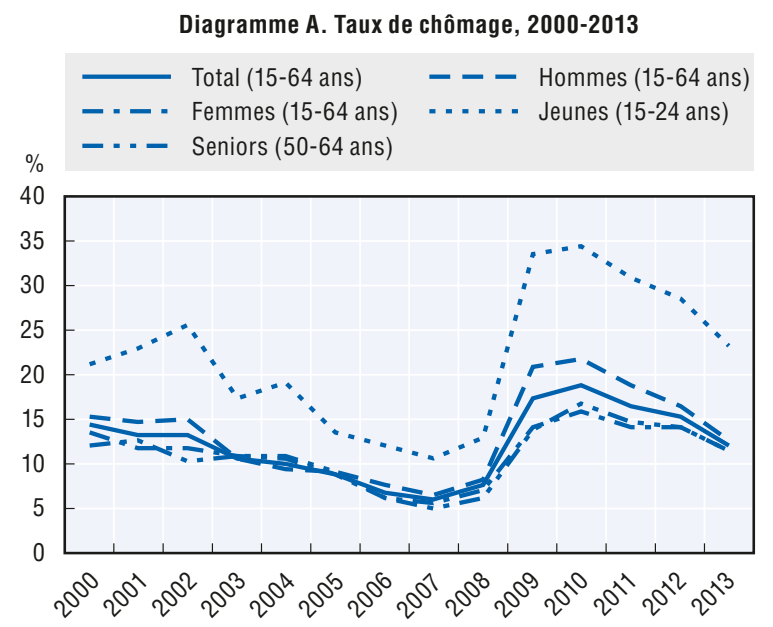

Diagramme B. Taux de travail indépendant, 2013
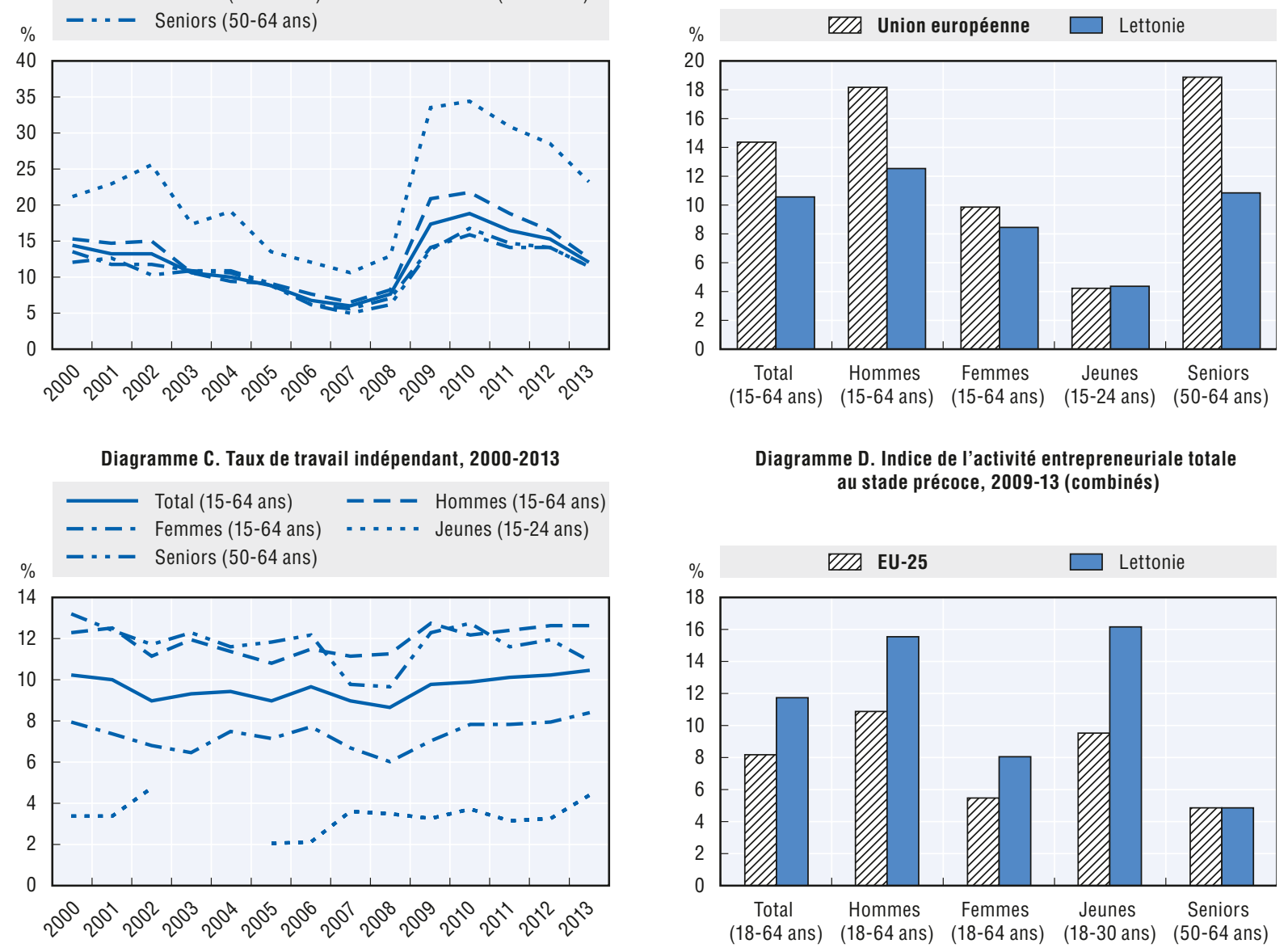

Diagramme E. Nombre total des entrepreneurs au stade précoce qui ivisagent de créer plus de 19 emplois dans les 5 ans, 2009-2013 (combinés)

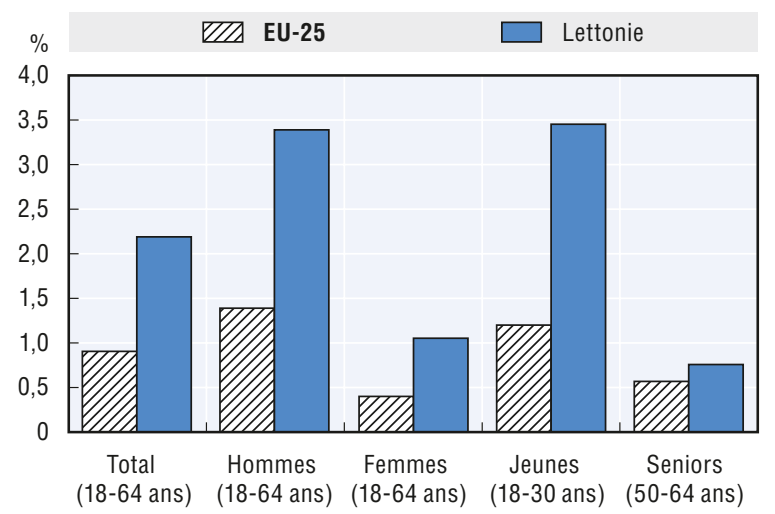

Sources: Diagramme A. Eurostat, Enquête sur les forces de travail, 2000-2013; Diagramme B. Eurostat, Enquête sur les forces de travail, 2013; Diagramme C. Eurostat, Enquête sur les forces de travail, 2000-2013; Diagramme D. Présentation tabulaire spéciale de l'enquête sur la population adulte du Global Entrepreneurship Monitor, 2009-2013; Diagramme E. Présentations tabulaires spéciales de l'enquête sur la population adulte du Global Entrepreneurship Monitor, 2009-2013. 


\section{Lituanie: aide au travail indépendant}

Cette note de pays présente brièvement un programme national visant à encourager les chômeurs à s'établir comme travailleurs indépendants. Elle comprend également des données clés relatives à l'entrepreneuriat inclusif en Lituanie.

Description: l'aide au travail indépendant est une aide à la création d'activités indépendantes ou au recrutement de personnes au chômage par des microentreprises (entreprise de moins de 10 employés). Elle peut être allouée aux personnes inscrites comme demandeurs d'emploi auprès de l'agence locale pour l'emploi et aux personnes handicapées.

Problème abordé: en Lituanie, les travailleurs indépendants doivent cotiser à la sécurité sociale même s'ils ne gagnent aucun revenu. Cette situation dissuade les personnes qui souhaiteraient créer leur entreprise, en particulier les chômeurs qui disposent généralement de peu d'épargne.

Approche: deux types de subventions sont accordés aux chômeurs ou aux personnes handicapées impliqués dans l'entrepreneuriat. La première est une subvention qui peut être versée aux chômeurs afin de couvrir partiellement les dépenses d'acquisition de certificats professionnels (licences, par exemple) et le paiement des cotisations sociales. Elle est allouée au cas par cas par un représentant de l'agence locale pour l'emploi. Afin de bénéficier de cette aide, le candidat doit déposer une demande et fournir une copie de son certificat professionnel ainsi qu'un justificatif de paiement des impôts sur le revenu et des cotisations sociales. L'agence locale pour l'emploi rend sa décision dans un délai de cinq jours ouvrables après réception de la demande. L'aide est versée si le certificat professionnel est délivré pour une durée minimale d'un mois. En cas de renouvellement du certificat, la durée de l'aide ne peut excéder 12 mois. Son montant s'élève à 25 \% du revenu minimum légal mensuel fixé par le gouvernement. Le deuxième type de subvention est une aide à la création d'emplois. Elle peut être accordée aux chômeurs handicapés (dont la capacité de travail est de moins de 40 \%) et aux anciens chômeurs qui ont: i) créé une entreprise dans les 30 mois suivants leur dernier jour d'inscription auprès de l'agence pour l'emploi; et ii) créé un emploi pour une personne actuellement inscrite comme demandeur d'emploi. Les bénéficiaires du Fonds d'ajustement à la mondialisation qui souhaitent créer leur entreprise sont également éligibles. Pour l'octroi de cette aide, la candidature doit comporter une description de l'activité prévue, les documents justificatifs indiquant les fonds requis ainsi que le titre de propriété ou le contrat de bail de location des locaux. L'agence locale pour l'emploi rend sa décision dans un délai de dix jours ouvrables après réception de la demande. Le montant de cette aide ne peut excéder 40 fois le revenu minimum légal et les employeurs doivent prendre à leur charge 20 à $35 \%$ des dépenses liées à la création de postes. De plus, le bénéficiaire doit maintenir le poste créé pendant au moins trois ans. En cas de non-respect des conditions, il doit rembourser l'aide perçue, en totalité ou en partie.

Impact: selon les informations du programme de mentorat, environ 10000 personnes perçoivent chaque année la subvention destinée à couvrir les dépenses d'acquisition de certificats professionnels et le paiement des cotisations sociales. De plus, chaque année, environ 30 à 40 postes aidés sont créés pour les personnes au chômage et handicapées. Environ deux tiers de ces postes survivent au moins trois ans.

Facteurs de réussite: ce programme montre la pertinence d'une subvention destinée à aider les chômeurs à surmonter un obstacle institutionnel (l'obligation de payer les charges sociales et d'acquérir des licences quel que soit le niveau de revenu). L'allégement des formalités administratives sera un facteur important dans le succès et la réplicabilité de ce programme. 


\section{Données clés relatives à l'entrepreneuriat inclusif}

\section{Graphique 26.1. Données relatives à l'entrepreneuriat et au travail indépendant en Lituanie}

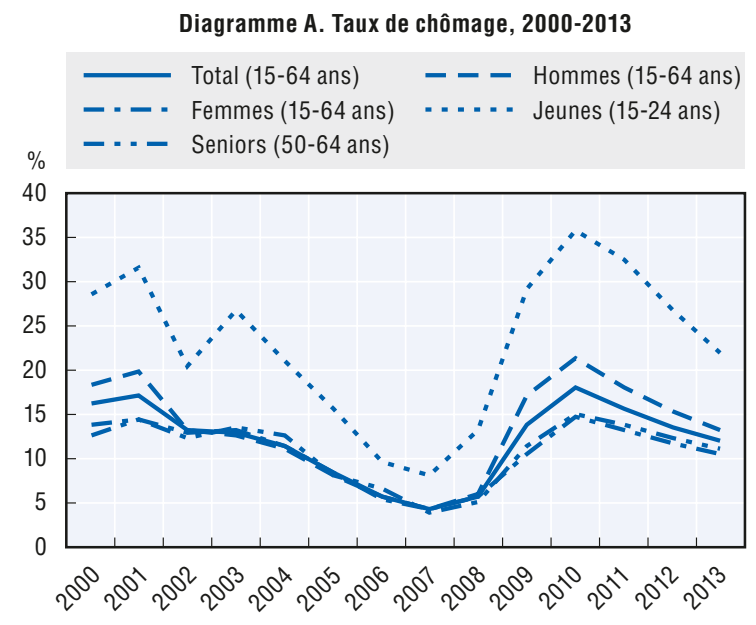

Diagramme B. Taux de travail indépendant, 2013
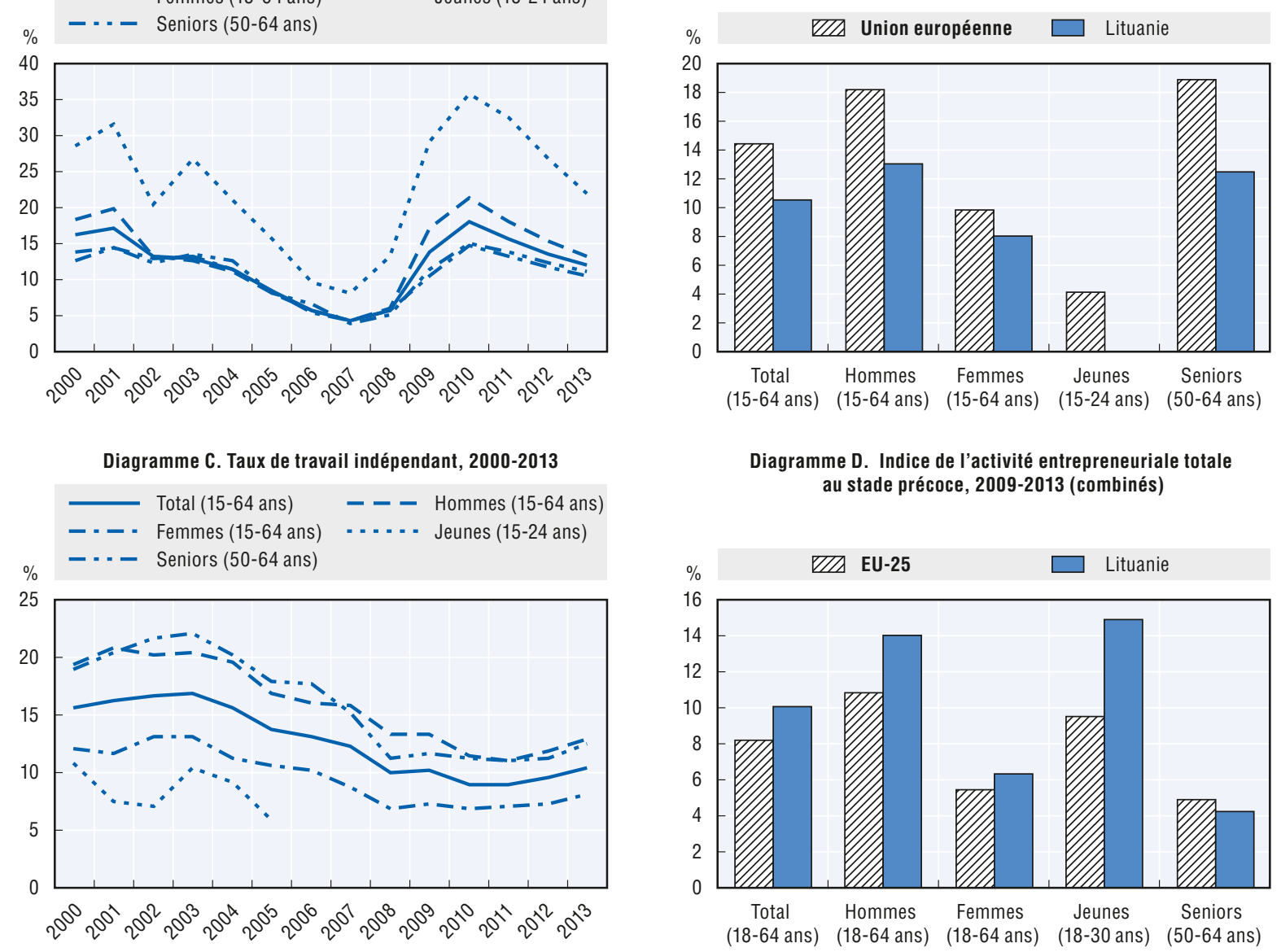

Diagramme D. Indice de l'activité entrepreneuriale totale au stade précoce, 2009-2013 (combinés)

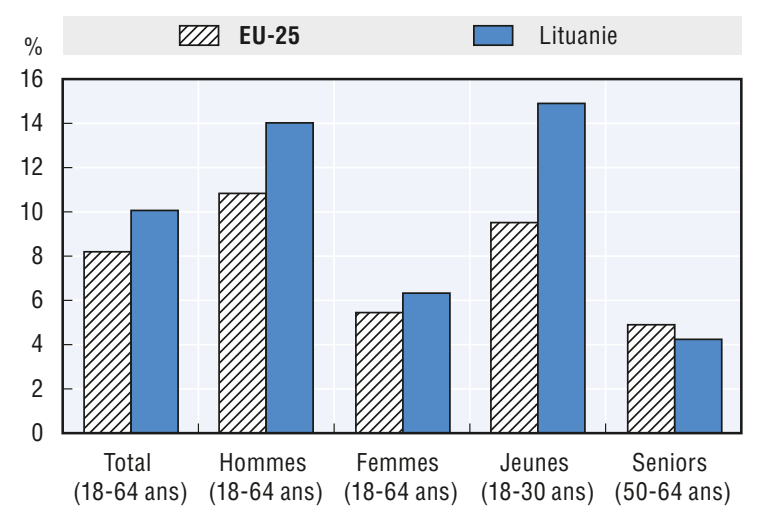

Diagramme E. Nombre total des entrepreneurs au stade précoce qui envisagent de créer plus de 19 emplois dans les 5 ans, 2009-2013 (combinés)

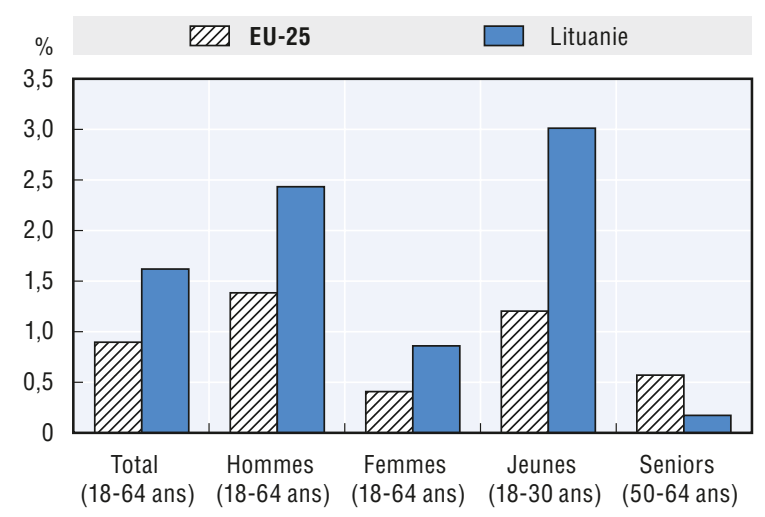

Sources: Diagramme A. Eurostat, Enquête sur les forces de travail, 2000-2013; Diagramme B. Eurostat, Enquête sur les forces de travail, 2013; Diagramme C. Eurostat, Enquête sur les forces de travail, 2000-2013; Diagramme D. Présentation tabulaire spéciale de l'enquête sur la population adulte du Global Entrepreneurship Monitor, 2009-2013; Diagramme E. Présentations tabulaires spéciales de l'enquête sur la population adulte du Global Entrepreneurship Monitor, 2009-2013. 


\section{Luxembourg: programme de mentorat d'entreprises}

Cette note de pays présente brièvement un programme de mentorat généraliste qui, du fait de la situation démographique, cible la population immigrée. Elle comprend également des données clés relatives à l'entrepreneuriat inclusif au Luxembourg.

Description: lancé en février 2010, le programme de mentorat d'entreprises (Business Mentoring Programme) s'adresse aux entrepreneurs qui ont besoin d'aide pour créer, développer ou reprendre une entreprise. Même si ce programme est ouvert à tous, il cible en priorité les immigrés.

Problème abordé: au Luxembourg, 44 \% des résidents ne sont pas des citoyens nationaux (originaires d'Allemagne, de Belgique et de France notamment). Ces personnes sont confrontées à des difficultés administratives et d'autres obstacles lorsqu'elles créent une entreprise. La complexité administrative inhérente à la création d'entreprises pèse encore davantage sur les immigrés, car ils ne peuvent être conseillés par des réseaux familiaux locaux. En outre, les jeunes ont tendance à être davantage attirés par le secteur public que par l'entrepreneuriat, d'où une proportion de petites entreprises plus faible que la moyenne de l'Union européenne.

Approche: le programme a été conçu pour aider les personnes qui disposent des compétences techniques de base en gestion d'entreprise, mais ont besoin de conseils supplémentaires en matière de compétences entrepreneuriales. Il est destiné aux entrepreneurs novices qui sont en cours de création d'entreprises ou gèrent leur entreprise depuis moins de trois ans. Ce programme fait appel à des professionnels expérimentés pour encadrer ces nouveaux entrepreneurs pendant une période comprise entre 12 et 18 mois. Il compte actuellement 48 duos de mentorat, dont $77 \%$ des bénéficiaires ne sont pas des ressortissants du pays (52\% de Français) et $44 \%$ des mentors sont luxembourgeois (22\% de Français). Un tiers des bénéficiaires sont des femmes, et trois entreprises sur 48 poursuivent un objectif social (créer des postes pour les personnes handicapées, au chômage ou en décrochage scolaire). La plupart des bénéficiaires ont entre 30 et 45 ans. Par contre, les mentors sont principalement des hommes (86 \%) âgés de 50 à 65 ans.

Impact: après avoir participé à ce programme, $90 \%$ des bénéficiaires ont reconnu avoir approfondi leurs capacités de gestion et de direction. Après deux saisons d'activité, le programme de mentorat peut se prévaloir de résultats quantitatifs: $95 \%$ des bénéficiaires exercent toujours et enregistrent une augmentation de leur personnel de $28 \%$ et de leurs revenus de $29 \%$.

Facteurs de réussite: ce programme est la preuve qu'un programme de mentorat peut servir à transférer les compétences et les connaissances d'entrepreneurs expérimentés aux travailleurs étrangers et aux citoyens nationaux. La clarté du programme, des conditions d'éligibilité, des critères de sélection et des rôles du mentor et du bénéficiaire a été un facteur de réussite majeur. 


\section{Données clés relatives à l'entrepreneuriat inclusif}

\section{Graphique 27.1. Données relatives à l'entrepreneuriat et au travail indépendant au Luxembourg}

Diagramme A. Taux de chômage, 2000-2013

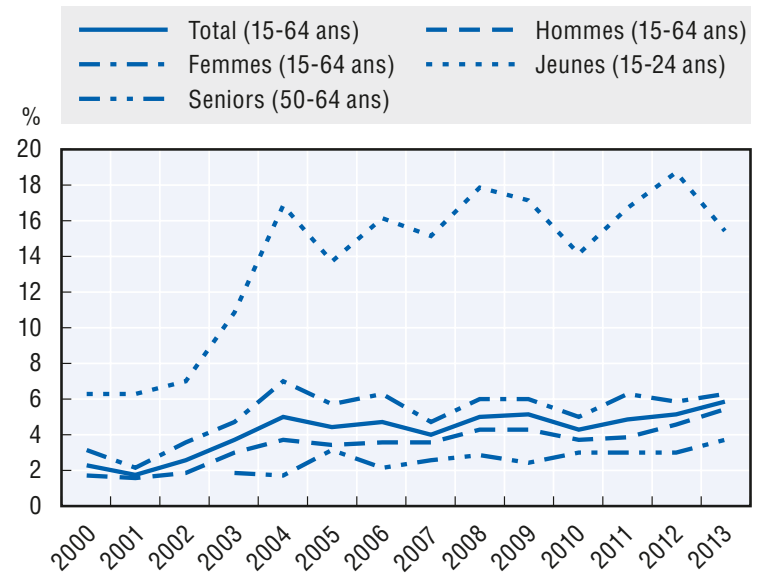

Diagramme C. Taux de travail indépendant, 2000-2013

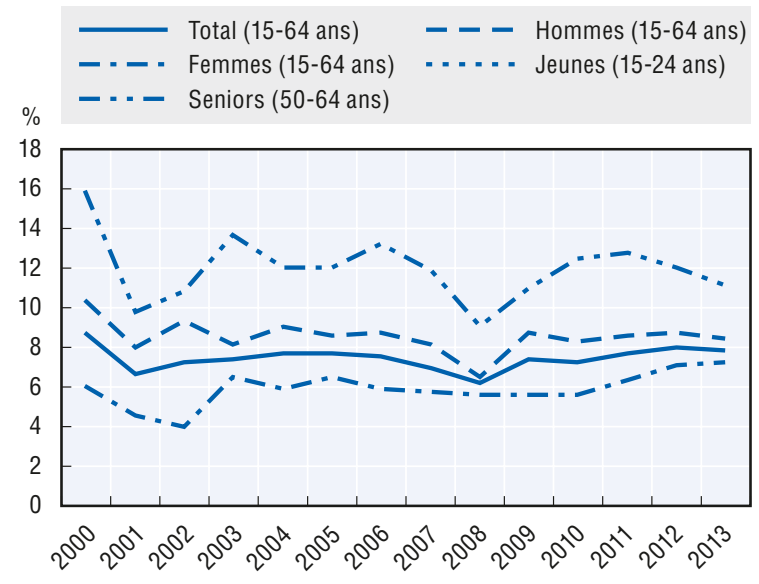

Diagramme E. Nombre total des entrepreneurs au stade précoce qui visagent de créer plus de 19 emplois dans les 5 ans, 2009-2013 (combinés)

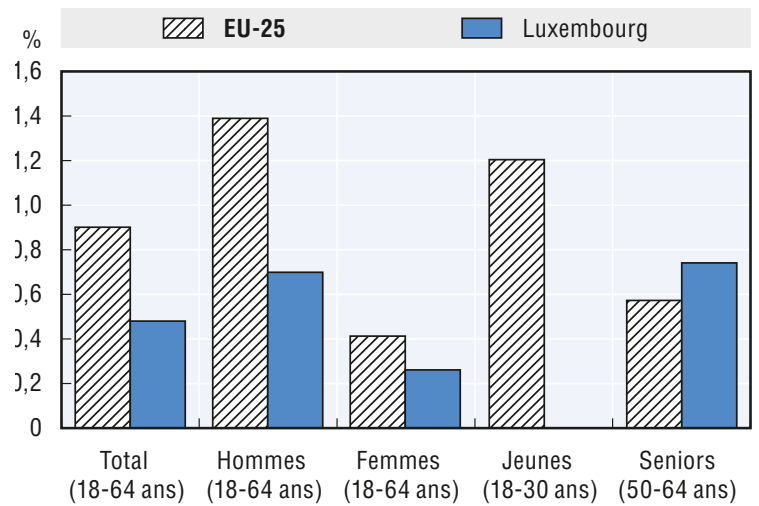

Diagramme B. Taux de travail indépendant, 2013

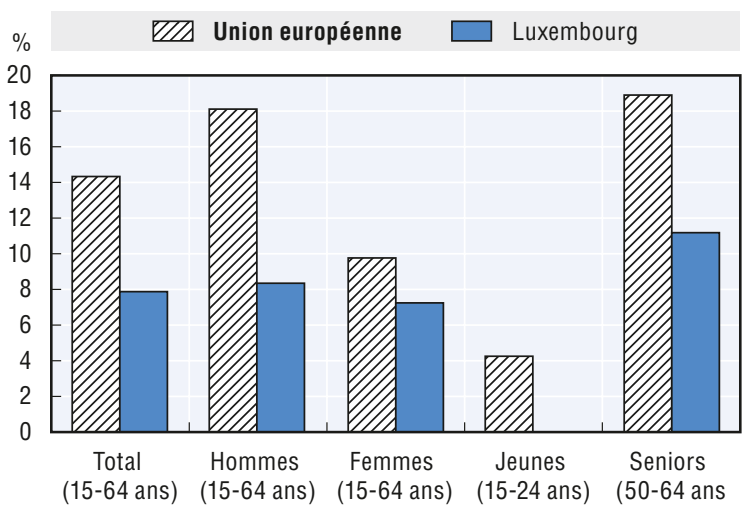

Diagramme D. Indice de l'activité entrepreneuriale totale au stade précoce, 2009-2013 (combinés)

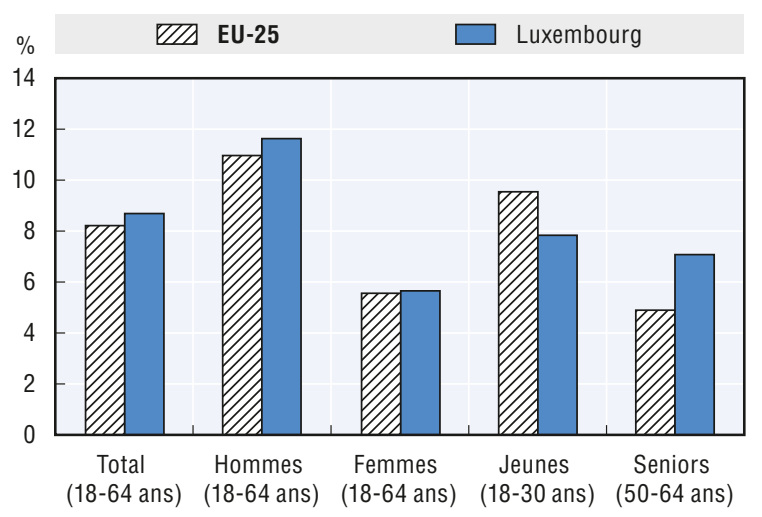

Sources: Diagramme A. Eurostat, Enquête sur les forces de travail, 2000-2013; Diagramme B. Eurostat, Enquête sur les forces de travail, 2013; Diagramme C. Eurostat, Enquête sur les forces de travail, 2000-2013; Diagramme D. Présentation tabulaire spéciale de l'enquête sur la population adulte du Global Entrepreneurship Monitor, 2009-2013; Diagramme E. Présentations tabulaires spéciales de l'enquête sur la population adulte du Global Entrepreneurship Monitor, 2009-2013. 


\section{Malte: projet My WoW}

Cette note de pays présente brièvement un programme visant à motiver les étudiants menacés de décrochage scolaire en leur proposant, ainsi qu'à leurs enseignants, une formation à l'entrepreneuriat. Elle comprend également des données clés relatives à l'entrepreneuriat inclusif à Malte.

Description: le projet My WoW (World of Work) proposait des programmes de formation à l'entrepreneuriat, l'un destiné aux étudiants et l'autre aux éducateurs, ainsi que des projets de «mini-entreprise» en milieu scolaire, l'objectif étant de développer les compétences entrepreneuriales et d'insuffler un esprit d'entreprise chez les jeunes. Ce projet a été financé par le programme d'entrepreneuriat par l'éducation de 2013 du ministère des finances, de l'économie et de l'investissement et du ministère de l'éducation et de l'emploi.

Problème abordé: Malte enregistre le deuxième taux le plus élevé de jeunes en décrochage scolaire $(22,6 \%)$ de l'Union européenne. Cette situation a des répercussions non seulement sur le chômage, mais également sur la pauvreté et l'exclusion sociale. Le programme d'éducation nationale de Malte (2012) suggère que le décrochage scolaire est dû au manque de motivation face aux difficultés scolaires et au sentiment d'ennui à l'école.

Approche: les élèves ciblés par ce projet sont des collégiens âgés de 13 ans en classe de quatrième au collège St. Ignatius situé à Handaq, Malte. Cinquante-huit élèves ont participé au projet, dont 35 présentaient des résultats scolaires faibles. Le projet My WoW a pour objectif de remédier au problème de démotivation en proposant aux élèves une expérience d'apprentissage alternative visant à rendre l'école plus attrayante tout en développant leurs connaissances, attitudes et compétences entrepreneuriales au moyen d'expériences concrètes. Les éducateurs impliqués dans le projet ont d'abord reçu une formation pour renforcer leurs propres compétences entrepreneuriales et développer leur esprit d'entreprise pour pouvoir ensuite les transmettre à leurs élèves. Ces derniers ont également reçu une formation en compétences entrepreneuriales, puis ont participé à un projet de mini-entreprise au cours duquel ils ont conçu, fabriqué et vendu des cartes de vœux faites à la main. Les sessions de formation des enseignants étaient composées de modules d'introduction et d'éducation à l'entrepreneuriat, de créativité et d'innovation, et d'un atelier sur la production d'idées et d'un autre sur l'évaluation et la concrétisation des idées. La formation des élèves comprenait également des modules d'introduction à l'entrepreneuriat, de créativité et d'innovation, ainsi que des ateliers pratiques sur la pensée créative, le travail d'équipe et le renforcement de la confiance. Les séances pour les élèves ont eu lieu une fois par semaine, durant un créneau horaire réservé aux activités extrascolaires.

Impact: 30 élèves aux résultats scolaires faibles sur les 35 participants (plus sujets au décrochage scolaire que les autres) ont participé au projet, avec enthousiasme pour la majeure partie d'entre eux, et ont indiqué s'être découvert de nouveaux talents, avoir renforcé leur confiance en eux et avoir acquis des compétences entrepreneuriales importantes. Les éducateurs ont également noté des résultats positifs: ils ont indiqué que le projet avait eu un impact positif sur leurs élèves en termes de promotion de l'entrepreneuriat et des qualités entrepreneuriales, de renforcement de la confiance en soi des élèves), de sensibilisation aux compétences et connaissances nécessaires pour créer une entreprise et de sensibilisation à l'emploi indépendant comme possibilité de carrière.

Facteurs de réussite: le projet démontre comment l'éducation à l'entrepreneuriat peut servir de moteur de motivation pour les jeunes à risque. L'aspect pratique du projet a été considéré comme l'un des facteurs de son succès. Les éducateurs ont besoin de temps et de soutien pour ce type de projet, car leur charge de travail peut constituer une entrave à leur participation. 


\section{Données clés relatives à l'entrepreneuriat inclusif}

\section{Graphique 28.1. Données relatives à l'entrepreneuriat et au travail indépendant à Malte}

Diagramme A. Taux de chômage, 2000-2013

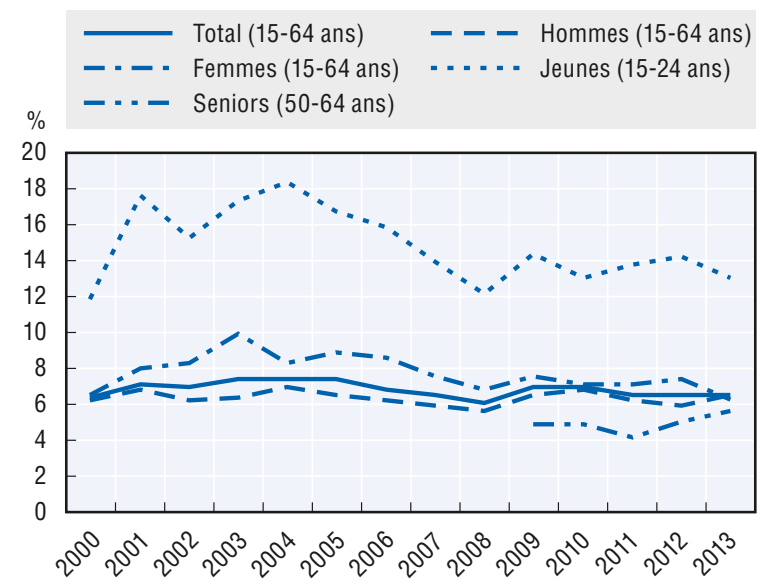

Diagramme C. Taux de travail indépendant, 2000-2013

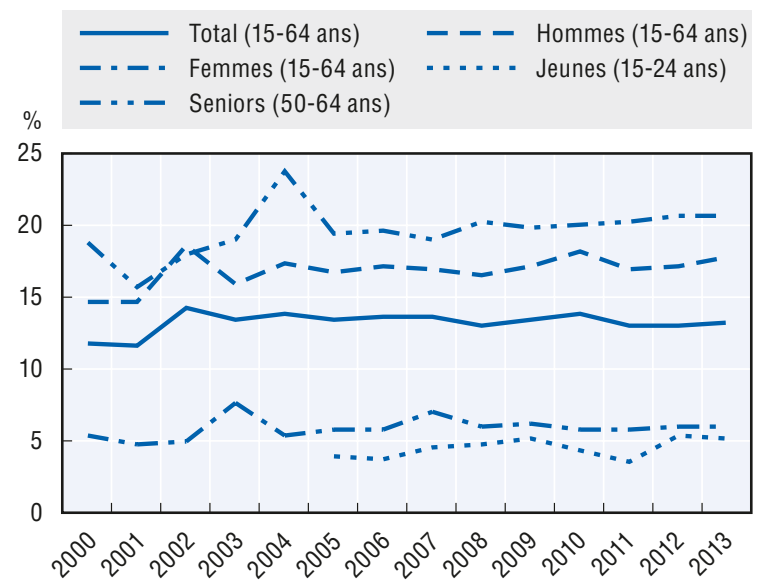

Diagramme B. Taux de travail indépendant, 2013

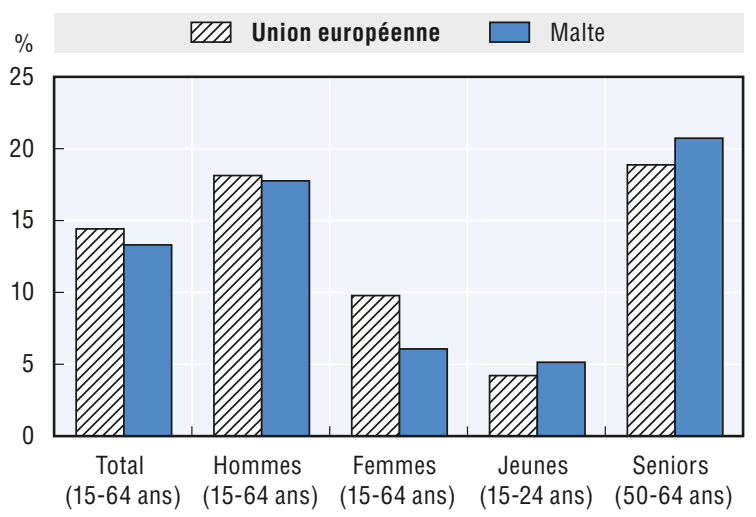

Sources: Diagramme A. Eurostat, Enquête sur les forces de travail, 2000-2013; Diagramme B. Eurostat, Enquête sur les forces de travail, 2013; Diagramme C. Eurostat, Enquête sur les forces de travail, 2000-2013. 


\section{Pays-Bas: Bbz 2004, Besluit Bijstand voor Zelfstandigen (Aide à la décision pour les entrepreneurs)}

Cette note de pays présente brièvement un programme national d'aide financière aux chômeurs et d'autres groupes défavorisés qui décident de s'établir comme travailleurs indépendants. Elle comprend également des données clés relatives à l'entrepreneuriat inclusif aux Pays-Bas.

Description: cette initiative propose des prêts aux chômeurs qui souhaitent s'établir comme travailleurs indépendants. Les entrepreneurs âgés de plus de 55 ans et ceux qui connaissent des difficultés financières sont également éligibles à ces prêts. L'initiative a été lancée sous l'égide du ministère néerlandais des affaires sociales et de l'emploi, de l'UWV (l'organisme néerlandais chargé de la gestion des prestations d'aide sociale liées à l'emploi) et des administrations municipales néerlandaises. Les municipalités mettent le programme en œuvre et décident du nombre et du montant des prêts accordés aux bénéficiaires. Elles déclarent ensuite ces montants au ministère, qui rembourse les municipalités.

Problème abordé: le coût des prestations de chômage versées à une personne sans emploi moyenne peut être considérable, mais peut être réduit si cette personne décide de créer sa propre entreprise. Le montant des prestations sociales de complément de revenus versées aux personnes qui créent leur entreprise s'élèverait à environ 56000 euros répartis sur 24 mois, alors qu'un bénéficiaire de prestations sociales qui ne participe pas à un programme d'insertion coûte 97000 euros. Les économies générées par ce programme s'élèveraient donc en moyenne à 41000 euros par bénéficiaire. De plus, la création d'entreprises peut conduire à une sortie définitive du chômage. Si leur entreprise connaît un échec, ils auront au moins acquis de nouvelles compétences utiles sur le marché du travail. La baisse du niveau d'employabilité des chômeurs de longue durée étant un obstacle au retour à l'emploi, ce programme cherche également à enrayer la perte d'attractivité de ces personnes sur le marché du travail.

Approche: ce programme vise à utiliser les économies escomptées sur les prestations sociales des chômeurs qui se lancent dans le travail indépendant pour financer et soutenir la création d'entreprises. L'initiative se déroule en quatre étapes. Tout d'abord, la phase de sélection ou d'admission permet de déterminer l'éligibilité des candidats et s'ils remplissent les conditions spécifiques à chaque région. Cette première phase établit si les candidats potentiels disposent des compétences adéquates pour le travail indépendant. La deuxième étape prévoit une phase de préparation. Les participants élaborent leur plan d'affaires, avec le soutien de la municipalité si besoin, tout en continuant à percevoir leurs prestations de chômage. Certaines régions font appel à un cabinet de conseil pour les aider durant cette phase ou leur proposer des formations. Cette étape peut durer jusqu'à un an. La troisième phase consiste à évaluer la viabilité de l'idée d'entreprise. Les municipalités évaluent le projet d'entreprise au cours des six premiers mois du programme, après la première année, puis après la deuxième année pour s'assurer que les idées évoluent dans le bon sens. Enfin, la dernière phase consiste en l'octroi d'un prêt au titre de la création d'entreprises ou d'un complément de revenus pour les frais de subsistance des participants. Dans la plupart des municipalités, d'autres services sont également proposés après la création de l'entreprise (par exemple, conseil en entreprise). Le budget varie d'une année sur l'autre selon le nombre de participants. En 2013, le budget s'est élevé à 13,5 millions d'euros.

Impact: une évaluation de ce programme, menée en 2011, a conclu qu'après 48 mois, les participants étaient plus susceptibles de ne plus solliciter de prestations sociales que les autres chômeurs (74 \% contre 56 \%).

Facteurs de réussite: les raisons du succès de ce programme résident dans la personnalisation du soutien et le suivi constant des progrès des participants. Cette approche reste onéreuse, mais son coût est compensé par la baisse du montant des prestations de chômage versées. 


\section{Données clés relatives à l'entrepreneuriat inclusif}

\section{Graphique 29.1. Données relatives à l'entrepreneuriat et au travail indépendant aux Pays-Bas}
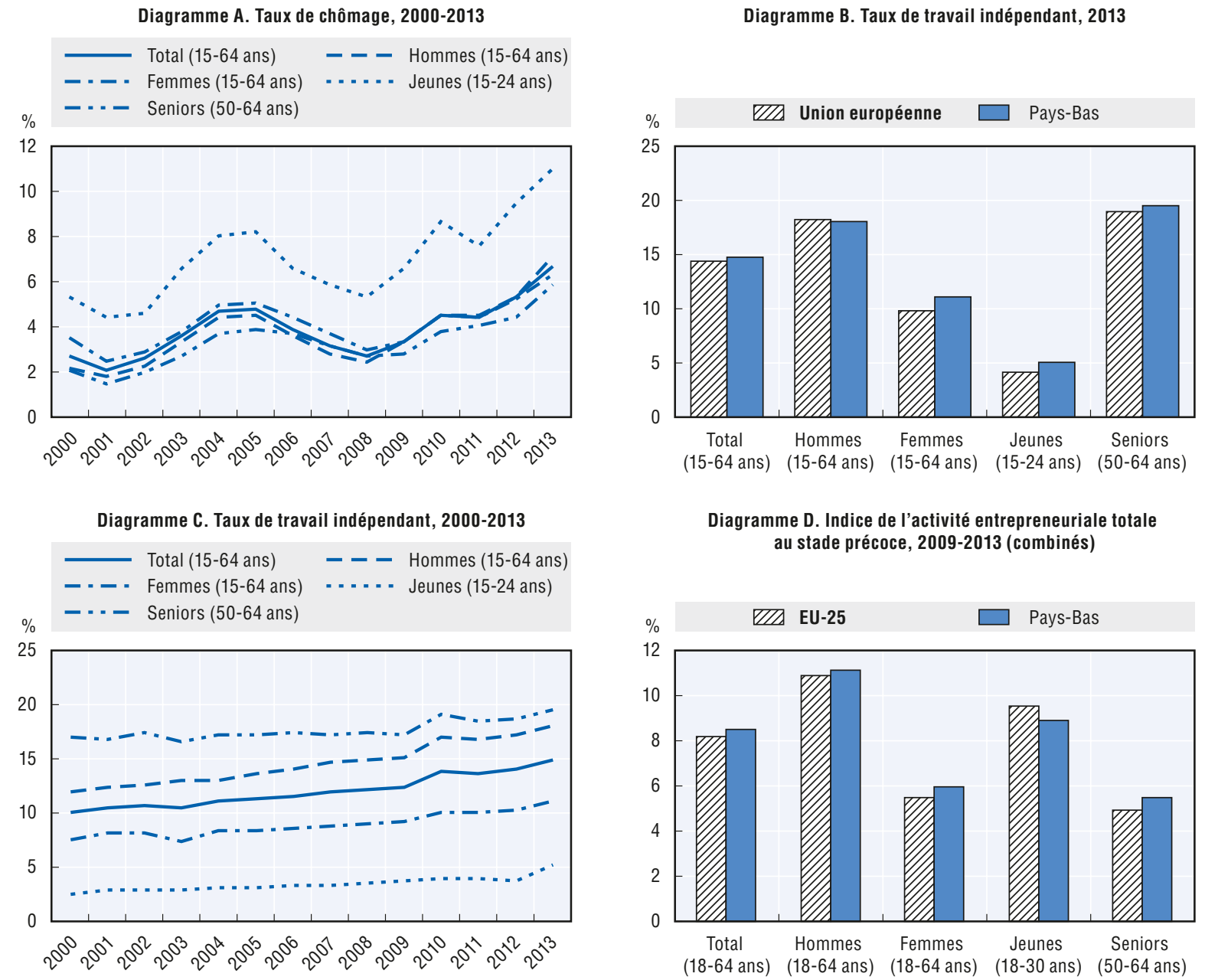

Diagramme D. Indice de l'activité entrepreneuriale totale au stade précoce, 2009-2013 (combinés)

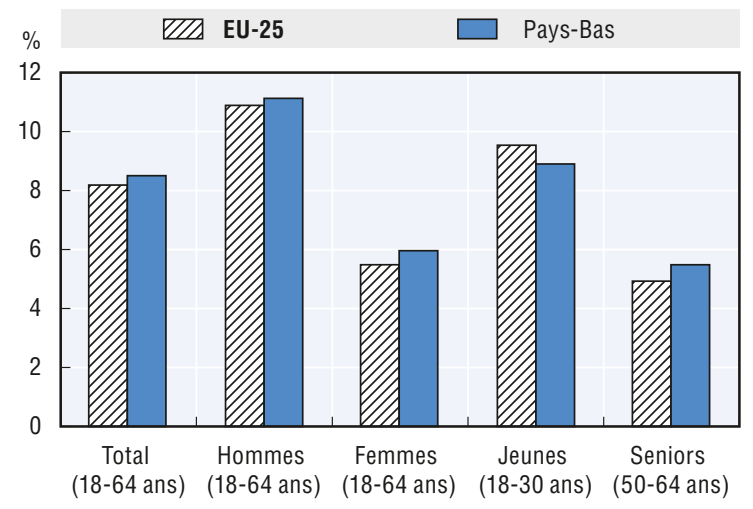

Diagramme E. Nombre total des entrepreneurs au stade précoce qui envisagent de créer plus de 19 emplois dans les 5 ans, 2009-2013 (combinés)

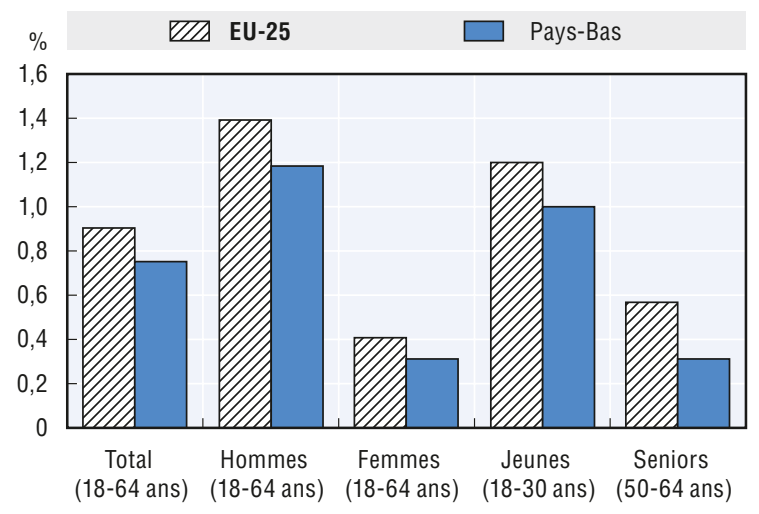

Sources: Diagramme A. Eurostat, Enquête sur les forces de travail, 2000-2013; Diagramme B. Eurostat, Enquête sur les forces de travail, 2013; Diagramme C. Eurostat, Enquête sur les forces de travail, 2000-2013; Diagramme D. Présentation tabulaire spéciale de l'enquête sur la population adulte du Global Entrepreneurship Monitor, 2009-2013; Diagramme E. Présentations tabulaires spéciales de l'enquête sur la population adulte du Global Entrepreneurship Monitor, 2009-2013. 


\section{Pologne: Wings for business: un atelier pour l'entrepreneuriat des personnes handicapées}

Cette note de pays présente brièvement un programme régional d'aide à l'entrepreneuriat des personnes handicapées. Elle comprend également des données clés relatives à l'entrepreneuriat inclusif en Pologne.

Description: ce programme aide les personnes handicapées au chômage dans la région de la Grande-Pologne (Wielkopolska). Il fournit une aide financière à la création d'entreprises et des services de formation et de conseil en entreprise. Cette initiative est mise en œuvre par l'agence régionale pour l'emploi de Poznań et s'inscrit dans le cadre d'un programme national de promotion de l'entrepreneuriat et de l'emploi indépendant en Pologne.

Problème abordé: des études menées en Grande-Pologne montrent que les personnes handicapées sont défavorisées sur le marché du travail et sont davantage menacées d'exclusion sociale. La situation est encore plus difficile pour celles âgées de plus de 45 ans. Les entraves à la création d'entreprises incluent notamment le manque d'informations sur le travail indépendant et de formations et les difficultés d'accès aux financements.

Approche: au total, 22 personnes, toutes inscrites comme demandeurs d'emploi, y ont participé. Un comité d'admission a évalué l'idée d'entreprise de chacun des candidats, leurs qualifications et leur expérience professionnelle. D’autres facteurs comme le type de handicap, le sexe et l'âge ont également été pris en compte. Chaque participant a mené une évaluation de ses besoins avec l'aide d'un conseiller et élaboré un plan d'action individuel. Des formations d'une durée allant jusqu'à 78 heures ont été dispensées en fonction des besoins identifiés et complétées par des séances de conseil en entreprise individuelles. Les personnes ayant suivi une formation ont bénéficié d'une subvention d'un montant maximal de 40000 zlotys polonais (PLN) (soit environ 10000 euros) pour créer et développer leur entreprise. Une fois l'entreprise immatriculée, une aide financière mensuelle d'un montant de 1500 PLN (environ 350 euros) pouvait être perçue pour couvrir le coût des cotisations de sécurité sociale et des impôts. Une formation complémentaire de 24 heures maximum et un soutien personnalisé de 27 heures ainsi que des services de coaching, de mentorat et de conseil aux entreprises ont également été proposés aux participants. Les participants pouvaient aussi bénéficier du remboursement de leurs frais de transport, des services d'un assistant personnel ainsi que des informations et du matériel mis à leur disposition sur le site internet du projet. Le budget total de ce projet s'est élevé à 1,9 million de PLN (environ 460000 euros). Il a été financé à 85 \% par le Fonds social européen.

Impact: les 22 participants avaient créé leur entreprise à la fin de janvier 2014.

Facteurs de réussite: les résultats de l'évaluation montrent que les formateurs et les conseillers étaient qualifiés pour travailler auprès de chômeurs désireux de créer leur entreprise et leur ont apporté un soutien utile lors des séances de coaching et de formation. Il était également important que l'aide financière couvre non seulement le démarrage de l'entreprise, mais également les frais de subsistance pendant les six premiers mois de l'entreprise. 


\section{Données clés relatives à l'entrepreneuriat inclusif}

\section{Graphique 30.1. Données relatives à l'entrepreneuriat et au travail indépendant en Pologne}
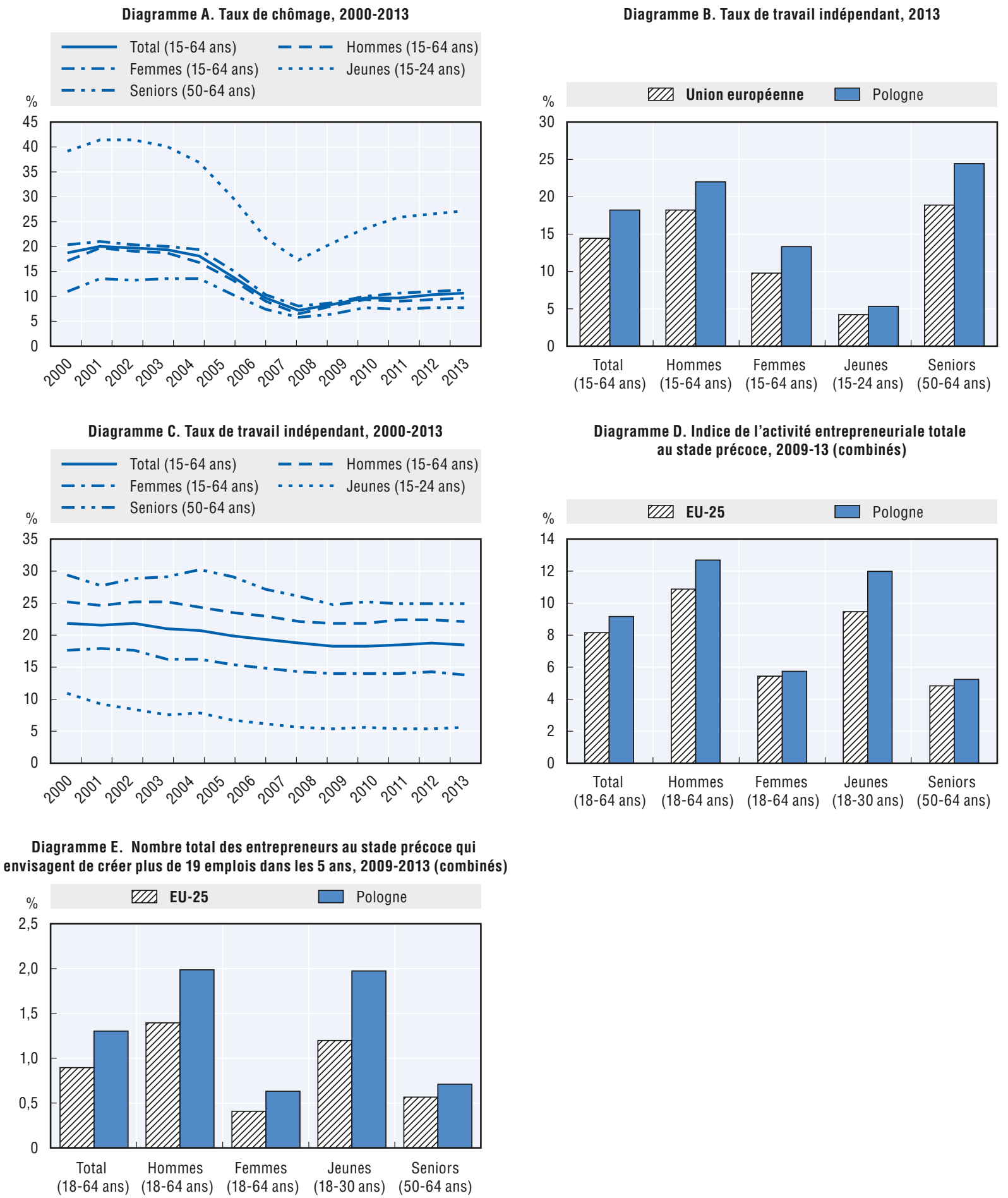

Sources: Diagramme A. Eurostat, Enquête sur les forces de travail, 2000-2013; Diagramme B. Eurostat, Enquête sur les forces de travail, 2013; Diagramme C. Eurostat, Enquête sur les forces de travail, 2000-2013; Diagramme D. Présentation tabulaire spéciale de l'enquête sur la population adulte du Global Entrepreneurship Monitor, 2009-2013; Diagramme E. Présentations tabulaires spéciales de l'enquête sur la population adulte du Global Entrepreneurship Monitor, 2009-2013. 


\section{Portugal: projet pour la promotion de l'entrepreneuriat des immigrés (PEI)}

Cette note de pays présente brièvement un programme d'aide à l'entrepreneuriat des immigrés, qui propose des formations et du coaching au niveau local. Elle comprend également des données clés relatives à l'entrepreneuriat inclusif au Portugal.

Description: le projet pour la promotion de l'entrepreneuriat des immigrés a été mis en œuvre entre le $1^{\text {er }}$ avril 2009 et le 30 mai 2014. Il visait à améliorer l'intégration des immigrés, en particulier des femmes et des personnes vivant dans les quartiers défavorisés. Il a soutenu la création d'entreprises et l'emploi indépendant à travers des formations et un programme de coaching personnalisé.

Problème abordé: une étude du Haut-commissariat portugais pour l'immigration et le dialogue interculturel (ACIDI) a montré que les immigrés ont tendance à s'implanter dans des secteurs à faible valeur ajoutée présentant peu d'obstacles à l'entrée. Elle montre également que de nombreux entrepreneurs immigrés auraient besoin de développer leur confiance en eux et leurs compétences sociales et de gestion.

Approche: le projet fait appel à des acteurs locaux (par exemple, associations d'immigrés, banques, ONG et autres organisations de la société civile) pour mettre en œuvre les activités leur permettant de mieux comprendre les communautés cibles. Ses deux activités principales étaient la formation et le coaching. Dix séances de formation sur la gestion d'entreprise, le respect des réglementations et l'accès aux financements, ainsi que huit rendez-vous individuels étaient proposés à chacun des participants (ou équipe entrepreneuriale) pour les aider à développer leur plan d'affaires, à établir des liens avec la communauté locale des entrepreneurs et avec d'autres réseaux professionnels. Le projet PEI était géré par trois responsables de projet à temps plein, assistés par un employé à temps partiel dans chacune des institutions partenaires. Chaque cours était assuré par un formateur professionnel, qui proposait également des séances de coaching individuel. Les réseaux sociaux comme Facebook ont également été beaucoup utilisés pour promouvoir le projet et diffuser des informations aux participants. Le projet PEI a été financé par le Fonds européen d'intégration des ressortissants de pays tiers (FEINPT) et l'ACIDI. Son budget total était d'environ 875000 euros.

Impact: le projet a permis de toucher 1450 participants immigrés, dont 777 ont reçu un certificat de présence à la formation. Les participants ont élaboré 305 idées d'entreprise avec l'aide des formateurs et des coaches et 75 entreprises impliquant 80 des participants ont été créées. Le projet a reçu le premier prix de la catégorie «Entrepreneuriat responsable et inclusif» lors du Prix européen de la promotion de l'esprit d'entreprise 2012.

Facteurs de réussite: cette approche locale et personnalisée semble avoir encouragé les immigrés à participer au programme et à créer des entreprises. 


\section{Données clés relatives à l'entrepreneuriat inclusif}

\section{Graphique 31.1. Données relatives à l'entrepreneuriat et au travail indépendant au Portugal}

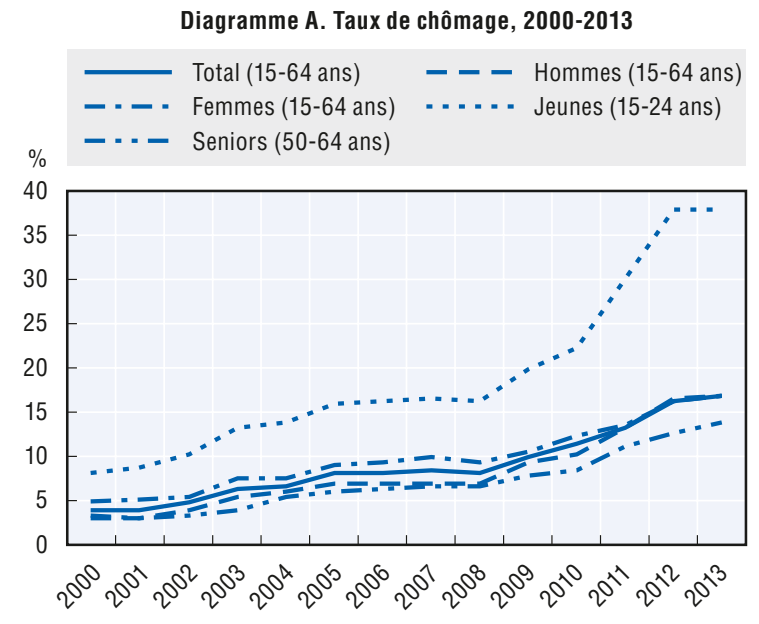

Diagramme B. Taux de travail indépendant, 2013
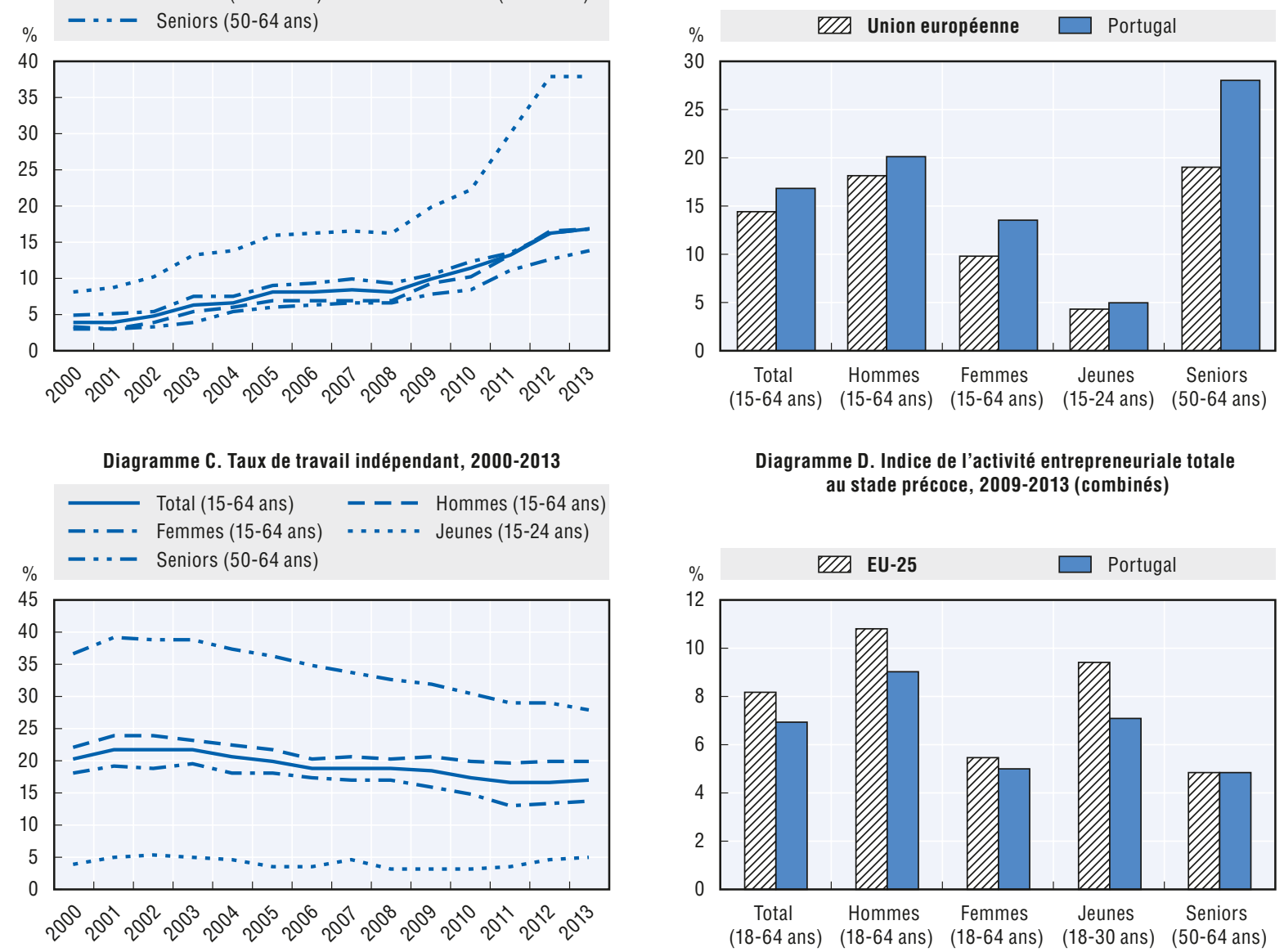

Diagramme D. Indice de l'activité entrepreneuriale totale au stade précoce, 2009-2013 (combinés)

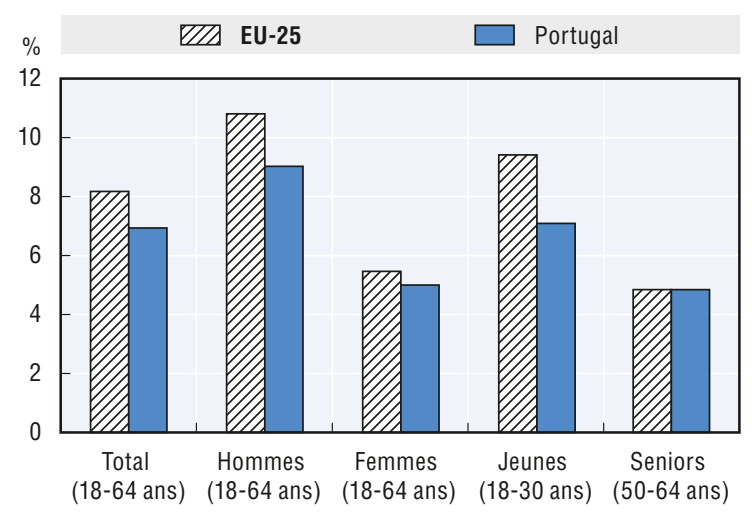

Diagramme E. Nombre total des entrepreneurs au stade précoce qui envisagent de créer plus de 19 emplois dans les 5 ans, 2009-2013 (combinés)

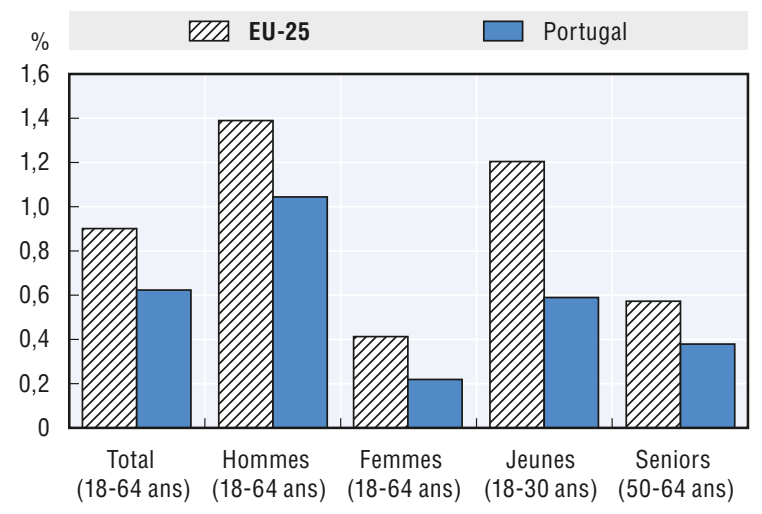

Sources: Diagramme A. Eurostat, Enquête sur les forces de travail, 2000-2013; Diagramme B. Eurostat, Enquête sur les forces de travail, 2013; Diagramme C. Eurostat, Enquête sur les forces de travail, 2000-2013; Diagramme D. Présentation tabulaire spéciale de l'enquête sur la population adulte du Global Entrepreneurship Monitor, 2009-2013; Diagramme E. Présentations tabulaires spéciales de l'enquête sur la population adulte du Global Entrepreneurship Monitor, 2009-2013. 


\section{Roumanie: Fem.RRom}

Cette note de pays présente brièvement un programme de développement de coopératives sociales avec la participation de femmes roms. Elle comprend également des données clés relatives à l'entrepreneuriat inclusif en Roumanie.

Description: Fem.RRom est un projet multirégional mis en œuvre en Roumanie en 20102013 par le ministère du travail, de la famille, de la protection sociale et des personnes âgées, en partenariat avec l'Agence nationale pour les Roms et de nombreuses organisations grecques et portugaises. Ce projet avait pour objectif d'améliorer l'accès des femmes roms au marché du travail et à l'entrepreneuriat en soutenant la création de coopératives sociales. Les participantes devaient être des femmes roms âgées de 15 à 59 ans et diplômées de l'enseignement secondaire.

Problème abordé: en Roumanie, les femmes roms sont victimes de discriminations graves du fait de leur situation sociale, de leur origine ethnique et de leur sexe. Elles ont donc peu d'opportunités sur le marché du travail et sont fortement menacées d'exclusion sociale. De plus, le rôle domestique de la femme est très ancré dans la culture rom. En effet, des études montrent que 77 \% des femmes roms n'exercent pas d'activité rémunérée en Roumanie (Comşa, Rughiniş et Tufiş, 2008). Malgré ces difficultés, il n'existe pas de services pour l'emploi destinés aux femmes roms.

Approche: ce projet a débuté par une évaluation des besoins socio-économiques, éducatifs et professionnels des femmes roms et des opportunités des Roms de développer des coopératives sociales dans les régions couvertes par le projet (nord-ouest, sud-ouest et centre). Puis un guichet unique pour l'emploi a été créé dans chaque région du projet afin de conseiller les Roms et de leur proposer des services pour l'emploi adaptés à leurs besoins, y compris des formations pour soutenir le développement de coopératives sociales. Dans les trois régions couvertes, huit projets de coopératives sociales ont été soumis et cinq ont été sélectionnés (trois dans la vente de fleurs, un dans le lavage automobile à sec et un dans les services de nettoyage et de placement professionnel). Les cinq projets de coopératives sélectionnés ont bénéficié d'une aide juridique pour l'immatriculation, la préparation du plan d'affaires et la recherche de financements. Les bénéficiaires ont pu emprunter des équipements et percevoir une aide mensuelle pour chaque employé (environ 95 euros). Le budget total du projet, financé à 98 \% par le Fonds social européen et le gouvernement roumain, s'élevait à 18,5 millions de lei roumains (RON) (environ 4,1 millions d'euros).

Impact: plus de 1000 femmes roms ont bénéficié des services de ce projet et 550 d'entre elles ont reçu une formation professionnelle et entrepreneuriale. Les cinq coopératives ont été fondées par 26 femmes, dont 16 Roms, et ont créé quelque 98 emplois pour des femmes roms.

Facteurs de réussite: ce projet montre l'importance d'adapter le soutien au contexte local. Il illustre également bien la façon dont des partenariats internationaux peuvent faciliter l'apprentissage grâce à des expériences du monde entier.

Référence: Comșa, M., Rughiniș, C., et Tufiș, C. (2008), «Atitudini față de muncă în România (Attitudes à l'égard de l'emploi en Roumanie)», Bucarest, Fondation Soros pour la Roumanie. 


\section{Données clés relatives à l'entrepreneuriat inclusif}

\section{Graphique 32.1. Données relatives à l'entrepreneuriat et au travail indépendant en Roumanie}

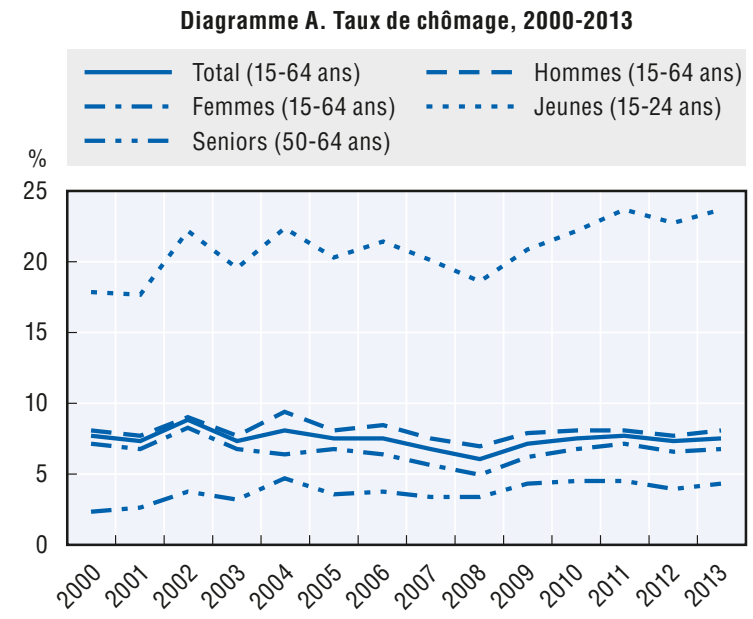

Diagramme B. Taux de travail indépendant, 2013

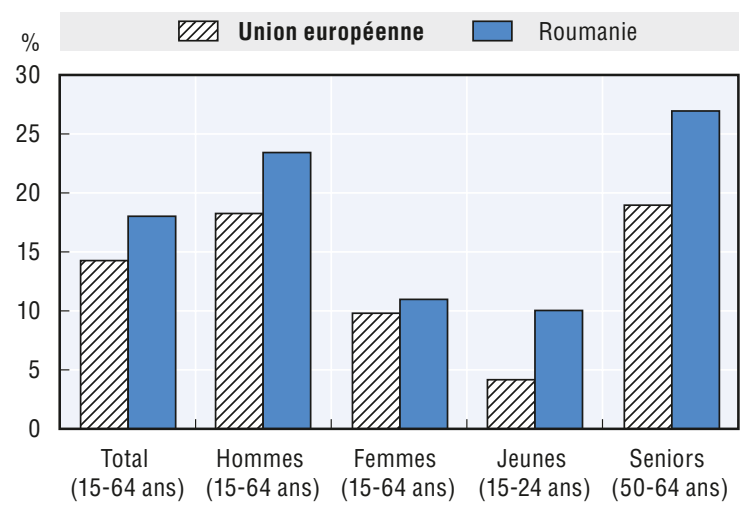

Diagramme C. Taux de travail indépendant, 2000-2013

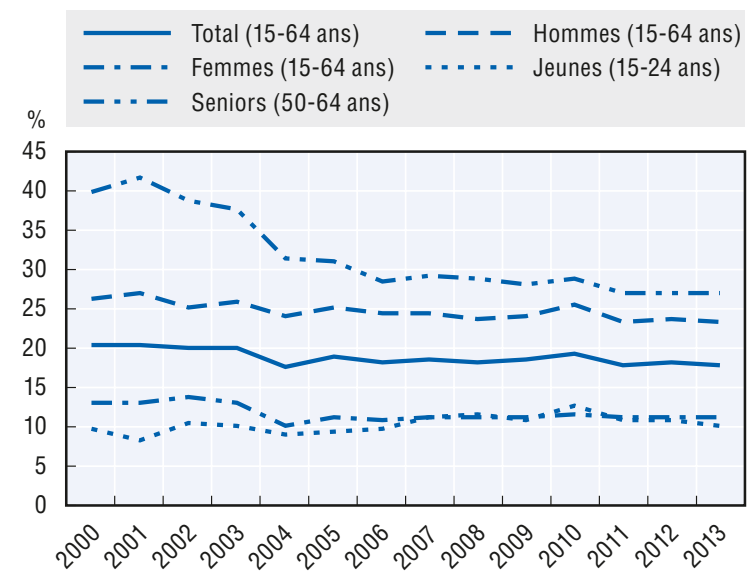

Diagramme D. Indice de l'activité entrepreneuriale totale au stade précoce, 2009-2013 (combinés)

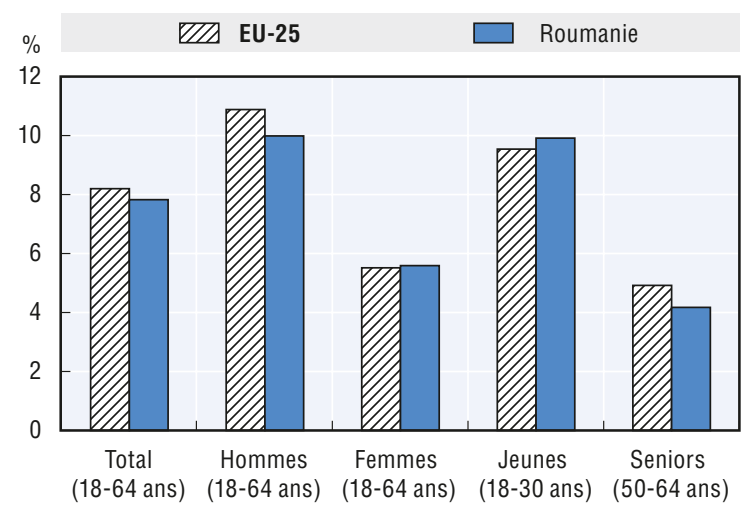

Diagramme E. Nombre total des entrepreneurs au stade précoce qui envisagent de créer plus de 19 emplois dans les 5 ans, 2009-2013 (combinés)

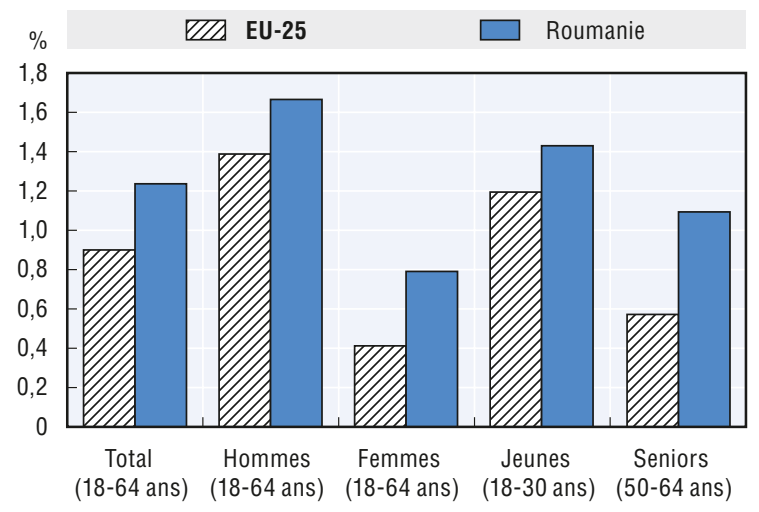

Sources: Diagramme A. Eurostat, Enquête sur les forces de travail, 2000-2013; Diagramme B. Eurostat, Enquête sur les forces de travail, 2013; Diagramme C. Eurostat, Enquête sur les forces de travail, 2000-2013; Diagramme D. Présentation tabulaire spéciale de l'enquête sur la population adulte du Global Entrepreneurship Monitor, 2009-2013; Diagramme E. Présentations tabulaires spéciales de l'enquête sur la population adulte du Global Entrepreneurship Monitor, 2009-2013. 


\section{République slovaque: contribution financière au travail indépendant}

Cette note de pays présente brièvement un programme national visant à encourager les chômeurs à s'établir comme travailleurs indépendants grâce à des incitations financières. Elle comprend également des données clés relatives à l'entrepreneuriat inclusif en République slovaque.

Description: ce projet s'inscrit dans le cadre des politiques actives de marché du travail mises en œuvre par le bureau central du travail, des affaires sociales et familiales (COLSAF). Les aides et formations sont gérées par les bureaux locaux et régionaux du COLSAF et ciblent les personnes au chômage et handicapées qui souhaitent créer une entreprise.

Problème abordé: le manque de financements est l'une des principales difficultés auxquelles les chômeurs et les personnes handicapées sont confrontés lorsqu'ils créent leur entreprise ou s'établissent comme indépendant. Parallèlement, ces groupes disposent d'un niveau d'épargne relativement faible, l'accès aux aides générales à la création d'entreprises étant plus difficile en République slovaque que dans l'ensemble de l'Union européenne (Piklová et al., 2013). Leur faible niveau de compétences entrepreneuriales peut constituer un autre obstacle, même si les entrepreneurs potentiels peuvent ne pas l'admettre. Ce projet a en effet permis d'identifier que les chômeurs slovaques ont tendance à surestimer leur capacité à créer et gérer une entreprise.

Approche: le candidat à la contribution financière au travail indépendant doit signer un accord écrit qui stipule que le bureau local pour l'emploi lui fournira une formation pour créer son entreprise ou devenir travailleur indépendant. Cette formation est dispensée soit en interne par l'agence locale pour l'emploi, soit en externe par des experts selon le type et l'objectif de la future entreprise. Le candidat doit ensuite soumettre un plan d'affaires dont la viabilité est examinée par une commission. Une subvention peut être allouée aux projets d'entreprise jugés viables. Son montant varie selon la région de résidence des participants. Leurs bénéficiaires s'engagent à maintenir leur activité pour une durée minimale de 24 mois. Nombre des bénéficiaires sont des personnes handicapées (47 \%) et des chômeurs de longue durée (29 \%) (Bořík et al., 2013). De plus, 40,1 \% des bénéficiaires sont des femmes (Bureau de la statistique, 2013).

Impact: plus de 70 millions d'euros de subventions ont été alloués à plus de 10000 personnes au cours de la période 2011-2013. Le suivi indique que 84 \% des bénéficiaires étaient toujours en activité 15 mois après la période initiale de 24 mois.

Facteurs de réussite: le principal facteur de réussite de cette initiative réside dans la formation dispensée aux bénéficiaires pour les aider à concrétiser leur plan d'affaires. Le service de conseil en entreprise a également joué un rôle important lors de la phase de démarrage.

Références: Bořík, V. et M. Caban (2013), «Pilotné hodnotenie dopadov vybraných opatrení aktívnej politiky trhu práce», MPSVR SR, ÚPSVR, disponible à l'adresse suivante: http://www.esf. gou.sk/new/index.php?sID=dcf9ce6533e691d34a5e99387f29f492\&mod=search_results\&w=hodnotenie.

Pilková A., M. Holienka et J. Rehaket (2013), Podnikanie na Slovensku: Nadpriemerná podnikatel'ská aktivita $v$ podpriemernom podnikatel'skom prostredí, Univerzita Komenského v Bratislave, Fakulta managementu.

Bureau de la statistique de République slovaque (2014), «Unemployed by the Labour Force Sample Survey in 2013", disponible à l'adresse suivante: http://portal.statistics.sk/showdoc. do? docid $=67076$. 


\section{Données clés relatives à l'entrepreneuriat inclusif}

\section{Graphique 33.1. Données relatives à l'entrepreneuriat et au travail indépendant en République slovaque}

Diagramme A. Taux de chômage, 2000-2013

Diagramme B. Taux de travail indépendant, 2013

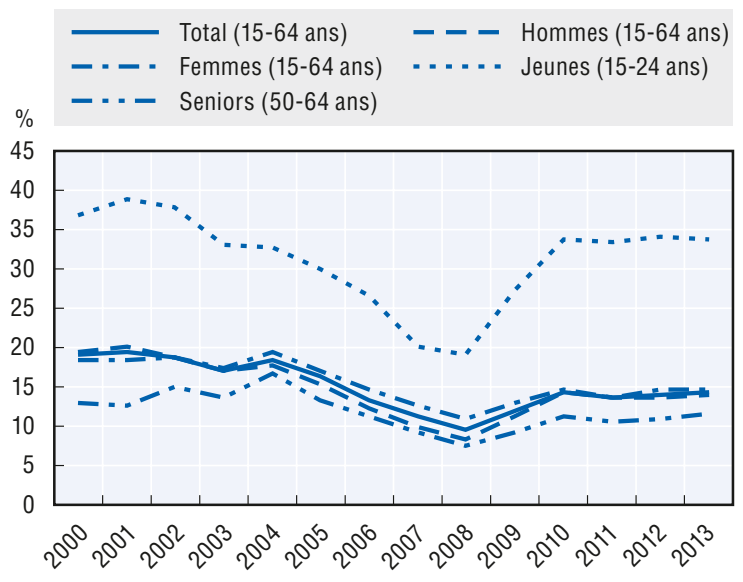

Diagramme C. Taux de travail indépendant, 2000-2013
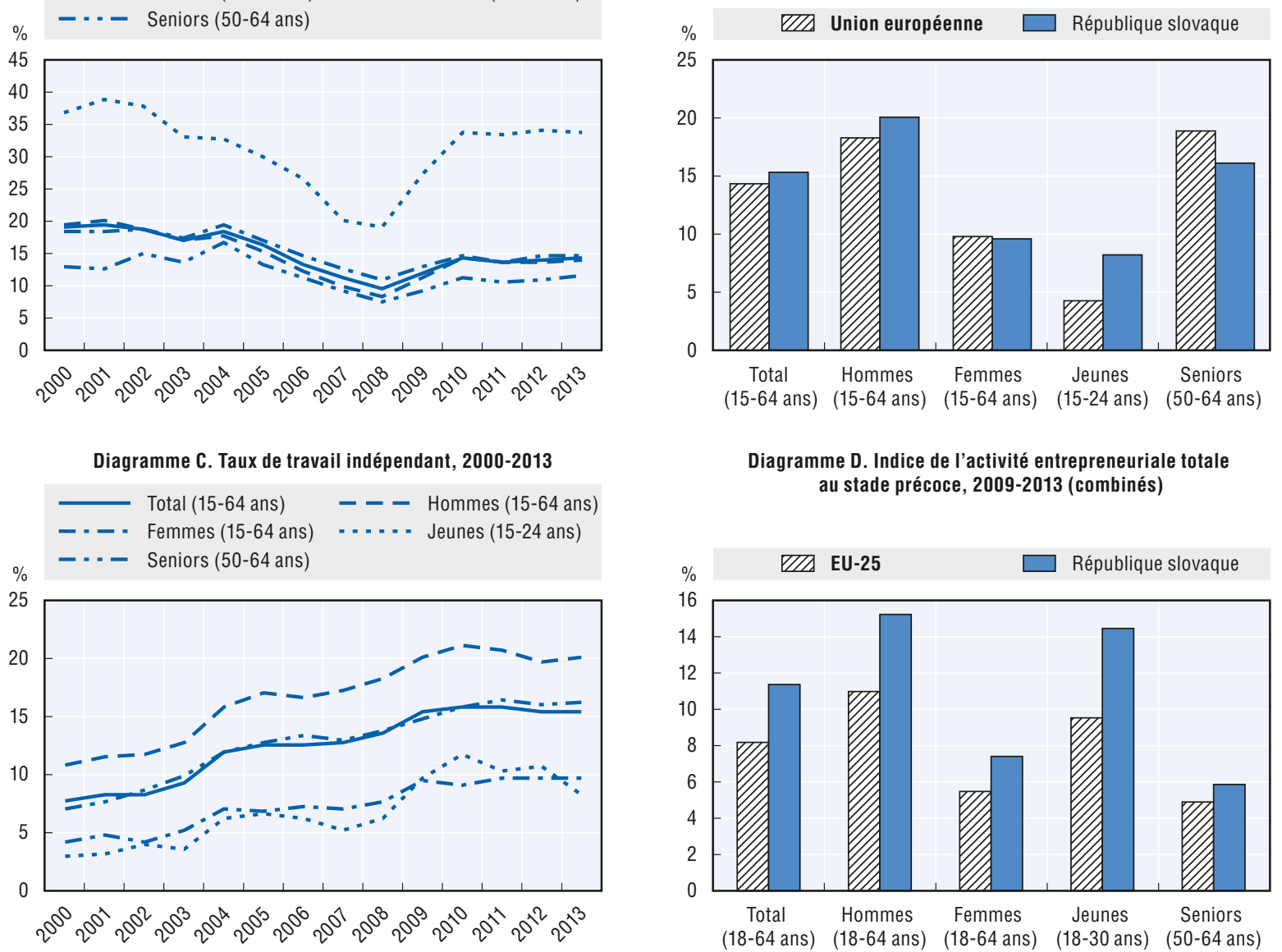

Diagramme D. Indice de l'activité entrepreneuriale totale au stade précoce, 2009-2013 (combinés)

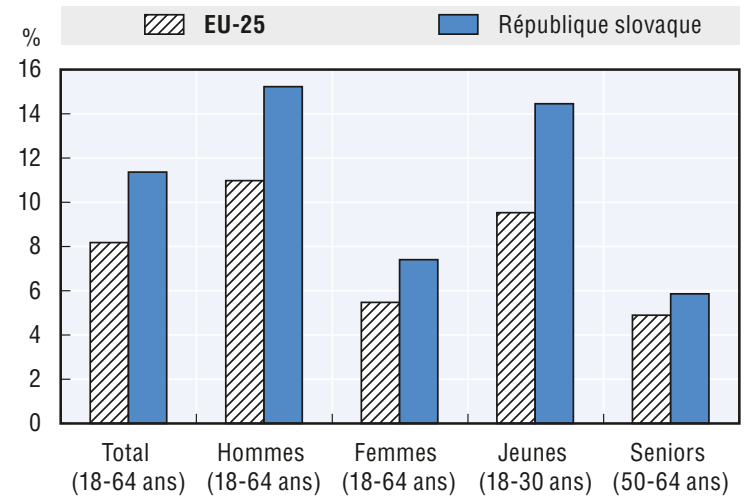

Diagramme E. Nombre total des entrepreneurs au stade précoce qui envisagent de créer plus de 19 emplois dans les 5 ans, 2009-2013 (combinés)

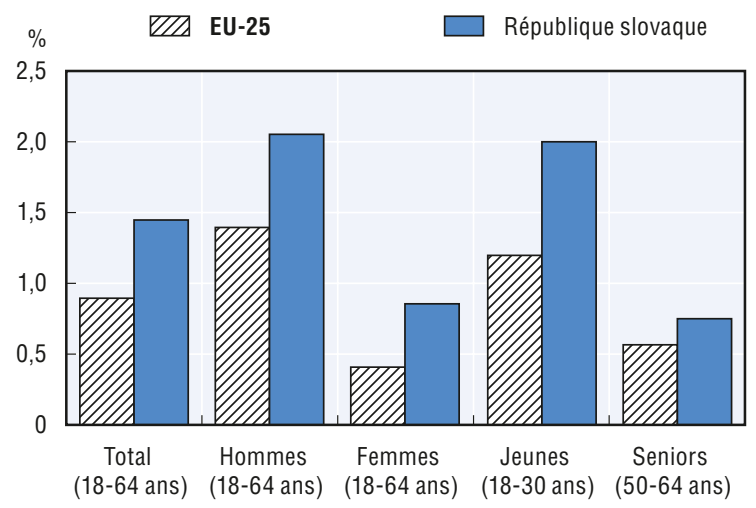

Sources: Diagramme A. Eurostat, Enquête sur les forces de travail, 2000-2013; Diagramme B. Eurostat, Enquête sur les forces de travail, 2013; Diagramme C. Eurostat, Enquête sur les forces de travail, 2000-2013; Diagramme D. Présentation tabulaire spéciale de l'enquête sur la population adulte du Global Entrepreneurship Monitor, 2009-2013; Diagramme E. Présentations tabulaires spéciales de l'enquête sur la population adulte du Global Entrepreneurship Monitor, 2009-2013. 


\section{Slovénie: P2P — Podjetnice za podjetnice do enakih možnosti v podjetništvu (Les femmes entrepreneurs pour l'égalité des chances entrepreneuriales des femmes)}

Cette note de pays présente brièvement un programme de formation et de soutien aux femmes entrepreneurs. Elle comprend également des données clés relatives à l'entrepreneuriat inclusif en Slovénie.

Description: mis en œuvre en 2013, le projet P2P proposait aux femmes des services de mentorat et de formation afin qu'elles renforcent leurs compétences pour créer et développer leur propre entreprise dans la région du Karst en Slovénie. Le projet s'adressait aux femmes entrepreneurs dont l'entreprise était encore dans les phases précoces de développement (c'està-dire dont l'entreprise a été créée depuis moins de deux ans). Il a été mis en œuvre par le centre de l'entrepreneuriat KonektOn Ltd et l'Institut pour le développement de l'entrepreneuriat familial et féminin, et cofinancé par le ministère du travail, des affaires sociales, de la famille et de l'égalité des chances.

Problème abordé: dans toute la Slovénie, à l'exception d'une région (Obalno-kraška), les femmes ont moins tendance à se tourner vers l'entrepreneuriat que les hommes (Podgornik et al., 2009). Les femmes entrepreneurs font face à des difficultés plus graves que les hommes, notamment liées à l'équilibre entre le travail et la vie de famille, la faiblesse des réseaux et le manque de qualifications et d'expérience appropriées.

Approche: l'objectif du projet P2P est de stimuler le potentiel d'entrepreneuriat de femmes et de leur donner les moyens de réaliser concrètement cette possibilité. Ses activités incluaient l'organisation de groupes de pairs regroupant des femmes entrepreneurs afin de favoriser l'échange et la diffusion des expériences, des idées et des informations par le biais de l'apprentissage par les pairs et du mentorat, d'encourager la confiance en soi et la création de réseaux. Des ateliers ont été organisés au centre KonektOn. Ils portaient sur cinq thèmes: l'égalité des sexes dans l'entrepreneuriat; la difficulté à développer des idées d'entreprise; l'équilibre entre vie privée et vie professionnelle; les réseaux comme facteur de réussite; et la compréhension de l'environnement des affaires. Les femmes entrepreneurs intéressées par ce projet pouvaient s'inscrire au programme de mentorat, sous réserve de prouver qu'elles avaient créé une entreprise au cours des deux dernières années. Au total, 25 femmes entrepreneurs ont été sélectionnées pour ce programme.

Impact: sur les 25 participantes, 16 ont répondu au questionnaire de satisfaction. Leur note globale de 6,63 sur 7 révèle un niveau de satisfaction élevé. L'enquête a également montré que de nombreuses participantes ont continué à demander de l'aide et des informations aux groupes de pairs après la fin du projet.

Facteurs de réussite: ce projet pilote constitue un modèle d'entrepreneuriat collaboratif. La création de mécanismes d'aide pour la promotion de l'entrepreneuriat féminin reste un moyen efficace de renforcer l'entrepreneuriat au sein de ce groupe cible. Les organisateurs cherchent actuellement à transposer ce programme régional à l'échelle nationale.

Référence: Podgornik, R., Tominc, P., et Rebernik, M. (2009), «Regional analysis of selected key factors influencing the early-stage entrepreneurial activity in Slovenia», in Širec, K., et Rebernik, M. (eds.), Dynamics of Slovenian entrepreneurship: Slovenian Entrepreneurship Observatory 2008, Maribor, Faculté des sciences économiques et commerciales, p. 87-104. 


\section{Données clés relatives à l'entrepreneuriat inclusif}

\section{Graphique 34.1. Données relatives à l'entrepreneuriat et au travail indépendant en Slovénie}

Diagramme A. Taux de chômage, 2000-2013
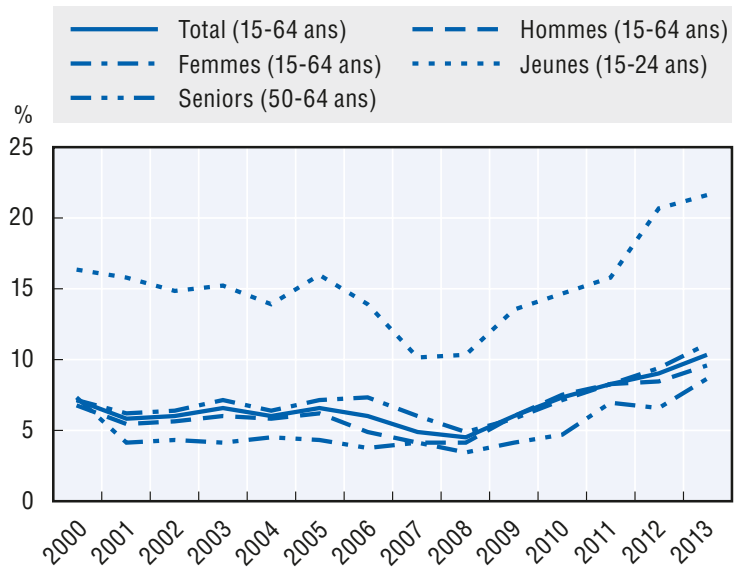

Diagramme C. Taux de travail indépendant, 2000-2013

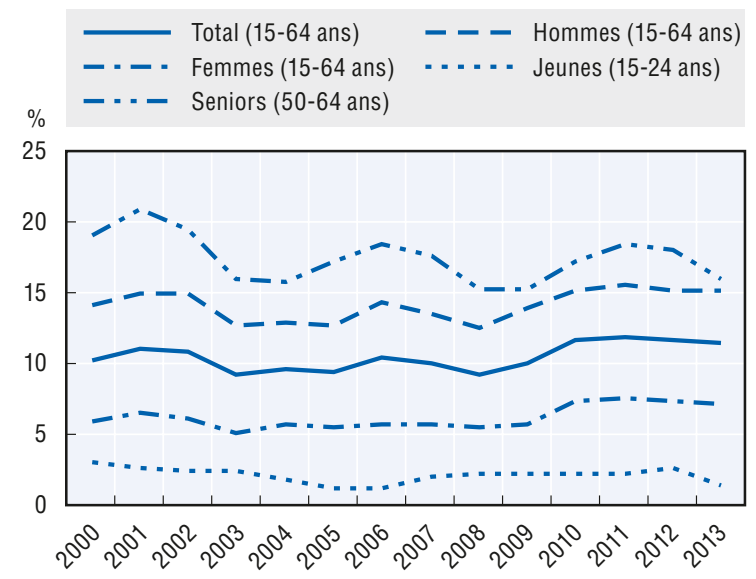

Diagramme E. Nombre total des entrepreneurs au stade précoce qui envisagent de créer plus de 19 emplois dans les 5 ans, 2009-2013 (combinés)

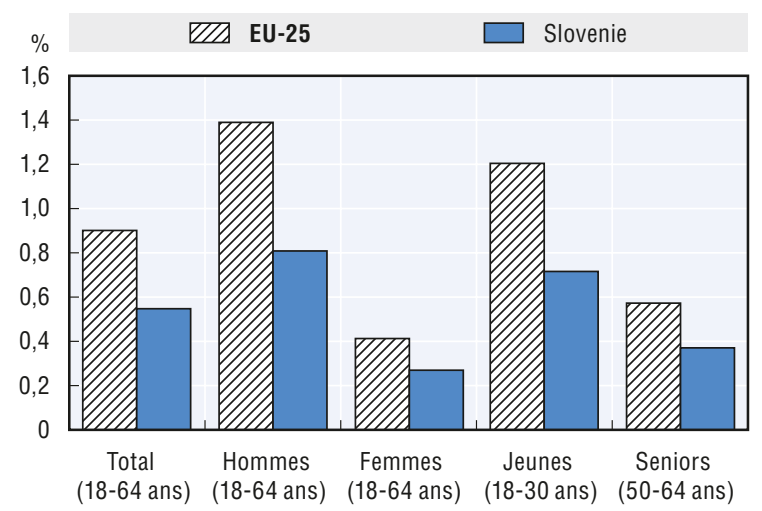

Diagramme B. Taux de travail indépendant, 2013

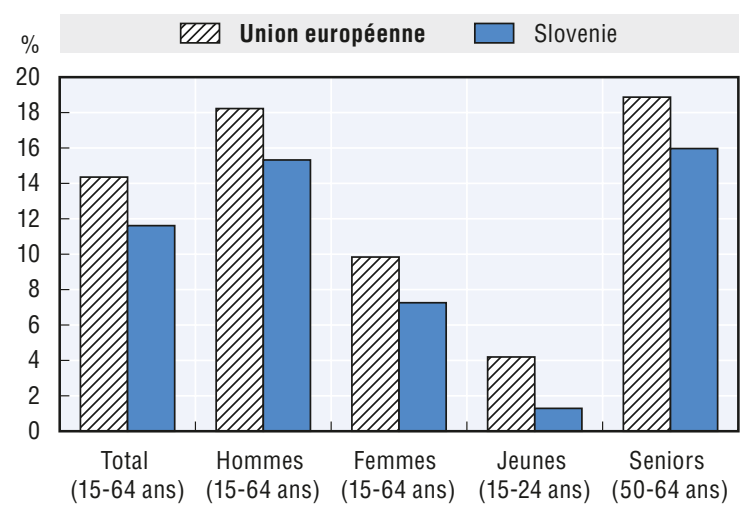

Diagramme D. Indice de l'activité entrepreneuriale totale au stade précoce, 2009-2013 (combinés)

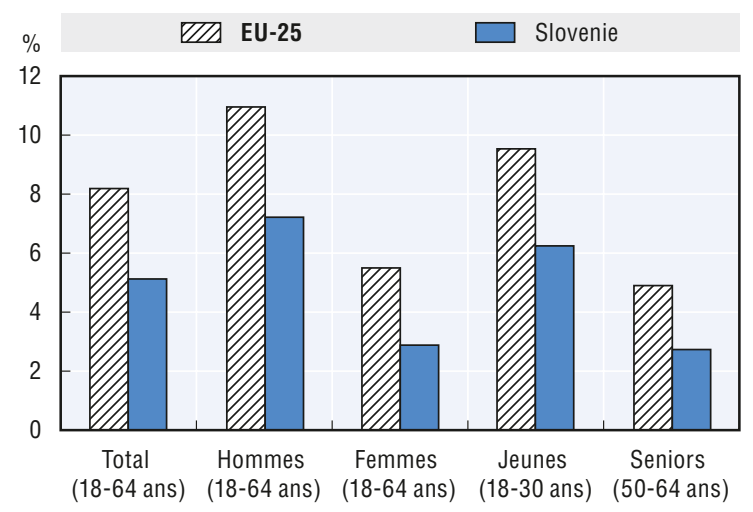

Sources: Diagramme A. Eurostat, Enquête sur les forces de travail, 2000-2013; Diagramme B. Eurostat, Enquête sur les forces de travail, 2013; Diagramme C. Eurostat, Enquête sur les forces de travail, 2000-2013; Diagramme D. Présentation tabulaire spéciale de l'enquête sur la population adulte du Global Entrepreneurship Monitor, 2009-2013; Diagramme E. Présentations tabulaires spéciales de l'enquête sur la population adulte du Global Entrepreneurship Monitor, 2009-2013. 


\section{Espagne: Red de Cooperación de Emprendedoras (Réseau de coopération entre femmes entrepreneurs)}

Cette note de pays présente brièvement un programme visant à établir et entretenir des réseaux de coopération au sein des groupes de femmes entrepreneurs. Elle comprend également des données clés relatives à l'entrepreneuriat inclusif en Espagne.

Description: l'objectif du réseau Red de Cooperación de Emprendedoras (RCE) est de favoriser la création et l'utilisation de réseaux de coopération par des femmes entrepreneurs et d'améliorer ainsi l'accès de ces dernières aux ressources et aux opportunités leur permettant de renforcer leur capacité d'innovation et la compétitivité de leurs entreprises. Pour ce faire, ce programme propose des activités de mise en réseau et de formation aux femmes entrepreneurs ou qui souhaitent le devenir. Le programme a été lancé par Andalucía Emprende en collaboration avec l'Instituto Andaluz de la Mujer.

Problème abordé: en Andalousie, seules 13,8 \% des femmes exercent une activité indépendante, contre $23,4 \%$ des hommes. De même, seulement $25,4 \%$ des indépendantes ont des employés, contre $32,4 \%$ des indépendants. Ainsi, les femmes ne représentent qu'un tiers des travailleurs indépendants et seulement un quart des employeurs. Des études montrent que pour construire leurs réseaux professionnels, les femmes font face à des difficultés qui entravent leur accès aux ressources, aux partenaires commerciaux, aux fournisseurs et aux clients.

Approche: Andalucía Emprende représente le principal point d'accès du programme avec son réseau rassemblant plus de 200 centres d'aide au développement entrepreneurial (CADE) répartis dans toute la région. Les CADE ont organisé des événements promotionnels au début du programme en 2007-2008 pour faire connaître le programme, et toutes les femmes ayant contacté l'un des CADE durant cette période pour quelque raison que ce soit ont été informées de la possibilité d'y participer. Le réseau comporte trois composantes: une plateforme en ligne, des événements de mise en réseau et des formations. Premièrement, la plateforme en ligne permet de renforcer la visibilité du programme auprès de toutes les entreprises participantes et offre la possibilité d'entrer en contact avec d'autres femmes entrepreneurs. De plus, des événements de mise en réseau ont été organisés régulièrement pour faciliter les rencontres physiques entre les membres du réseau. Plus de 120 petits déjeuners ont notamment été organisés avec les participants. Cinq conférences ont également eu lieu sur des thèmes tels que l'industrie du tourisme, le développement à l'international et la collaboration entre l'Afrique et l'Espagne. Enfin, près d'une centaine de formations ont été dispensées sur les thèmes suivants: coopération, marketing, nouvelles technologies et compétences entrepreneuriales (par exemple, négociation, communication, gestion du temps). Avec le temps, de plus en plus de femmes ont exprimé le souhait de développer leurs réseaux au-delà de la seule communauté féminine. C'est pourquoi la décision a été prise en 2013 d'étendre l'initiative pour promouvoir la coopération entre tous les types d'entrepreneurs d'Andalousie (hommes et femmes) dès 2014.

Impact: durant la période 2008-2013, Andalucía Emprende et l'Instituto Andaluz de la Mujer ont organisé plus de 2500 actions ciblant les femmes entrepreneurs, qui ont permis de toucher plus de 22800 participants. Au total, 3268 femmes entrepreneurs ont intégré le réseau, soit plus de $20 \%$ des entreprises créées par des femmes en Andalousie chaque année. Concernant les activités du réseau, 2939 femmes ont participé aux petits déjeuners et 2178 femmes ont suivi une formation. À l'occasion de ces activités, ou directement sur le portail internet, 1827 prises de contact ont été établies avec des entrepreneurs en quête d'assistance. Le personnel du RCE a également conseillé 1312 participants.

Facteurs de réussite: le principal facteur de réussite du RCE a été son rôle d'animateur, qui invitait (sans l'exiger) à une participation active. Pour ce type d'activité, il est important d'atteindre un grand nombre d'entrepreneurs pour créer un réseau cohérent et complet. Les nombreux centres de soutien (CADE) qui servent de points d'accès pour les femmes entrepreneurs ont été essentiels. 


\section{Données clés relatives à l'entrepreneuriat inclusif}

\section{Graphique 35.1. Données relatives à l'entrepreneuriat et au travail indépendant en Espagne}

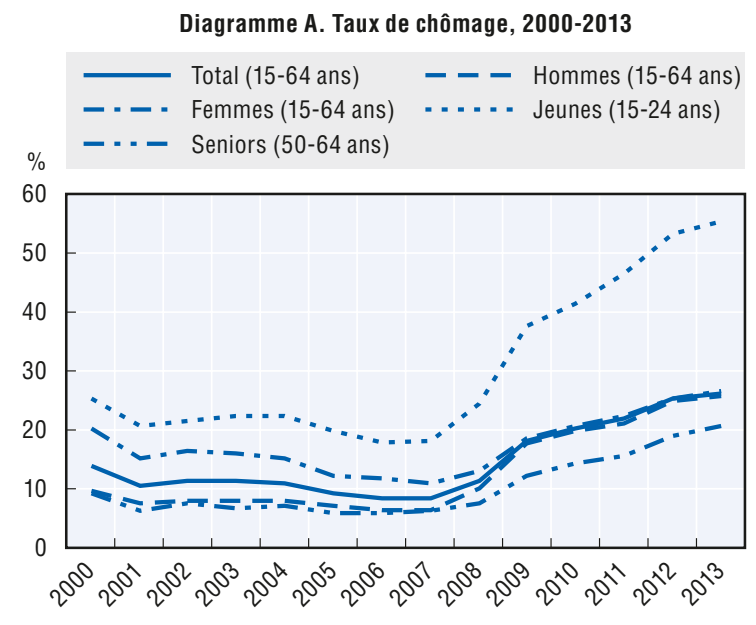

Diagramme B. Taux de travail indépendant, 2013

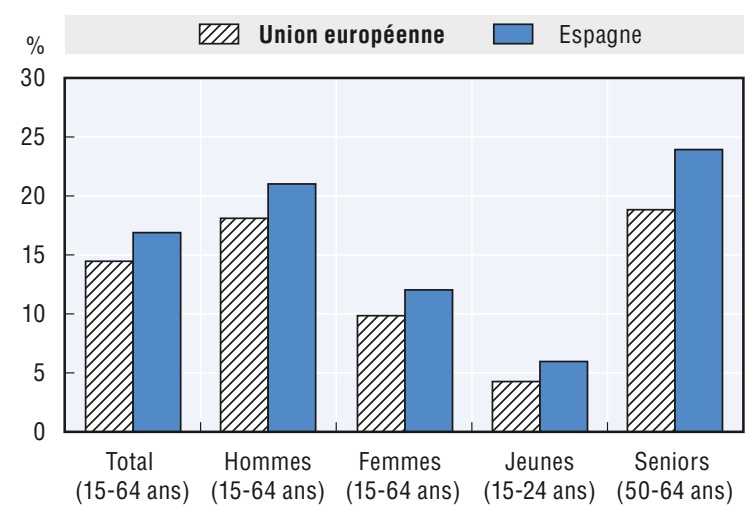

Diagramme C. Taux de travail indépendant, 2000-2013

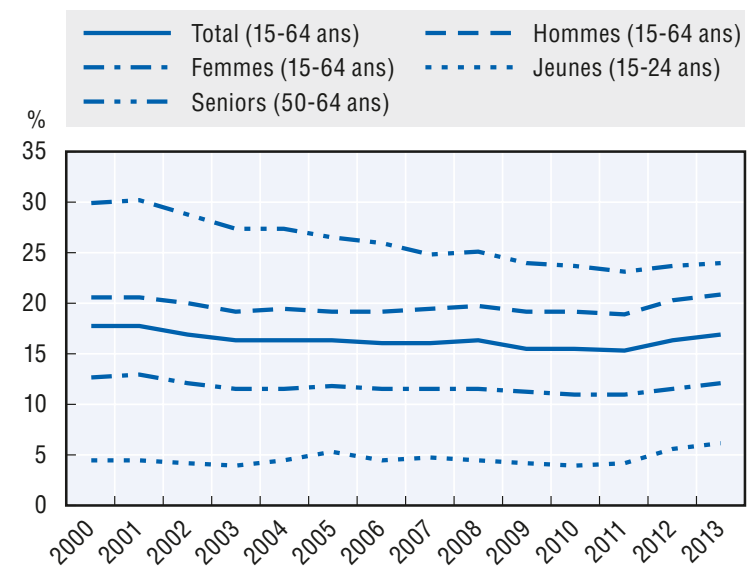

Diagramme D. Indice de l'activité entrepreneuriale totale au stade précoce, 2009-2013 (combinés)

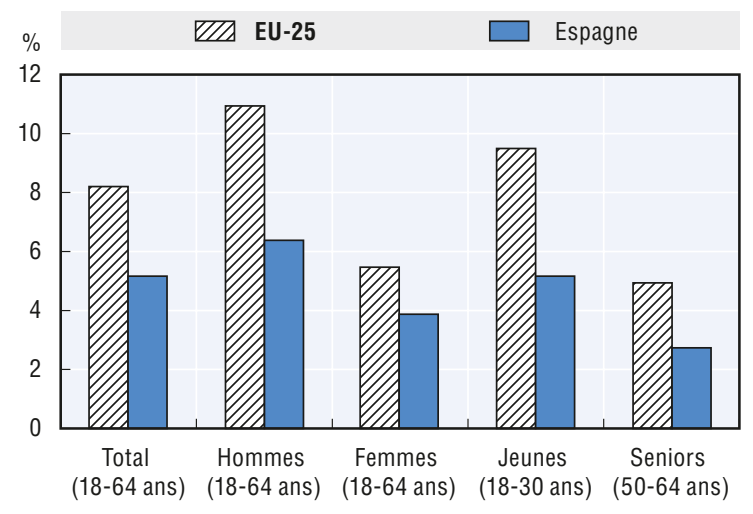

Diagramme E: Nombre total des entrepreneurs au stade précoce qui envisagent de créer plus de 19 emplois dans les 5 ans, 2009-2013 (combinés)

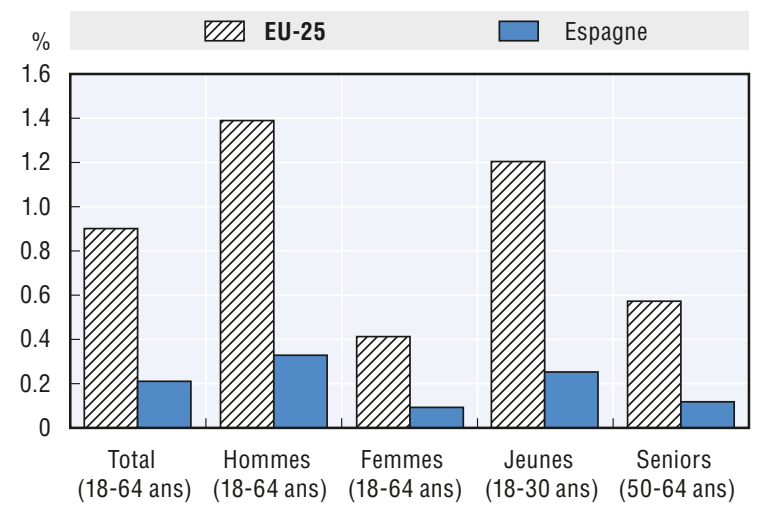

Sources: Diagramme A. Eurostat, Enquête sur les forces de travail, 2000-2013; Diagramme B. Eurostat, Enquête sur les forces de travail, 2013; Diagramme C. Eurostat, Enquête sur les forces de travail, 2000-2013; Diagramme D. Présentation tabulaire spéciale de l'enquête sur la population adulte du Global Entrepreneurship Monitor, 2009-2013; Diagramme E. Présentations tabulaires spéciales de l'enquête sur la population adulte du Global Entrepreneurship Monitor, 2009-2013. 


\section{Suède: Inkubator 55+}

Cette note de pays présente brièvement une couveuse d'entreprises sociales mise en place par et pour les seniors. Elle comprend également des données clés relatives à l'entrepreneuriat inclusif en Suède.

Description: cette couveuse a été mise en place à titre pilote dans le cadre de la politique gouvernementale visant à encourager les innovations sociales dans le secteur du bien-être des personnes âgées. Ce projet a été mis en œuvre par Vinnova, l'agence suédoise pour l'innovation, et gérée par la couveuse d'entreprises de l'université de Stockholm. Il a pour objectif de soutenir les projets d'entrepreneuriat social portés par et pour les seniors de plus de 55 ans.

Problème abordé: en Suède, on estime que 21 \% de la population sera âgée de plus de 65 ans en 2020. Si cette situation pèse sur le système économique et social du pays, elle peut également représenter une opportunité. Les personnes de plus de 55 ans sont de plus en plus actives, et la demande de services et produits destinés à cette tranche d'âge est en constante augmentation.

Approche: le programme poursuivait trois objectifs: exploiter les connaissances et l'expérience des entrepreneurs seniors sur leur tranche d'âge pour créer des entreprises sociales, contribuer à l'emploi des seniors en leur permettant de travailler et leur donner l'occasion d'utiliser leur expérience et leurs talents. La couveuse de l'université de Stockholm (CSES) a mis en œuvre ce programme pilote à l'automne 2012 et l'a intégré à son mode de fonctionnement habituel. Les participants ont ainsi pu bénéficier des offres de coaching, des formations et des événements du CSES. Inkubator 55+ a également recruté des coaches pour intervenir spécifiquement auprès des participants de ce programme pilote et a organisé des formations et des événements. Des entrepreneurs potentiels de toute la Suède ont pu postuler. Plus de 40 candidatures ont été reçues et évaluées. Les candidats ont été sélectionnés au regard de la faisabilité de leur projet d'entreprise et de leurs capacités entrepreneuriales. Lors de la procédure de sélection, tout a été fait pour créer un groupe d'entrepreneurs diversifié en termes de participation au marché du travail (c'est-à-dire retraités, actifs, chômeurs), d'expérience entrepreneuriale et de sexe. Les personnes sélectionnées ont pu profiter de la couveuse pendant 4 à 5 mois.

Impact: étant donné qu'il s'agissait d'un projet pilote, l'impact n'a pu être évalué qu'à partir des résultats produits. Sur les 40 candidatures, six projets ont été sélectionnés pour le programme et trois se sont concrétisés.

Facteurs de réussite: les principaux facteurs de succès de ce projet sont l'existence d'un marché non exploité de l'entrepreneuriat par et pour les seniors (du côté de l'offre comme de la demande) et l'intégration des nouvelles activités pour seniors dans un programme de couveuse établi. Les connaissances et services de la couveuse (CSES) ont été complétés par des activités spécifiques visant à consacrer davantage de temps et d'aide aux plus de 55 ans. 


\section{Données clés relatives à l'entrepreneuriat inclusif}

\section{Graphique 36.1. Données relatives à l'entrepreneuriat et au travail indépendant en Suède}

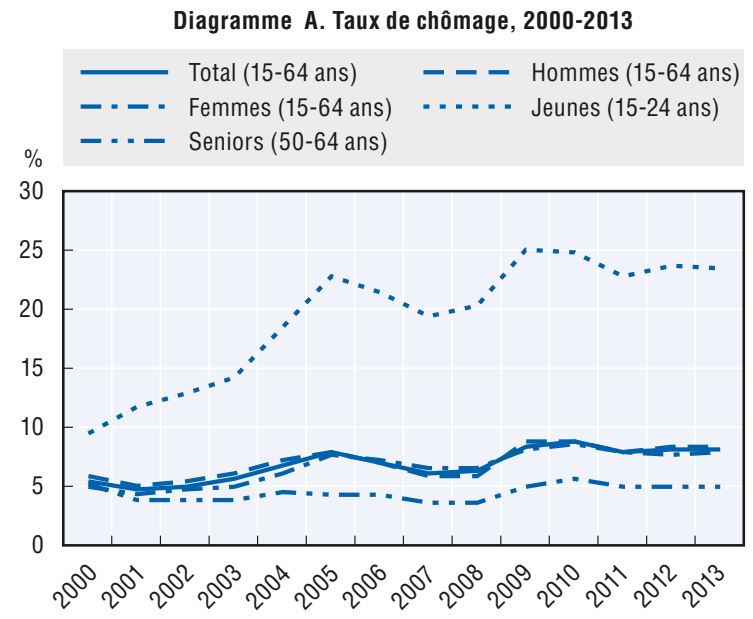

Diagramme B. Taux de travail indépendant, 2013

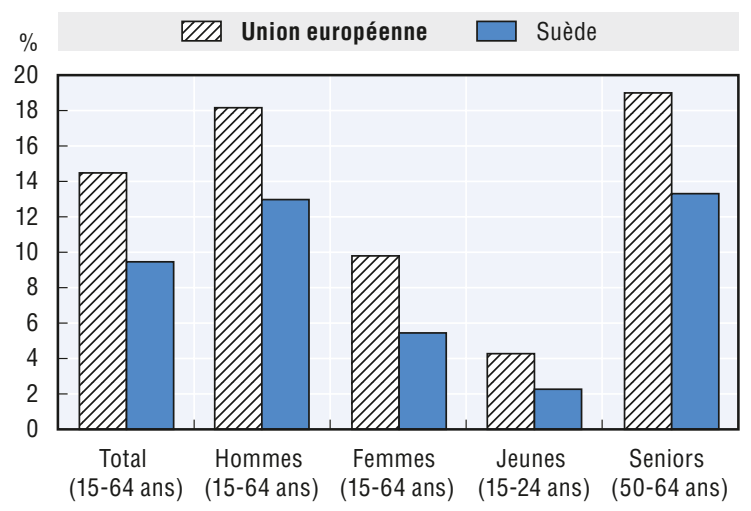

Diagramme C. Taux de travail indépendant, 2000-2013

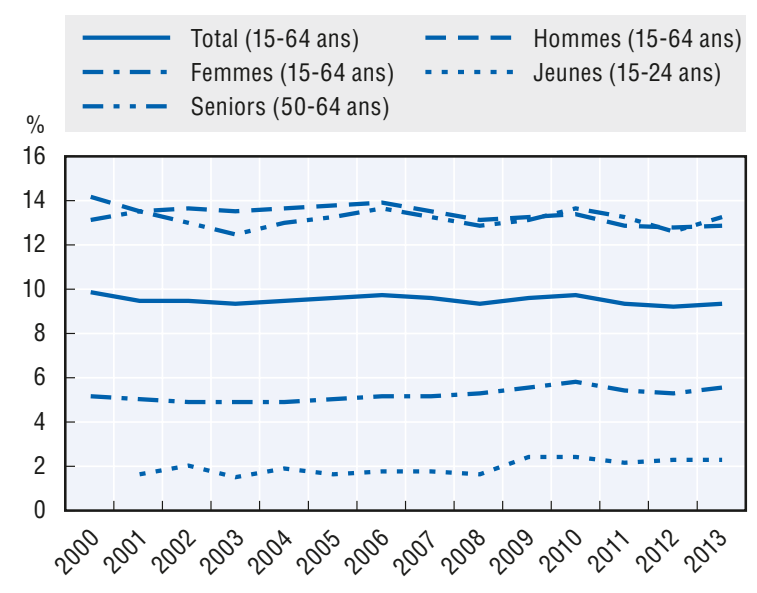

Diagramme D. Indice de l'activité entrepreneuriale totale au stade précoce, 2009-2013 (combinés)

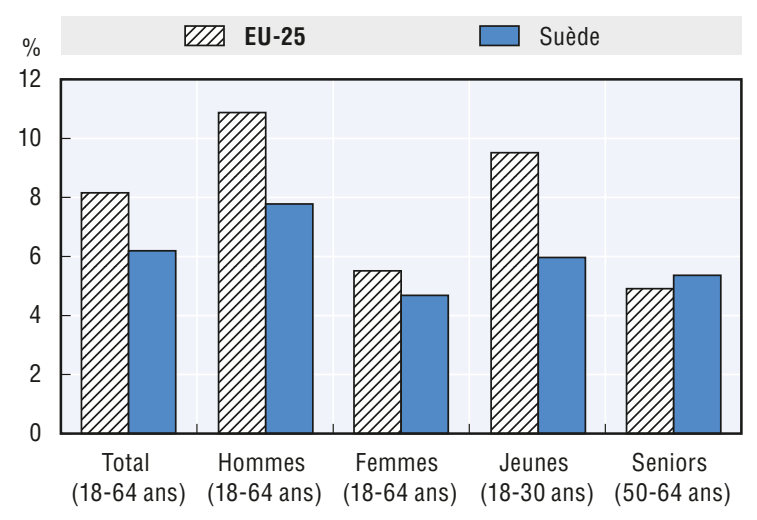

Diagramme E. Nombre total des entrepreneurs au stade précoce qui envisagent de créer plus de 19 emplois dans les 5 ans 2009-2013 (combinés)

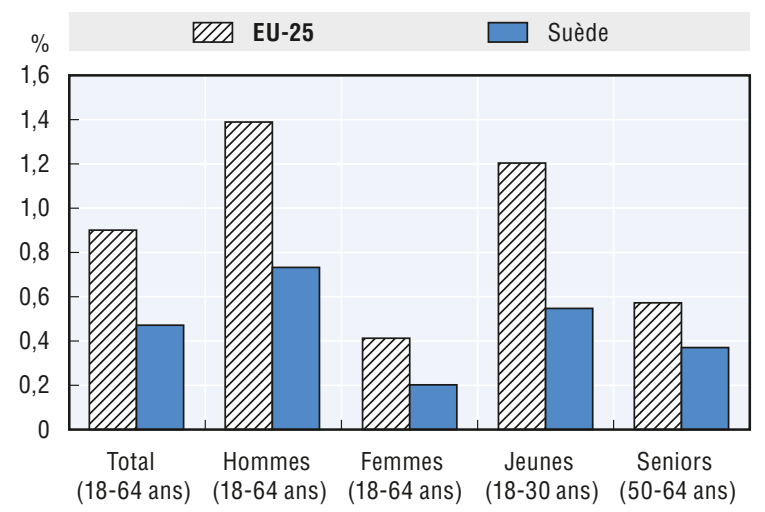

Sources: Diagramme A. Eurostat, Enquête sur les forces de travail, 2000-2013; Diagramme B. Eurostat, Enquête sur les forces de travail, 2013; Diagramme C. Eurostat, Enquête sur les forces de travail, 2000-2013; Diagramme D. Présentation tabulaire spéciale de l'enquête sur la population adulte du Global Entrepreneurship Monitor, 2009-2013; Diagramme E. Présentations tabulaires spéciales de l'enquête sur la population adulte du Global Entrepreneurship Monitor, 2009-2013. 


\section{Royaume-Uni: Buy Sunderland First}

Cette note de pays présente brièvement un programme visant à utiliser les passations de marchés publics pour soutenir les entreprises locales dans une région gravement touchée par le chômage. Elle comprend également des données clés relatives à l'entrepreneuriat inclusif au Royaume-Uni.

Description: cette initiative a été lancée par le conseil municipal de Sunderland dans le but d'aider les entreprises locales à remporter les appels d'offres publics de faible valeur de la ville. Elle est mise en œuvre par un organe central du conseil municipal et utilise un site internet pour gérer les appels d'offres et diverses activités de soutien et de promotion.

Problème abordé: la ville de Sunderland étant située dans une région confrontée à un taux de chômage relativement élevé, le conseil municipal souhaite soutenir la création et le maintien des petites entreprises locales. Les dépenses municipales effectuées dans le cadre de la passation de marchés publics de biens et de services peuvent avoir un impact considérable sur l'économie locale, c'est pourquoi le conseil cherche à en optimiser les retombées économiques tout en respectant les règles applicables aux marchés publics. Pour les marchés d'une valeur supérieure au seuil de mise en concurrence défini par la directive européenne relative à la procédure de passation des marchés publics (c'est-à-dire 207000 euros soit environ 172000 GBP), les procédures internationales établies sont obligatoires et le conseil ne peut donner la préférence à des fournisseurs locaux. Pour les contrats d'un montant inférieur, la procédure de passation de marchés publics est plus souple et permet de soutenir l'entrepreneuriat local. Pour les contrats de moins de 75000 GBP (90 000 euros), le règlement intérieur du conseil municipal de Sunderland exigeait du commanditaire qu'il reçoive trois offres. Cette procédure dissuadait toutefois les nouvelles entreprises de proposer leurs services ou de répondre aux appels d'offres du conseil, car leur interlocuteur n'était pas clairement défini (il n'existait pas de point de contact unique ni de répertoire des fournisseurs). Il a donc été décidé de centraliser le système de soumission d'offres pour renforcer le contrôle sur les dépenses en matière de marchés de faible valeur et améliorer l'équilibre entre le soutien à l'économie locale et de sélectionner des offres compétitives.

Approche: ce système a été mis en place pour permettre à tous les fournisseurs (pas nécessairement locaux) de s'inscrire gratuitement sur un site internet dédié (http://www. buysunderlandfirst.co.uk/) et créer ainsi un répertoire de fournisseurs, classés par catégorie de biens et de services. Lorsqu'un appel d'offres est lancé par le conseil, le système sélectionne de façon aléatoire trois fournisseurs, dont deux locaux, dans la catégorie concernée. Ce groupe de soumissionnaires peut être complété par d'autres fournisseurs inscrits au répertoire. Le ratio de 2 fournisseurs locaux pour un fournisseur extérieur doit toutefois être respecté. Cette approche permet de mettre les fournisseurs en concurrence tout en offrant la possibilité à de nouveaux fournisseurs locaux de s'implanter sur le marché. Cette initiative a été lancée en mars 2010, et les premiers appels d'offres ont été ouverts en avril 2010. Le système répertorie actuellement 3000 fournisseurs, dont environ 1400 de Sunderland. Cette initiative est peu coûteuse, le principal coût étant l'achat de la licence du logiciel. Suite au succès de cette initiative, le conseil a apporté plusieurs changements: il a adapté le système d'appels d'offres au seuil de mise en concurrence de l'Union européenne; renforcé l'aide du service municipal des passations de marchés aux entreprises locales; créé un groupe de contact pour entretenir des relations avec les représentants du secteur local; et pris en compte la volonté d'optimiser les opportunités économiques locales dans l'évaluation de chaque passation de marché.

Impact: le pourcentage des contrats remportés par des fournisseurs locaux est passé de $38 \%$ en 2011-2012 à 52 \% en 2013-2014. Celui des contrats remportés par des fournisseurs régionaux est passé de $52 \%$ à $85 \%$ sur cette même période. Globalement, $37 \%$ des marchés municipaux ont été alloués en 2013-2014 à des entreprises locales, contre seulement 22 \% en 2008-2009

Facteurs de réussite: cette initiative prouve qu'il est possible d'encourager les nouveaux et petits entrepreneurs locaux à participer aux appels d'offres publics tout en respectant les règles applicables en la matière et en maintenant un équilibre entre le soutien à l'économie locale et le choix du plus offrant. 


\section{Données clés relatives à l'entrepreneuriat inclusif}

\section{Graphique 37.1. Données relatives à l'entrepreneuriat et au travail indépendant au Royaume-Uni}

Diagramme A. Taux de chômage, 2000-2013
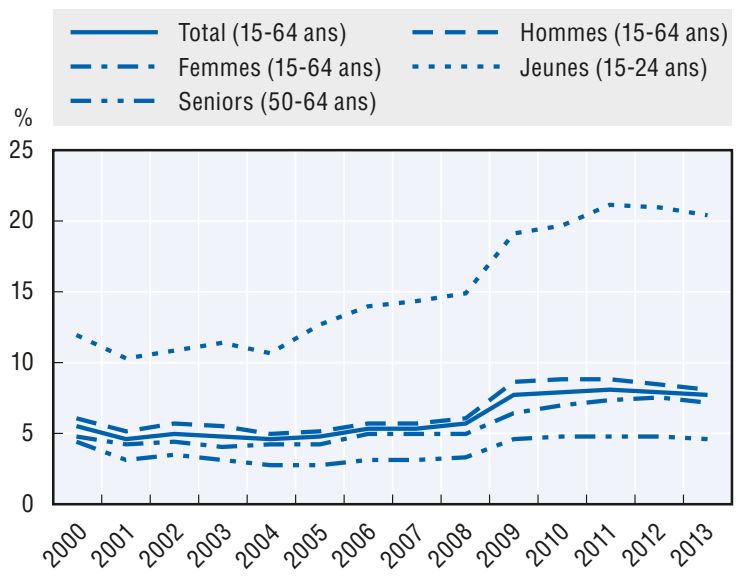

Diagramme C. Taux de travail indépendant, 2000-2013

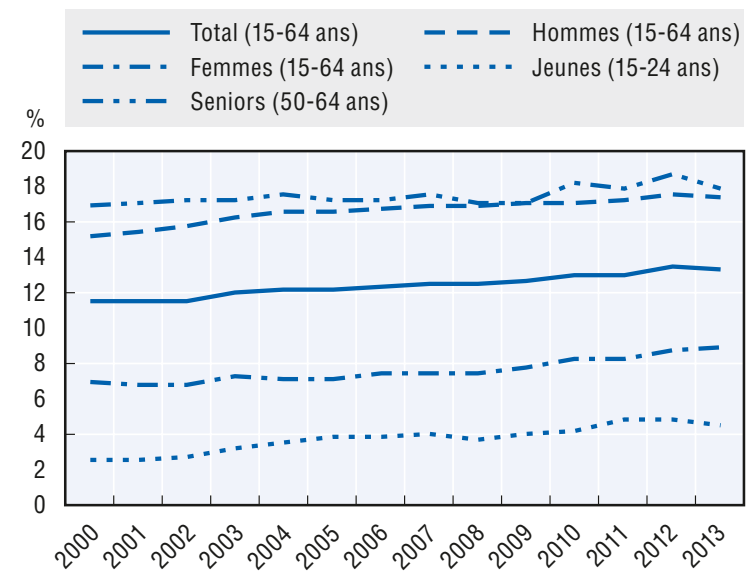

Diagramme E. Nombre total des entrepreneurs au stade précoce qui envisagent de créer plus de 19 emplois dans les 5 ans, 2009-2013 (combinés)

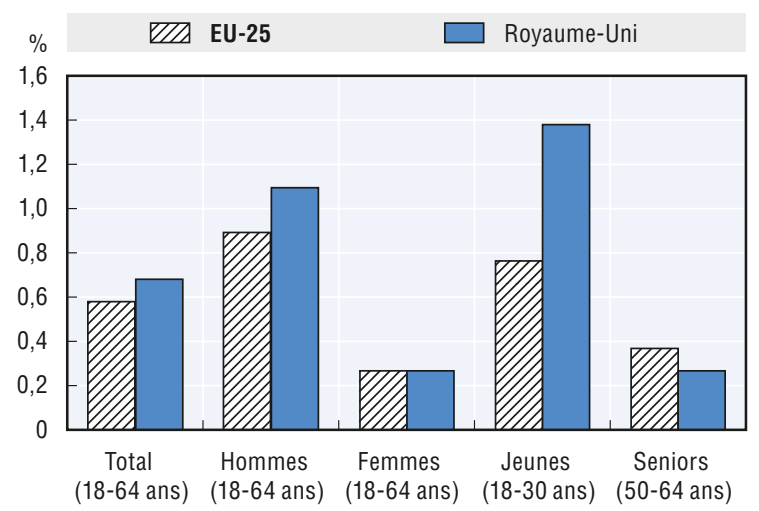

Diagramme B. Taux de travail indépendant, 2013

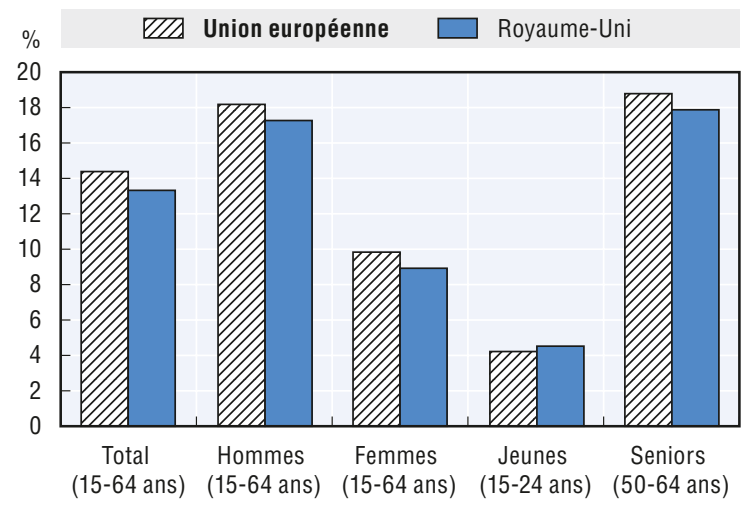

Diagramme D. Indice de l'activité entrepreneuriale totale au stade précoce, 2009-2013 (combinés)

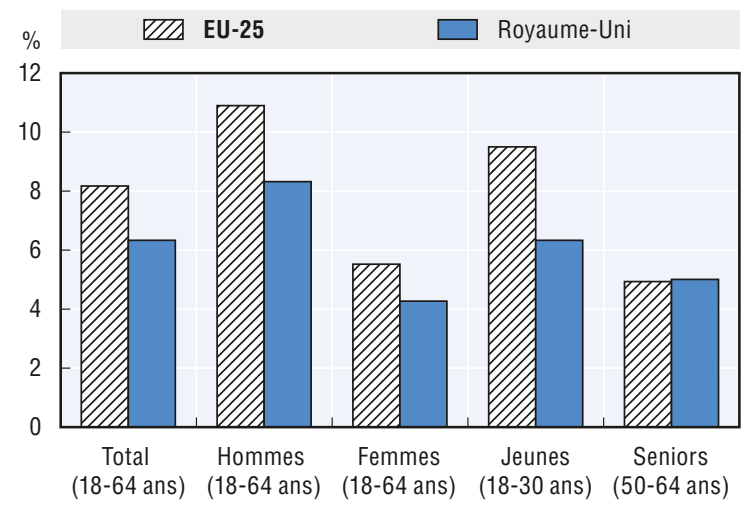

Sources: Diagramme A. Eurostat, Enquête sur les forces de travail, 2000-2013; Diagramme B. Eurostat, Enquête sur les forces de travail, 2013; Diagramme C. Eurostat, Enquête sur les forces de travail, 2000-2013; Diagramme D. Présentation tabulaire spéciale de l'enquête sur la population adulte du Global Entrepreneurship Monitor, 2009-2013; Diagramme E. Présentations tabulaires spéciales de l'enquête sur la population adulte du Global Entrepreneurship Monitor, 2009-2013. 



\section{Glossaire}

Actifs en garantie: actifs demandés par le prêteur à l'emprunteur pour l'émission d'un prêt. Il s'agit généralement de biens (bien immobilier, véhicule, etc.) qui peuvent être saisis par le prêteur en cas de défaut de paiement.

Activité entrepreneuriale totale au stade précoce (TEA): mesure utilisée par le Global Entrepreneurship Monitor, équivalant à la somme de la proportion de la population impliquée dans une activité entrepreneuriale naissante et de la proportion de la population qui a créé une entreprise au cours des 42 derniers mois.

Capital social: valeur des réseaux sociaux, qu'il s'agisse de la famille, des amis ou des collègues, et des contacts professionnels et personnels qui permettent d'ouvrir de nouvelles portes. Dans l'entrepreneuriat, le capital social donne accès aux connaissances, aux réseaux de clients, aux fournisseurs et au soutien professionnel, et peut ainsi augmenter les chances de réussite d'une entreprise donnée.

Coaching: relation habituellement de courte durée destinée à développer les compétences d'un entrepreneur. Il s'agit d'un processus collaboratif, dans lequel les participants occupent des rôles clairement définis. Le coach est chargé de développer des objectifs à court terme et de guider son élève vers ces objectifs en formulant des commentaires constructifs. L'élève est chargé de produire des idées et des solutions, de prendre des mesures pour atteindre les objectifs et de faire part de ses progrès.

Compétences entrepreneuriales: combinaison de compétences techniques, de compétences en gestion des affaires et de compétences personnelles requises pour se lancer dans l'entrepreneuriat et le travail indépendant et pour poursuivre sur cette voie. Elles incluent notamment le travail d'équipe, la négociation, le développement stratégique, la planification financière et le marketing.

Conseil en entreprise: service d'aide au développement des entreprises proposant des conseils professionnels. Une approche courante consiste à proposer des services de conseil en entreprise dans le cadre de programmes d'aide intégrés et de conditionner l'octroi de l'aide financière à la demande de ce type de service.

Coûts des effets d'aubaine: mesure dans laquelle les participants auraient créé une nouvelle entreprise en l'absence de subvention. Le comportement de ces «participants d'aubaine» n'est pas influencé par le programme, mais leur participation ne contribue pas à la valeur économique générée par le programme et engendre une dépense publique. Le coût social de cette dépense correspond à la somme du coût de distorsion ou de la charge excédentaire de la taxe qui le finance.

Couveuses: les couveuses d'entreprises sont des structures destinées à soutenir la création et la croissance des sociétés entrepreneuriales, par un large éventail de ressources et de services d'appui aux entreprises, offerts à la fois au sein de la couveuse directement et par son réseau de contacts. Les couveuses varient au niveau du mode de mise en œuvre de leurs services, de leur structure organisationnelle et du type de bénéficiaires. S'il existe des couveuses virtuelles/ en ligne, la plupart des programmes accueillent dans leurs locaux des entreprises qui vont être lancées ou qui viennent de l'être, pour une période de temps limitée. Le fait qu'une jeune 
entreprise suive avec succès un programme de couveuse d'entreprise accroît ses chances de survie et de croissance.

Effets de déplacement: mesure dans laquelle les entreprises subventionnées s'emparent de l'activité et des emplois des entreprises non subventionnées.

Entrepreneur: personne (propriétaire d'entreprise) qui cherche à générer de la valeur, par la création ou l'expansion d'une activité économique, en identifiant et en exploitant de nouveaux produits, processus ou marchés (voir le programme d'indicateurs de l'entrepreneuriat de l'OCDE). Il est possible de se comporter de manière entrepreneuriale dans le secteur public, dans une entreprise sociale ou en qualité de salarié d'une entreprise.

Entrepreneuriat à temps partiel: Entrepreneuriat mené à temps partiel. Il s'agit le plus souvent d'un travail indépendant à temps partiel: la personne consacre moins de 35 heures par semaine à une activité indépendante. Cette forme d'entrepreneuriat sert souvent à compléter d'autres activités telles qu'un emploi salarié, le travail ménager non rémunéré ou des activités d'apprentissage.

Entrepreneuriat en série: processus consistant à créer des entreprises et à les revendre lorsqu'elles sont encore jeunes plutôt que de les diriger pendant toute leur durée de vie.

Entrepreneuriat inclusif: entrepreneuriat qui contribue à l'inclusion sociale et qui donne à tout le monde les mêmes chances de démarrer et de diriger une entreprise. Les groupes cibles sont les groupes défavorisés et sous-représentés dans l'entrepreneuriat et le travail indépendant, dont les jeunes, les femmes, les seniors, les minorités ethniques et les immigrés, les personnes handicapées et de nombreux autres groupes.

Entrepreneuriat parallèle: situation dans laquelle un entrepreneur dirige plus d'une entreprise. Ces entreprises peuvent offrir des biens et des services complémentaires à la même clientèle, créant ainsi des synergies entre elles. Il peut également s'agir d'entreprises sans rapport entre elles, destinées à fournir un revenu plus stable à l'entrepreneur.

Entrepreneuriat social: entrepreneuriat dans lequel l'objectif principal est d'avoir un impact social plutôt que de rapporter des bénéfices aux propriétaires ou actionnaires. Les entreprises sociales délivrent des biens et des services au marché de manière entrepreneuriale et innovante et utilisent les bénéfices pour atteindre des objectifs sociaux avant tout. Elles sont gérées de manière ouverte et responsable et, plus particulièrement, impliquent les travailleurs, les consommateurs et les parties prenantes concernées par leurs activités commerciales.

Entrepreneurs handicapés: entrepreneurs atteints d'une invalidité. La grande majorité d'entre eux souffrent de handicaps "cachés», y compris de troubles de la santé mentale, de douleurs chroniques et de troubles musculosquelettiques. Une proportion très restreinte a des handicaps visibles, par exemple, les personnes se déplaçant en fauteuil roulant ou les déficients visuels. De nombreux pays ont maintenant recensé les barrières systémiques qui affectent les entrepreneurs handicapés au sein de l'entrepreneuriat, comme des attitudes négatives et l'exclusion de la société (consciemment ou non).

Entrepreneurs issus d'une minorité ethnique ou immigrés: les entrepreneurs issus d'une minorité ethnique sont nés dans leur pays de résidence, appartiennent à une minorité ethnique et conservent des liens forts avec leur culture ethnique. Les entrepreneurs immigrés ont migré dans un autre pays. S'ils peuvent appartenir au même groupe ethnique que la population majoritaire du pays, ils ne seront probablement pas aussi coutumiers de ses règles, de sa culture et de ses institutions.

Entrepreneurs seniors: ce terme désigne habituellement les entrepreneurs de plus de 50 ans, également connus sous le nom d'«entrepreneurs grisonnants», d'«entrepreneurs âgés», d'«entrepreneurs du troisième âge» et de «seniorpreneurs». On estime qu'ils joueront un rôle de plus en plus important dans l'activité économique, compte tenu du vieillissement de la population et du déclin de la population traditionnellement en âge de travailler. 
Équilibre vie professionnelle-vie privée: concept impliquant d'établir les bonnes priorités entre le «travail» (carrière et ambition) et le mode de vie (santé, plaisir, loisirs, famille et développement spirituel).

Évaluation: l'évaluation a pour objectif de mesurer la pertinence, l'impact, l'efficacité et la rentabilité d'un programme ou d'une mesure. Les évaluations peuvent être qualitatives et/ ou quantitatives. Les évaluations efficaces sont planifiées dès la conception de la mesure, et des indicateurs sont collectés tout au long de sa mise en œuvre pour alimenter l'évaluation. L'évaluation doit être conçue et mise en œuvre de manière à fournir des informations utiles aux décideurs, selon les circonstances politiques, les contraintes du programme et les ressources disponibles. Ses résultats doivent être utilisés pour améliorer la conception des mesures.

Exclusion financière: situation d'accès inexistant ou limité aux services financiers. Par exemple, les personnes n'ayant pas de compte en banque peuvent rencontrer des difficultés pour obtenir un prêt pour la création de leur entreprise, et un prêt revient beaucoup plus cher aux personnes ne disposant pas de garanties réelles. L'exclusion financière accroît les risques de pauvreté.

Financement islamique: activités de financement conformes à la charia (loi islamique), qui interdit aux prêteurs d'appliquer des taux d'intérêt aux emprunteurs. Le prêt n'est pas exclu, mais les prêteurs doivent être traités comme des parties prenantes. Jusqu'ici, ce type de financement a plus souvent été utilisé par de grands fonds d'investissement qu'en soutien aux entrepreneurs.

Garantie de prêt: engagement d'un tiers à couvrir une partie des pertes liées à un défaut de paiement. Elle peut être apportée par un gouvernement et/ou par une association professionnelle privée. Elle est assortie d'un fonds servant de garantie.

Groupes défavorisés: groupes rencontrant des obstacles supplémentaires pour participer pleinement au marché du travail et à la société. Leur position défavorable est souvent due à des caractéristiques individuelles telles qu'une expérience limitée du monde du travail, un faible niveau d'instruction ou un capital social limité, mais peut également être liée à des caractéristiques partagées au sein d'un groupe. Par conséquent, les groupes défavorisés rencontrent des discriminations intentionnelles ou non.

Groupes sous-représentés: groupes de la société moins représentés dans l'économie d'entreprise que leur proportion dans la population globale, par exemple les femmes et les personnes handicapées.

Inclusion sociale: action positive prise pour inclure tous les secteurs de la société dans une activité économique et sociale. Notamment en veillant à ce que les groupes marginalisés ou en situation de pauvreté participent davantage aux décisions les concernant, leur permettant ainsi d'améliorer leur niveau de vie et leur bien-être global.

Indicateurs de l'exploitation d'entreprise: ensemble de mesures quantitatives indiquant le nombre de personnes qui ont établi des entreprises commerciales en activité. Il peut s'agir du nombre d'entreprises, du chiffre d'affaires, des niveaux d'exportation, des travailleurs, etc. Les décideurs politiques peuvent utiliser ces indicateurs pour mesurer le nombre d'entrepreneurs et d'entreprises dans une économie donnée.

Indicateurs de la création d'entreprise: ensemble de mesures quantitatives indiquant le nombre de personnes envisageant de créer une entreprise qui créent effectivement une entreprise inscrite au registre de commerce. En d'autres termes, ces indicateurs ont trait à la création d'entreprise, à savoir le moment où l'idée entrepreneuriale devient réalité et où l'entreprise apporte une contribution économique. Les décideurs politiques peuvent utiliser ces indicateurs pour mesurer en partie la force de la culture entrepreneuriale.

Indicateurs de précréation d'entreprise: ces mesures cernent l'attitude de la société vis-àvis de l'entrepreneuriat et le niveau d'intérêt affiché par les gens pour créer une entreprise. 
Jeunes entrepreneurs: entrepreneurs en fin d'adolescence ou dans la vingtaine. La fourchette d'âge exacte dépend du contexte. Le Global Entrepreneurship Monitor définit par exemple les jeunes entrepreneurs comme les 18-30 ans, tandis que pour l'Eurobaromètre Flash, il s'agit des 15-24 ans.

Mentorat: le mentorat est une relation professionnelle dans laquelle une personne expérimentée (le mentor) aide une autre (l'élève) à développer des compétences et des connaissances qui renforceront son développement professionnel et personnel. Ces relations sont habituellement de plus longue durée que le coaching.

Mesures actives du marché du travail: mesures visant à aider les chômeurs et d'autres personnes à participer au marché du travail. Elles incluent habituellement le courtage (mise en correspondance des vacances d'emploi et des demandeurs d'emploi), la formation (pour améliorer et adapter les compétences des demandeurs d'emploi) et la création d'emplois directs (soit par l'emploi dans le secteur public, soit par la subvention du travail dans le secteur privé).

Microcrédit: prêts de faible montant à des emprunteurs qui ont des difficultés à obtenir des crédits auprès d'établissements bancaires traditionnels. Les taux d'intérêt, supérieurs à ceux des banques traditionnelles, reflètent le profil à risque de l'emprunteur. Dans l'Union européenne, le plafond du microcrédit est fixé à 25000 euros.

Modèle: entrepreneur expérimenté qui peut donner à d'autres l'envie de se lancer dans la création d'entreprises ou le travail indépendant.

Orientation: informations mises à la disposition d'entrepreneurs potentiels et en activité afin de les orienter vers des sources d'information et d'assistance professionnelles.

Participation au marché du travail: mesure de la partie active de la force de travail d'une économie. Le taux de participation au marché du travail désigne la proportion de personnes qui sont soit employées, soit en recherche active de travail. Les personnes qui ne cherchent plus activement un travail ne sont pas reprises dans le taux de participation. La situation d'une personne influencera la probabilité qu'elle travaille ou qu'elle cherche du travail. Par exemple, les étudiants et les retraités ne recherchent pas souvent de travail et sont donc exclus des taux d'activité et de chômage publiés. Durant une récession économique, le taux de participation diminue habituellement: le manque de possibilités d'emplois salariés décourage de nombreux travailleurs potentiels, qui arrêtent alors de chercher du travail.

Responsabilité sociale des entreprises (RSE): la responsabilité sociale des entreprises (RSE) fait référence aux efforts mis en œuvre par certaines entreprises pour prendre leurs responsabilités à l'égard de leur impact sur la société. Comme le montrent les études, la RSE est un élément de plus en plus important dans la compétitivité des entreprises. Elle présente des avantages en termes de gestion des risques, d'économies, d'accès aux capitaux, de relation clientèle, de gestion des ressources humaines et de capacités d'innovation.

Services d'aide au développement des entreprises: services destinés à améliorer les performances de l'entreprise en améliorant sa capacité à faire face à la concurrence et à accéder aux marchés. Les services d'appui incluent généralement la formation, le mentorat, l'accompagnement individualisé, la consultance, l'assistance marketing, l'information, l'assistance pour le développement et le transfert de technologies et le réseautage. Tant les aspects stratégiques (questions à moyen et à long terme qui améliorent la performance) qu'opérationnels (gestion journalière) sont inclus.

Services de proximité: tentative systématique de fournir des services au-delà des limites traditionnelles pour atteindre des groupes particuliers d'une communauté. Les services de proximité peuvent servir à informer les gens de l'existence de services (plus traditionnels), ainsi qu'à toucher et mobiliser des groupes spécifiques et ceux qui n'ont pas l'habitude de recourir aux services traditionnels. Une approche possible consiste à fournir les services dans des lieux que les membres des communautés ciblées fréquentent déjà (centres communautaires, maisons de 
jeunes, lieux de culte, centres commerciaux, etc.) plutôt qu'à installer un bureau d'information et essayer d'y attirer les gens.

Taux d'entrepreneuriat naissant: proportion des membres de la population qui sont activement impliqués dans la création d'une entreprise dont ils seront propriétaires en tout ou en partie. Cette activité n'a pas rapporté de traitement, de salaire ou toute autre rémunération aux propriétaires depuis plus de trois mois. C'est l'une des mesures développées par le Global Entrepreneurship Monitor pour quantifier les activités entrepreneuriales au sein d'une économie.

Taux de détention d'entreprises établies: mesure de la proportion des membres de la population adulte qui sont actuellement dirigeants-propriétaires d'une entreprise établie qui verse des traitements, des salaires ou toute autre rémunération aux propriétaires depuis plus de 42 mois. Cette mesure a été développée par le Global Entrepreneurship Monitor et contribue à donner des informations sur le niveau d'activités entrepreneuriales au sein d'une économie.

Taux de détention de nouvelles entreprises: proportion des membres de la population qui sont actuellement dirigeants-propriétaires d'une nouvelle entreprise qui verse des traitements, des salaires ou toute autre rémunération aux propriétaires depuis plus de trois mois mais moins de 42 mois. C'est l'une des mesures développées par le Global Entrepreneurship Monitor pour quantifier les activités entrepreneuriales au sein d'une économie.

Travail indépendant: statut professionnel dans le cadre duquel les personnes travaillent à leur propre compte dans leur propre entreprise et perçoivent un retour économique en échange de leur travail, sous la forme de traitements, de bénéfices, d'avantages en nature ou de gain familial (pour les travailleurs familiaux). Les travailleurs indépendants peuvent travailler seuls ou employer d'autres personnes. Ils dirigent souvent leur entreprise en qualité d'entreprise à propriétaire unique, de contractant indépendant, de membre d'un partenariat ou d'entreprise non constituée en société. 


\section{ORGANISATION DE COOPÉRATION ET DE DÉVELOPPEMENT ÉCONOMIQUES}

L'OCDE est un forum unique en son genre où les gouvernements oeuvrent ensemble pour relever les défis économiques, sociaux et environnementaux que pose la mondialisation. L'OCDE est aussi à l'avantgarde des efforts entrepris pour comprendre les évolutions du monde actuel et les préoccupations qu'elles font naître. Elle aide les gouvernements à faire face à des situations nouvelles en examinant des thèmes tels que le gouvernement d'entreprise, l'économie de l'information et les défis posés par le vieillissement de la population. L'Organisation offre aux gouvernements un cadre leur permettant de comparer leurs expériences en matière de politiques, de chercher des réponses à des problèmes communs, d'identifier les bonnes pratiques et de travailler à la coordination des politiques nationales et internationales.

Les pays membres de l'OCDE sont: l'Allemagne, l'Australie, l'Autriche, la Belgique, le Canada, le Chili, la Corée, le Danemark, l'Espagne, l'Estonie, les États-Unis, la Finlande, la France, la Grèce, la Hongrie, l'Irlande, l'Islande, Israël, l'Italie, le Japon, le Luxembourg, le Mexique, la Norvège, la Nouvelle-Zélande, les Pays-Bas, la Pologne, le Portugal, la République slovaque, la République tchèque, le Royaume-Uni, la Slovénie, la Suède, la Suisse et la Turquie. La Commission européenne participe aux travaux de l'OCDE.

Les Éditions OCDE assurent une large diffusion aux travaux de l'Organisation. Ces derniers comprennent les résultats de l'activité de collecte de statistiques, les travaux de recherche menés sur des questions économiques, sociales et environnementales, ainsi que les conventions, les principes directeurs et les modèles développés par les pays membres.

\section{LA COMMISSION EUROPÉENNE}

La direction générale de l'emploi, des affaires sociales et de l'inclusion de la Commission européenne mène des initiatives politiques, législatives et financières en vue de stimuler la création d'emplois de meilleure qualité, lutter contre la pauvreté et l'exclusion sociale, promouvoir la justice et la protection sociales, favoriser la libre circulation des travailleurs, garantir la mobilité de la main-d'œuvre, faire la promotion des droits des travailleurs, encourager la solidarité entre les générations et contribuer au meilleur fonctionnement des marchés du travail, au plein emploi, au progrès social ainsi qu'à une économie sociale de marché hautement compétitive au sein de l'Union européenne dans le contexte de la stratégie Europe 2020. 


\section{Pallier la pénurie d'entrepreneurs 2015}

\section{POLITIQUES EN FAVEUR DU TRAVAIL INDÉPENDANT ET DE L'ENTREPRENEURIAT}

Pallier la pénurie d'entrepreneurs 2015 est la troisième publication de la série de rapports annuels qui fournissent des données et une analyse des politiques sur l'entreprenariat inclusif. L'entreprenariat inclusif comprend le marché des start-ups et le travail indépendant qui contribuent à l'inclusion sociale et aussi à la croissance économique, ainsi que les activités d'entrepreneuriat par les groupes sociaux tels que les jeunes, les femmes, les seniors, les immigrés et les chômeurs. Le rapport contient des données sur l'ampleur et la portée des activités d'entreprenariat et du travail indépendant dans les pays de l'Union européenne par les groupes sociaux ciblés, ainsi que les obstacles auxquels ils sont confrontés. Chaque chapitre thématique traite des problèmes et des défis politiques actuels, et fournit des recommandations pour les responsables politiques de l'Union européenne. Le rapport fournit également des exemples inspirants sur les pratiques de bonnes politiques de chacun des 28 membres de l'Union européenne.

\section{Table des matières}

\section{Résumé}

Guide de lecture

Chapitre 1. La politique d'entrepreneuriat inclusif de l'Union européenne

Partie I: L'entrepreneuriat inclusif en Europe - Taux d'activité et obstacles

Chapitre 2. Le travail indépendant et l'entrepreneuriat chez les femmes

Chapitre 3. Le travail indépendant et l'entrepreneuriat chez les jeunes

Chapitre 4. Le travail indépendant et l'entrepreneuriat chez les seniors

Chapitre 5. Le travail indépendant et l'entrepreneuriat chez les chômeur

Chapitre 6. Le travail indépendant et l'entrepreneuriat chez les personnes nées à l'étranger

Partie II: Les politiques d'entrepreneuriat inclusif

Chapitre 7. Soutenir la croissance des entrepreneurs appartenant à des groupes sous-représentés et défavorisés

Chapitre 8. Mécanismes de coaching et de mentorat efficaces pour les entrepreneurs appartenant à des groupes sous-représentés et défavorisés

Partie III: Profils des pays: exemples de politiques et données clés sur l'entrepreneuriat inclusif

Veuillez consulter cet ouvrage en ligne: $h$ ttp://dx.doi.org/10.1787/9789264249936-fr.

Cet ouvrage est publié sur OECD iLibrary, la bibliothèque en ligne de l'OCDE, qui regroupe tous les livres, périodiques et bases de données statistiques de l'Organisation. Rendez-vous sur le site www.oecd-ilibrary.org pour plus d'informations.

OECDpublishing www.oecd.org/publishing
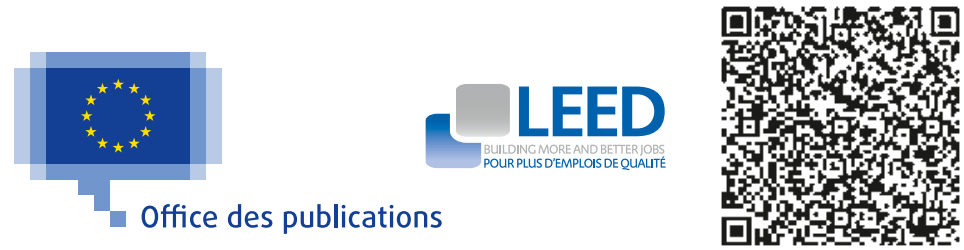

ISBN 978-92-64-24991-2 842015012 P

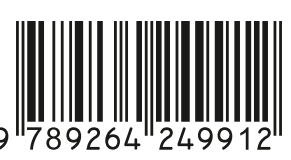

